U N I VER S IDA D D E S A L A M A N C A

FACULTAD DE MEDICINA

DEPARTAMENTO DE CIRUGÍA

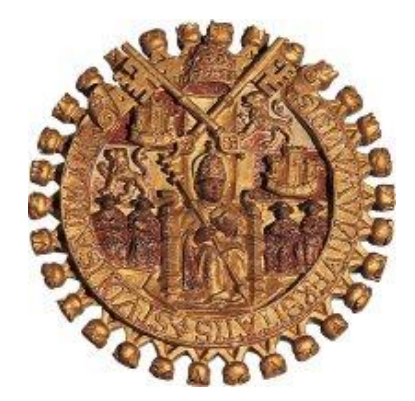

TESIS DOCTORAL

\title{
EFECTOS TERMOCUTÁNEOS DE LA ANESTESIA EPIDURAL LUMBAR EN LAS EXTREMIDADES INFERIORES DE SUJETOS SANOS Y CON ARTERIOPATÍA CRÓNICA
}

MARÍA HEREDIA RODRÍGUEZ

Directores

Dr. Javier González de Zárate Apiñániz (Universidad de Valladolid)

Prof. Dr. Francisco S. Lozano Sánchez (Universidad de Salamanca) 

PROF. DR. D. CLEMENTE MURIEL VILLORIA, Director del Departamento de Cirugía de la Facultad de Medicina de la Universidad de Salamanca

\section{CERTIFICA}

Que la presente Tesis Doctoral titulada "Efectos termocutáneos de la anestesia epidural lumbar en las extremidades inferiores de sujetos sanos y con arteriopatía crónica", realizada por Dña. María HEREDIA RODRIGUEZ para optar al Grado de Doctor, reúne todos los requisitos para su presentación y defensa ante el Tribunal Calificador.

Y para que conste y obre los efectos oportunos, firma el presente certificado en Salamanca, a veintitrés de enero de dos mil doce.

Fdo.: Prof. Dr. D. Clemente Muriel Villoria 



\section{DR. D. JAVIER GONZÁlEZ DE ZÁRATE APIÑÁNIZ,}

Colaborador Honorífico del Departamento de Cirugía de la Facultad de Medicina de la Universidad de Valladolid; y

PROF. DR. D. FRANCISCO LOZANO SÁNCHEZ, Catedrático de Cirugía Vascular de la Facultad de Medicina de la Universidad de Salamanca

\section{CERTIFICAN}

Que la presente Tesis Doctoral titulada "Efectos termocutáneos de la anestesia epidural lumbar en las extremidades inferiores de sujetos sanos y con arteriopatía crónica", presentada por Dña. María HEREDIA RODRIGUEZ, ha sido realizada bajo nuestra dirección en las Facultades de Medicina de las Universidades de Salamanca y Valladolid, y reúne todos los requisitos para optar al Grado de Doctor, por lo que otorgamos la autorización para que sea presentada y defendida.

Y para que conste y obre los efectos oportunos, firman el presente certificado en Salamanca, a once de enero de dos mil doce.

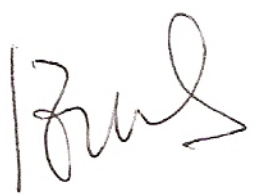

Fdo: Dr. Javier González de Zárate Apiñániz

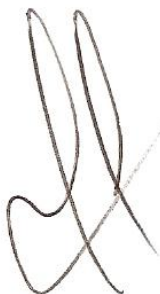

Fdo: Prof. Dr. Francisco Lozano Sánchez 

A mis padres y hermana 



\section{AGRADECIMIENTOS}

A los directores Javier González de Zárate, por su paciencia e insistencia, por su buen humor y su tiempo...; y Francisco S. Lozano, por transmitirme su entusiasmo por la investigación ya desde los cursos de doctorado.

A Eduardo Tamayo, por su inmensa ayuda para sacar adelante este trabajo, por aclarar ideas, plantear preguntas... y animarme a continuar estudiando.

A José Ignacio, Jefe del Servicio de Anestesiología y Reanimación del Hospital Clínico de Valladolid, por sus insistencia, uno y otro día, en la realización y finalización de la Tesis..., y contagiarme su entusiasmo por la Medicina.

A mis compañeros de especialidad del Clínico de Valladolid, que se han interesado por la evolución de este trabajo, por haber hecho posible con su ayuda la recogida de la muestra que hemos estudiado, y haber compartido conmigo sus conocimientos y preguntas...

A los cirujanos del mismo Hospital por su paciencia, ya que en ocasiones la recogida de datos retrasaba en cierta medida el comienzo de la cirugía. Y a aquellos cirujanos vasculares que se han ofrecido a echarme una mano, me han aportado bibliografía, han contestado a mis preguntas...

A las enfermeras del quirófano y antequirófano, por su ayuda, interés y ánimos.

A los celadores, por su colaboración.

A los pacientes, sin cuyo consentimiento a participar en este estudio, no habría sido posible llevarlo a cabo. Por su confianza y aguante. 
A Inmaculada Fierro y Mari Fé, que me han ayudado con la parte estadística de la Tesis. Por la paciencia que han derrochado.

A mi familia, por su cariño, ayuda, interés... A Álvaro y Laura, mis sobrinos, por aguantarse sus ganas de jugar juntos estas últimas semanas...

A mis amigos, por hacer los momentos de relax inmensamente agradables, por su cariño....

A todos aquellos de los que quizás me esté olvidando y que de una u otra manera han aportado su granito de arena durante la realización de este trabajo. 


\section{SIGLAS Y ABREVIATURAS}

AAS Ácido acetilsalicílico

AINES Antiinflamatorios no esteroideos

AL Anestésico local

ARA II Antagonistas de los receptores de la angiotensina II

ASA American Society of Anesthesiologists. Sociedad Americana de Anestesiología

B Basal

CAPRIE Clopidogrel versus aspirin in patients at risk of ischemic events. Clopidogrel vs aspirina en pacientes con riesgo de sucesos isquémicos

M Diabetes mellitus

DS Desviación estándar

EI Extremidades inferiores

ESTIME Evaluation of science, technology and innovation capabilities in the mediterranean countries. Evaluación de la ciencia, tecnología y capacidad de innovación en los países mediterraneos

FC Frecuencia cardiaca

Fig(s) Figura(s)

G Gauge

HDL High density lipoprotein. Lipoproteína de alta densidad HPI Hobby products international. Productos de juego internacionales (termómetro)

HTA Hipertensión arterial

IECA Inhibidor de la enzima convertidora de la angiotensina

IMAO Inhibidores de la monoaminooxidasa 
ITB Índice tobillo-brazo

L Lumbar

LCR Líquido cefalorraquídeo

LDL Low-density lipoprotein. Lipoproteína de baja densidad

Min. Minutos

n Tamaño muestral

NA Noradrenalina

PCR Proteína $\mathrm{C}$ reactiva

$\mathrm{PO}_{2} \quad$ Presión parcial de oxígeno

PTA Angioplasty transluminal percutaneous. Angioplastia transluminal percutánea

R Respuesta

SIC Sociedad Internacional de Cirugía.

SPSS Statistical package for the social sciences. Paquete estadístico para las ciencias sociales

T Torácico

TAD Tensión arterial diastólica

TAS Tensión arterial sistólica

U.I. Unidades internacionales 


\section{ÍNDICE}

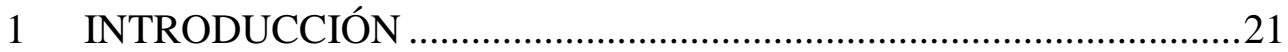

2 LA ANESTESIA/ANALGESIA EPIDURAL ....................................27

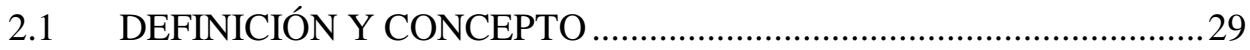

2.2 BREVE RECUERDO HISTÓRICO .......................................................

2.3 ANATOMÍA DEL ESPACIO EPIDURAL ………………………..........

2.4 EFECTOS FISIOLÓGICOS DE LA ANESTESIA EPIDURAL ............38

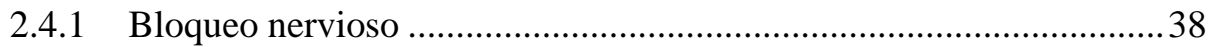

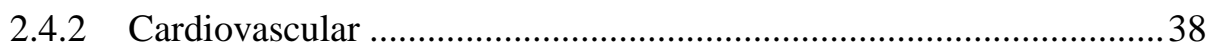

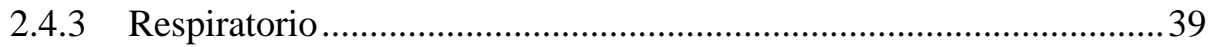

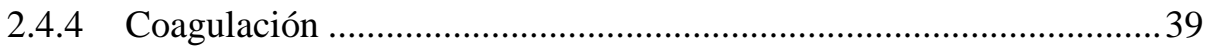

2.4.5 Gastrointestinal y de otras vísceras ................................................... 40

2.4.6 Termorregulación............................................................................. 40

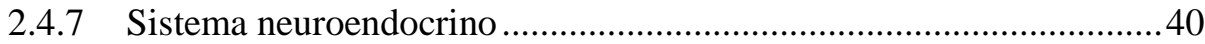

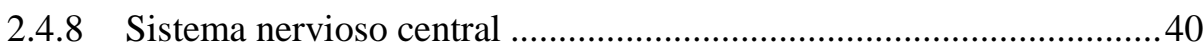

2.5 TÉCNICA Y MATERIAL PARA REALIZAR UNA ANESTESIA EPIDURAL …………………………........................ 41

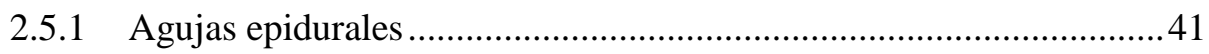

2.5.2 Posición del paciente ....................................................................... 41

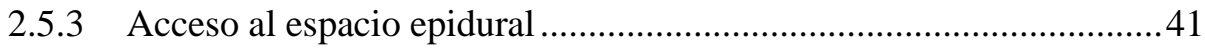

2.5.3.1. Preparación de la zona cutánea ………………………………...... 42

2.5.3.2. Forma de acceso desde la piel........................................................... 42

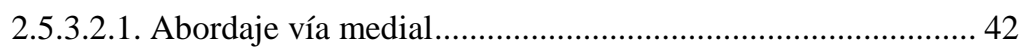

2.5.3.2.2. Abordaje paramedial........................................................... 43

2.5.3.3. Localización del espacio epidural ....................................................... 43

2.5.3.3.1. Técnica de la pérdida de resistencia ...................................... 43

2.5.3.3.2. Técnica de la gota pendiente................................................. 44

2.5.3.3.3. Otras técnicas....................................................................... 44

2.5.4 Introducción de un catéter epidural .................................................... 44 
2.5.5 Introducción del anestésico local en el espacio epidural .45

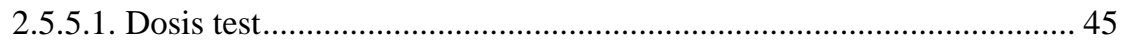

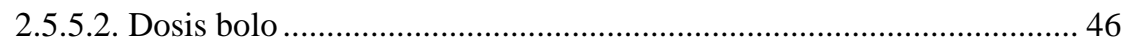

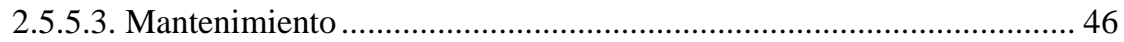

2.6 DETERMINANTES DEL NIVEL DE BLOQUEO EPIDURAL ...........47

2.6.1 Volumen de anestésico local ......................................................47

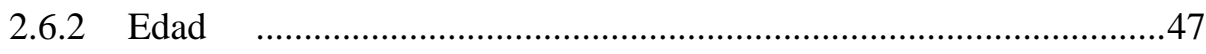

2.6.3 Embarazo............................................................................4

2.6.4 Velocidad de infusión del anestésico local.....................................48

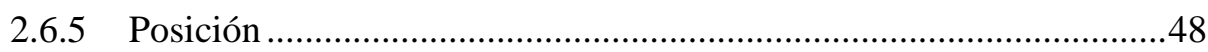

2.7 DETERMINANTES DEL INICIO, DURACIÓN E INTENSIDAD

DEL BLOQUEO EPIDURAL .......................................................48

2.7.1 Selección del anestésico local ......................................................48

2.7.2 Adicción de coadyuvantes.........................................................49

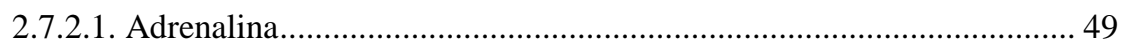

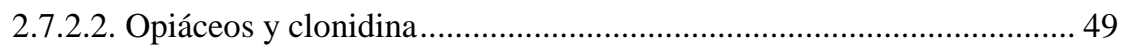

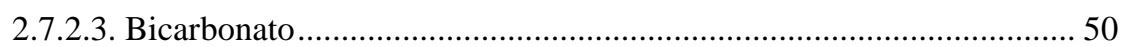

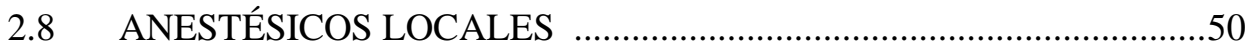

2.9 CONTRAINDICACIONES DE LA ANESTESIA EPIDURAL ...........52

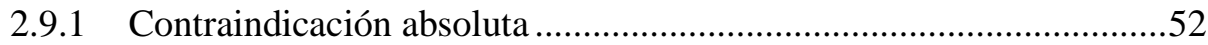

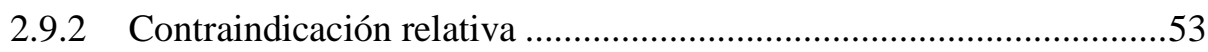

2.10 COMPLICACIONES DE LA ANESTESIA EPIDURAL ....................53

2.10.1 Colocación errónea de la aguja o del catéter .................................53

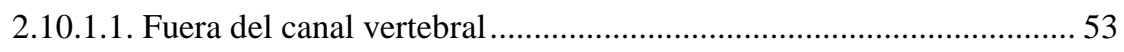

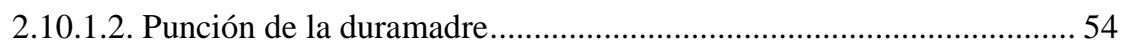

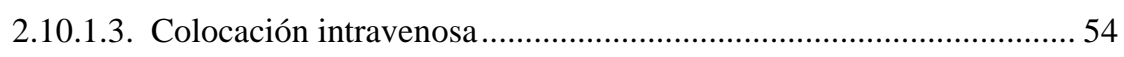

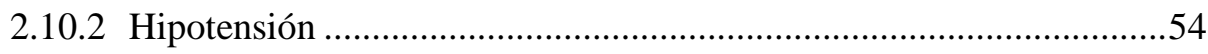

2.10.3 Toxicidad aguda generalizada ..................................................55

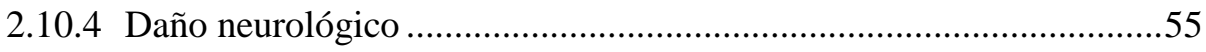

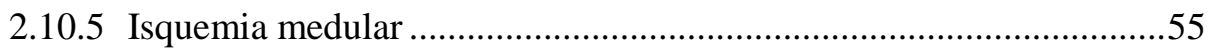

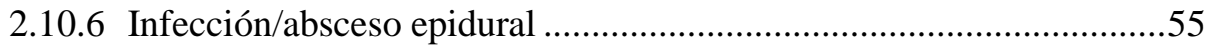

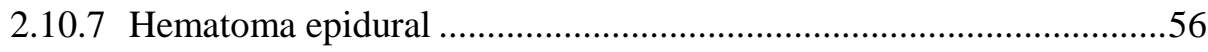




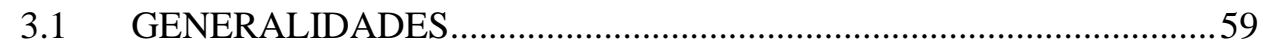

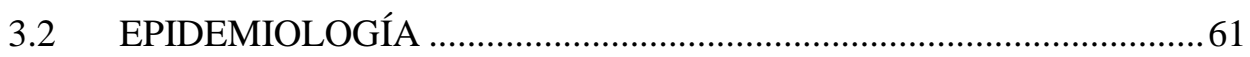

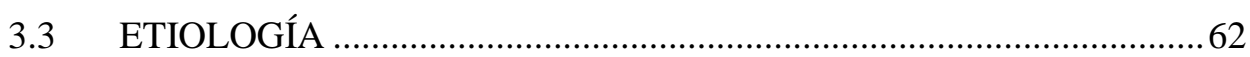

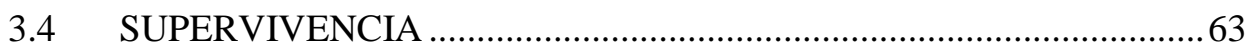

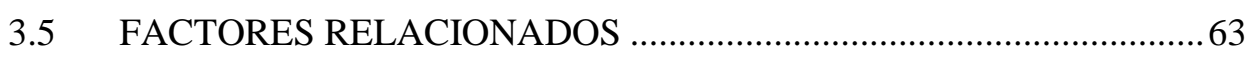

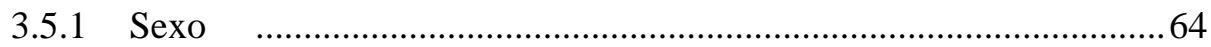

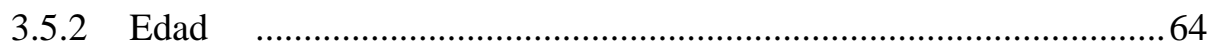

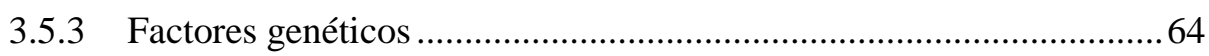

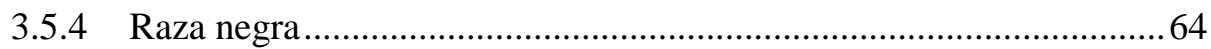

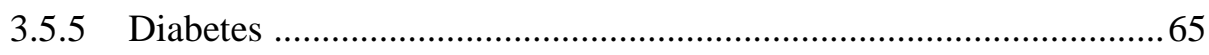

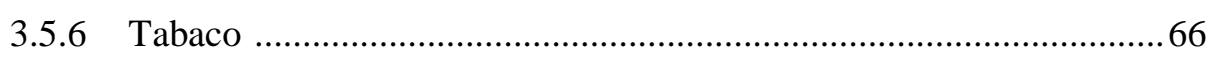

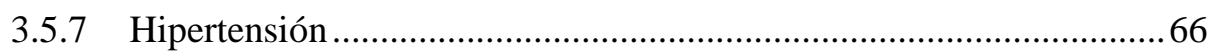

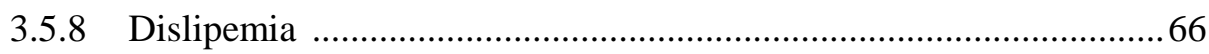

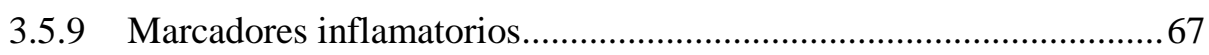

3.5.10 Hiperviscosidad sanguínea y estado de hipercoagulabilidad ..............67

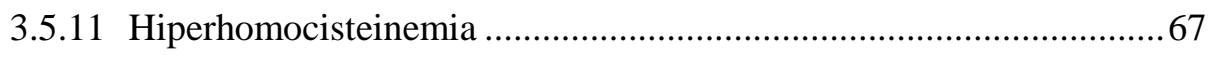

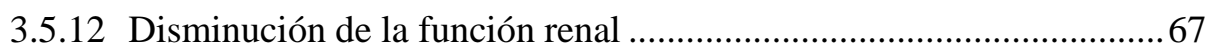

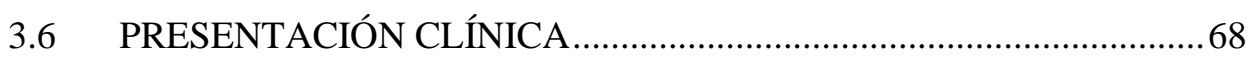

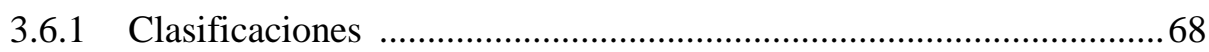

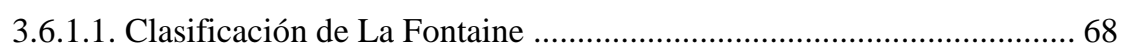

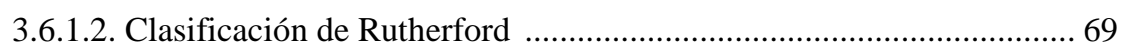

3.6.1.3. Correspondencia de las dos clasificaciones clásicas ............................ 70

3.6.2 Presentación clínica atendiendo al lugar de la obstrucción .................70

3.6.2.1. Obstrucción aorto-ilíaca..................................................................... 71

3.6.2.2. Obstrucción fémoro-poplítea ........................................................... 72

3.6.2.3. Obstrucción tibio-peronea.................................................................. 73

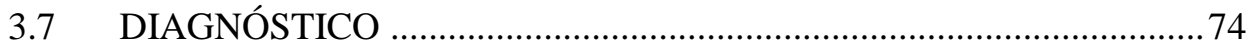

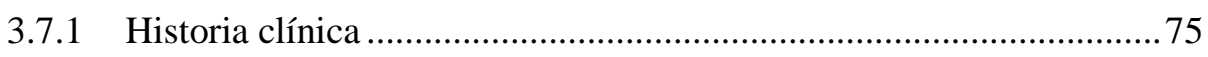

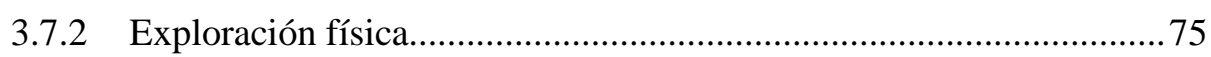

3.7.3 Estudios vasculares no invasivos .................................................... 
3.7.3.1. Doppler continuo y pulsado …........................................................ 76

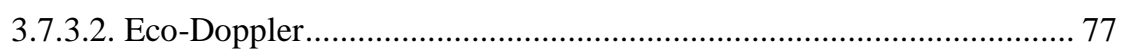

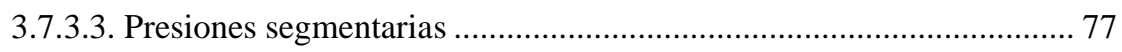

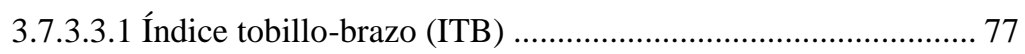

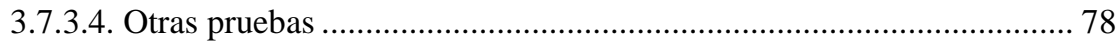

3.7.4 Exploraciones invasivas: Arteriografía .......................................78

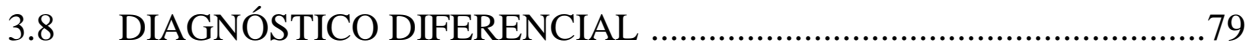

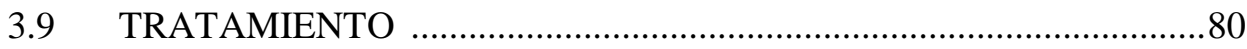

3.9.1 Modificación de los hábitos de vida............................................81

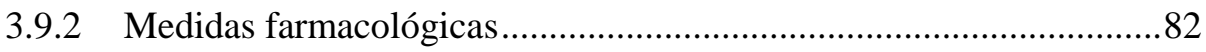

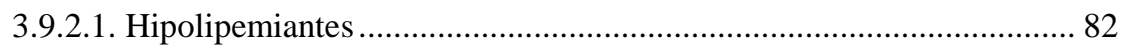

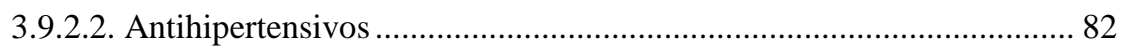

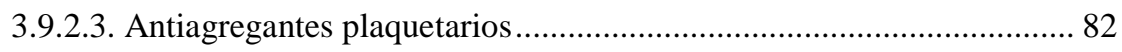

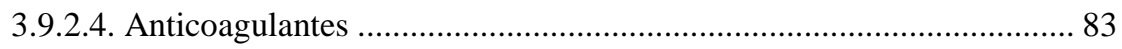

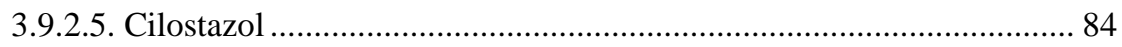

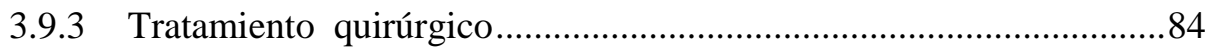

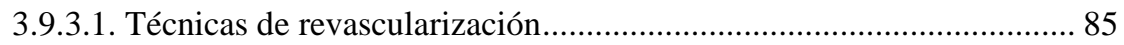

3.9.3.1.1. Cirugía convencional: Derivación vascular ........................ 85

3.9.3.1.2. Cirugía convencional: Endarterectomía............................... 87

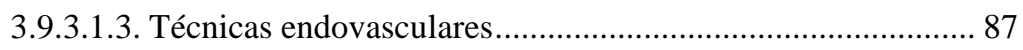

3.9.3.2. Técnicas quirúrgicas hiperemiantes alternativas ............................... 89

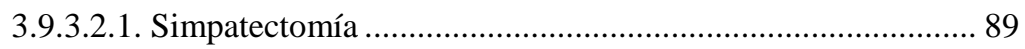

3.9.3.2.2. Estimulación de cordones posteriores.................................. 91

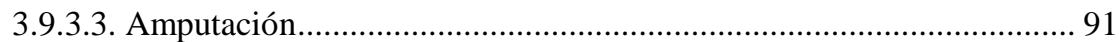

4 LA ANESTESIA/ANALGESIA EPIDURAL EN LA ARTERIOPATIA PERIFÉRICA CRÓNICA .................................. 93

4.1 EN LA CIRUGÍA VASCULAR DE LAS EXTREMIDADES

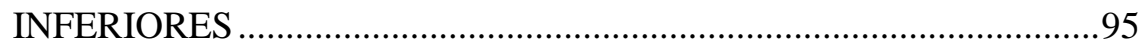

4.2 EN EL TRATAMIENTO DEL DOLOR POSTOPERATORIO.............98

4.3 EN EL TRATAMIENTO DEL DOLOR POR INSUFICIENCIA ARTERIAL PERIFÉRICA Y DE LA INSUFICIENCIA VASCULAR TISULAR .............................................................98 
5 HIPÓTESIS Y OBJETIVOS 107

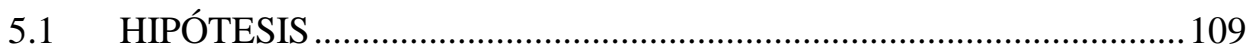

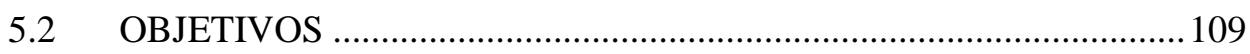

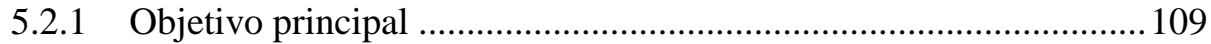

5.2.2 Objetivos secundarios …………………………............................. 110

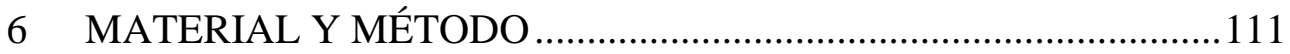

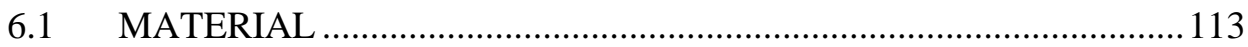

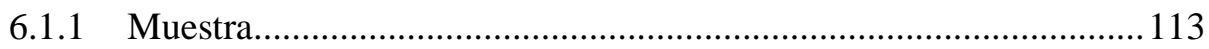

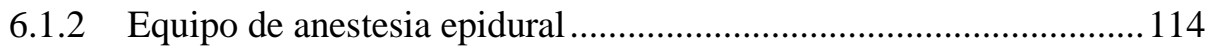

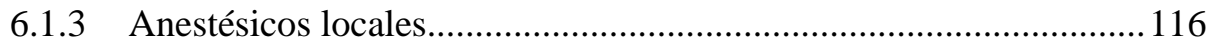

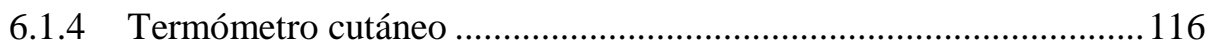

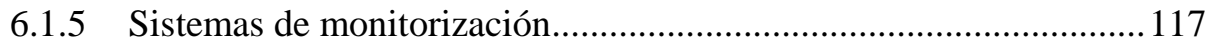

6.1.6 Hoja de recogida de datos ................................................................. 117

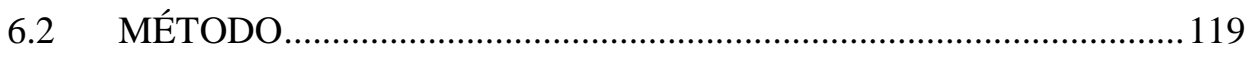

6.2.1 Diseño del protocolo de estudio y autorización de la Comisión de Investigación del Centro................................................................119

6.2.2 División de la muestra de la población a estudio ...............................119

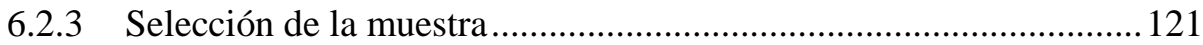

6.2.4 Protocolo para el manejo de los pacientes en la realización de la

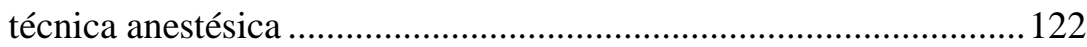

6.2.4.1. Recepción e identificación............................................................. 123

6.2.4.2. Procedimientos anestésicos............................................................. 123

6.2.5 Protocolo para el manejo del paciente para en la medición de

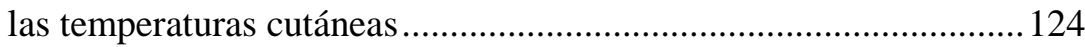

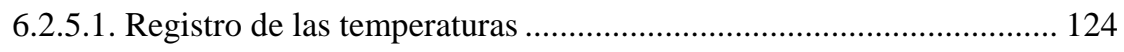

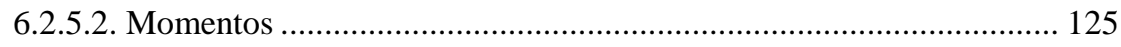

6.2.6 Protocolo para el manejo del paciente en la medición de los niveles metaméricos de bloqueo sensitivo alcanzados .......................125

6.2.6.1. Registro del nivel de bloqueo sensitivo ........................................... 125

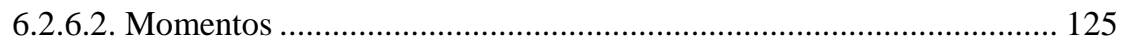

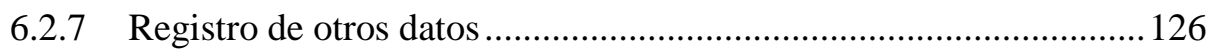


6.2.7.1. Datos antropométricos y antecedentes

6.2.7.2. Datos de la enfermedad y de la intervención quirúrgica .................... 126

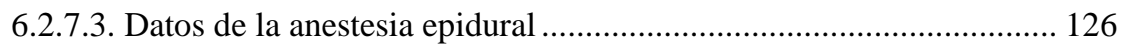

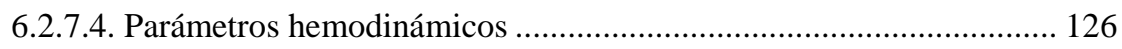

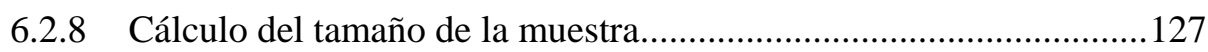

6.2.9 Análisis estadístico de los resultados .........................................127

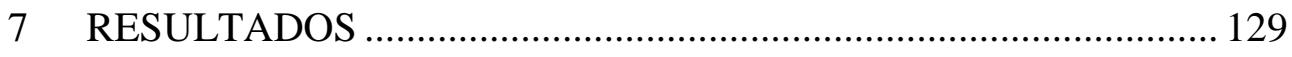

7.1 CARACTERÍSTICAS DE LA MUESTRA: PACIENTES

CONTROLES Y PACIENTES VASCULARES ..............................131

7.2 CARACTERÍSTICAS DE LA REALIZACIÓN DE LA TÉCNICA EPIDURAL Y DEL BLOQUEO SENSITIVO CONSEGUIDO EN LOS CONTROLES Y VASCULARES.

7.3 ANÁLISIS DE LA TEMPERATURA CUTÁNEA EN LAS EXTREMIDADES, OMBLIGO Y PEZÓN DE CONTROLES y

VASCULARES: GRUPO I, II, II $_{\mathrm{a}}$ y $\mathrm{II}_{\mathrm{b}}$

7.3.1 Análisis de la temperatura intergrupos, en los distintos momentos de medición.

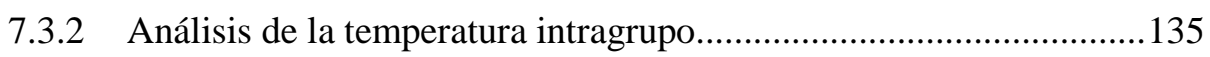

7.3.3 Análisis de las variaciones de la temperatura intergrupo ..................136

7.3.4 Análisis de las variaciones de la temperatura intragrupo .................142

7.4 ANÁLISIS DE LAS CONSTANTES HEMODINÁMICAS DE

LOS PACIENTES VASCULARES.

7.5 CARACTERÍSTICAS DE LA MUESTRA: GRUPO $\mathrm{II}_{\mathrm{R}+}, \mathrm{II}_{\mathrm{R}-} \mathrm{y}$ CONTROL

7.6 CARACTERÍSTICAS DE LA REALIZACIÓN DE LA TÉCNICA EPIDURAL Y DEL BLOQUEO SENSITIVO CONSEGUIDO DEL GRUPO $\mathrm{II}_{\mathrm{R}+}, \mathrm{II}_{\mathrm{R}-}$ y CONTROL 148

7.7 ANÁLISIS DE LA TEMPERATURA CUTÁNEA EN LAS EXTREMIDADES, OMBLIGO Y PEZÓN DEL GRUPO II $\mathrm{R}_{\mathrm{R}+}, \mathrm{II}_{\mathrm{R}-}$ y CONTROL 150 
7.7.1 Análisis de la temperatura intergrupos, en los distintos momentos de medición

7.7.2 Análisis de la temperatura intragrupo

7.7.3 Análisis de las variaciones de la temperatura intergrupos

7.7.4 Análisis de las variaciones de la temperatura intragrupo

7.8 ANÁLISIS DE LAS CONSTANTES HEMODINÁMICAS DE LOS PACIENTES CON ARTERIOPATÍA PERIFÉRICA CRÓNICA: GRUPO $\mathrm{II}_{\mathrm{R}+\mathrm{y}} \mathrm{II}_{\mathrm{R}-}$

7.9 ANÁLISIS DE CORRELACIÓN DE LA VARIACIÓN DE LA TEMPERATURA EN EL PIE DE LOS PACIENTES VASCULARES

7.10 ANÁLISIS MULTIVARIANTE: MODELO DE REGRESIÓN LOGÍSTICA 164

8 DISCUSIÓN 165

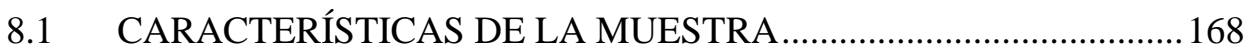

8.2 CARACTERÍSTICAS DE LA ANESTESIA EPIDURAL ................... 170

8.3 CAMBIOS DE LA TEMPERATURA CUTÁNEA DESPUÉS DE REALIZAR UNA ANESTESIA EPIDURAL EN PERSONAS SIN Y CON ENFERMEDAD ARTERIAL PERIFÉRICA CRÓNICA.

8.3.1 Comportamiento termocutáneo de las extremidades en personas sin enfermedad arterial periférica, durante los 30 minutos que siguieron a la inyección vía epidural de bupivacaína $0,5 \%$

8.3.2 Comportamiento termocutáneo de las extremidades en personas con enfermedad arterial periférica, durante los 30 minutos que siguieron a la inyección de bupivacaína $0,5 \%$ vía epidural

8.3.3 Comportamiento termocutáneo de las regiones cefálicas del cuerpo, durante los 30 minutos que siguieron a la inyección vía epidural de bupivacaína $0,5 \%$

8.4 FACTORES QUE INFLUYERON EN LOS CAMBIOS DE LA TEMPERATURA CUTÁNEA DE LAS EXTREMIDADES 
INFERIORES, DE PERSONAS CON ENFERMEDAD ARTERIAL PERIFÉRICA OCLUSIVA CRÓNICA, DESPUÉS DE UNA ANESTESIA EPIDURAL LUMBAR...................................178

8.5 CAMBIOS HEMODINÁMICOS EN LAS PERSONAS CON ENFERMEDAD ARTERIAL PERIFÉRICA OCLUSIVA CRÓNICA, DESPUÉS DE UNA ANESTESIA EPIDURAL

LUMBAR

8.6 CONSIDERACIONES A NUESTRO ESTUDIO Y FUTUROS TRABAJOS 186

8.6.1 La muestra de la población de estudio 186

8.6.2 Material utilizado para detectar un aumento de flujo sanguíneo a una zona del cuerpo

8.6.3 Tiempo de seguimiento de la muestra ............................................189

8.7 APLICACIÓN CLÍNICA DE NUESTROS RESULTADOS .................191

8.7.1 Para confirmar el establecimiento efectivo y la extensión del bloqueo anestésico epidural

8.7.2 Para prever la utilidad de una simpatectomía definitiva en personas con arteriopatía periférica crónica

9 CONCLUSIONES 


\section{INTRODUCCIÓN}





\section{INTRODUCCIÓN}

La anestesia y /o analgesia epidural, denominada también extradural o peridural, se ha convertido en una técnica rutinaria en el manejo del paciente durante el periodo perioperatorio; incluso se ha extendido fuera de la práctica quirúrgica, a salas de parto, clínicas del dolor, unidades de cuidados intensivos y salas de hospitalización (1). Consiste dicha técnica en inyectar en el espacio epidural -situado en el canal vertebral, por fuera de la duramadre- anestésicos locales, asociados en ocasiones a otros fármacos (clonidina, opioides, adrenalina, bicarbonato), con el fin de producir un bloqueo metamérico de la conducción nerviosa; es decir, para bloquear:

a) La sensibilidad térmica y dolorosa (analgesia)

b) La propiocepción

c) El sistema nervioso vegetativo simpático (simpatectomía) y

d) La actividad motora (relajación muscular), de la zona del cuerpo que esté inervada por las raíces nerviosas embebidas en el anestésico local (2).

En las personas que no padecen patología vascular, la simpatectomía metamérica de la anestesia epidural, provoca, como han mostrado Cousins y otros, una vasodilatación arterial y venosa (2-4), con aumento del flujo sanguíneo, de la temperatura cutánea (2,4-6), de la presión parcial de oxígeno capilar y venosa de la piel y de la saturación de oxígeno (5), del área bloqueada. Sin embargo, el efecto de la simpatectomía en pacientes con arteriopatía periférica crónica, se dice que es impredecible $(2,4,7)$. 


\section{INTRODUCCIÓN}

El estudio de la temperatura cutánea se ha utilizado en el diagnóstico de varias patologías, como por ejemplo, en alteraciones del sistema nervioso simpático, en cuadros de dolor crónico (síndrome de dolor regional complejo), en la arteriopatía periférica distal y en cuadros de isquemia aguda...entre otras $(2,6)$.

Conocer la modificación de la temperatura cutánea después de una anestesia epidural, debido a la simpatectomía y a la característica distribución metamérica del bloqueo que esta técnica produce (2), tiene su importancia, pues podría ayudarnos, entre otras cosas:

- En la evaluación de la extensión $(8,9)$ y/o eficacia $(10,11)$ del bloqueo anestésico

- A comprobar la utilidad del bloqueo simpático en tratamientos de cuadros dolorosos o

- Para el diagnóstico de cuadros de hiperexcitabilidad del sistema nervioso simpático $(2,12)$.

La arteriopatía periférica crónica es una patología muy frecuente, ocasionada habitualmente por una aterosclerosis generalizada, en la que existe una disminución del flujo sanguíneo, fundamentalmente en las extremidades inferiores. Con frecuencia estos pacientes precisan ser intervenidos para mejorar la circulación sanguínea de sus extremidades, así como el dolor, muchas veces mantenido por una hiperexcitabilidad de su sistema nervioso simpático $(2,13)$. Una de las técnicas anestésicas utilizadas con frecuencia en estos pacientes, para la realización de las diversas técnicas quirúrgicas revascularizadoras de sus extremidades inferiores, es la epidural (13). 


\section{INTRODUCCIÓN}

Por todo lo anteriormente expuesto, pensamos que el estudio termocutáneo después de una anestesia epidural, podría tener una utilidad clínica diagnóstica, pronóstica y terapéutica en esta patología, en la que existe un flujo sanguíneo disminuído a las extremidades.

Tras la puesta al día del estado de conocimiento de la anestesia epidural y de la arteriopatía periférica oclusiva crónica, en este estudio presentamos los efectos térmico-cutáneos y clínicos de la anestesia epidural con bupivacaína en sujetos sin arteriopatía periférica y en pacientes con arteriopatía periférica crónica, con el fin de observar si hay diferencias termo-cutáneas atendiendo a la presencia o no de lesiones vasculares oclusivas. 

2 LA ANESTESIA/ANALGESIA EPIDURAL 



\subsection{DEFINICIÓN Y CONCEPTO $(14,15)$}

El bloqueo epidural es una técnica metamérica de gran utilidad clínica en la práctica de la anestesia y analgesia locorregional. Consiste en inyectar en el espacio epidural anestésicos locales y/u otros fármacos, que producen un bloqueo de la sensibilidad (dolor, temperatura), un bloqueo motor, propioceptivo y del sistema nervioso simpático, que dependerá del tipo y características del fármaco utilizado (14).

Es una técnica que tiene aplicaciones múltiples, y se utiliza fundamentalmente $(14,15)$ :

- En cirugía, como técnica anestésica única o combinada con otras (subaracnoidea, general) para el control del dolor durante el periodo intraoperatorio, presenta ventajas evidentes: la disminución de la respuesta al estrés de la cirugía, del sangrado intraoperatorio y de tromboembolismos postoperatorios.

- Para el tratamiento eficaz del dolor postoperatorio, sin los efectos secundarios de los analgésicos intravenosos.

- Para el control del dolor crónico.

- Para el control del dolor del parto, sola o combinada con la técnica subaracnoidea. 


\subsection{BREVE RECUERDO HISTÓRICO $(14,16)$}

La práctica de la anestesia epidural es hoy en día habitual en los quirófanos, en las unidades del dolor, en las salas de hospitalización y de partos... Todo ello, gracias al intenso desarrollo que dicha técnica ha experimentado desde sus inicios, en 1901. Fue entonces, cuando dos médicos franceses, el radiólogo Jean-Athanase Sicard (1872-1929) y el cirujano Fernand Cathelin (1873-1945), trabajando independientemente el uno del otro, inyectaron, entre otras sustancias, como morfina, yoduro de potasio, etc., soluciones de cocaína en el espacio epidural a través del hiato sacro, para tratar el lumbago. Fueron ellos quienes describieron por primera vez el bloqueo caudal.

El descubrimiento y aplicación definitiva de la técnica de la anestesia-analgesia epidural sucedió un poco más avanzado el siglo XX. Fue por primera vez comunicada oficialmente a la sociedad científica de Estados Unidos en 1931, por el cirujano italiano Achille Mario Dogliotti Ferrara (1897-1966). Pero el descubrimiento real de la anestesia epidural se había llevado a cabo 10 años antes, por el médico militar español Fidel Pagés Miravé (1886-1923) (Fig. 1). 


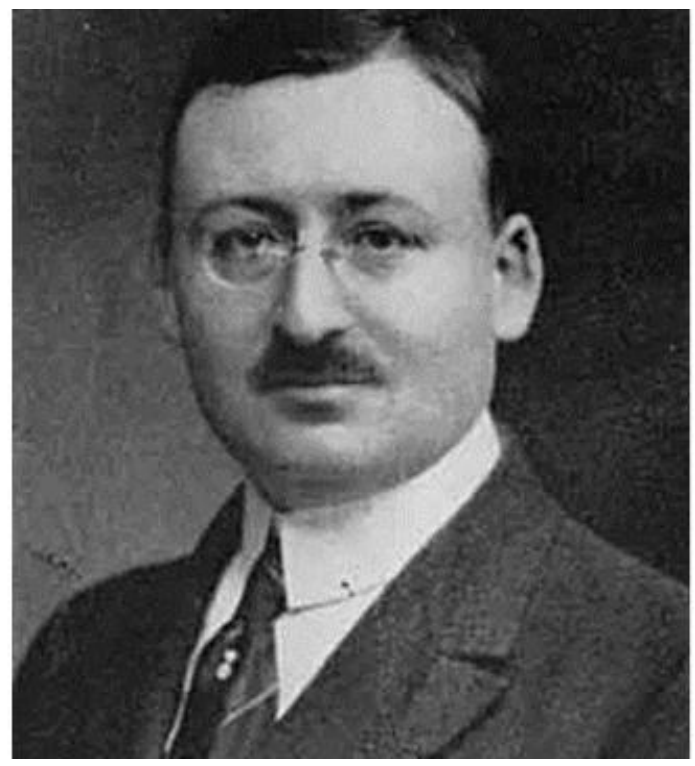

Figura 1: Fidel Pagés. Descubridor de la "anestesia metamérica"

En marzo de 1921, Fidel Pagés escribió un artículo titulado “Anestesia Metamérica”, que publicó a la vez en la Revista Española de Cirugía y en la Revista de Sanidad Militar. Decía entre otras cosas en su artículo: "En el mes de noviembre del pasado año, al practicar una raquianestesia, tuve la idea de detener la cánula en pleno conducto raquídeo, antes de atravesar la duramadre, y me propuse bloquear las raíces fuera del espacio meníngeo y antes de atravesar los agujeros de conjunción, puesto que la punta de la aguja había atravesado el ligamento amarillo correspondiente [...]. Hice la disolución de [...] (375mg de novocaína) en $25 \mathrm{cc}$ de suero fisiológico, procediendo a inyectarlo entre las vértebras lumbares $2^{\mathrm{a}}$ y $3^{\mathrm{a}}$ [...]. El resultado de este intento nos animó a seguir estudiando este método, al que en clínica denominamos de anestesia metamérica, por la posibilidad que nos proporciona de privar de sensibilidad a un segmento del cuerpo, dejando con ella a las porciones que están por encima y por debajo del segmento medular de donde proceden las raíces bloqueadas”. En este trabajo Pagés hace una completa revisión bibliográfica, 
una exposición de las bases anatómicas de su procedimiento, describe al detalle la técnica de la anestesia metamérica por punción epidural -distinta, como es sabido, de la de la raquianestesia- la extensión y particularidades de la misma, los fenómenos colaterales, y sus ventajas e inconvenientes. Pero desgraciadamente, el 21 de septiembre de 1923, Fidel Pagés falleció víctima de un accidente de tráfico, por lo que ello le privó de dar difusión y reclamar la paternidad del descubrimiento.

En 1931, el ya citado cirujano italiano Dogliotti (Fig.2), desconociendo el artículo que había publicado diez años antes Fidel Pagés, presentó como original la técnica de la anestesia epidural lumbar a la que llamó “peridural segmentaria”. Incluso, en 1932 la presentó en el Congreso de la Sociedad Internacional de cirugía (SIC) celebrado en Madrid, sin que ningún asistente interviniera para recordar el papel de Pagés. La técnica, a partir de este momento, comenzó a difundirse con rapidez por todo el mundo, pasándose a conocer como "técnica de Dogliotti". La primera publicación de Dogliotti sobre esta técnica, la hizo en el Bolletino e memorie della Societá piemontese di chirurgia, en relación con un trabajo que presentó en la reunión clínica del 18 de abril de 1931 en dicha sociedad. El trabajo se titulaba "Un promettente Metodo di Anestesia Tronculare in Studio: la Rachianestesia Peridurale Segmentaria", en el que informaba haber realizado exitosamente operaciones abdominales empleando la anestesia epidural por vía lumbar, con una sola dosis de anestésico. 


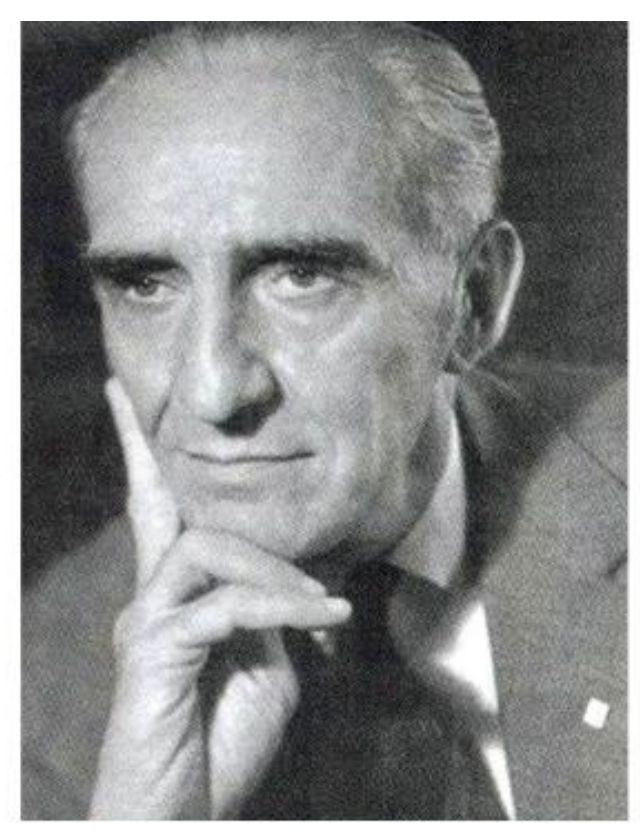

Figura 2: Achille Mario Dogliotti Ferrara

En esta época, el abordaje del espacio epidural, dependía exclusivamente del tacto del que la realizara, de tal manera que cuando notaban que habían atravesado el ligamento amarillo y, viendo que no refluía líquido cefalorraquídeo (LCR), suponían que estaban en el espacio epidural. Dogliotti, en 1933, describe también el acceso al espacio epidural por el método de la "pérdida de resistencia", realizado mediante una jeringa con solución salina conectada a la aguja para acceder a dicho espacio. Por la misma época, otro cirujano, esta vez en Argentina, Alberto Gutiérrez, describió otra forma de localización del espacio epidural: El método de la "gota pendiente". Además, este mismo cirujano publicó en 1932, una clase de Clínica Quirúrgica dictada por él en mayo, en la que por primera vez reivindicó para Pagés, el descubrimiento de la técnica de la anestesia epidural. La Academia de Cirugía de Madrid propuso entonces denominar a la técnica anestésica epidural, como técnica de Pagés-Dogliotti. 
La realización de anestesias epidurales de forma continua, mediante la introducción de un catéter ureteral muy fino, a través de una aguja de Tuohy con punta de Huber, se debe al médico cubano Pío Manuel María Martínez Curbelo (1906-1952) (Fig. 3). Fue el primero en realizarlas, en 1947, en el Hospital de Emergencias de La Habana, en una mujer de 40 años de edad aquejada de un quiste gigante de ovario. Posteriormente lo publicó en 1949 en la revista "Current Research in Anesthesia \& Analgesia".

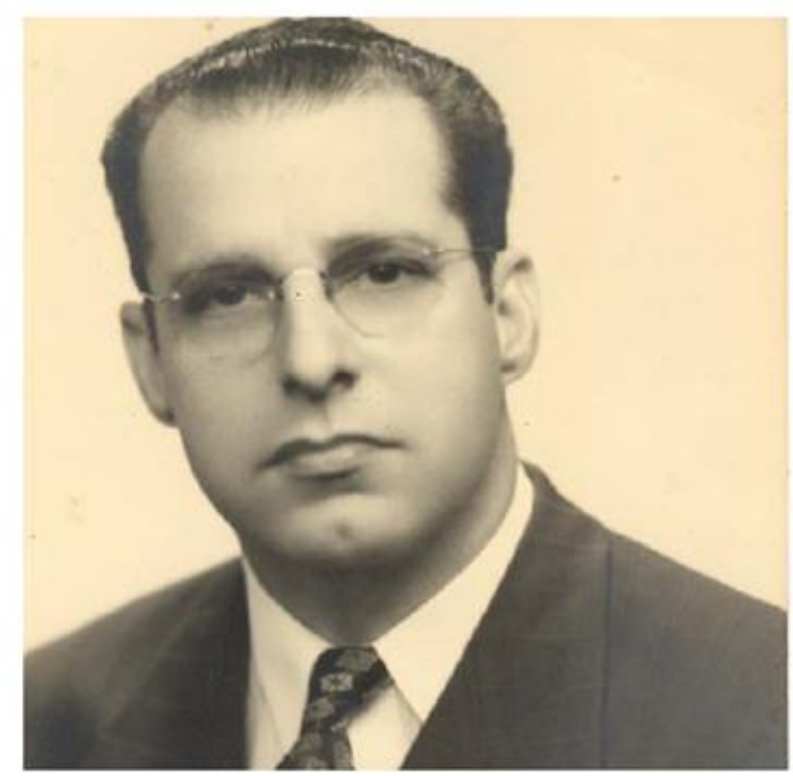

Figura 3: Pío Manuel María Martínez Curbelo

Curbelo, que era un gran conocedor del efecto bloqueador de los impulsos simpáticos preganglionares, aplicó también la técnica de la anestesia/analgesia epidural en las arteriopatías periféricas. En 1957, en el 51st Congress of the Southern Medical Association, presenta una conferencia titulada "Bloqueos simpáticos lumbares con anestesia epidural continua como tratamiento de las enfermedades vasculares de los miembros inferiores", en la que mostraba cómo la anestesia epidural continua limitaba 
el área de necrosis, favorecía la circulación colateral y reducía la extensión de las amputaciones de miembros inferiores en situación de isquemia aguda, causada por trombosis arterial.

La aplicación y generalización en nuestro medio de la anestesia epidural para la cirugía es reciente. En los últimos 15-20 años se ha ido aprendiendo y sistematizando su uso tanto para anestesia como para analgesia, y como técnica diagnóstica y terapéutica (simpatectomía epidural).

\subsection{ANATOMÍA DEL ESPACIO EPIDURAL $(14,17)$}

Para entender el funcionamiento de la anestesia epidural es necesario conocer sus fundamentos anatómicos.

El espacio epidural es una cavidad situada dentro del canal vertebral. Se extiende desde la base del cráneo (agujero occipital) hasta la membrana sacrocoxígea, (a la altura de la segunda vértebra sacra) (Fig. 4), pudiéndose abordar a lo largo de todo su recorrido (cervical, torácico, lumbar y caudal). Tiene una comunicación directa con el espacio paravertebral. 


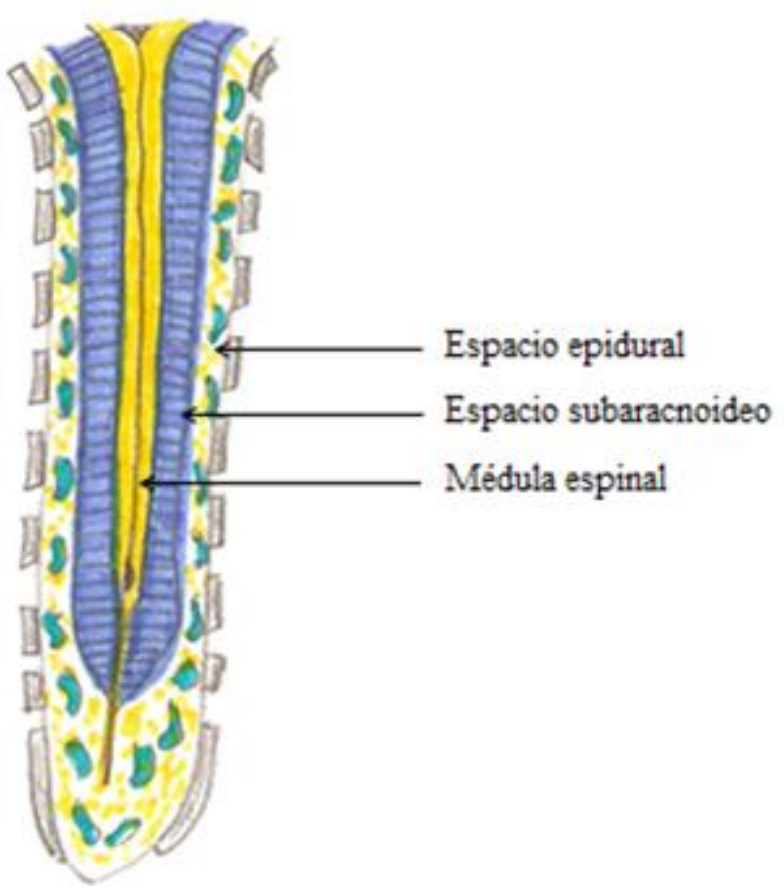

Figura 4: Corte longitudinal columna vertebral

Posteriormente está limitado por el ligamento amarillo, las superficies anteriores de las láminas vertebrales y apófisis articulares. Anteriormente, por el ligamento longitudinal posterior que cubre los cuerpos vertebrales y discos intervertebrales. Lateralmente está limitado por los agujeros intervertebrales y los pedículos vertebrales. Internamente está limitado por la duramadre medular (Fig. 5). 


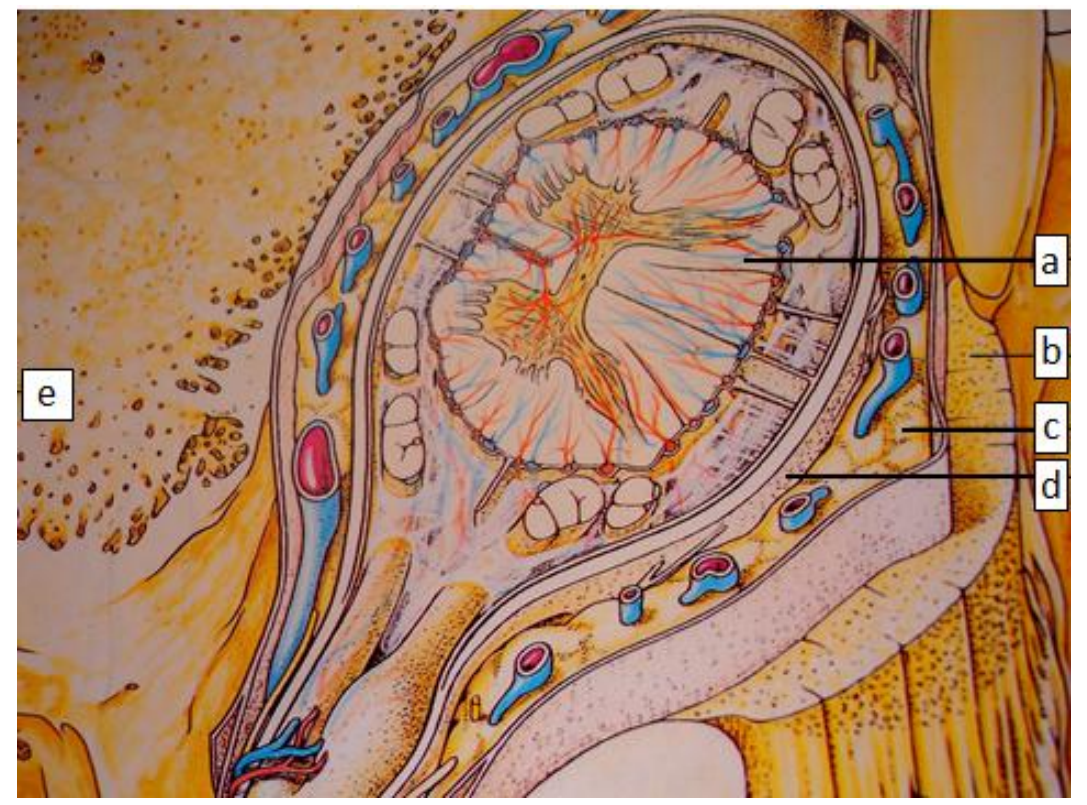

Figura 5: Corte sagital columna vertebral: a) médula espinal, b) ligamento amarillo, c) espacio epidural, d) duramadre, e) cuerpo vertebral

En su interior contiene tejido graso, vasos linfáticos y venas. Las venas epidurales, que no tienen válvulas, se comunican directamente con venas intracraneales y, a través de los agujeros intervertebrales, con venas pélvicas y el plexo venoso sacro.

La anchura del espacio epidural es mayor en el centro y menor a medida que nos acercamos a los laterales. Es de 5-6 mm de ancho en la línea media de la región lumbar y de 3-5 mm de ancho en la línea media de la región torácica. 


\subsection{EFECTOS FISIOLÓGICOS DE LA ANESTESIA EPIDURAL $(14,17)$}

\subsubsection{Bloqueo nervioso}

Los anestésicos locales depositados en el espacio epidural actúan directamente sobre las raíces nerviosas raquídeas localizadas en la parte lateral del espacio, donde están rodeadas por una vaina de duramadre. Parte del anestésico puede acceder al líquido cefalorraquídeo por captación de la duramadre. El inicio del bloqueo es más lento, y la intensidad del bloqueo sensitivo y motor es menor que con la anestesia intradural. La anestesia se desarrolla de forma metamérica pudiéndose realizar un bloqueo selectivo de una zona del cuerpo

\subsubsection{Cardiovascular}

Los cambios cardiovasculares (hipotensión arterial y bradicardia/taquicardia), que suceden después de una anestesia epidural, son por el bloqueo simpático que se produce. La hipotensión arterial es proporcional a la extensión del bloqueo. Se provoca una vasodilatación arterial y venosa, que ocasiona una disminución de las resistencias vasculares sistémicas y del retorno venoso. La bradicardia sucede cuando el nivel de bloqueo alcanza la metámera torácica cuarta (T4), interrumpiendo la conducción de las fibras simpáticas cardiacas y de las extremidades superiores, o también por un reflejo vagal protector cardiaco, reflejo de Bezold-Jarisch, iniciado por mecanorreceptores del ventrículo izquierdo, en respuesta a una disminución del retorno venoso, y por tanto del volumen telesistólico, que provoca una disminución de la frecuencia cardiaca para alargar el tiempo de llenado del corazón (18). Otras veces, cuando el nivel de bloqueo no alcanza la metámera T4, puede suceder una activación de las fibras simpáticas cardiacas y una vasoconstricción de las extremidades 


\section{LA ANESTESIA/ANALGESIA EPIDURAL}

superiores modulado por barorreceptores, que intenta compensar las resistencias vasculares disminuidas de una región del cuerpo.

\subsubsection{Respiratorio}

Cuando los niveles de bloqueo anestésico conseguidos no son muy cefálicos, la anestesia epidural no tiene ningún efecto sobre la ventilación. A medida que los niveles de bloqueo ascienden hacia el área torácica, comienza a producirse, de forma ascendente, una parálisis de los músculos intercostales. Esto suele tener poco efecto sobre la ventilación de los pacientes quirúrgicos que se encuentran en una posición supina y mantienen intacta la función diafragmática. Puede tener un efecto perjudicial en pacientes que tengan una reserva respiratoria disminuida (ej. obesos mórbidos).

La función de la tos se deteriora en pacientes con bloqueo de la región abdominal y torácica, lo que puede ser perjudicial en los pacientes con enfermedad pulmonar obstructiva crónica.

Cuando se usa la epidural con fines exclusivamente analgésicos para cirugía abdominal inferior, abdominal superior o torácica, la repercusión sobre la ventilación es mínima, incluso puede mejorar debido al mejor control del dolor y al uso de menores dosis de opiáceos vía sistémica.

\subsubsection{Coagulación}

La anestesia epidural disminuye el riesgo de trombosis venosa $\mathrm{y}$ posterior embolismo pulmonar, debido a una respuesta simpática disminuida a la cirugía. También la anestesia epidural reduce el sangrado durante la cirugía de cadera, pelvis y abdomen inferior. 


\subsubsection{Gastrointestinal y de otras vísceras}

La anestesia epidural al reducir el consumo de opiáceos y mantener la actividad parasimpática, disminuye el íleo paralítico postoperatorio.

Además debido a la supresión del sistema nervioso simpático, la anestesia epidural produce atonía vesical y uretral.

\subsubsection{Termorregulación}

Es frecuente la hipotermia después de una cirugía bajo anestesia epidural, debido a la redistribución del calor del compartimento central al periférico, que está vasodilatado, y del periférico vasodilatado al medio ambiente. Además, también se pierde el mecanismo vasoconstrictor termorregulador normal del organismo.

\subsubsection{Sistema neuroendocrino}

Cuando el nivel de bloqueo alcanza la metámera T5, se inhibe parte del componente nervioso de la respuesta al estrés de la cirugía, mediante el bloqueo de las fibras nerviosas simpáticas aferentes a la médula adrenal, y mediante el bloqueo simpático y somático de las vías que conducen el dolor.

\subsubsection{Sistema nervioso central}

Según el grado de extensión del bloqueo epidural, se produce una depresión del sensorio (sedación) por disminución de las aferencias sensitivas. 


\subsection{TÉCNICA Y MATERIAL PARA REALIZAR UNA ANESTESIA EPIDURAL $(17,19)$}

\subsubsection{Agujas epidurales}

La aguja más frecuentemente utilizada para la localización del espacio epidural, es la de Tuohy 18 Gauge (G) (Fig. 6). Esta aguja tiene un borde principal romo, con una abertura lateral y una pared fina que permite el paso de un catéter de calibre 22.

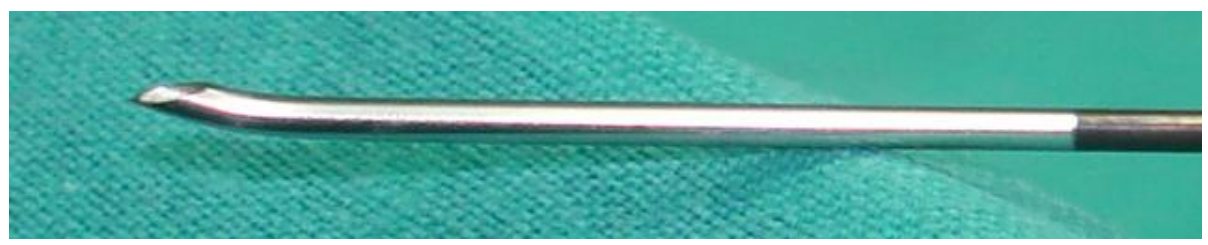

Figura 6: Aguja de Tuohy

\subsubsection{Posición del paciente}

La posición del paciente puede ser sentado o en decúbito lateral con flexión de las rodillas.

\subsubsection{Acceso al espacio epidural}

El acceso al espacio epidural debe hacerse en la línea media, independientemente de que la zona de punción cutánea sea medial o paramedial, ya que en esta zona el espacio epidural es más ancho y por tanto la posibilidad de puncionar la duramadre es menor. Además, existe un menor riesgo de pinchar raíces nerviosas y vasos sanguíneos que suelen localizarse más lateralmente. 


\subsubsection{Preparación de la zona cutánea}

Se palpa el espacio entre dos apófisis espinosas (espacio interespinoso) por dónde se va a introducir la aguja epidural. Se desinfecta el área de la piel de forma ampliada, y con guantes estériles, se realiza un habón cutáneo y en profundidad en los ligamentos que vayan a ser atravesados, con un anestésico local de acción rápida como la lidocaína (Fig. 7).
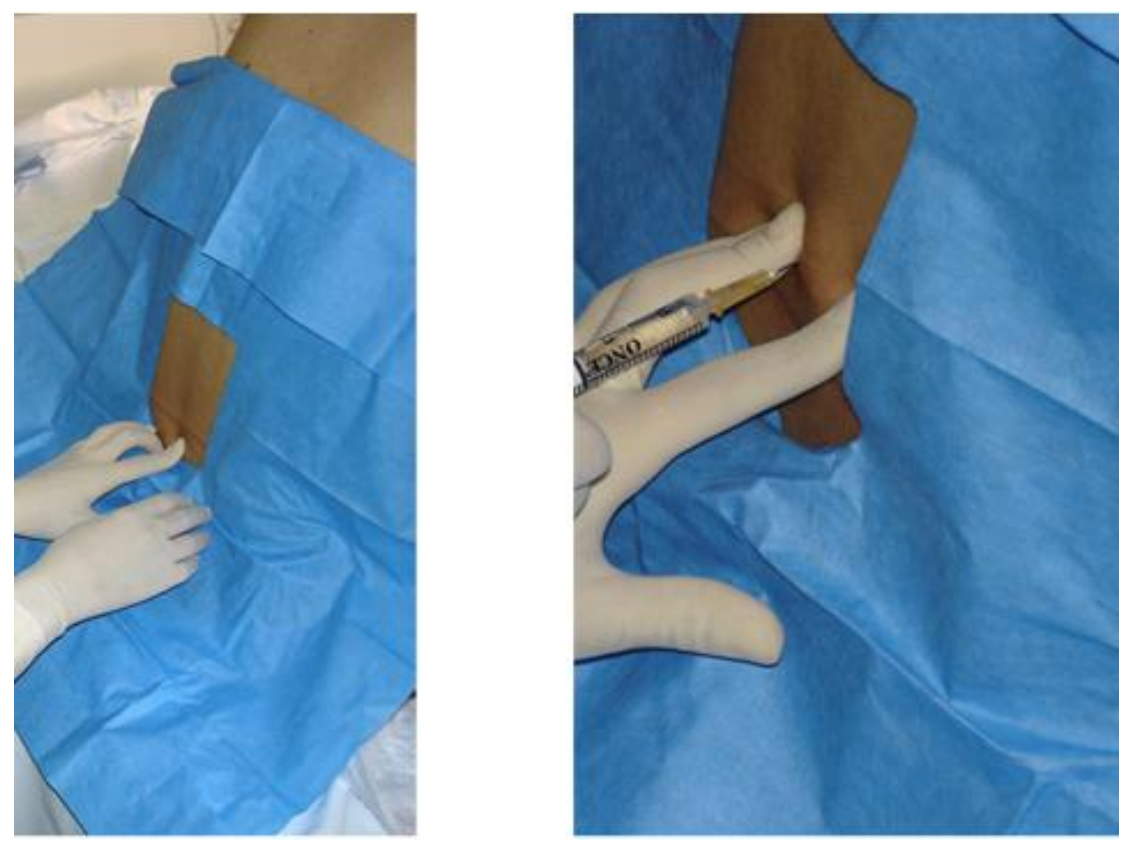

Figura 7: Localización del espacio interespinoso e infiltración de la piel con anestésico local

\subsubsection{Forma de acceso desde la piel}

2.5.3.2.1. Abordaje vía medial: Se punciona en la línea que une dos apófisis espinosas contiguas, introduciendo la aguja en el espacio interespinoso, e intentando seguir la angulación cefálica de estas. Antes de llegar al espacio epidural se atravesará el ligamento supraespinoso e interespinoso (Fig. 8) 


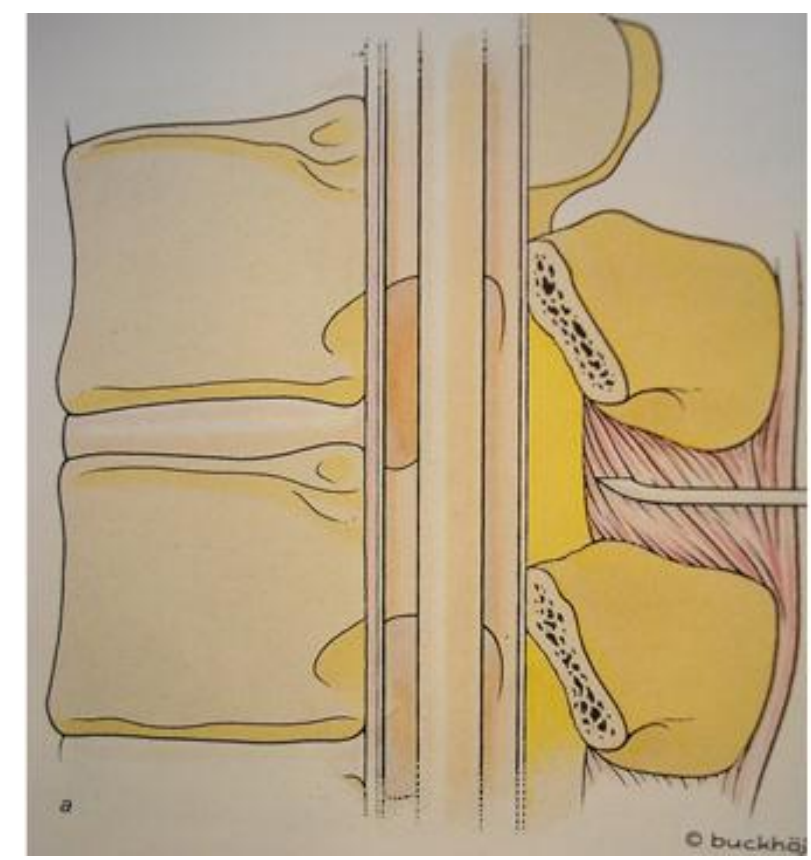

Figura 8: Abordaje del espacio epidural. Aguja situada en el ligamento interespinoso

2.5.3.2.2. Abordaje paramedial: Es un abordaje útil en pacientes que no pueden flexionar adecuadamente su espalda, o en aquellos en los que el ligamento interespinoso esté muy osificado. Se punciona la piel $1,5 \mathrm{~cm}$ laterales y $1 \mathrm{~cm}$ caudalmente al espacio interespinoso seleccionado. La punta de la aguja se orienta medialmente y ligeramente cefálica, pasando lateralmente al ligamento supraespinoso

\subsubsection{Localización del espacio epidural}

2.5.3.3.1. Técnica de la pérdida de resistencia: Se conecta una jeringa de baja resistencia, con $3 \mathrm{ml}$ de suero fisiológico o de aire, a la aguja epidural después de retirar su fiador, y se hace avanzar la aguja a la vez que se presiona el émbolo de la jeringa de forma constante en el caso del suero, o de forma intermitente en el caso del aire. En el momento que la punta de 
la aguja atraviesa el ligamento amarillo, llegada al espacio epidural, se percibe una importante pérdida de resistencia.

2.5.3.3.2. Técnica de la gota pendiente: Se deposita una gota se suero fisiológico en el extremo opuesto a la punta de la aguja y a la vez la hacemos avanzar. En el momento de atravesar el ligamento amarillo y llegar por tanto al espacio epidural, se observa como la gota de suero salino se retrae dentro de la aguja.

2.5.3.3.3. Otras técnicas: El espacio epidural se puede localizar ayudándose de otros dispositivos, como el balón de Macintosh, el episensor y otros, que no han demostrado mayor fiabilidad en la localización del espacio epidural, que la técnica clásica.

\subsubsection{Introducción de un catéter epidural}

Una vez localizado el espacio epidural, se suele introducir a través de la aguja un catéter radiopaco, dejando unos 3-4 $\mathrm{cm}$ dentro del espacio epidural y fijándolo después adecuadamente a la piel para que no se mueva. Así se pueden realizar anestesias y tratamientos de dolor prolongados, ya que la aguja epidural, una vez localizado el espacio e introducido el anestésico local hay que retirarla (Fig. 9). 

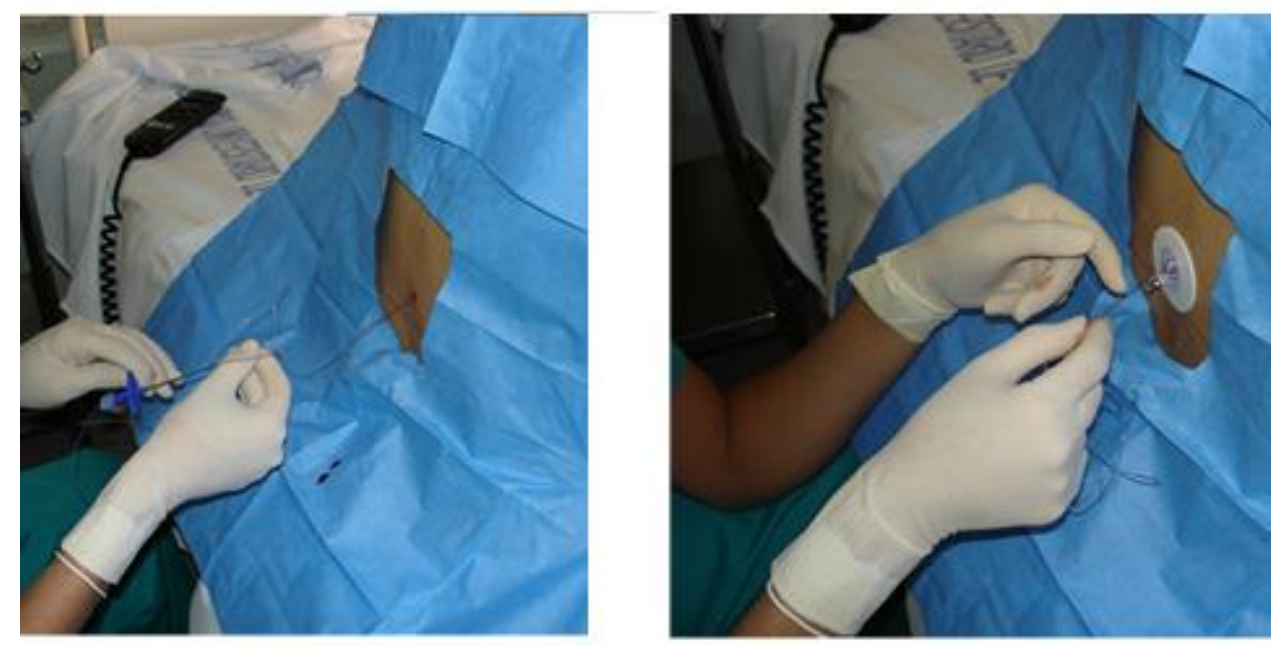

Figura 9: Retirada de la aguja epidural y fijación del catéter

\subsubsection{Introducción del anestésico local en el espacio epidural}

Antes de la inyección del anestésico local en el espacio epidural se debe aspirar con una jeringa a través de la aguja o del catéter, para comprobar que la punta de la aguja o catéter están localizadas dentro de este espacio y no dentro de un vaso sanguíneo (refluiría sangre) o dentro del espacio intradural (refluiría LCR).

\subsubsection{Dosis test}

A través de la aguja epidural o a través del catéter, en el caso de dejar colocado éste, se debe introducir una dosis pequeña de anestésico local con adrenalina (3ml de lidocaína 2\% con adrenalina 1:200.000 ó bupivacaína al 0,25\% con adrenalina al 1:200.000), que producirá mínimo bloqueo sensitivo en el caso de que se haya depositado en el espacio epidural. Si se ha inyectado dentro de un vaso sanguíneo inesperadamente, el paciente podrá notar hormigueo peribucal, sabor metálico, pitido de oídos entre otros, 
y se observará un aumento de su frecuencia cardiaca. Si se ha depositado en el espacio intradural, se observará un bloqueo espinal rápido.

\subsubsection{Dosis bolo}

Se inyectará la dosis de anestésico local deseada de cinco en cinco mililitros, esperando unos 5 minutos entre cada inyección, hasta alcanzar el nivel deseado. Siempre hay que realizar una aspiración con la jeringa entre cada inyección, para verificar la correcta colocación de la punta de la aguja o catéter.

\subsubsection{Mantenimiento}

La anestesia y/o analgesia se conserva con bolos repetidos o mediante una infusión continua de anestésico local y/u otros fármacos (opiáceos) por el catéter.

Es importante la determinación del nivel de bloqueo sensitivo conseguido y cada 5-10 minutos, el control de la tensión arterial y la frecuencia cardiaca. 
2.6 DETERMINANTES DEL NIVEL DE BLOQUEO EPIDURAL (14, $15,17)$

La extensión de la anestesia epidural se relaciona con varios factores: volumen, edad, embarazo, velocidad de infusión del anestésico local y posición.

\subsubsection{Volumen de anestésico local}

La extensión del bloqueo se relaciona con el volumen de anestésico epidural infundido. Se ha sugerido un máximo de 1,6 ml de anestésico local por metámera a bloquear. Este volumen puede ser sobrepasado si se usan los fármacos de forma muy diluida, como sucede para el control del dolor postoperatorio o para la analgesia del parto. A mayor volumen inyectado, mayor extensión del bloqueo.

\subsubsection{Edad}

El volumen de anestésico local debe reducirse aproximadamente un $50 \%$ en las personas ancianas. La progresiva estenosis de los agujeros intervertebrales que sucede a medida que avanza la edad, produce una disminución de la diseminación del anestésico local al espacio paravertebral, elevando el nivel cefálico del bloqueo.

\subsubsection{Embarazo}

En el embarazo se debe disminuir un $30 \%$ el volumen de anestésico local inyectado. La compresión de la vena cava inferior provoca un aumento del tamaño de las venas epidurales, y por tanto una disminución del tamaño 
real del espacio epidural, pudiendo elevarse igualmente el nivel del bloqueo anestésico.

\subsubsection{Velocidad de infusión del anestésico local}

Una inyección rápida del anestésico local en el espacio epidural produce un bloqueo de peor calidad que una inyectada más lentamente, a una velocidad de aproximadamente $0.5 \mathrm{ml} / \mathrm{seg}$. Una inyección muy rápida de grandes volúmenes de fármacos tiene el efecto potencial de aumentar la presión en el espacio epidural. Ese aumento de presión puede producir cefalea, aumento de presión intracraneal, y la posibilidad de isquemia medular por disminución del flujo sanguíneo espinal.

\subsubsection{Posición}

La posición del paciente por efecto de la gravedad, influye en el nivel de bloqueo epidural. Los pacientes que se sitúen semisentados tendrán un bloqueo más caudal. Los pacientes que se encuentren en decúbito lateral, tendrán un mayor bloqueo en la zona declive.

\subsection{DETERMINANTES DEL INICIO, DURACIÓN E INTENSIDAD DEL BLOQUEO EPIDURAL $(14,15,17)$}

\subsubsection{Selección del anestésico local}

El inicio y la duración del bloqueo anestésico dependen del tipo de anestésico local utilizado, y la intensidad de su concentración (Tabla 1). A mayor concentración del anestésico local mayor intensidad del bloqueo, de tal forma que concentraciones bajas, son analgésicas, y producen sólo 
bloqueo simpático y sensitivo; concentraciones elevadas, son anestésicas, y producen intenso bloqueo sensitivo, simpático, motor y propioceptivo.

Tabla 1: Anestésicos locales de uso más frecuente. Características e indicaciones habituales

\begin{tabular}{|l|c|c|c|l|}
\hline \multicolumn{1}{|c|}{ Agente } & $\begin{array}{c}\text { Concentración } \\
(\%)\end{array}$ & $\begin{array}{c}\text { Inicio } \\
(\mathrm{min})\end{array}$ & $\begin{array}{c}\text { Duración } \\
(\mathrm{min})\end{array}$ & \multicolumn{1}{|c|}{$\begin{array}{c}\text { Indicaciones } \\
\text { habituales }\end{array}$} \\
\hline Clorprocaína & $2-3$ & $5-15$ & $30-90$ & Obstetricia \\
Lidocaína & $1-2$ & $5-15$ & $60-120$ & Obstetricia/Cirugía \\
Mepivacaína & $1-2$ & $5-15$ & $60-150$ & Cirugía \\
Prilocaína & $1-3$ & $5-15$ & $60-150$ & Cirugía \\
Bupivacaína & $0,25-0,75$ & $15-20$ & $120-240$ & $\begin{array}{l}\text { Obstetricia/Cirugía } \\
\text { Obstetricia/Cirugía }\end{array}$ \\
Levobupivacaína & $0,25-0,75$ & $15-20$ & $120-240$ & $\begin{array}{l}\text { /Postoperatorio } \\
\text { Obstetricia/Cirugía }\end{array}$ \\
Ropivacaína & $0,2-0,75$ & $15-20$ & $120-240$ & /Postoperatorio \\
\hline
\end{tabular}

min, minutos

\subsubsection{Adicción de coadyuvantes}

\subsubsection{Adrenalina}

La adrenalina a una concentración de 1:200.000 prolonga la duración del bloqueo, por disminución de la absorción del anestésico local del espacio epidural al torrente sanguíneo.

\subsubsection{Opiáceos y clonidina}

Cuando uno de estos fármacos se añade a la solución de anestésico local provoca un comienzo más rápido del bloqueo, prolonga su duración y mejora su calidad. 


\subsubsection{Bicarbonato}

El bicarbonato añadido a la solución de anestésico local $(1 \mathrm{ml}$ de bicarbonato al $8,4 \%$ añadido a la lidocaína o mepivacaína y $0,1 \mathrm{ml}$ de bicarbonato al 8,4\% añadido a la bupivacaína o levobupivacaína) provoca un comienzo precoz del bloqueo. Esto se debe a que los anestésicos locales son bases débiles, por lo que al alcalinizar el ambiente dónde se introducen, aumenta la cantidad de anestésico local en forma no ionizada, que es la parte activa.

\subsection{ANESTÉSICOS LOCALES $(14,15,17)$}

Los anestésicos locales son bases débiles, cuya acción farmacológica principal consiste en la inhibición, parcial o total, de la conducción nerviosa.

Se clasifican químicamente en dos grupos diferentes: los aminoésteres y los aminoamidas.

- Los aminoésteres son relativamente inestables en solución, fácilmente hidrolizados en el plasma por la enzima colinesterasa y con un producto de degradación con alta capacidad alergénica. Este grupo incluye a la procaína, tetracaína y clorprocaína.

- Los aminoamidas son más estables, no son hidrolizados en el plasma, sino que sufren una degradación enzimática en el hígado, y sus productos de degradación tienen menor capacidad alergénica. A este grupo pertenecen la mepivacaína, la prilocaína, la lidocaína, la bupivacaína, la levobupivacaína y la ropivacaína. 
Los anestésicos locales que pueden ser utilizados para anestesia epidural son los siguientes: Clorprocaína, lidocaína, prilocaína, mepivacaína, bupivacaína, levobupivacaína y ropivacaína. (ver tabla 1), aunque los que más frecuentemente se utilizan en la práctica diaria son los cuatro últimos.

La bupivacaína, anestésico local usado en nuestro estudio, tiene un inicio de acción lento (15-20 min), pero con una duración larga (120-240 min), dependiendo fundamentalmente de la dosis (tabla 1). Se utiliza para cirugía a concentraciones anestésicas $(0,5-0,75 \%)$ y para el tratamiento del dolor a concentraciones analgésicas (0,0625-0,25\%) habitualmente, aunque en ocasiones es necesario utilizar concentraciones mayores, cuando el dolor es de gran intensidad (ej. dolor isquémico). A nivel local produce vasodilatación.

Para que los anestésicos locales utilizados en el espacio epidural produzcan el efecto buscado, es necesario que se administren en volumen suficiente para bloquear las metámeras deseadas y con una concentración adecuada. El volumen va a depender de la altura de bloqueo requerida y de las características del paciente (antropométricas, embarazo, edad, etc.). Un esquema de dosificación general en una epidural lumbar sería: para cirugía abdominal, 15-25 $\mathrm{ml}$ de anestésico local, y para la cirugía de las extremidades inferiores, cadera y periné, $10-15 \mathrm{ml}$ de anestésico local, pero habrá que modificarlo de acuerdo con la situación clínica. Para decidir la concentración del anestésico local, es preciso saber qué tipo de fibra nerviosa se desea bloquear: nervios raquídeos (gran espesor de la cubierta y por tanto necesidad de altas concentraciones), nervios autonómicos y sensitivos (cubierta menor y por tanto necesidad de menores 
concentraciones), o lo que es lo mismo, si se desea un bloqueo completo (alta concentración) o incompleto (concentraciones bajas).

\subsection{CONTRAINDICACIONES DE LA ANESTESIA EPIDURAL} $(14,15,17)$

Hay situaciones en las que la anestesia epidural está contraindicada. Encontramos dos tipos:

\subsubsection{Contraindicación absoluta}

- Infección sistémica o del lugar de punción.

- Hipertensión intracraneal.

- Hipovolemia grave, shock.

- Alergia a los anestésicos locales (muy raro a las amidas).

- Rechazo del método anestésico.

- Diátesis hemorrágica y alteraciones de la coagulación (tiempo de protrombina $<60 \%$, tiempo parcial de tromboplastina activada prolongado $>15$ segundos del control)

- Fibrinógeno $<120 \mathrm{mg} / \mathrm{dl}(1,2 \mathrm{~g} / \mathrm{l})$.

- Trombopenia <100.000 plaquetas/mm3.

- Terapéutica anticoagulante (excepción: heparinización profiláctica a bajas dosis: heparina cálcica subcutánea 5000-7500 U.I./ 24h).

- Algunas afecciones neurológicas como la meningitis por ejemplo. 


\subsubsection{Contraindicación relativa}

Influye la valoración de la relación riesgo-beneficio y la experiencia del anestesiólogo en las técnicas de anestesia regional.

- Enfermedades del raquis, artrosis, dorsalgias.

- Predisposición a las neuropatías (diabetes descompensada, porfiria, sífilis terciaria, poliomielitis, deficiencias vitamínicas, etc.).

- Inestabilidad psíquica.

- Oclusiones intestinales orgánicas.

- Historia de cefaleas crónicas.

- Enfermedades virales.

- Patología cardiaca: pericarditis constrictiva, estenosis aórtica, bloqueo auriculoventricular de III grado, lesión valvular descompensada, infarto reciente, tratamiento con betabloqueantes $\mathrm{y} / \mathrm{o}$ con inhibidores de la monoaminooxidasa (IMAO).

\subsection{COMPLICACIONES DE LA ANESTESIA EPIDURAL $(14,15,17)$}

\subsubsection{Colocación errónea de la aguja o del catéter}

\subsubsection{Fuera del canal vertebral}

Debe sospecharse cuando, tras 15-20 minutos de la administración del anestésico local, no se percibe ningún efecto. Muchas veces la punta de la aguja está situada en la musculatura paravertebral. 


\subsubsection{Punción de la duramadre}

Suele suceder por un avance rápido de la aguja una vez atravesado el ligamento amarillo. Cuando se pincha la duramadre, refluye LCR de una forma clara, debido al gran grosor de la aguja. Tras este suceso, es frecuente el desarrollo de una cefalea postpunción dural (localización fronto-occipital, disminuye en el decúbito y aumenta con el ortostatismo y con las maniobras de Valsalva), de comienzo inmediato o a los 2-3 días, y que habitualmente cede al cabo de una semana. Si no cede a la semana, hay que pensar en la existencia de una fístula de LCR. En los casos en los que no se diagnostica la punción de la duramadre y se introduce en el espacio subaracnoideo la dosis de anestésico local correspondiente a la epidural, se puede provocar una anestesia espinal completa (parada respiratoria, hipotensión grave, pérdida de conciencia).

\subsubsection{Colocación intravenosa}

Cuando la aguja o catéter está situado dentro de un vaso sanguíneo, se observa un flujo libre de sangre a través de éstos. Es necesario retirar y volver a pinchar en un espacio adyacente. La inyección de fármacos dentro de un vaso sanguíneo ocasionará síntomas característicos de intoxicación por anestésico local (ver apartado 2.10.3. "toxicidad aguda generalizada”).

\subsubsection{Hipotensión}

Generalmente se debe a una disminución de las resistencias vasculares periféricas, como consecuencia de un bloqueo simpático extenso. También puede suceder por hipovolemia y/o por oclusión de la cava (ej. embarazadas, obesos). 


\subsubsection{Toxicidad aguda generalizada}

En la anestesia epidural muchas veces es necesario grandes cantidades de anestésicos locales. Una absorción excesiva desde el espacio epidural o la inyección del anestésico local en un vaso sanguíneo, puede darnos un cuadro tóxico agudo generalizado. Los primeros síntomas son neurológicos (acúfenos, sordera, sabor metálico, fasciculaciones perioorales y perioculares, alucinaciones, cuadros de agitación-ansiedad-pánico, convulsiones y coma), seguidos de síntomas del sistema cardiovascular (taquicardia e hipertensión y posteriormente bradicardia e hipotensión).

\subsubsection{Daño neurológico}

Se produce por traumatismo directo de la médula o de una raíz nerviosa. El paciente nota un dolor lancinante o una parestesia clara.

\subsubsection{Isquemia medular}

La médula espinal es irrigada por la arteria espinal anterior y dos arterias espinales posteriores (ramas de la primera). Entran en el espacio epidural a través de los agujeros de conjunción intervertebrales, alcanzando las raíces nerviosas espinales en la región de los manguitos durales. Si la aguja epidural se inserta cerca de la raíz nerviosa, puede suceder una isquemia medular por traumatismo de una arteria espinal.

\subsubsection{Infección/absceso epidural}

Ante cualquier sospecha de meningitis (por sintomatología clásica) o de absceso epidural (fiebre o febrícula, malestar general que se acompañe de molestias difusas en la zona metamérica inervada afecta), hay que hacer 
pruebas diagnósticas (imagen, laboratorio) para confirmarlo y tratarlo sin dilación.

\subsubsection{Hematoma epidural}

Un paciente anticoagulado es una contraindicación para la realización de un bloqueo epidural, por riesgo de provocar un hematoma en el espacio epidural y secundariamente daño neurológico. Ante la mínima sospecha de hematoma epidural (incontinencia de esfínteres, debilidad en las extremidades inferiores...) hay que realizar pruebas de imagen para descartarlo. Si existe hematoma hay que drenarlo con urgencia (aconsejable no superar las 6 primeras horas después del diagnóstico). 
3 ARTERIOPATÍA PERIFÉRICA OCLUSIVA CRÓNICA 



\subsection{GENERALIDADES}

La arteriopatía periférica oclusiva crónica, también llamada insuficiencia arterial periférica oclusiva crónica, es una enfermedad caracterizada por la obstrucción al flujo sanguíneo del árbol vascular periférico, fundamentalmente de las extremidades inferiores (Fig. 10). La causa más frecuente es una aterosclerosis generalizada $(13,20)$.

Es una enfermedad de instauración progresiva. Comienza con una fase subclínica de larga duración que puede llegar a dar síntomas en algún momento de su evolución, y que finalmente tiene la posibilidad de terminar con la amputación parcial o total del miembro. La fase clínica se suele expresar con síntomas diversos: inespecíficos (lividez, frialdad) o característicos (claudicación intermitente ${ }^{1}$, dolor de reposo $\left.{ }^{2}\right)(13,21)$.

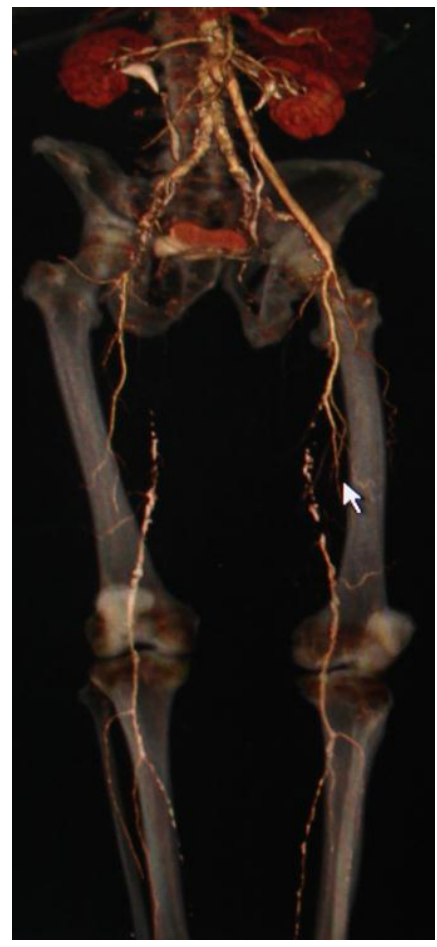

Figura 10: Prueba de imagen de un paciente con insuficiencia arterial periférica crónica

\footnotetext{
${ }^{1}$ Dolor con la deambulación de una distancia (más o menos corta), que se localiza con frecuencia en los gemelos y que cede con el reposo, obligando a pararse. Se debe a un fracaso de los mecanismos de compensación vascular ante un aumento de las necesidades de oxígeno, que origina una hipoxia tisular. La severidad de la claudicación intermitente depende del grado de estenosis, de la presencia y cantidad de circulación colateral y de la intensidad del ejercicio (13)
} 
Esta enfermedad provoca una gran carga de sufrimiento en el paciente y cuidadores. También constituye una fuente importante de costes económicos directos e indirectos para el sistema sanitario (20).

Afecta fundamentalmente a personas de edad avanzada, con frecuencia con muchos problemas médicos graves y complejos acompañantes (coronariopatía, enfermedad cerebrovascular, insuficiencia respiratoria, estenosis de la arteria renal) y con unas reservas físicas disminuidas. Todo esto hace que su manejo sea complicado $(13,22-24)$.

El objetivo común de todas las opciones terapéuticas, médicas o quirúrgicas, en el tratamiento de la arteriopatía periférica oclusiva crónica, es restablecer la perfusión de los tejidos anteriormente vascularizados por las arterias obstruidas (25). Cuando se plantea tratamiento quirúrgico, el anestesiólogo debe elegir la técnica anestésica que va a utilizar durante la cirugía y para el tratamiento del dolor en el postoperatorio. Aún sigue manteniéndose en controversia qué técnica anestésica es la más adecuada para estos pacientes (13).

A pesar del avance de las técnicas quirúrgicas y de las de diagnóstico precoz, todavía se detectan casos de isquemia crónica crítica en los que las técnicas quirúrgicas de revascularización pueden estar contraindicadas: paciente de alto riesgo quirúrgico o anestésico, características no revascularizables de la lesión $(13,26)$. En estos casos se aplican alternativas cuyo objetivo es paliar los síntomas y los efectos de esta enfermedad. Entre estas medidas se encuentran la simpatectomía lumbar, la administración de

\footnotetext{
${ }^{2}$ Dolor no relacionado con el movimiento y que generalmente cede con la posición declive del miembro. Suele indicar un grado de compromiso vascular arterial mayor que el dolor de claudicación intermitente (13).
} 
prostaglandinas por vía parenteral, la angiogénesis terapéutica y la neuroestimulación eléctrica espinal (20,27-29).

\subsection{EPIDEMIOLOGÍA}

La prevalencia de la insuficiencia arterial periférica crónica de las extremidades inferiores es menor que la de las enfermedades cardiacas, pero mayor que la de las enfermedades cerebrovasculares. Además, multiplica por 2 a 4 el riesgo de infarto de miocardio, ictus y muerte (20).

Su prevalencia aumenta con la edad: es muy alta en la población mayor de 70 años (15-20\%) y en los pacientes entre 50 y 69 años que sean diabéticos o fumadores de más de 10 paquetes al año, pero también se puede presentar en personas más jóvenes $(20,22)$. La prevalencia en la población general basada en métodos objetivos, es del 3-10 \% (30,31,32). La mayor parte se presenta de forma asintomática con una relación 1:3-1:4 entre sintomáticos/asintomáticos, de tal forma que en muchas ocasiones el paciente desconoce la presencia de la enfermedad (20).

En España existen pocos trabajos que evalúen la prevalencia de la arteriopatía periférica oclusiva de las extremidades inferiores. Uno de ellos, el estudio ESTIME, observa una prevalencia en la población mayor de 55 años del $8,5 \%$ (10,2\% en varones y 6,3\% en mujeres) (33).

Es una patología que ocasiona un gran absentismo laboral, por lo que no tiene sólo una repercusión social y de calidad de vida importante, sino también económica. En España 1.600 .000 personas laboralmente activas 
presentan algún grado de isquemia crónica de las extremidades inferiores (33).

\subsection{ETIOLOGÍA}

La aterosclerosis es la responsable (95\% de los casos), de la arteriopatía periférica oclusiva crónica. Afecta a múltiples arterias del organismo (extremidades, corazón, cerebro, riñón...), que hace que sean pacientes con una alta morbi-mortalidad (13).

Las placas de ateroma obstruyen de forma progresiva las arterias, disminuyendo la perfusión de los tejidos. En ocasiones puede interrumpirse de forma brusca y total el flujo sanguíneo de un vaso (isquemia aguda) por embolización o formación de un trombo sobre una placa de ateroma rota.

Es un problema que comienza en la juventud. La rapidez de su progresión depende de muchos factores, unos modificables y otros no. La supresión de los factores modificables puede hacer que la enfermedad progrese más lentamente (13).

Existen también otras causas menos frecuentes de enfermedad arterial oclusiva crónica: aneurismas, tromboangeítis obliterante (enfermedad de Buerger), enfermedad de Takayasu, enfermedad de Horton (arteritis de la temporal), atrapamiento poplíteo, la displasia fibromuscular, o arteritis específicas provocadas por la salmonella, la sífilis..., embolias, traumatismos continuos, etc. (13). 


\subsection{SUPERVIVENCIA}

La presencia de arteriopatía periférica oclusiva crónica indica que existe un grado de aterosclerosis sistémica importante, que por ella misma, provoca un aumento de la mortalidad de estos pacientes, independientemente de los factores de riesgo (20).

La morbimortalidad en la arteriopatía periférica crónica a los 5, 10 y 15 años de su diagnóstico, es del 30\%, 50\% y 70\% respectivamente. La causa más frecuente por la que mueren estos pacientes es por eventos coronarios $(40-60 \%)(20)$.

La morbilidad de la extremidad es (20):

- Claudicación estable: 70-80\% de los pacientes

- Empeoramiento de la claudicación: 10-20\% de los pacientes

- Isquemia crítica de la extremidad: 1-2\% de los pacientes

El pronóstico de pérdida de las dos piernas y de mortalidad es significativamente mayor en los diabéticos y en aquellos que siguen fumando (34).

\subsection{FACTORES RELACIONADOS}

Entre los factores relacionados con la arteriopatía periférica oclusiva crónica están: 


\subsubsection{Sexo}

$\mathrm{Su}$ prevalencia es ligeramente mayor en hombres que en mujeres, sobre todo en edades jóvenes. La claudicación intermitente está presente con más frecuencia en hombres que en mujeres (relación 1:2 a 1:3). Sin embargo la prevalencia de isquemia crítica de la extremidad es mayor en la mujer (20).

\subsubsection{Edad}

La prevalencia va aumentanto con con la edad, tanto en el sexo masculino como en el femenino (Tabla 2) (20).

Tabla 2: Prevalencia atendiendo a la edad y sexo

\begin{tabular}{|c|c|c|c|}
\hline \multicolumn{4}{|c|}{ PREVALENCIA } \\
\hline & $<45$ años & $45-64$ años & $>65$ años \\
\hline Hombres & $2,7 \%$ o & $100,7 \%$ o & $134,3 \%$ \\
Mujeres & $1,7 \%$ o & $33,4 \%$ o & $94,2 \%$ o \\
\hline
\end{tabular}

\subsubsection{Factores genéticos}

La tendencia a desarrollar aterosclerosis en algunos grupos familiares puede ser debida a factores genéticos hereditarios, que aumentan la posibilidad de tener hiperlipidemia, hipertensión arterial (HTA), diabetes, síndrome de Werner, etc. (20).

\subsubsection{Raza negra}

La raza negra multiplica por dos el riesgo de arteriopatía periférica oclusiva respecto a los de raza blanca, sin que pueda ser explicado por una 
mayor presencia de otros factores de riesgo como diabetes, hipertensión u obesidad (35).

\subsubsection{Diabetes (20)}

La arteriopatía periférica oclusiva de miembros inferiores está presente en el $13 \%$ de los diabéticos. Un $75 \%$ de estos diabéticos mueren por complicaciones vasculares.

El riesgo de desarrollar arteriopatía periférica de un diabético frente a uno que no lo es, se multiplica por veinte, aumentando un $26 \%$ el riesgo por cada $1 \%$ de elevación de la hemoglobina A1c. El riesgo de padecer claudicación intermitente se multiplica por dos.

El comienzo de la enfermedad sucede de forma más precoz y con problemas arteriales más graves que en los pacientes que no tienen diabetes. Debido a la neuropatía diabética y a la resistencia disminuida a la infección que padecen, tienen un mayor riesgo de desarrollar úlceras, infecciones y de necesitar una amputación.

La diabetes es la responsable del $50-70 \%$ de todas las amputaciones no traumáticas, y son de 5 a 10 veces más frecuente que en los no diabéticos.

Provoca que la incidencia de desarrollar una enfermedad vascular (coronaria, cerebro-vascular o vascular periférica) en la mujer se iguale a la del hombre.

En los diabéticos se afecta menos el sector aorto-ilíaco y más las arterias femoral profunda y tibiales, aunque cuando existe afectación aorto- 
iliaca hay mayor frecuencia de enfermedad coronaria y cerebro-vascular asociada.

\subsubsection{Tabaco (20)}

Se asocia a un aumento del riesgo de padecer arteriopatía periférica oclusiva de las extremidades inferiores. Los fumadores tienen de 1,4 a 4,46 veces más probabilidad de desarrollarla que los no fumadores. También se relaciona con un comienzo precoz de la enfermedad.

Hay una relación directa entre el número de cigarrillos y la gravedad de la enfermedad, el riesgo de amputación, de oclusión de derivaciones arteriales (el riesgo de oclusión se multiplica por tres si se sigue fumando) y de mortalidad. El abandono del hábito tabáquico reduce la mortalidad, la tasa de amputación, y la incidencia de claudicación intermitente, aunque no está claro si aumenta la distancia a la que aparece claudicación.

\subsubsection{Hipertensión}

Existe una relación más débil entre la hipertensión arterial y la arteriopatía periférica oclusiva crónica, que la que existe con el tabaco y la diabetes. Los hipertensos tienen una probablidad de 1.5 a 2.2 veces mayor de padecerla que los no hipertensos (20).

\subsubsection{Dislipemia (20)}

Por cada $40 \mathrm{mg} / \mathrm{dl}(1 \mathrm{mmol} / \mathrm{l})$ de elevación sérica del colesterol aumenta la probabilidad de arteriopatía periférica oclusiva de 1.2 a 1.68 veces. La reducción de la hiperlipidemia se asocia con una disminución de 
la progresión de la arteriopatía periférica oclusiva crónica y de la incidencia de claudicación intermitente.

El aumento de lipoproteína (a), es un factor de riesgo independiente de arteriopatía periférica oclusiva crónica.

\subsubsection{Marcadores inflamatorios}

Algunos estudios recientes han relacionado el aumento de la proteína $\mathrm{C}$ reactiva (PCR) con el desarrollo de síntomas de arteriopatía periférica oclusiva crónica en los cinco años posteriores (36).

\subsubsection{Hiperviscosidad sanguínea y estado de hipercoagulabilidad}

Se han observado niveles elevados de hematocrito y de fibrinógeno, en pacientes con arteriopatía periférica oclusiva crónica $(20,37)$. La hiperviscosidad sanguínea y la hipercoagulabilidad se relacionan con un peor pronóstico de la enfermedad $(20,38)$.

\subsubsection{Hiperhomocisteinemia}

La hiperhomocisteinemia se relaciona con una prevalencia mayor de arterosclerosis y de arteriopatía periférica oclusiva. La prevalencia en la población general es de $1 \%$, y en la población de gente joven con arteriopatía periférica es del $30 \%(20,39)$.

\subsubsection{Disminución de la función renal}

La insuficiencia renal se acompaña de arteriopatía periférica precoz y se considera un factor de riesgo independiente de desarrollar arteriopatía periférica oclusiva en las mujeres postmenopaúsicas $(20,40)$. 


\subsection{PRESENTACIÓN CLÍNICA}

La arteriopatía periférica oclusiva crónica de las extremidades inferiores suele cursar de forma asintomática. Se diagnostica con frecuencia de forma casual, en la consulta de atención primaria, mediante el índice tobillo-brazo (ver apartado 3.7.3.3 "presiones segmentarias") (41).

Cuando cursa con síntomas, éstos son muy variados: alteraciones tróficas de la piel, dolor con el ejercicio físico, dolor de reposo, úlceras necróticas, etc. Dependen del grado y velocidad de instauración de la obstrucción (con o sin formación de colaterales) y de la actividad física habitual de la persona.

\subsubsection{Clasificaciones (20)}

Habitualmente la gravedad y sintomatología de la enfermedad se define, por su sencillez, según las clasificaciones clásicas de La Fontaine o de Rutherford.

\subsubsection{Clasificación de La Fontaine}

En 1920 apareció la clasificación de La Fontaine. Divide la isquemia crítica de miembros inferiores en cuatro grados clínicos:

Grado I: Asintomático³.

Graso II: Claudicación intermitente

Grado IIa: Claudicación a >150 metros

Grado IIb: Claudicación a <150 metros

Grado III: Dolor en reposo ${ }^{4}$

\footnotetext{
${ }^{3}$ Existen lesiones ateromatosas que no provocan dolor (obstrucción incompleta del vaso y/o desarrollo de vasos colaterales y/o bajo nivel de actividad física).
} 


\section{ARTERIOPATÍA PERIFÉRICA OCLUSIVA CRÓNICA}

Grado IV: Úlceras o necrosis en la extremidad con independencia de la capacidad del paciente para caminar ${ }^{5}$.

En la literatura anglosajona usan el término "isquemia crítica", para definir una situación de isquemia en la que existe un alto riesgo de pérdida de una extremidad o parte de ella. Debe cumplir dos criterios: dolor de reposo persistente, que requiere analgesia de forma habitual durante más de dos semanas y/o úlceras o gangrena en el pie o los dedos, además de presión sistólica en el tobillo inferior a $50 \mathrm{mmHg}$. Este criterio de isquemia crítica equivaldría a los grados III y IV de la clasificación de la Fontaine.

\subsubsection{Clasificación de Rutherford (Tabla 3)}

Tabla 3: Clasificación de Rutherford, para pacientes con arteriopatía periférica oclusiva crónica

\begin{tabular}{|c|c|c|}
\hline GRADO & CATEGORÍA & CLÍNICA \\
\hline 0 & 0 & Asintomático \\
\hline I & 1 & Claudicación leve \\
\hline & 2 & Claudicación moderada \\
\hline II & 3 & Claudicación grave \\
\hline III & 4 & Dolor isquémico en reposo \\
\hline IV & 5 & Pérdida menor de tejido \\
\hline
\end{tabular}

${ }^{4}$ Dolor continuo que aparece sin la realización de actividad física, progresivamente intolerable, que empeora con la elevación de la extremidad y mejora con el declive de la misma. Suele acompañarse de alteraciones de la sensibilidad, piel fría y pálida. El factor desencadenante suele ser un trauma sobre una zona al límite de perfusión, o menos frecuente un microémbolo o la formación de un trombo a nivel local.

${ }^{5}$ Aparece en el 1-3\% de los pacientes que tienen síntomas 
3.6.1.3. Correspondencia de las dos clasificaciones clásicas (Tabla 4)

Tabla 4: Correspondencia de las clasificaciones clásicas

\begin{tabular}{|c|c|c|c|c|}
\hline \multicolumn{2}{|r|}{ FONTAINE } & \multicolumn{3}{|c|}{ RUTHERFORD } \\
\hline Grado & Clínica & Grado & Categoría & Clínica \\
\hline I & Asintomático & 0 & 0 & Asintomático \\
\hline Ia & Claudicación leve & I & 1 & Claudicación leve \\
\hline \multirow{2}{*}{$\mathrm{Ib}$} & \multirow{2}{*}{$\begin{array}{l}\text { Claudicación moderada- } \\
\text { grave }\end{array}$} & I & 2 & $\begin{array}{l}\text { Claudicación } \\
\text { moderada }\end{array}$ \\
\hline & & I & 3 & Claudicación grave \\
\hline \multirow{2}{*}{ II } & \multirow{2}{*}{$\begin{array}{l}\text { Dolor isquémico en } \\
\text { reposo }\end{array}$} & II & 4 & $\begin{array}{l}\text { Dolor isquémico en } \\
\text { reposo }\end{array}$ \\
\hline & & III & 5 & $\begin{array}{l}\text { Pérdida menor de } \\
\text { tejido }\end{array}$ \\
\hline V & Ulceración o gangrena & IV & 6 & $\begin{array}{l}\text { Pérdida mayor de } \\
\text { tejido }\end{array}$ \\
\hline
\end{tabular}

\subsubsection{Presentación clínica atendiendo al lugar de la obstrucción $(13,42)$}

Parece que existe una correlación general, aunque no absoluta, entre los síntomas y la localización de la lesión estenosante. Las localizaciones de la obstrucción se pueden resumir en tres:

- Obstrucción aorto-iliaca (enfermedad aorto-iliaca 24\% e íliofemoral $4 \%)$.

- Obstrucción fémoro-poplítea (enfermedad fémoro-poplítea 50\% y poplítea 5\%).

- Obstrucción tibio-peronea (17\%). 


\subsubsection{Obstrucción aorto-ilíaca}

Suele comenzar con la obstrucción progresiva de las dos arterias iliacas primitivas, y se extiende hasta la aorta terminal, pudiendo llegar a ocluir su luz completamente (Síndrome de Leriche) (Fig. 11). Los síntomas y signos clásicos suelen ser: claudicación intermitente bilateral (generalmente de glúteos y muslos), impotencia/amenorrea, ausencia completa de pulsos, palidez, frialdad, atrofia muscular y cicatrización tórpida de las heridas de las extremidades inferiores.

La prevalencia es mayor en los hombres que en las mujeres (relación 3:1). Tiene un comienzo temprano, entre los 35 y 55 años de edad.

Se relaciona con la hipertensión arterial (50\% son hipertensos), hiperlipemia, tabaquismo y tiene escasa relación con la diabetes. El 75\% de los pacientes padecen cardiopatía isquémica

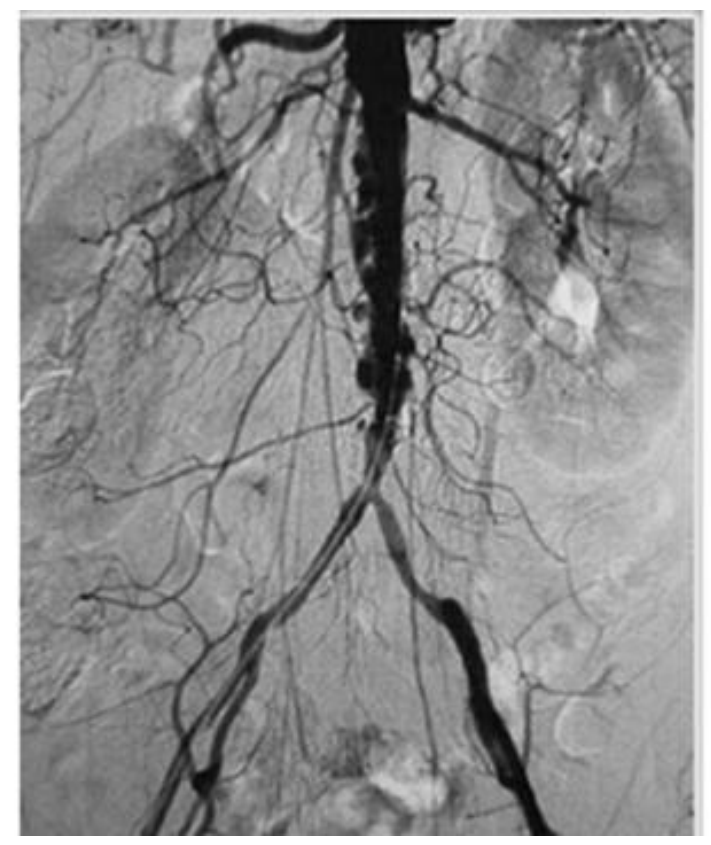

Figura 11: Arteriografía de un paciente con Síndrome de Leriche 


\section{ARTERIOPATÍA PERIFÉRICA OCLUSIVA CRÓNICA}

\subsubsection{Obstrucción fémoro-poplítea (Fig. 12)}

Generalmente sucede por una obstrucción de la arteria femoral superficial (50\% de los casos). El origen suele ser microtraumas continuos y posterior obstrucción del vaso, por la tracción oblicua de la arteria femoral superficial en la parte superior del canal de Hunter, por parte de la fascia de los aductores. Los síntomas habituales son una claudicación intermitente de los gemelos (bilateral en el 50\% de los casos) y parestesias en el tarso. Existe pulso femoral en la ingle, pero están ausentes los poplíteos y distales. Son frecuentes las lesiones tróficas y las necrosis

La edad habitual de comienzo es entre los 50-70 años. Suele existir una alta incidencia de tabaquismo, HTA, diabetes, cardiopatía isquémica y lesiones de los troncos supraaórticos.

Las oclusiones aisladas de la arteria poplítea generalmente se deben a trombosis de un aneurisma poplíteo, atrapamiento poplíteo o degeneración quística de la media. 


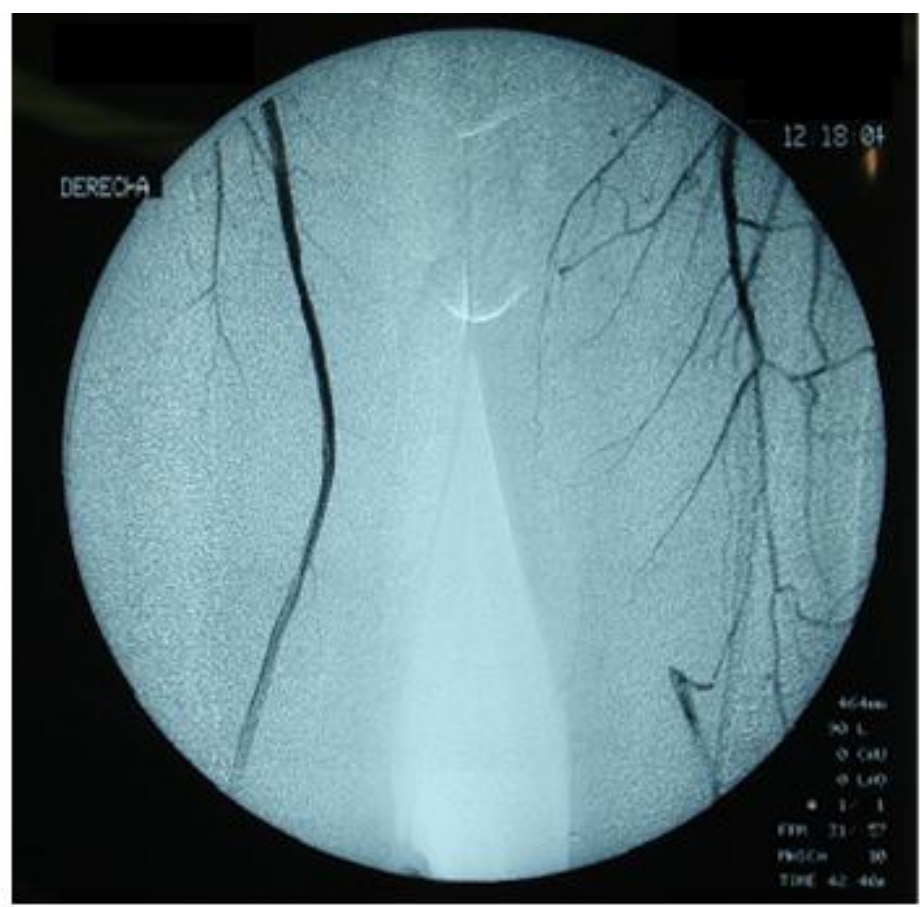

Figura 12: Arteriografía. Obstrucción femoropoplítea de la extremidad inferior izquierda y con abundantes vasos colaterales

\subsubsection{Obstrucción tibio-peronea (Fig. 13)}

La afectación ateromatosa de las arterias tibiales es la menos frecuente de todas las causas de isquemia arterial crónica. Los síntomas suelen ser claudicación plantar o del antepie. Existe: ausencia de pulsos pedios y tibiales posteriores, hiperestesias al tacto del pie, atrofia músculocutánea y úlceras isquémicas en los dedos. Es más frecuente en pacientes con diabetes y tromboangeítis obliterante 


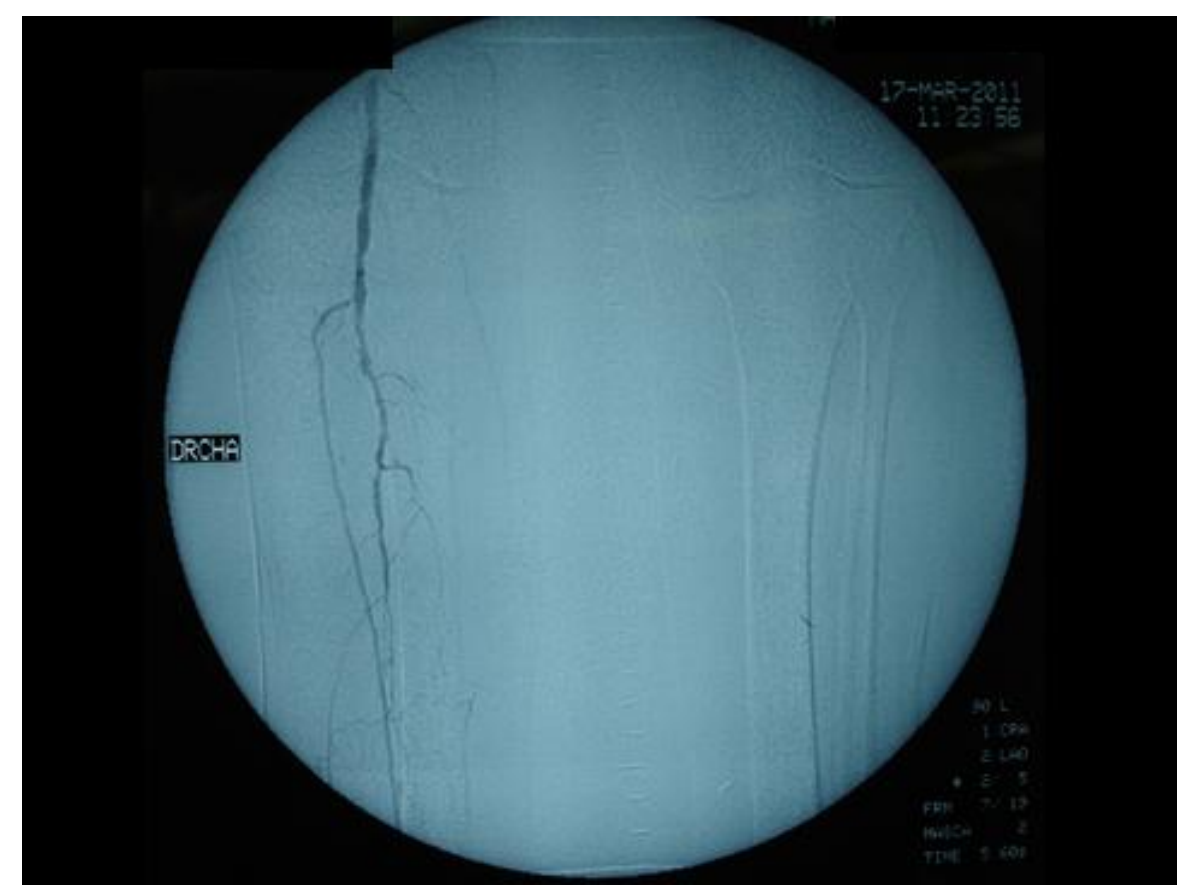

Figura 13: Arteriografía. Obstrucción tibio-peronea de extremidad inferior derecha

\subsection{DIAGNÓSTICO $(13,20,42)$}

El diagnóstico de la arteriopatía periférica oclusiva crónica debe hacerse en pacientes sintomáticos y en aquellos que todavía no presentan síntomas clínicos. La detección de la arteriopatía periférica en los pacientes asintomáticos ayuda a identificar personas con un alto riesgo de tener placas de ateroma en otros lugares del organismo.

El diagnóstico se basa fundamentalmente en la sospecha, a través de la historia clínica y exploración física; y se confirma mediante pruebas invasivas o no invasivas. 


\subsubsection{Historia clínica}

Habrá que investigar sobre:

- La presencia de factores relacionados con la enfermedad: Edad, hábitos tóxicos (tabaco), diabetes, hipertensión arterial, obesidad, hiperhomocisteinemia, etc.

- $\quad$ La actividad física habitual ${ }^{6}$

- Las características de los síntomas, en caso de existir: forma de aparición, progresión, qué tiene que hacer para que desaparezcan, localización ${ }^{7}$, etc.

\subsubsection{Exploración física}

- Inspección de las extremidades: pérdida de vello en las piernas, sequedad y pérdida de brillo de la piel, onicomicosis, úlceras, necrosis, trayectos de linfangitis, edema, eritema, palidez, cianosis, tiempo de relleno venoso prolongado, test de Buerger positivo $^{8}$ (Fig. 14)

\footnotetext{
${ }^{6}$ Se ha visto que el nivel de actividad en los pacientes con arteriopatía periférica, incluso en ausencia de claudicación, está disminuido $(43,44)$. Esta disminución de la actividad puede enmascarar los síntomas e infraestimar el alcance y severidad del problema.

${ }^{7}$ Existe una correlación general pero no absoluta, entre los síntomas y el sitio de la lesión: Glúteos y cadera (problema aorto-iliaco), muslo (arteria femoral común o aorto-iliaca), 2/3 proximales del gemelo (arteria femoral superficial), 1/3 distal del gemelo (arteria poplítea), pie (arteria tibial o peronea).

${ }^{8}$ Frialdad del pie elevando la extremidad y, calor y enrojecimiento proximal a los dedos con el descenso de la misma.
} 

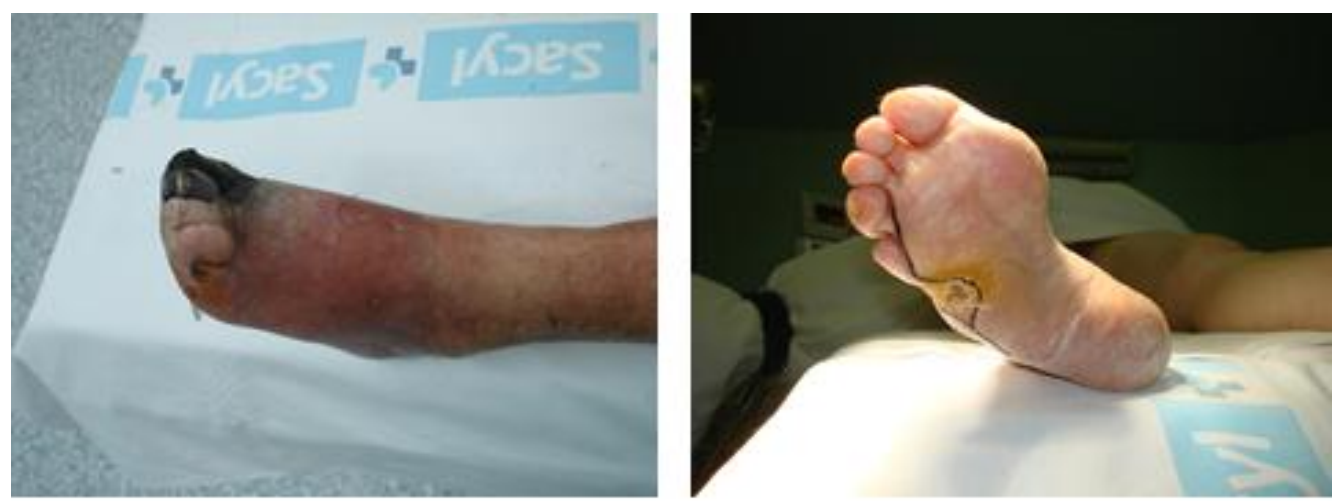

Figura 14: Signos característicos en la extremidad inferior de pacientes con enfermedad arterial periférica oclusiva crónica: Necrosis, edema, úlceras, pérdida de vello y sequedad de la piel

- Palpación de la temperatura a lo largo de las extremidades inferiores: Frialdad.

- Palpación de pulsos a lo largo de las extremidades inferiores: Pulso disminuido o ausente por debajo del nivel de la estenosis $\mathrm{u}$ obstrucción completa.

- Auscultación de soplos: Orienta sobre el lugar de la estenosis

\subsubsection{Estudios vasculares no invasivos}

Su objetivo es confirmar la existencia de lesiones, su localización, repercusión hemodinámica, y/o el estado del lecho arterial distal. Las más habituales son:

\subsubsection{Doppler continuo y pulsado}

Aporta información sobre la presencia o ausencia de flujo y características hemodinámicas del mismo (laminar, turbulento, velocidad del flujo, resistencias distales...) en cada uno de los vasos de las extremidades. 


\subsubsection{Eco-Doppler}

Aporta información morfológica de las lesiones (placas de ateroma, ulceraciones, trombos intraluminales), e información sobre las alteraciones hemodinámicas que producen.

\subsubsection{Presiones segmentarias}

Permiten determinar la presión de la sangre en cada sector de la extremidad (muslo, pierna, tobillo y dedo gordo del pie) y correlacionarlas con las de la extremidad contralateral y con la presión del brazo (considerada como normal).

\subsubsection{1 Índice tobillo-brazo (ITB)}

Es uno de los métodos de diagnóstico más utilizados para sospechar la presencia de la enfermedad y medir su severidad. Es barato, rápido y fácil de realizar. Se obtiene dividiendo la presión arterial sistólica del tobillo (obtenida por Doppler) por la del brazo. Se considera patológico cuando su valor es $<0,9$. Su valor se correlaciona con la sintomatología del paciente, aunque esta enfermedad habitualmente se presenta de forma asintomática (relación 3:1).

Tiene un alto grado de sensibilidad y especificidad para el diagnóstico de la arteriopatía periférica: Sensibilidad del 95\% en pacientes asintomáticos con un ITB $\leq$ a 0.9 para detectar una arteriografía alterada, y especificidad del 100\% con ITB normal en detectar individuos sanos. 
En los pacientes diabéticos, los vasos periféricos con frecuencia están calcificados, por lo que esta prueba puede dar falsos negativos, debido a la imposibilidad de compresión de los vasos.

\subsubsection{Otras pruebas}

La pletismografía, la presión parcial de oxígeno capilar (PO2 transcutánea), la capilaroscopia, la resonancia nuclear magnética, etc.

\subsubsection{Exploraciones invasivas: Arteriografía}

Es la mejor prueba para el diagnóstico definitivo de la arteriopatía periférica oclusiva crónica. Mediante la inyección de un contraste radiológico y radiología se puede conocer la extensión y topografía de las lesiones estenóticas, así como la presencia de vasos colaterales (Fig. 15). Es útil para realizar diagnósticos diferenciales con otros procesos que cursan con isquemia aguda, especialmente con los embolismos arteriales $\mathrm{y}$, sobre todo para planificar la estrategia quirúrgica.

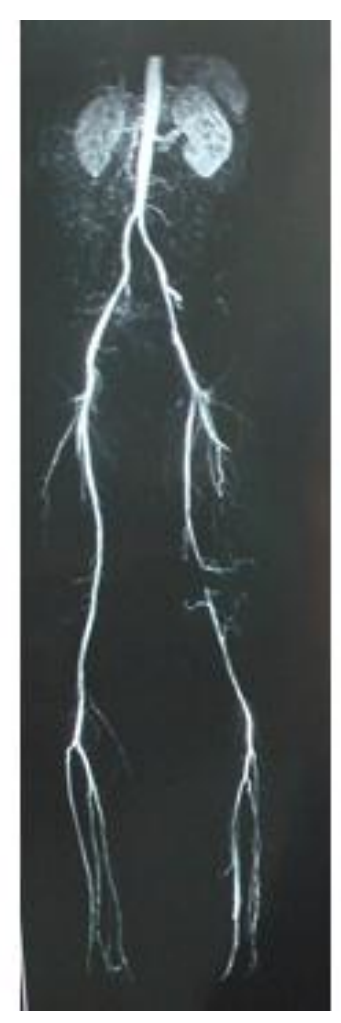

Figura 15: Arteriografía 


\subsection{DIAGNÓSTICO DIFERENCIAL $(20,42)$}

En general hay que descartar trauma o radiación en las piernas, presencia de vasculitis, consumo de vasoconstrictores (ej. ergotamina para las migrañas), compresiones externas de los vasos, claudicación vasoespástica ${ }^{9}$

Dependiendo del lugar donde sospechemos la obstrucción, habrá que descartar también ciertas patologías (Tabla 5 y 6):

Tabla 5: Diagnóstico diferencial de la arteriopatía periférica oclusiva a nivel aorto-iliaco

\begin{tabular}{|c|c|}
\hline SOSPECHA & Obstrucción aorto-iliaca \\
\hline \multirow{7}{*}{ DESCARTAR } & Lumbociática \\
\hline & Hernia discal \\
\hline & $\begin{array}{l}\text { Estenosis del canal } \\
\text { vertebral lumbosacro }\end{array}$ \\
\hline & Lesiones del plexo crural \\
\hline & Sacroileitis \\
\hline & Coxartrosis \\
\hline & $\begin{array}{l}\text { Trauma continuos en } \\
\text { deportistas de élite (ej. } \\
\text { ciclistas): endofibrosis } \\
\text { iliacas }\end{array}$ \\
\hline
\end{tabular}

\footnotetext{
${ }^{9}$ No hay síntomas con el reposo en cambio sí con el estrés. En ocasiones se ha dicho que pueden existir lesiones ateroscleróticas subyacentes.
} 
Tabla 6: Diagnóstico diferencial de la arteriopatía periférica oclusiva a nivel fémoropoplíteo

\begin{tabular}{|c|c|c|}
\hline SOSPECHA & \multicolumn{2}{|c|}{ Obstrucción fémoro-poplítea } \\
\hline DESCARTAR & $\begin{array}{l}\text { Trombosis venosa profunda } \\
\text { Flebitis superficiales } \\
\text { Dolores musculares difusos } \\
\text { (eritromelalgia, síndrome de } \\
\text { las piernas inquietas) } \\
\text { Calambres musculares } \\
\text { nocturnos }^{10} \\
\text { Aumento de presión del } \\
\text { compartimento muscular }^{11} \\
\text { Neuropatías periféricas } \\
\text { Síndrome del compartimento } \\
\text { tibial anterior } \\
\text { Miopatías (distrofia de } \\
\text { Duchenne, Becker, miotónica } \\
\text { de Steinert...) }\end{array}$ & $\begin{array}{l}\text { Alteraciones de la placa } \\
\text { motora (miastenia gravis, } \\
\text { síndrome de Eaton- } \\
\text { Lambert...) } \\
\text { Alteraciones metabólicas o } \\
\text { enzimáticas } \\
\text { (hiperparatiroidismo, } \\
\text { hiper/hipo tiroidismo, } \\
\text { enfermedad de Cushing y } \\
\text { Adisson, acromegalia...), } \\
\text { colagenosis (polimiositis, } \\
\text { lupus, síndrome de Sjögren, } \\
\text { periarteritis nodosa...) } \\
\text { Intoxicaciones (etilismo } \\
\text { crónico, ingesta crónica de } \\
\text { corticoides, cloroquina, } \\
\text { penicilamina...) }\end{array}$ \\
\hline
\end{tabular}

\subsection{TRATAMIENTO $(13,20)$}

Los objetivos son:

- Evitar la progresión de la enfermedad y su recurrencia

- Conseguir la remisión de la sintomatología y mantenerla

- Mejorar la calidad de vida del paciente

${ }^{10}$ Suele suceder en personas mayores o debilitadas, generalmente debido a problemas neuromusculares más que vasculares. No se relacionan con el ejercicio.

${ }^{11}$ Dolor en los gemelos que suele suceder en los atletas o en la gente que hace ejercicio de forma crónica, y que no se asocia con un alivio del dolor en reposo 
Se intenta a través de la modificación de los hábitos de vida, medidas farmacológicas y quirúrgicas (endovasculares, de reconstrucción/derivación vascular, tratamientos alternativos, amputación).

En los pacientes con arteriopatía periférica tratados se observó lo siguiente:

- Primer tratamiento: tratamiento médico $25 \%$, tratamiento de revascularización 50\%, amputación primaria $25 \%$.

- Un año después: Problema resuelto el 25\%; defunciones 25\%, vivos después de amputar 30\%, continúan con isquemia crítica de las extremidades inferiores $20 \%$.

\subsubsection{Modificación de los hábitos de vida}

- Abandonar el tabaco.

- Realizar ejercicio físico: Así se enlentece la progresión de la enfermedad y aumenta la distancia a la que aparece el dolor de claudicación por aumento de la red de circulación colateral. Precaución en diabéticos, ya que un ejercicio excesivo sin calzado adecuado, puede precipitar la aparición de lesiones ulcerosas en los pies. Hay pacientes en los que el ejercicio puede estar contraindicado (enfermedad coronaria avanzada, enfermedades músculoesqueléticas o neurológicas).

- Dietas saludables para prevenir la hipercolesterolemia, hipertrigliceridemia, obesidad, HTA, hiperglucemia... 


\subsubsection{Medidas farmacológicas}

3.9.2.1. Hipolipemiantes (estatinas, niacina, fibratos)

Mantener en límites normales o bajos los niveles de LDL $(<125$ $\mathrm{mg} / \mathrm{dl}$ ), triglicéridos, lipoproteína (a), y elevados los de HDL. Las estatinas mejoran la distancia a la que aparece la claudicación.

3.9.2.2. Antihipertensivos (IECAs, ARA II, tiazidas, betabloqueantes)

Mantener una tensión arterial $<140 / 90 \mathrm{mmHg}$ ó 130/80 mmHg, si son diabéticos o nefrópatas. Los inhibidores de la enzima convertidora de angiotensina (IECAs) son la primera elección. En pacientes con enfermedad coronaria o hipertensión de difícil control en los que esté indicado el uso de betabloqueantes, se pueden administrar aunque sufran claudicación, en contra de la creencia extendida y hasta ahora no demostrada en ningún estudio aleatorizado, que estos fármacos estarían contraindicados en los pacientes con arteriopatía periférica por empeoramiento de sus síntomas.

3.9.2.3. Antiagregantes plaquetarios (AAS, clopidogrel, triflusal, prostaglandinas)

Deben usarse de forma crónica con el objetivo de disminuir la morbimortalidad cardiovascular. No se ha demostrado beneficio de ningún antiagregante en el control sintomático de la claudicación intermitente, ni en la mejora de la enfermedad en general. Los pacientes con arteriopatía periférica crónica a los que se les haya realizado una cirugía de derivación, deberán permanecer antiagregados indefinidamente. El ácido acetil salicílico (AAS) protege y es más seguro en cuanto al riesgo de hemorragia digestiva a dosis bajas (75-160mg/día) que a dosis más altas. El estudio CAPRIE ha 
demostrado superioridad del clopidogrel frente al AAS, en la reducción del infarto de miocardio, ictus y mortalidad de causa cardiovascular en estos pacientes. No se ha encontrado beneficio de la doble antiagregación en pacientes con arteriopatía periférica estable, ni en aquellos a los que se les haya colocado dispositivos intraarteriales para aumentar el flujo sanguíneo a las extremidades.

Las prostaglandinas además de producir efecto antiplaquetario, son vasodilatadoras, modificadoras de la activación de los leucocitos y estabilizadoras del daño endotelial. El más utilizado últimamente, y con resultados buenos es el iloprost (análogo de la prostaciclina). Se han visto resultados significativamente superiores a otros fármacos y a placebo, en términos de desaparición del dolor en reposo, la curación de las lesiones isquémicas y la reducción del número de amputaciones incluso en isquemia crítica de extremidades inferiores.

\subsubsection{Anticoagulantes}

Las heparinas (no fraccionadas y de bajo peso molecular) están prácticamente limitadas a las formas agudas o críticas de la isquemia.

Por otra parte, el uso de dicumarínicos queda reservado para casos particulares de especial trombogenicidad y en las derivaciones vasculares realizadas por debajo de la rodilla con vena, sobre todo cuando la vena es de mala calidad o la salida distal no es óptima.

No se ha demostrado beneficio de ningún anticoagulante en el control sintomático de la claudicación intermitente. 


\subsubsection{Cilostazol}

Inhibidor de la fosfodiesterasa III con efecto vasodilatador, metabólico y actividad antiagregante. Es el fármaco de elección para el tratamiento de la claudicación intermitente, aumentando la distancia a la que aparece claudicación y mejorando sus síntomas. Debido a su efecto inhibidor de la fosfodiesterasa III, no debe usarse en los pacientes con insuficiencia cardiaca congestiva.

\subsubsection{Tratamiento quirúrgico}

De los pacientes sintomáticos, un $70 \%$ no experimentan cambios en los síntomas a los 10 años del diagnóstico, pero un 20-30\% sufren un empeoramiento precisando una intervención quirúrgica, y un $10 \%$ amputación. También hay situaciones en las que a pesar de seguir un tratamiento médico adecuado, los síntomas interfieren mucho en la actividad diaria del paciente, deteriorando notablemente su calidad de vida (corta distancia de la claudicación, edad, actividad laboral y de ocio). En estos casos también hay que plantearse un tratamiento quirúrgico. En las isquemias críticas (dolor de reposo isquémico o lesiones tróficas), siempre está indicada la revascularización con el objetivo de salvar la extremidad.

Existen diversas técnicas quirúrgicas. Hay que valorar la indicación de un tipo u otro teniendo en cuenta el estado físico del paciente y las características morfológicas de las lesiones. Las técnicas quirúrgicas más habituales son: 


\section{ARTERIOPATÍA PERIFÉRICA OCLUSIVA CRÓNICA}

a) Técnicas de revascularización: Cirugía abierta de derivación vascular, endarterectomía o cirugía endovascular.

b) Técnicas alternativas hiperemiantes: simpatectomía, estimuladores de cordones posteriores.

c) Amputación.

\subsubsection{Técnicas de revascularización}

Pueden ser de dos tipos: Cirugía convencional (derivación vascular, endarterectomía) y cirugía endovascular.

Se recomienda la cirugía endovascular para lesiones estenóticas únicas menores de $3 \mathrm{~cm}$ en la arteria iliaca común o en la arteria iliaca externa, en lesiones únicas menores de $1 \mathrm{~cm}$ de la arteria tibial o peronea, o para otras lesiones únicas, cortas y segmentarias. La cirugía convencional se recomienda para la oclusión completa de la arteria femoral superficial, arteria poplítea o de la trifurcación proximal. Las lesiones que no cumplan las características anteriores deben ser tratadas según el juicio del cirujano.

\subsection{Cirugía convencional: Derivación vascular (Bypass)}

Pretende crear una ruta alternativa a la zona de estenosis del vaso, con material sintético (Dacron, politetrafluoroetileno-Gore-Tex ${ }^{\circledR}$-) o con una vena autóloga (generalmente safena), y así conducir sangre arterial a la región distal a la estenosis. Puede realizarse dentro de la misma arteria, o desde otra con flujo sanguíneo adecuado (Figs. 16-19).

Las derivaciones realizadas con vena son más duraderas a largo plazo que las realizadas con material sintético (Dacron y polietetrafluoroetileno). 
Algunos ejemplos de estas derivaciones vasculares serían:

a) Atendiendo a la localización

- Derivación fémoro-poplítea (bypass anatómico)

- Derivación aorto-femoral (bypass anatómico)

- Derivación fémoro-femoral (bypass extra-anatómico)

- Derivación axilo-femoral (bypass extra-anatómico)

b) Atendiendo al material utilizado:

- Con vena safena invertida

- Con vena safena in situ

- Con venas del brazo

- Con material sintético (Dacron, Gore-Tex®)

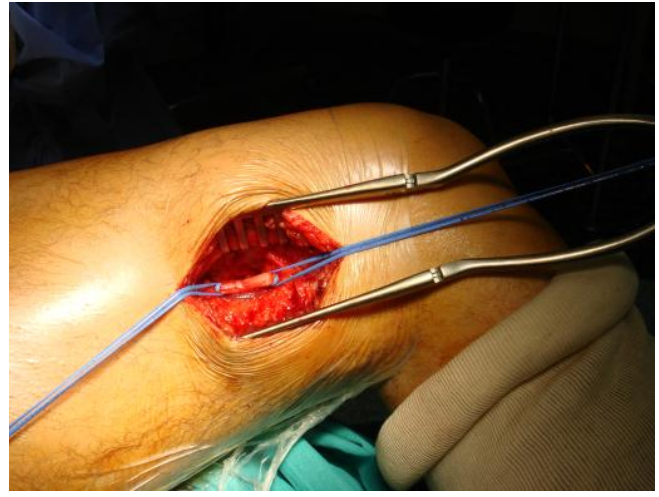

Figura 16: Exposición de la arteria poplítea obstruida

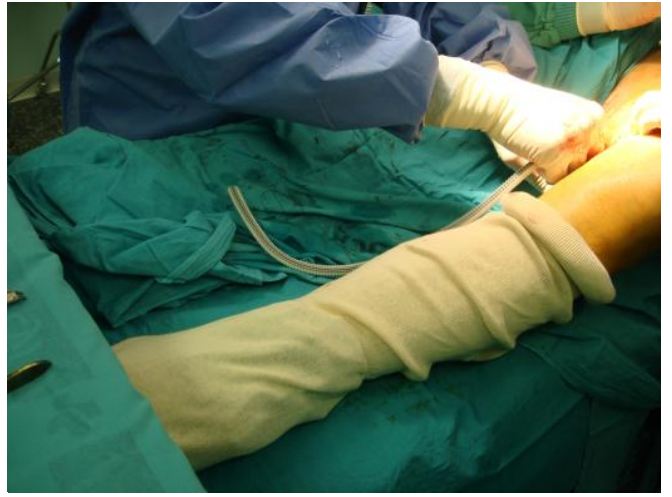

Figura 17: Colocación de material sintético (Dacron) 


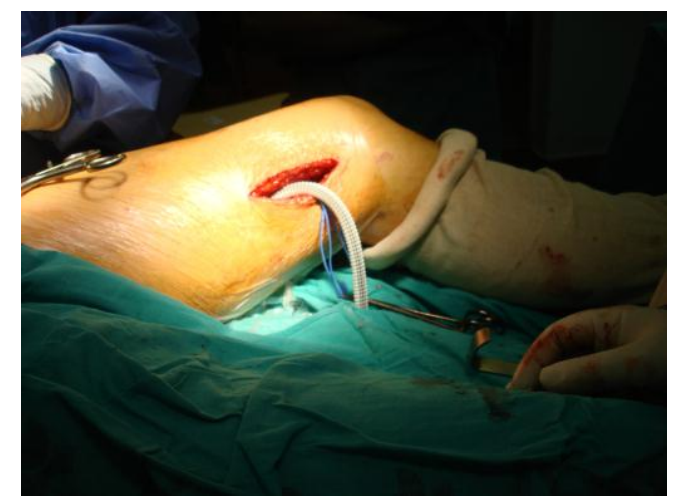

Figura 18: Material de Dacron suturado a la arteria

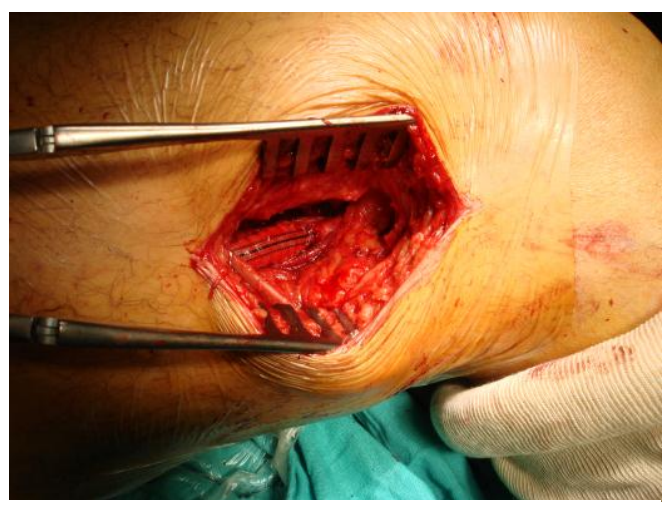

Figura 19: Bypass finalizado

\subsection{Cirugía convencional: Endarterectomía}

Consiste en la extirpación de la placa de ateroma, con exposición directa y adecuada de la región de estenosis del vaso arterial. Los resultados en las lesiones cortas de grandes vasos son muy buenos, y empeoran con lesiones más extensas o con vasos de menor calibre.

La mejora de la calidad de los materiales protésicos y de las técnicas endovasculares, ha hecho que cada vez se utilice menos en el tratamiento de la arteriopatía periférica de las extremidades inferiores (45).

\subsection{Técnicas endovasculares: Angioplastia transluminal} percutánea (PTA) con o sin implantación de stent

Consiste en la dilatación de una estenosis arterial por placas de ateroma, mediante un catéter introducido a través de la piel, hinchando y deshinchando varias veces un globo que tiene en su extremo (Fig. 20). 

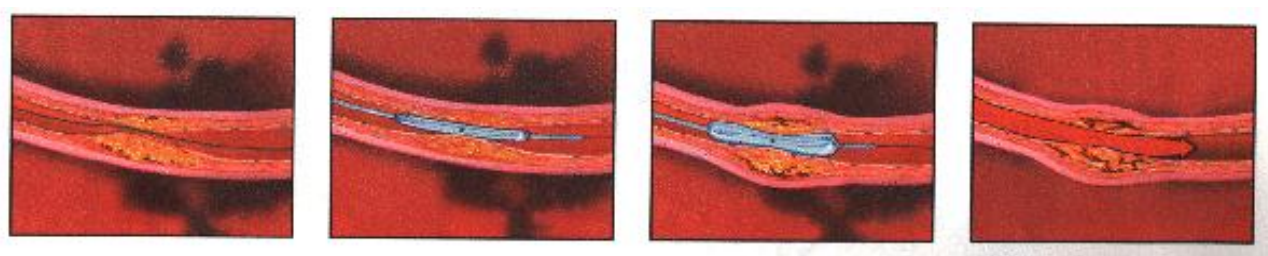

Figura 20: Angioplastia

La PTA ha surgido como alternativa a la cirugía convencional. Está asociada a una menor morbi-mortalidad, se reduce el número de anestesias generales, los pacientes tienen una más rápida recuperación con menor estancia hospitalaria y una más rápida incorporación a la actividad diaria normal; por todo ello, el coste relativo es más bajo.

Se ha utilizado para dilatar lesiones en múltiples localizaciones y de diferentes características; aunque, donde mejores resultados se han obtenido es en el tratamiento de lesiones estenosantes segmentarias, localizadas y de corta extensión de la arteria femoral superficial.

Las complicaciones más frecuentes con esta técnica son dificultades para el paso del catéter a través de la zona estenótica $(3,8 \%)$. También pueden existir hemorragias severas, disecciones arteriales, émbolos distales que producen una isquemia aguda, formación de un falso aneurisma o de una fistula arterio-venosa.

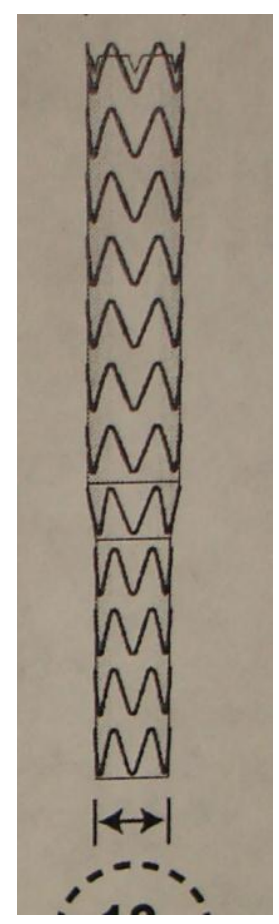

Figura 21: Stent 
El éxito inicialmente es del 88,6\% y desciende a los 5 años al 48,2\%. De los pacientes operados mediante una PTA, un 25\% tiene que ser reintervenido por la técnica clásica, al no haber sido efectiva la primera técnica quirúrgica. La permeabilidad a largo plazo es menor que con la cirugía de revascularización convencional.

La PTA, puede asociare a la colocación de un stent (expandible con balón o autoexpandible), que ayuda a mantener el vaso dilatado (Fig. 21)

3.9.3.2. Técnicas quirúrgicas hiperemiantes alternativas (5)

Cuando la cirugía se desestima (características del paciente o de las lesiones) o no ha sido efectiva, se pueden plantear medidas alternativas de tratamiento, con el fin de salvar la extremidad. Entre estas medidas están la simpatectomía y los estimuladores de cordones posteriores.

\subsection{Simpatectomía}

Pretende, mediante el bloqueo del sistema nervioso simpático, aumentar el flujo sanguíneo total de la extremidad por: la disminución del tono vasoconstrictor cutáneo normal, la disminución del tono vasoconstrictor cutáneo secundario al dolor, el aumento de la circulación colateral debido a un aumento del gradiente de presión a través del lugar de obstrucción del vaso... Además, favorece la curación de heridas. y diminuye la incidencia de trombosis de las derivaciones vasculares (2).

Esta técnica se realiza generalmente a nivel lumbar, de forma quirúrgica o química, y la simpatectomía producida puede ser temporal o definitiva. $(2,50)$ 
La simpatectomía lumbar quirúrgica extirpa dos o más ganglios de la cadena simpática lumbar, generalmente desde la segunda vértebra lumbar (L2) a la cuarta (L4). Se recomienda llegar hasta la L4 para evitar la reinervación por colaterales; y se intenta evitar llegar a L1, para evitar problemas eyaculatorios y de impotencia masculinos $(2,50)$.

- La simpatectomía lumbar química, generalmente se realiza mediante la inyección de alcohol o fenol, de forma percutánea, en los ganglios simpáticos paravertebrales. Puede producirse un bloqueo simpático definitivo o temporal (regeneración de la cadena ganglionar). También puede producirse un bloqueo temporal por la inyección de anestésicos locales periganglionares o alrededor de las raíces nerviosas simpáticas (bloqueo de ganglios simpáticos, bloqueo paravertebral, epidural e intradural) $(2,50)$.

A principios del siglo $\mathrm{XX}$, cuando se comenzaron a realizar las primeras simpatectomías para tratar la enfermedad arterial periférica oclusiva crónica, era la única alternativa a la amputación. En la actualidad, debido a la mejora de las técnicas quirúrgicas, la simpatectomía como tratamiento de la arteriopatía oclusiva crónica, se limita a aquellos estados avanzados de la enfermedad sin posibilidad de revascularización $(47,49-53)$ y en úlceras cutáneas de fondo isquémico rebeldes y extensas (47,49). Aunque en la actualidad no existe una recopilación bibliográfica ordenada sobre la utilidad clínica de la simpatectomía lumbar (7).

La indicación de esta técnica en los pacientes diabéticos se ha cuestionado mucho, ya que con frecuencia mantienen una 
"autosimpatectomía" (neuropatía diabética evolucionada), y un peor estado de sus arterias (oclusión del árbol arterial distal, ineficiente sistema de colaterales). Así que en estos pacientes, no se acepta la indicación de la simpatectomía (49).

\subsection{Estimulación de cordones posteriores}

Los estimuladores de cordones posteriores son cables que, colocados en el espacio epidural, emiten señales eléctricas a los cordones posteriores de la médula espinal. Estos cables eléctricos se conectan a un generador de impulsos eléctricos situado en el espacio subcutáneo $(49,54)$.

Es una terapia utilizada generalmente para el control del dolor crónico (posterior a una cirugía de columna, síndrome regional complejo, dolor isquémico refractario a otros tratamientos) (54).

Esta técnica se propone como terapia de recurso en pacientes con una isquemia crítica no revascularizable, con el objetivo de disminuir el dolor y mejorar la función circulatoria $(49,54)$. El incremento del flujo sanguíneo (vasodilatación) parece ser debido a una disminución de la acción vasoconstrictora simpática, secundaria al alivio del dolor (49). El aumento del flujo periférico permite mejorar el metabolismo distal, y la curación de heridas y cambios tróficos de piel y uñas (55).

\subsubsection{Amputación}

Cuando todas las técnicas de revascularización o medidas alternativas no son efectivas o posibles (estado físico del paciente o de la extremidad), hay que cortar la zona sin riego sanguíneo (20). Lógicamente, es una situación muy temida. 
No es estrictamente necesario que el paciente haya pasado por una claudicación, empeorado hasta dolor de reposo y después ulceración, para llegar a la amputación. Se ha visto que más de la mitad de los pacientes que fueron amputados por debajo de la rodilla por problemas isquémicos, no tenían síntomas de isquemia en las piernas durante los 6 meses anteriores (56).

La amputación puede realizarse a varios niveles, que va desde los dedos hasta la amputación completa de la extremidad.

La incidencia de amputación mayor es de 120-500/1.000.000 habitantes/año. Aunque si se tiene en cuenta la población exclusivamente de diabéticos, la incidencia es mucho mayor (20).

El 10\% fallece en el periodo perioperatorio (20). 


\section{LA ANESTESIA/ANALGESIA}

\section{EPIDURAL EN LA ARTERIOPATIA PERIFÉRICA CRÓNICA}





\section{LA ANESTESIA/ANALGESIA EPIDURAL EN LA ARTERIOPATIA PERIFÉRICA CRÓNICA}

En la actualidad es común el uso de la técnica epidural en pacientes con enfermedad arterial periférica de las extremidades inferiores. Se utiliza para:

1. La anestesia-analgesia intraoperatoria.

2. La analgesia postoperatoria.

3. El tratamiento del dolor provocado por la insuficiencia arterial periférica y,

4. Para mejorar la perfusión tisular (57,58).

\subsection{EN LA CIRUGÍA VASCULAR DE LAS EXTREMIDADES INFERIORES}

El paciente candidato a cirugía vascular periférica habitualmente presenta patología asociada (metabólica, respiratoria, cardiaca, etc.) y grados superiores a III en la clasificación ASA (American Society of Anesthesiologists) del estado físico del paciente, con mayor riesgo de complicaciones y muerte asociados a la anestesia y cirugía (13).

Aunque prácticamente todos los fármacos y técnicas anestésicas, de forma aislada o combinados, se han utilizado satisfactoriamente para este tipo de cirugía, existe controversia, todavía no resuelta, sobre si la elección de una u otra técnica anestésica (anestesia general $v s$ regional) en el paciente vascular, influye en el pronóstico $(13,59)$. En opinión de Tovey y colaboradores (60), más importante que la técnica anestésica elegida, lo que 


\section{LA ANESTESIA/ANALGESIA EPIDURAL EN LA ARTERIOPATIA PERIFÉRICA CRÓNICA}

más influye en el pronóstico de estos pacientes, es la optimización de los cuidados perioperatorios (normotermia, volumen intravascular adecuado, buena analgesia). Sin embargo, en la práctica clínica es muy frecuente el uso de técnicas de anestesia locorregional para la cirugía vascular periférica. Las razones esgrimidas para evitar el uso de la anestesia general incluyen: La ausencia de todos los problemas derivados del manejo de la vía aérea (broncoespasmo), de los relajantes musculares (retraso en el despertar y destete), de la ventilación mecánica (atelectasias pulmonares, neumonía), entre otras (13). No obstante, en ciertos casos va a ser inevitable la realización de una anestesia general (paciente anticoagulado/antiagregado, rechazo de la técnica locorregional, cirugía espinal previa, deformidades del raquis, cirugía de larga duración, cuando el bloqueo con técnicas locorregionales no cubra el área quirúrgica, en algunos pacientes con patología severa, etc.) (17).

La anestesia locorregional puede presentar importantes ventajas en el paciente con arteriopatía periférica: 1. Facilidad técnica (17), 2. Evita la instrumentación de la vía aérea (17), 3. Mantiene la conciencia del paciente, y se evita el uso de abundante medicación diminuyendo la disfunción cognitiva postoperatoria (13), 4. Aumenta la permeabilidad de las anastomosis (49), 5. Disminuye la respuesta al estrés de la cirugía (61), 6. Reduce los estados de hipercoagulabilidad postoperatoria (62,63), 7. Disminuye la agregación plaquetaria (49), 8. Posibilita el uso continuo de la técnica (catéter), facilitando la analgesia y la realización de curas dolorosas en el postoperatorio... 


\section{LA ANESTESIA/ANALGESIA EPIDURAL EN LA ARTERIOPATIA PERIFÉRICA CRÓNICA}

Los inconvenientes de los bloqueos mayores neuroaxiales (epidural y subaracnoideo) incluyen (3): 1. Riesgo de aparición de alteraciones hemodinámicas (hipotensión arterial y bradicardia), 2. Posibilidad de un bloqueo incompleto, 3. Imposibilidad de reversión inmediata de la técnica, 4. Contraindicación en el paciente anticoagulado/antiagregado por el riesgo de hematoma en el neuroeje, 5. Necesidad de respetar los tiempos de seguridad de anticoagulación/antiagregación para la colocación y retirada del catéter..., que en ocasiones provoca el rechazo de la técnica.

Respecto a la anestesia subaracnoidea, a pesar de la facilidad y rapidez en su realización y la ventaja de un menor riesgo de hematoma espinal, presenta ciertos inconvenientes respecto a la epidural: mayor frecuencia de alteraciones hemodinámicas, duración limitada del tiempo de anestesia y de la analgesia postoperatoria $(3,17)$. Más recientemente, incluso se ha propuesto el uso de bloqueos nerviosos periféricos (dosis única o continuos con catéter), con ayuda de ultrasonografía, para las intervenciones y postoperatorio de cirugía vascular periférica $(13,17)$.

Lo mejor, en general, siempre que no esté contraindicado, es usar la técnica de anestesia y analgesia que sea más familiar en cada institución, ya que por ejemplo, una falta de familiaridad y un manejo incorrecto de un catéter epidural puede provocar complicaciones muy serias (ej. hematoma espinal) (13). 


\section{LA ANESTESIA/ANALGESIA EPIDURAL EN LA ARTERIOPATIA PERIFÉRICA CRÓNICA}

\subsection{EN EL TRATAMIENTO DEL DOLOR POSTOPERATORIO}

El dolor agudo postoperatorio después de los procedimientos de cirugía vascular periférica es de ligero a moderado, y se controla bien con antiinflamatorios no esteroideos (AINES), paracetamol, metamizol y tramadol (13). No obstante, la epidural con concentraciones bajas de anestésicos locales produce alivio del dolor, reduce la duración de la ventilación mecánica, mejora la perfusión de las extremidades, y se han encontrado indicios débiles de que mejora el resultado de la cirugía y reduce la incidencia de complicaciones cardiacas $(64,65)$. Sin embargo, hay quién opina que el riesgo de hematoma epidural frente al alivio del dolor asociado a la cirugía no justifica su uso (66). Por experiencia sabemos que hay casos (cirugía no resolutiva de isquemia, úlceras vasculares dolorosas, y/o neuropatía dolorosa previa), en los que se produce un dolor postoperatorio intenso que, de forma individualizada, justificaría su empleo. Una adecuada analgesia postoperatoria reduce la tasa de complicaciones, acorta la convalecencia y evita la aparición de dolor crónico (67-69).

\subsection{EN EL TRATAMIENTO DEL DOLOR POR INSUFICIENCIA ARTERIAL PERIFÉRICA Y DE LA INSUFICIENCIA VASCULAR TISULAR}

En la evolución de la arteriopatía periférica crónica es frecuente la aparición de dolor. El dolor de origen vascular es de etiología múltiple (isquemia, lesión nerviosa, úlceras, edema, etc.), de mecanismo fisiopatológico mixto (nociceptivo y neuropático) y se puede presentar de forma aguda (por trombosis arterial/embolización) y/o crónica (formación 


\section{LA ANESTESIA/ANALGESIA EPIDURAL EN LA ARTERIOPATIA PERIFÉRICA CRÓNICA}

de trombo progresivamente sobre una placa de ateroma). Por su gravedad y severidad, el dolor vascular debe ser tratado enérgica y eficazmente, no sólo de forma sintomática, sino atendiendo a su fisiopatología $(55,58,70)$.

El espacio epidural se utiliza con frecuencia para tratar el dolor en la insuficiencia arterial periférica crónica, fundamentalmente cuando los fármacos por vía oral o intravenosa no son suficientes para aliviarlo (55). Dentro del espacio epidural se pueden infundir fármacos (anestésicos y/o analgésicos) y/o implantar estimuladores de cordones posteriores, con el objetivo de producir bloqueo sensitivo (analgesia) y bloqueo del sistema nervioso simpático (aumento del flujo sanguíneo y analgesia) (17,71).

El sistema nervioso simpático es el responsable del mantenimiento del tono vasoconstrictor cutáneo normal de la piel, contribuyendo entre otras cosas, a la termorregulación del organismo (72). Claude Bernard (1813-1878) (Fig. 22) fue el primero en publicar, en 1852, el efecto del sistema nervioso simpático sobre los vasos sanguíneos cutáneos. Posteriormente, en 1899, el cirujano francés Mathieu Jaboulay (1860-1913) (Fig. 23), mediante la simpatectomía quirúrgica de la arteria femoral, mejoró la cicatrización de úlceras cutáneas en el pie. 


\section{LA ANESTESIA/ANALGESIA EPIDURAL EN LA ARTERIOPATIA PERIFÉRICA CRÓNICA}

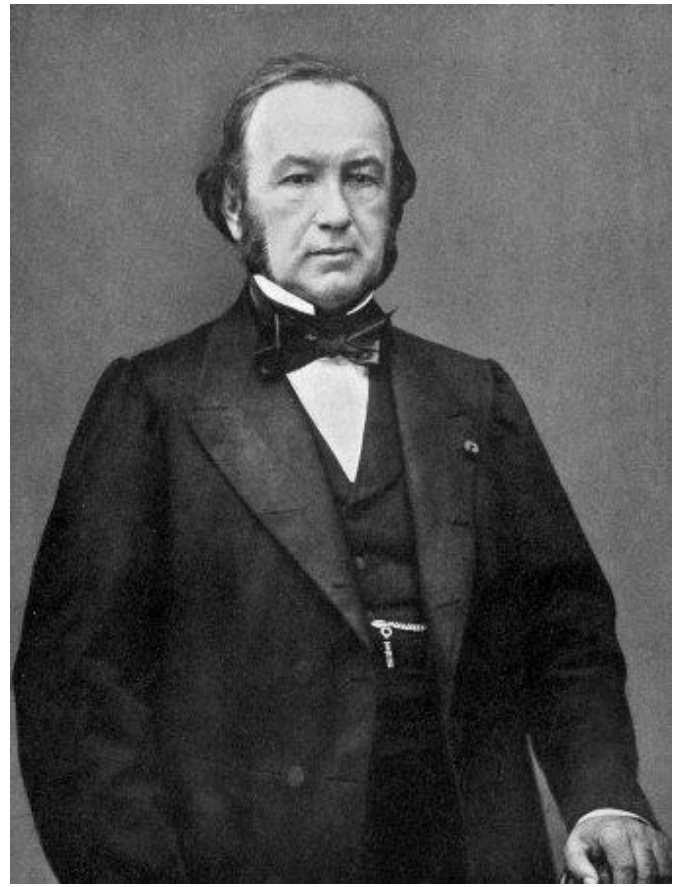

Figura 22: Claude Bernard

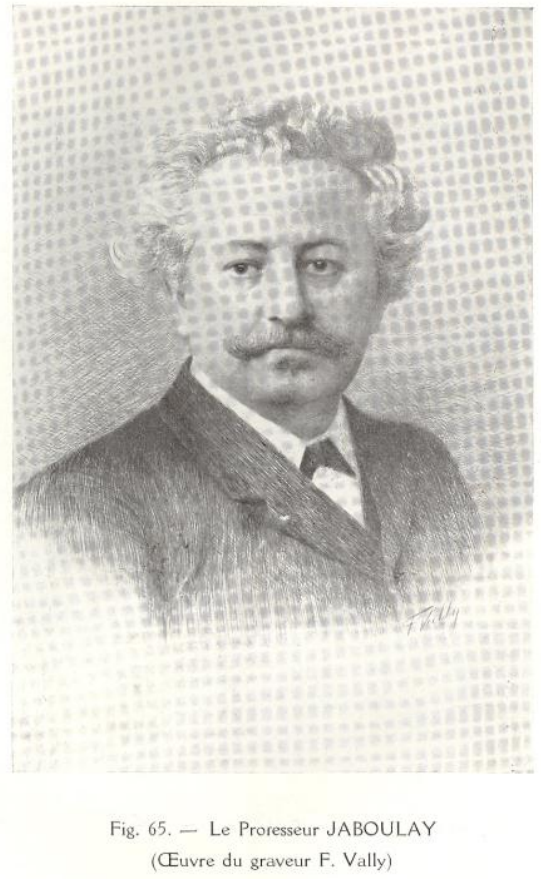

Figura 23: Mathieu Jaboulay

Pero a partir de 1920, el estudio de los efectos clínicos de la simpatectomía quirúrgica, despertó mucho interés entre los médicos del momento. Así, en Estados Unidos, el profesor de anatomía John I. Hunter (1898-1924) y el traumatólogo N.D. Royle, fueron los primeros en describir que después de las simpatectomías lumbares quirúrgicas realizadas a sus pacientes, con el objetivo de tratar una parálisis espástica, sucedía un aumento de la temperatura cutánea en los pies, secundaria a un aumento del flujo sanguíneo cutáneo. Posteriormente, A.W. Adson y G.E. Brown, también en Estados Unidos, impresionados por los cambios en la temperatura, color, y actividad de las glándulas sudoríparas de las piernas de los pacientes que habían sido tratados de su parálisis espástica mediante una simpatectomía, comenzaron a realizar simpatectomías a los pacientes con problemas vasculares periféricos (73). 


\section{LA ANESTESIA/ANALGESIA EPIDURAL EN LA ARTERIOPATIA PERIFÉRICA CRÓNICA}

Clásicamente, el bloqueo simpático se ha considerado una modalidad diagnóstica y terapéutica en diferentes entidades patológicas (Tabla 7) (2):

Tabla 7: Usos del bloqueo del sistema nervioso simpático

\begin{tabular}{|c|}
\hline PARA EL ALIVIO DEL DOLOR \\
\hline Cólico renal (bloqueo simpático lumbar) \\
\hline Enfermedad arterial oclusiva (bloqueo simpático lumbar) \\
\hline Pancreatitis aguda y cáncer de páncreas (bloqueo del plexo celíaco) \\
\hline Dolor canceroso de víscera abdominal superior (bloqueo del plexo celíaco) \\
\hline Dolor cardiaco (bloqueo simpático torácico o del ganglio estrellado) \\
\hline $\begin{array}{l}\text { Enfermedad ósea de Paget (bloqueo del ganglio estrellado o bloqueo simpático } \\
\text { lumbar) }\end{array}$ \\
\hline $\begin{array}{l}\text { Síndrome del dolor regional complejo I y II (bloqueo simpático lumbar o del } \\
\text { ganglio estrellado) }\end{array}$ \\
\hline Síndrome postraumático, síndrome postcongelación, atrofia de Sudeck \\
\hline $\begin{array}{l}\text { PARA MEJORAR EL FLUJO SANGUÍNEO EN ENFERMEDADES } \\
\text { VASOESPÁSTICAS } \\
\text { (bloqueo simpático lumbar o del ganglio estrellado) }\end{array}$ \\
\hline Enfermedad de Raynaud \\
\hline Inyección intraarterial accidental de tiopental \\
\hline Síndrome postcongelación en fases iniciales \\
\hline $\begin{array}{l}\text { Patología arterial obliterante no tributaria de cirugía vascular (dolor de reposo en } \\
\text { extremidades inferiores no quirúrgico, úlceras cutáneas) }\end{array}$ \\
\hline Cirugía vascular (para mejorar el flujo sanguíneo postoperatorio) \\
\hline
\end{tabular}

El bloqueo simpático puede lograrse a través de métodos farmacológicos o mediante técnicas regionales (55). El bloqueo logrado mediante fármacos (alfa/beta bloqueantes, deplecionantes de NA) es 


\section{LA ANESTESIA/ANALGESIA EPIDURAL EN LA ARTERIOPATIA PERIFÉRICA CRÓNICA}

generalizado; es decir, de todo el organismo. No termina de existir un acuerdo sobre el efecto beneficioso o perjudicial de esta vasodilatación generalizada del organismo en pacientes con arteriopatía periférica crónica (74), ya que en ocasiones se ha llegado a hablar de un "efecto de robo" sanguíneo de las extremidades inferiores hacia áreas más proximales del tronco, también vasodilatadas (2), lo que sería perjudicial para este tipo de pacientes. El bloqueo locorregional del sistema nervioso simpático puede realizarse con técnicas de bloqueo anestésico a diferentes niveles: técnicas locorregionales neuroaxiales (subaracnoidea y epidural), y periféricas (ganglios de la cadena simpática, paravertebral, nervios periféricos), siendo progresivamente la extensión del bloqueo simpático más limitada, y disminuyendo por tanto el temido "efecto de robo" en los pacientes con insuficiencia arterial periférica crónica.

En el individuo sano, el bloqueo del sistema nervioso simpático produce: dilatación venosa (con acumulación sanguínea en su territorio), dilatación arterial (descenso de las resistencias periféricas) y, si la presión arterial sistémica no se altera, un aumento del flujo sanguíneo arteriolar y capilar (2). Se ha referido que el aumento más importante de flujo es a nivel de la piel, seguido de un aumento de la temperatura cutánea, de sensación de calor en la extremidad, de aumento de la presión parcial de oxígeno venoso cutáneo y de la saturación de oxígeno (5).

En el paciente con insuficiencia arterial periférica crónica el objetivo más específico y evidente del bloqueo del sistema nervioso simpático es mejorar la perfusión sanguínea, disminuyendo la isquemia y mejorando el dolor, por su efecto sobre la actividad vasomotora (55). La simpatectomía quirúrgica se utilizó con frecuencia en la segunda mitad del siglo XX, para 


\section{LA ANESTESIA/ANALGESIA EPIDURAL EN LA ARTERIOPATIA PERIFÉRICA CRÓNICA}

tratar la insuficiencia vascular crónica (75) y, debido a la mejora de las técnicas quirúrgicas de revascularización y por su efecto impredecible (sin cambios demostrables, aumento o descenso del flujo sanguíneo) (2), su uso ha decaído. En los pacientes con insuficiencia arterial periférica, después de una simpatectomía, se ha observado que puede producirse un efecto de robo de flujo sanguíneo hacia zonas con un menor grado de oclusión (robo proximal o hacia la pierna contralateral), y que no siempre se produce una mejora de la sintomatología (2). Además, se piensa que el flujo sanguíneo muscular está regulado por el metabolismo celular, posiblemente más que por el sistema nervioso simpático, encontrándose en ocasiones en un estado de máxima dilatación previa, entre otros motivos, por acumulación de metabolitos vasodilatadores durante el ejercicio. (2). Sin embargo, en los casos en que existe una hiperactividad del simpático (ej. fenómeno de Raynaud, síndrome de dolor regional complejo, intoxicación por ergotamina), el bloqueo de este sistema nervioso provoca el aumento del flujo sanguíneo muscular con mejoría de la sintomatología $(2,12,55,76,77)$. Además, parece que el bloqueo del simpático lumbar asociado a la cirugía vascular, puede mejorar el flujo de los vasos recanalizados, lo que puede ser de interés en el postoperatorio inmediato (2). Pero en el momento actual no existe en la bibliografía una recopilación ordenada sobre la utilidad clínica de la simpatectomía lumbar (7).

Para comprobar la eficacia del bloqueo simpático se han utilizado distintos métodos diagnósticos directos o indirectos (Tabla 8) (2): 


\section{LA ANESTESIA/ANALGESIA EPIDURAL EN LA ARTERIOPATIA PERIFÉRICA CRÓNICA}

Tabla 8: Métodos para definir la presencia de bloqueo simpático

Respuesta conductora cutánea

Prueba del sudor con nihidrina, azul de cobalto, almidón yodado

Pletismografía cutánea y respuesta al hielo

Aclaramiento de xenón 133

Aclaramiento de sodio 24

Medición del flujo sanguíneo cutáneo (Técnicas de doppler)
Contador electromagnético de flujo

Temperatura cutánea

Presión de perfusión distal

Presión parcial de oxígeno capilar

Prueba del sudor

Microneurografía (6)

Etc.

Uno de los métodos más utilizados como indicador de simpatectomía, es la temperatura cutánea: Método indirecto, de fácil realización y utilizado desde hace mucho tiempo (6,9-12,55,78-86).

La temperatura cutánea, también se ha utilizado como método para evaluar la eficacia del bloqueo anestésico (grado de bloqueo simpático y la extensión del bloqueo anestésico) de diferentes técnicas locorregionales (epidural, espinal, bloqueo axilar, bloqueo paravertebral) (10,12). En 1994, Shigeito Sato y colaboradores sugirieron que la observación de la temperatura del pie podía ser de utilidad para determinar, durante la cirugía, el momento en que debería aplicarrse una nueva dosis de anestésico local por catéteres localizados en el espacio paravertebral a nivel torácico (82). Asato y Takenanmi sugirieron en 1997, la posibilidad de utilizar las variaciones de la temperatura cutánea para evaluar la extensión del bloqueo anestésico en pacientes con dificultad para comunicarse con el medio (87).

Entre los principales hallazgos de los estudios sobre el comportamiento termocutáneo del bloqueo simpático, secundario a un bloqueo neuroaxial, está el aumento de la temperatura cutánea, 


\section{LA ANESTESIA/ANALGESIA EPIDURAL EN LA ARTERIOPATIA}

PERIFÉRICA CRÓNICA

preferentemente en áreas distales $(6,78,79,80,82,83,85,86)$, asociado en ocasiones a un descenso de la temperatura cutánea de áreas cefálicas, no afectadas por el bloqueo $(78,82,86)$. Hay autores que hablan de la existencia de una diferencia metamérica entre el nivel cefálico de bloqueo simpático y de bloqueo sensitivo $(9,78)$.

Nuestro grupo de investigación ha desarrollado diferentes estudios sobre los efectos térmico-cutáneos y centrales de las técnicas anestésicas, tanto de la anestesia general $(88,89)$ como de anestesia locorregional $(90,91)$, así como de los fenómenos de la vasoconstricción cutánea termorreguladora $(92,93,94)$ o tras hipotermia inducida $(95)$.

Siguiendo la línea de investigación de nuestro grupo, y por todo lo anteriormente expuesto, creemos que tiene sentido estudiar los efectos térmico-cutáneos de la anestesia epidural en sujetos sanos y en pacientes con arteriopatía periférica oclusiva crónica. 



\section{HIPÓTESIS Y OBJETIVOS}





\subsection{HIPÓTESIS}

Clásicamente, se ha considerado que el bloqueo simpático producido al realizar una anestesia epidural, debido a la supresión del tono vasoconstrictor cutáneo normal, provoca un aumento de la temperatura cutánea por aumento del flujo sanguíneo a las zonas bloqueadas (2). Sin embargo, nosotros pensamos y formulamos así nuestra hipótesis: "Después de realizar una anestesia epidural, las personas con enfermedad arterial periférica oclusiva crónica, presentarán un comportamiento termocutáneo distinto a los personas sanas, que puede estar en relación con la severidad de la arteriopatía".

\subsection{OBJETIVOS}

Después de realizar una anestesia epidural con bupivacaína al 0,5\% sin vasoconstrictor, nos planteamos en este estudio los siguientes objetivos:

\subsubsection{Objetivo principal}

Comparar los efectos termocutáneos en pacientes con y sin enfermedad arterial periférica oclusiva crónica. 


\subsubsection{Objetivos secundarios}

1. Describir y analizar los efectos termocutáneos en pacientes con y sin enfermedad arterial periférica oclusiva crónica.

2. Comparar los efectos termocutáneos de las extremidades que van a ser revascularizadas inmediatamente respecto de las que no van a ser intervenidas, de los pacientes con enfermedad arterial periférica oclusiva crónica.

3. Analizar posibles factores que puedan estar relacionados con los cambios termocutáneos en los pacientes con arteriopatía periférica oclusiva crónica.

4. Analizar el comportamiento hemodinámico (tensión arterial sistólica y diastólica, frecuencia cardiaca) en los pacientes con enfermedad arterial periférica oclusiva crónica. 
6 MATERIAL Y MÉTODO 

Con la autorización de la Comisión de Investigación del Hospital Clínico Universitario de Valladolid y el consentimiento informado escrito de los pacientes, hemos desarrollado un estudio prospectivo, descriptivo y comparativo, de los efectos termocutáneos durante el establecimiento de una anestesia epidural lumbar, en pacientes sin signos de arteriopatía periférica, y en pacientes con signos de arteriopatía periférica oclusiva crónica.

\subsection{MATERIAL}

\subsubsection{Muestra}

Nuestra muestra la constituimos con dos tipos de pacientes:

- 20 varones jóvenes sin clínica de arteriopatía periférica, ASA I ${ }^{12}$, sin hábitos tóxicos, que iban a ser sometidos a una cirugía infraumbilical bajo anestesia epidural.

- 24 varones con enfermedad arterial periférica oclusiva crónica, ASA III ó IV, que iban a ser sometidos a una cirugía de revascularización de una de sus extremidades inferiores (EI) bajo anestesia epidural.

12 ASA: Sistema de clasificación creado por la American Society of Anesthesiologists en 1941, y utilizado sistemáticamente por los anestesiólogos previo a anestesiar a un paciente, con el que se clasifica a éstos según su estado físico: ASA I: Paciente sin patología asociada. ASA II: Paciente con enfermedad sistémica leve (ej. hipertensión arterial bien controlada). ASA III: Paciente con enfermedad sistémica grave que limita su actividad, pero no le incapacita para la vida ordinaria (ej. hipertensión arterial grave o mal controlada). ASA IV: Paciente con enfermedad sistémica incapacitante que pone en peligro su vida (ej. insuficiencia renal crónica en programa de diálisis). ASA V: Paciente moribundo, que no se espera que sobreviva más de 24 horas con o sin tratamiento quirúrgico (96). 


\subsubsection{Equipo de anestesia epidural}

Para realizar la técnica anestésica utilizamos las bandejas de epidurales de Portex ${ }^{\circledR}$ desechables, que vienen preparadas de fábrica (Figs. 24 y 25). Constan de:

- 1 aguja Tuohy $18 \mathrm{G}$ x 80mm.

- 1 aleta para aguja Tuohy 18G.

- 1 jeringa de baja resistencia de $10 \mathrm{ml}$, específica para la detección del espacio epidural.

- 1 catéter epidural transparente $18 \mathrm{G}$ con la punta distal cerrada y con tres orificios laterales.

- 1 conector de catéter epidural 18G.

- 1 etiqueta de catéter epidural.

- 1 guía del catéter.

- 1 lockit: dispositivo de fijación para el catéter 18G.

- 1 filtro epidural plano de 0,2 micras y conexión Luer lock.

- 2 esponjas aplicadoras.

- 5 compresas blancas, $75 \times 75 \mathrm{~mm}$.

- 1 campo estéril para la bandeja, 750 x 750mm.

- 1 talla estéril fenestrada adhesiva para colocar sobre el paciente, $610 \times 700 \mathrm{~mm}$.

- 1 jeringa de plástico de 3ml, conexión Luer.

- 1 jeringa de plástico de $20 \mathrm{ml}$, conexión Luer.

- 1 aguja hipodérmica $18 \mathrm{G}$ x 40mm.

- 1 aguja hipodérmica 22G x 40mm.

- 1 aguja hipodérmica 25G x 16mm.

- 1 etiqueta adicional de los componentes. 


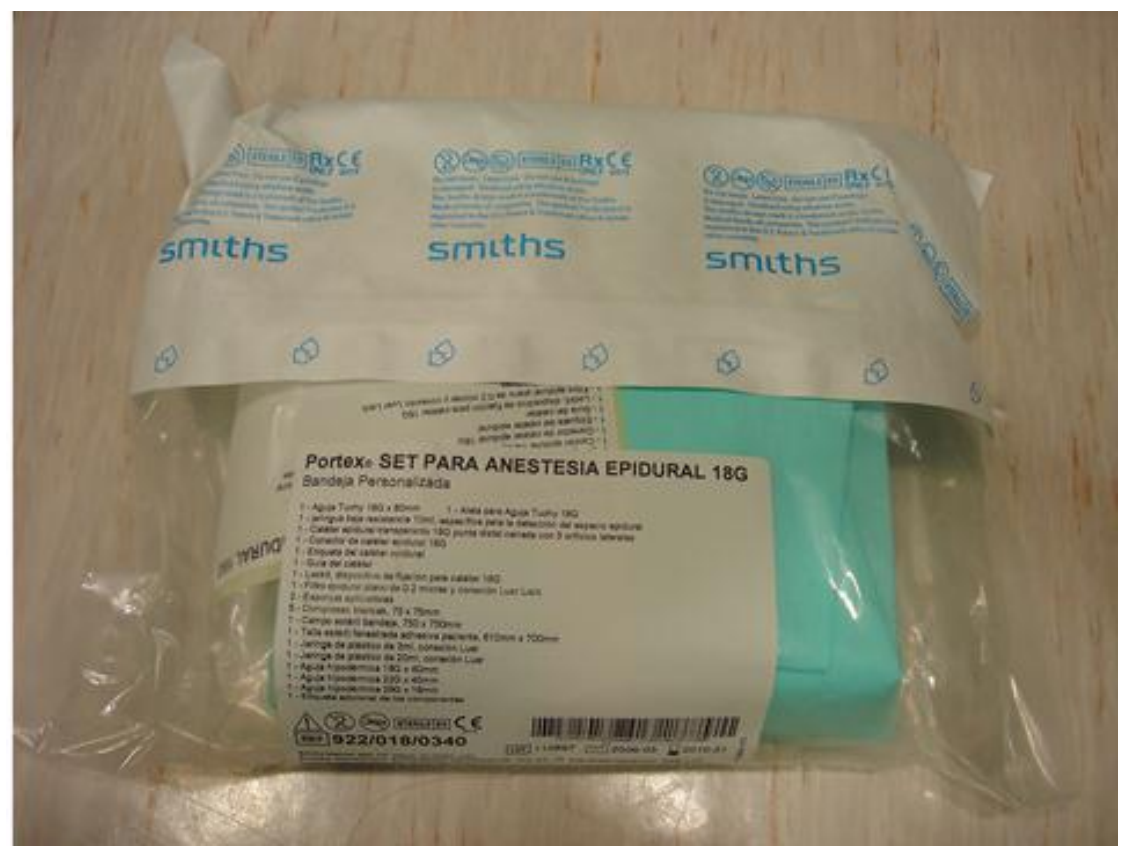

Figura 24: Exterior del equipo de epidurales utilizado

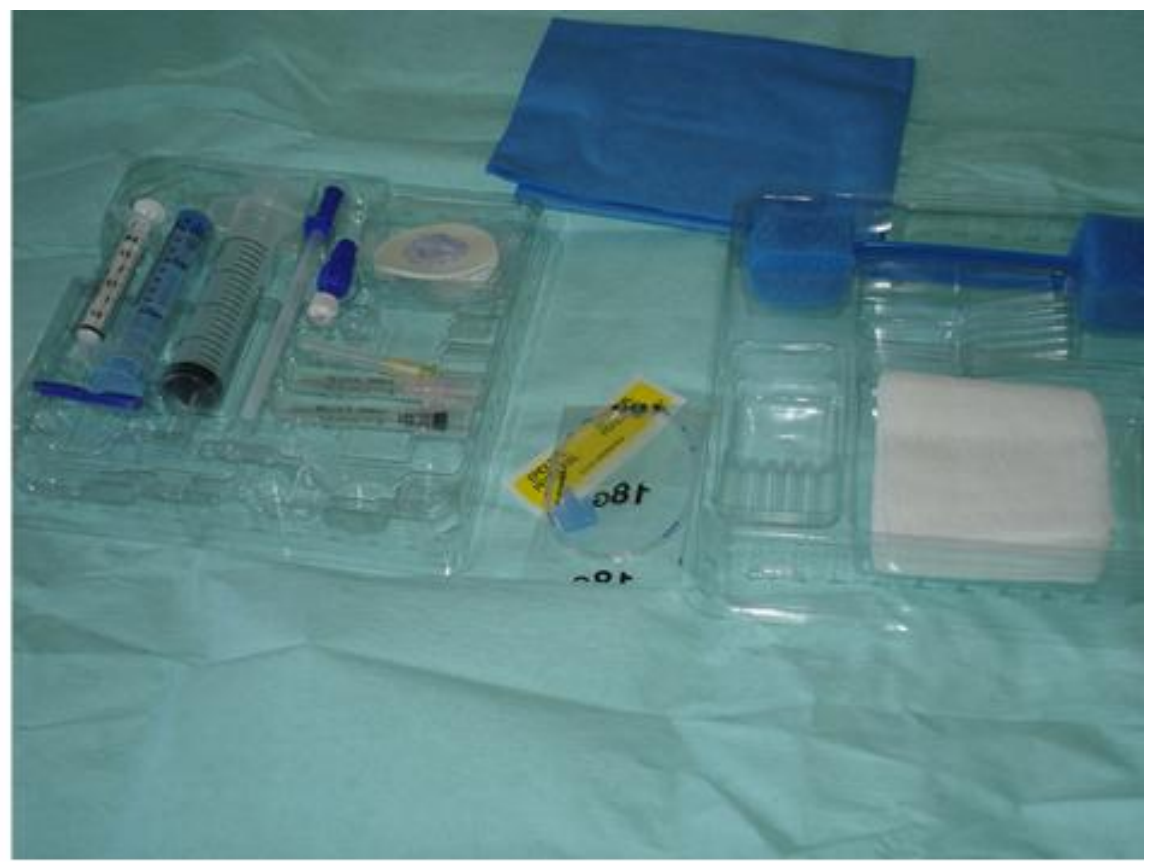

Figura 25: Material del equipo de epidurales de Portex ${ }^{\circledR}$ 


\subsubsection{Anestésicos locales}

Hemos utilizado ampollas de $10 \mathrm{ml}$ de bupivacaína al $0,5 \%$ sin vasoconstrictor, fabricadas por Braun ${ }^{\circledR}$ (Fig. 26).

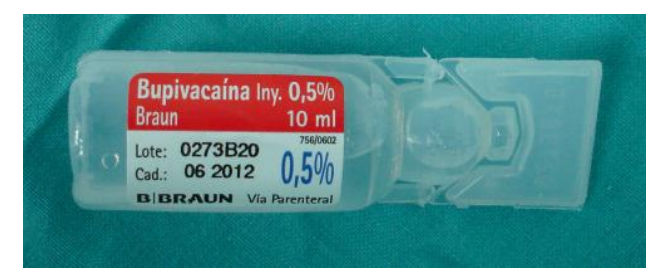

Figura 26: Ampollas del anestésico local utilizado

\subsubsection{Termómetro cutáneo}

La termometría cutánea la realizamos con un termómetro de absorción de radiación infrarroja (74151-HPI Racing Temp Gun ${ }^{\circledR}$ ) (Fig. 27), cuyo rango de temperatura oscila entre $-10^{\circ} \mathrm{C} \mathrm{y}+50^{\circ} \mathrm{C}$ y tiene una precisión de $\pm 0,1^{\circ} \mathrm{C}$.

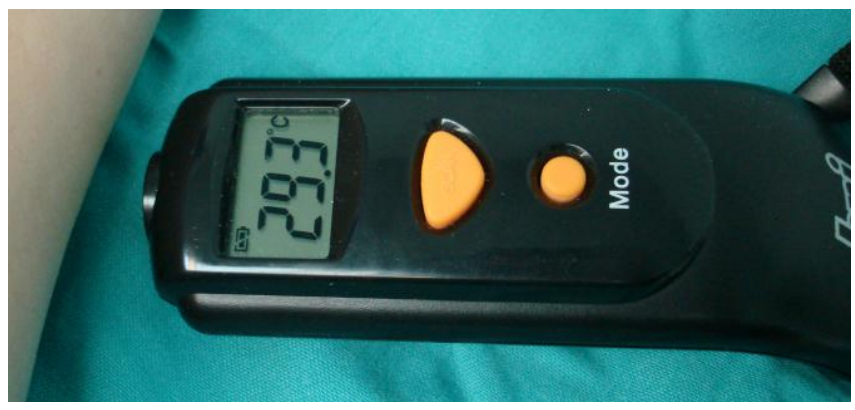

Figura 27: Termómetro de absorción de radiación infrarroja 


\subsubsection{Sistemas de monitorización}

Para determinar el nivel metamérico de bloqueo sensitivo al dolor mediante el método de pinprick, utilizamos una aguja intravenosa 20G; y para determinar el nivel metamérico de bloqueo sensitivo al frío, utilizamos una barra de hielo.

Para la monitorización de las constantes vitales usamos los monitores Datex Ohmeda Cardiocap/5 (Fig. 28), que registraban la derivación II del electrocardiograma, la frecuencia cardiaca y la pulsioximetría de forma continua, así como la tensión arterial de forma no invasiva cada 5 minutos.

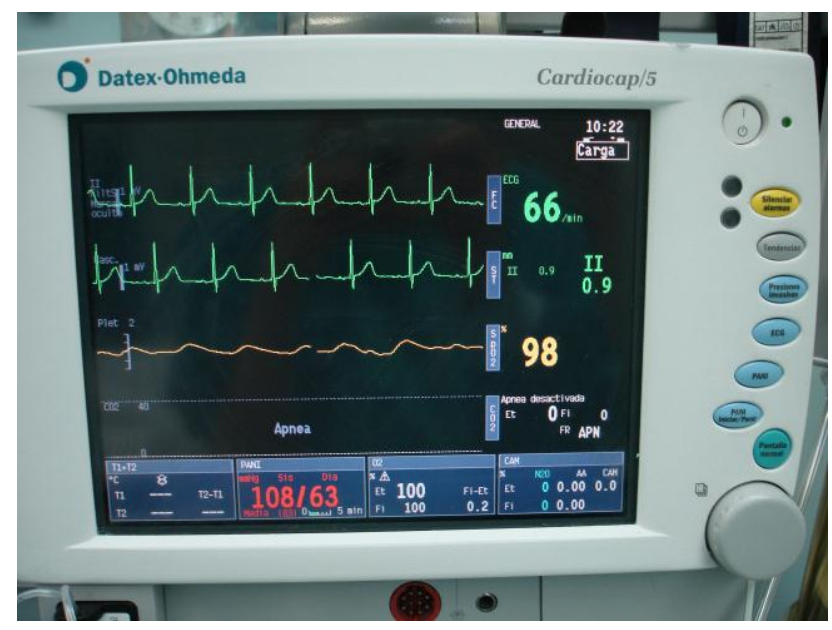

Figura 28: Monitor utilizado para el control hemodinámico de los pacientes

\subsubsection{Hoja de recogida de datos}

Todos los datos de los pacientes se registraron en unas hojas diseñadas al comienzo del estudio (Fig. 29). 


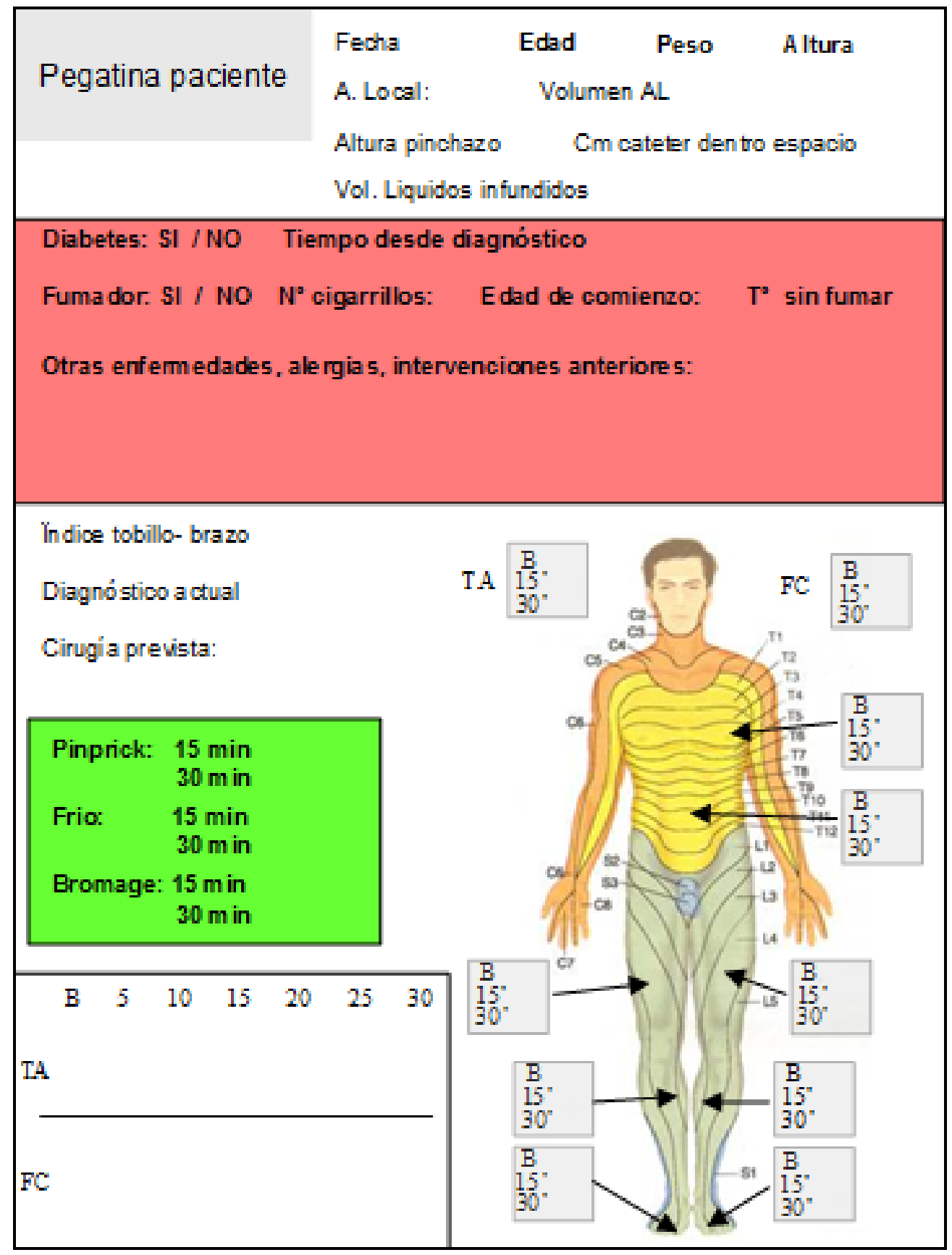

Figura 29: Hoja de recogida de datos 


\subsection{MÉTODO}

\subsubsection{Diseño del protocolo de estudio y autorización de la Comisión de Investigación del Centro}

Después del diseño y redacción del protocolo de investigación (introducción, hipótesis, objetivos, material y método), lo presentamos a la Comisión de Investigación del Hospital Clínico Universitario de Valladolid y obtuvimos su aprobación.

\subsubsection{División de la muestra de la población a estudio}

De los 20 varones jóvenes que hemos llamado "controles", recogimos la temperatura del ombligo, y del pezón, muslo, pantorrilla y pie sólo del hemicuerpo derecho.

De los 24 varones con enfermedad arterial periférica oclusiva crónica, que llamamos "vasculares", recogimos la temperatura del pezón derecho y del ombligo. Y la del muslo, pantorrilla y pie, la recogimos de ambas extremidades, tanto de la que iba a ser inmediatamente revascularizada mediante una derivación vascular como de la que no.

Dividimos la muestra de la siguiente forma (Fig. 30A). 


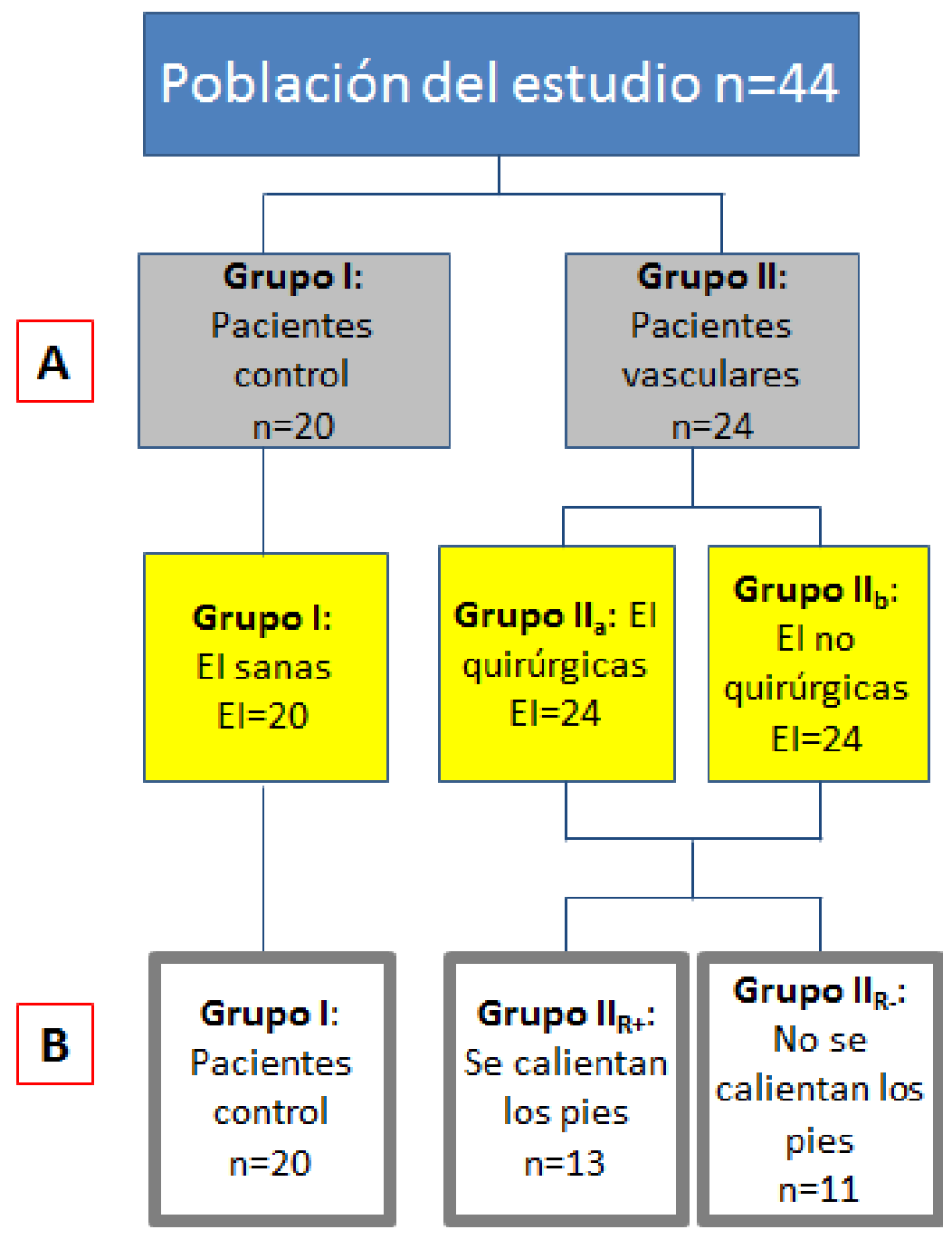

Figura 30: División de la muestra de la población a estudio. n, tamaño muestral (personas); EI, extremidades inferiores

Después de analizar los resultados, decidimos hacer una segunda división de la muestra de pacientes vasculares, atendiendo al calentamiento o no del pie considerado de forma aislada (Fig. 30B):

- Grupo $\mathrm{II}_{\mathrm{R}+}$ : Pacientes cuyos pies se calentaron $>1,5^{\circ} \mathrm{C}$ en los 30 minutos posteriores a la inyección del anestésico vía epidural. 
- Grupo $\mathrm{II}_{\mathrm{R}-\text { : }}$ Pacientes cuyos pies no se calentaron en las mismas condiciones.

\subsubsection{Selección de la muestra}

En una sala previa a los quirófanos por la que pasan todos los pacientes antes de ser operados en este hospital, que llamamos antequirófano, seleccionamos a los que cumplían los criterios de inclusión y no incurrían en criterios de exclusión (Tabla 10 y 11); y tras explicarles el estudio, solicitamos su participación y consentimiento informado escrito.

Tabla 10: Criterios de selección de los pacientes del grupo control (grupo I)

\begin{tabular}{|c|l|}
\hline \multicolumn{2}{|c|}{ GRUPO CONTROL } \\
\hline INCLUSIÓN & $\begin{array}{l}\text { ASA I } \\
\text { Sexo masculino } \\
\text { Edad: }>16 \text { años y }<30 \text { años } \\
\text { Programados para cirugía bajo anestesia locorregional }\end{array}$ \\
\hline EXCLUSIÓN & $\begin{array}{l}\text { ASA II } \\
\text { Ser fumador o estar tomando algún tipo de medicación } \\
\text { Padecer alguna enfermedad sistémica crónica o aguda } \\
\text { Pruebas de laboratorio alteradas } \\
\text { Rechazo de la anestesia epidural } \\
\text { Alteraciones psiquiátricas } \\
\text { Urgencias } \\
\text { Sexo femenino médica para la anestesia epidural }\end{array}$ \\
\hline
\end{tabular}




\section{MATERIAL Y MÉTODO}

Tabla 11: Criterios de selección de los pacientes vasculares (grupo II)

\begin{tabular}{|l|l|}
\hline \multicolumn{1}{|c|}{ GRUPO VASCULARES } \\
\hline INCLUSIÓN & $\begin{array}{l}\text { ASA III ó IV } \\
\text { Sexo masculino } \\
\text { Arteriopatía periférica oclusiva crónica diagnosticada por el } \\
\text { servicio de cirugía vascular y programados para cirugía de } \\
\text { revascularización de las extremidades inferiores (bypass o } \\
\text { angioplastia) bajo anestesia locorregional }\end{array}$ \\
\hline EXCLUSIÓN & $\begin{array}{l}\text { Contraindicación para la realización de la epidural } \\
\text { Rechazo de la anestesia epidural } \\
\text { Signos de necrosis o infección en las extremidades inferiores } \\
\text { (ej.osteomielitis, úlcera infectada...) } \\
\text { Amputación previa completa o parcial de las extremidades } \\
\text { inferiores } \\
\text { Cirugía vascular o simpatectomía quirúrgica/química } \\
\text { establecida previas } \\
\text { Isquemia aguda } \\
\text { Catéter epidural colocado previo a bajar al quirófano } \\
\text { Insuficiencia renal crónica diagnosticada en programa de } \\
\text { diálisis } \\
\text { Alteraciones psiquiátricas (demencias, esquizofrenia....) } \\
\text { Urgencias } \\
\text { Sexo femenino }\end{array}$ \\
\hline
\end{tabular}

\subsubsection{Protocolo para el manejo de los pacientes y la realización de la técnica anestésica}

Después de la recepción de los pacientes en el antequirófano, el resto del protocolo de manejo lo realizamos en los quirófanos, a una temperatura ambiente constante de $21^{\circ} \mathrm{C}$. 


\subsubsection{Recepción e identificación}

Tras identificar al paciente, revisar su historia clínica y comprobar el cumplimiento de los criterios del estudio, le explicábamos los procedimientos que se iban a realizar e intentábamos tranquilizarlo verbalmente. Ninguna persona fue premedicada.

\subsubsection{Procedimientos anestésicos}

Después de la aplicación de los sistemas de monitorización anestésica, (electrocardiograma, frecuencia cardiaca y presión arterial no invasiva), canalizábamos una vena periférica de una de las extremidades superiores con un catéter 18G, e iniciábamos una perfusión de suero ringer lactato que estaba a temperatura ambiente $(500 \mathrm{ml}$ en 10 minutos y otros $500 \mathrm{ml}$ en 30 minutos). Durante este tiempo el paciente permanecía en decúbito supino con una sábana encimera simple cubriéndolo. A continuación realizábamos los siguientes pasos para la ejecución de la técnica anestésica:

$1^{\circ}$. Colocación del paciente en posición sentado

$2^{\circ}$. Desinfección de la piel con povidona yodada

$3^{\circ}$. Infiltración de la piel con anestésico local

$4^{\circ}$. Localización del espacio epidural mediante la punción con una aguja Tuohy 18G insertada medialmente entre las vértebras L2-L3, utilizando la técnica de pérdida de resistencia con aire, con una jeringa de $10 \mathrm{cc}$ de baja resistencia

$5^{\circ}$. Introducción de 3,5 $\mathrm{cm}$ de catéter epidural en dicho espacio

$6^{\circ}$. Retirada de la aguja Tuohy y fijación del catéter epidural a la piel, para evitar su salida 


\section{MATERIAL Y MÉTODO}

$7^{\circ}$. Comprobación del correcto emplazamiento de la punta del catéter en el espacio epidural mediante el test de aspiración por el catéter epidural con una jeringa de $2 \mathrm{cc}^{13}$

$8^{\circ}$. Colocación del paciente en decúbito supino

$9^{\circ}$. Inyección de una dosis test de $3 \mathrm{ml}$ de bupivacaína $0,25 \%$ con vasoconstrictor por el catéter epidural y comprobación del efecto durante 5 minutos $^{14}$

$10^{\circ}$. Inyección en bolo por el catéter epidural de: $20 \mathrm{ml}$ de bupivacaína al 0,5\% en el grupo control, y de 14-16 ml de bupivacaína al $0,5 \%$ en el grupo de vasculares

\subsubsection{Protocolo para el manejo del paciente para en la medición de las temperaturas cutáneas}

\subsubsection{Registro de las temperaturas}

La temperatura cutánea la medimos mediante un termómetro de absorción de radiación infrarroja, que situábamos a un centímetro de la piel en los puntos de medición, evitando la piel encima de venas visibles: Dedo gordo del pie, pantorrilla, muslo, ombligo y pezón. (ver figura 29 "Hoja de recogida de datos"). En los controles (grupo I), la medición se hacía del hemicuerpo derecho, y en los pacientes vasculares (grupo II) se medían las dos extremidades inferiores, ombligo y pezón derecho. Se hacían tres mediciones seguidas en cada lugar, y se registraba la media de las temperaturas.

\footnotetext{
13 Importante que no refluya sangre o líquido cefalorraquídeo (ver apartado 2.5.5 "Introducción del anestésico local en el espacio epidural")

${ }^{14}$ Ver apartado 2.5.5.1 "Dosis test"
} 


\subsubsection{Momentos}

Después de la llegada del paciente al quirófano, esperábamos diez minutos para que se aclimatara, y antes de la punción epidural, realizábamos la primera medición de la temperatura cutánea (temperatura cutánea basal), en los distintos puntos (pie, pantorrilla, muslo, ombligo y pezón). A los 15 y 30 minutos de la inyección del bolo de anestésico local por el catéter epidural, repetíamos las mediciones.

\subsubsection{Protocolo para el manejo del paciente en la medición de los niveles metaméricos de bloqueo sensitivo alcanzados}

\subsubsection{Registro del nivel de bloqueo sensitivo}

El nivel de bloqueo sensitivo (dolor y frío) lo determinamos cada 10 centímetros y en sentido ascendente (desde los pies hasta el pezón), mediante pinchazos con una aguja 20G y la colocación sobre la piel de una barra de hielo en el hemicuerpo izquierdo, a nivel de la línea medio axilar. Dejamos registrada la metámera justo inferior a la que tuviera sensibilidad.

\subsubsection{Momentos}

A los 15 y 30 minutos de la inyección del bolo de anestésico local registrábamos el nivel de bloqueo sensitivo (al dolor y frío). 


\subsubsection{Registro de otros datos}

\subsubsection{Datos antropométricos y antecedentes}

Durante los 10 minutos de aclimatación y/o posterior al registro de las temperaturas, escribíamos en la hoja de recogida de datos lo siguiente: edad, peso, altura, antecedentes personales (hipertensión arterial, diabetes, años desde su diagnóstico, tabaquismo, años de fumador, número de cigarrillos, tiempo sin fumar) y medicación habitual. Estos datos los extraíamos de la historia clínica y mediante preguntas al paciente.

\subsubsection{Datos de la enfermedad y de la intervención quirúrgica}

En la hoja de recogida de datos registrábamos también el ITB y la intervención quirúrgica programada. Estos datos se extraían de la historia clínica.

\subsubsection{Datos de la anestesia epidural}

Dejábamos escrito en la hoja de recogida de datos: el nivel de punción, centímetros del catéter dentro del espacio epidural y volumen (ml) de anestésico local inyectado por el catéter epidural.

\subsubsection{Parámetros hemodinámicos}

Se monitorizó de forma continua la frecuencia cardiaca y la pulsioximetría, y cada 5 minutos la tensión arterial no invasiva. En la hoja de recogida de datos sólo dejamos registradas la frecuencia cardiaca y la tensión arterial de los pacientes, obtenidas en el momento basal y cada 5 minutos, durante los 30 minutos que duró la recogida de datos. 


\subsubsection{Cálculo del tamaño de la muestra}

Previamente a la recogida de datos, determinamos el número de pacientes requeridos para cada grupo, mediante un cálculo de la potencia, según los datos obtenidos en un estudio previo realizado por nuestro grupo de investigación en pacientes sanos (91). Partimos de la hipótesis que después de una anestesia epidural lumbar con bupivacaína al 0,5\%, el comportamiento termocutáneo en el pie de personas con arteriopatía periférica oclusiva crónica, tendría que ser distinto al de las personas sanas. Utilizando un test bilateral de comparación de dos medias y teniendo en cuenta una proporción esperada de pérdidas del 15\%, sería necesaria una muestra de 19 personas por grupo, para detectar una diferencia entre los grupos mayor de $1,5^{\circ} \mathrm{C}$, con un nivel de confianza (error alfa) del $95 \%$ y un poder estadísticos (error beta) del 90\%.

\subsubsection{Análisis estadístico de los resultados}

Los datos los hemos expresado como media \pm desviación estándar (DS), y como valor absoluto y porcentaje de la muestra. Para el análisis estadístico de los datos utilizamos el programa SPSS versión 19.0 para Windows 7, con licencia para la Universidad de Valladolid. Para comparar las variables cualitativas utilizamos el test de Fisher y el test de $\chi 2$; y para comparar variables cuantitativas la t-Student para muestras relacionadas al comparar distintos momentos, y la t-Student para muestras independientes al comparar distintos grupos en cada momento. Se analizó la correlación entre las variables usando el coeficiente de correlación de Pearson.

Para el análisis de los factores que influyen en la variación de la temperatura en el pie de enfermos con enfermedad arterial periférica 


\section{MATERIAL Y MÉTODO}

oclusiva crónica, se realizó un análisis de regresión logística por pasos hacia adelante. Se analizó la posible colinealidad de las variables a incluir en el modelo utilizado como criterio de inclusión: Tolerancia mayor de 0,4 o inflación de la varianza menor de 2,5, condición numérica menor de 10 y varianza o dos o más variables no mayores de 0,5 . La variable dependiente respondió a dos categorías: 1) Pacientes con incremento de la temperatura en el pie $>1,5^{\circ} \mathrm{C}$ de enfermos vasculares, y 2) pacientes sin incremento de la temperatura en el pie de enfermos vasculares.

El grado de significación estadística fue asumido cuando $\mathrm{p} \leq 0,05$. 


\section{RESULTADOS}





\subsection{CARACTERÍSTICAS DE LA MUESTRA: PACIENTES CONTROLES Y PACIENTES VASCULARES}

Después de analizar las características antropométricas y demográficas de nuestra muestra, observamos que los pacientes controles eran significativamente más jóvenes y más altos que los pacientes con arteriopatía periférica crónica. No encontramos diferencias significativas en el peso y sexo (Tabla 12).

Tabla 12: Características demográficas y antropométricas de los pacientes sin y con arteriopatía periférica

\begin{tabular}{|l|c|c|c|}
\hline \multicolumn{1}{|c|}{ VARIABLE } & $\begin{array}{c}\text { CONTROLES } \\
(\mathrm{n}=20)\end{array}$ & $\begin{array}{c}\text { VASCULARES } \\
(\mathrm{n}=24)\end{array}$ & p valor \\
\hline Edad (años) & $20,94 \pm 3,11$ & $70,17 \pm 11,12$ & $\mathbf{0 , 0 0 0 1}$ \\
Peso (kg) & $70,83 \pm 8,34$ & $71,13 \pm 12,29$ & 0,93 \\
Estatura (cm) & $172,50 \pm 4,03$ & $166,75 \pm 6,18$ & $\mathbf{0 , 0 0 1}$ \\
Sexo varón & $20(100)$ & $24(100)$ & 1.00 \\
\hline
\end{tabular}

Los datos se han expresado como media \pm desviación estándar (DS) y como valor absoluto y porcentaje de la muestra.; n, tamaño muestral (personas); kg, kilogramos; cm, centímetros

En los pacientes con enfermedad arterial periférica, la hipertensión arterial tenía una prevalencia del 66\%, y la diabetes mellitus del $45 \%$. Además, un $75 \%$ era o había sido fumador a lo largo de su vida. El grupo 


\section{RESULTADOS}

control, debido al cumplimiento de los criterios de inclusión, era ASA I y sin hábitos tóxicos (Tabla 13).

Tabla 13: Comorbilidades y hábitos de vida de los pacientes vasculares

\begin{tabular}{|l|c|}
\hline \multicolumn{1}{|c|}{ VARIABLE } & VASCULARES $(\mathrm{n}=24)$ \\
\hline HTA & $16(66,66)$ \\
DM & $11(45,83)$ \\
Años DM & $4,33 \pm 8,52$ \\
Fumador & $18(75)$ \\
Años fumador & $31,71 \pm 20,74$ \\
Años exfumador & $5,04 \pm 9,21$ \\
No cigarros/día & $18,96 \pm 15,03$ \\
\hline
\end{tabular}

Los datos se han expresado como media \pm desviación estándar (DS) y como valor absoluto y porcentaje de la muestra.; n, tamaño muestral (personas); HTA, hipertensión arterial; DM, diabetes mellitus; $\mathrm{N}^{\circ}$, número

Se observó que las extremidades de los pacientes vasculares pendientes de ser revascularizadas mediante una derivación vascular (bypass) (grupo $\mathrm{II}_{\mathrm{a}}$ ), tenían con más frecuencia ocluídas sus arterias, que las extremidades que no iban a ser intervenidas (grupo $\mathrm{II}_{\mathrm{b}}$ ). No había diferencia significativa en el ITB (Tabla 14). 
Tabla 14: Diagnóstico y localización de la obstrucción vascular

\begin{tabular}{|l|c|c|c|}
\hline \multicolumn{1}{|c|}{ VARIABLE } & $\begin{array}{c}\text { Grupo } \mathrm{II}_{\mathrm{a}} \\
(\mathrm{n}=24)\end{array}$ & $\begin{array}{c}\text { Grupo } \mathrm{II}_{\mathrm{b}} \\
(\mathrm{n}=24)\end{array}$ & p valor \\
ITB & $0,58 \pm 0,33$ & $0,60 \pm 0,28$ & 0,89 \\
Obstrucción femoral & $5(20)$ & $3(12)$ & 0,44 \\
Obstrucción poplítea & $18(75)$ & $8(33)$ & $\mathbf{0 , 0 0 4}$ \\
Obstrucción tibial anterior & $21(87)$ & $14(58)$ & $\mathbf{0 , 0 2}$ \\
Obstrucción tibial posterior & $22(91)$ & $16(66)$ & $\mathbf{0 , 0 3}$ \\
\hline
\end{tabular}

Los datos se han expresado como media \pm desviación estándar (DS) y como valor absoluto y porcentaje de la muestra. Grupo $\mathrm{II}_{\mathrm{a}}$, extremidad inferior quirúrgica; Grupo $\mathrm{II}_{\mathrm{b}}$, extremidad inferior no quirúrgica; n, tamaño muestral (extremidades inferiores); ITB, índice tobillobrazo

\subsection{CARACTERÍSTICAS DE LA REALIZACIÓN DE LA TÉCNICA EPIDURAL Y DEL BLOQUEO SENSITIVO CONSEGUIDO EN LOS CONTROLES Y VASCULARES}

En todos los pacientes el bloqueo epidural, medido por la pérdida de sensibilidad mediante la técnica pinprick y ausencia de dolor durante la cirugía, fue efectivo. No fue necesario el uso de fármacos vasopresores durante la recogida de los datos.

En los controles se utilizó un volumen de anestésico local significativamente mayor que en los pacientes con arteriopatía periférica (Tabla 15), sin embargo el nivel metamérico del bloqueo sensitivo, medido mediante pinprick de los pacientes vasculares, fue más cefálico (Tabla 16). 
Tabla 15: Características de la técnica epidural. Altura de punción y volumen de anestésico local

\begin{tabular}{|l|c|c|c|}
\hline \multicolumn{1}{|c|}{ VARIABLE } & $\begin{array}{c}\text { CONTROLES } \\
(\mathrm{n}=20)\end{array}$ & $\begin{array}{c}\text { VASCULARES } \\
(\mathrm{n}=24)\end{array}$ & p valor \\
\hline Espacio interespinoso L3 & $20(100)$ & $24(100)$ & 1.00 \\
\hline Anestésico local (ml) & $19,7 \pm 1,75$ & $13,75 \pm 1,82$ & $\mathbf{0 , 0 0 0 1}$ \\
\hline
\end{tabular}

Los datos se han expresado como media \pm desviación estándar (DS) y como valor absoluto y porcentaje de la muestra; $\mathrm{n}$, tamaño muestral (personas); ml, mililitros

Tabla 16: Características del bloqueo epidural

\begin{tabular}{|l|c|c|c|}
\hline \multicolumn{1}{|c|}{ VARIABLE } & $\begin{array}{c}\text { CONTROLES } \\
(\mathrm{n}=20)\end{array}$ & $\begin{array}{c}\text { VASCULARES } \\
(\mathrm{n}=24)\end{array}$ & p valor \\
\hline Dolor $30 \mathrm{~min}$ & $7,78 \pm 2,01$ & $5,67 \pm 2,97$ & $\mathbf{0 , 0 1}$ \\
\hline Frío $30 \mathrm{~min}$ & $6,22 \pm 2,07$ & $4,83 \pm 2,82$ & 0,08 \\
\hline
\end{tabular}

Los datos se han expresado como media \pm desviación estándar (DS); n, tamaño muestral (personas); min, minutos

\subsection{ANÁLISIS DE LA TEMPERATURA CUTÁNEA EN LAS EXTREMIDADES, OMBLIGO Y PEZÓN DE CONTROLES y} VASCULARES: GRUPO I, II, $\mathrm{II}_{\mathrm{a}}$ y $\mathrm{II}_{\mathrm{b}}$ (Tablas 17-22 y Figs. 31-36)

Después de analizar la temperatura del pie, pierna, muslo, ombligo y pezón, en el momento basal, a los 15 y 30 minutos de la realización de la anestesia epidural lumbar con bupivacaína, se observó lo siguiente: 


\subsubsection{Análisis de la temperatura intergrupos, en los distintos momentos de medición}

Las temperaturas de los pacientes controles, fueron significativamente mayores que las de los pacientes con arteriopatía periférica en todos los momentos de medición en el pie (Tabla 17, Fig. 31), y en los momentos 15 y 30 en la pierna (Tabla 18, Fig. 32). Sin embargo fueron significativamente menores, en los tres momentos de medición, en el ombligo (Tabla 20, Fig. 34). En el muslo y pezón no existían diferencias significativas (Tablas 19 y 21, Figs. 33 y 35). Tampoco había diferencias significativas en ninguno de los lugares de medición y en ninguno de los momentos entre las extremidades que iban a ser intervenidas (grupo $\mathrm{II}_{\mathrm{a}}$ ) y las que no (grupo $\mathrm{II}_{\mathrm{b}}$ ), de los pacientes con arteriopatía periférica (Tablas 1719, Figs. 31-33).

\subsubsection{Análisis de la temperatura intragrupo}

En el grupo control (grupo I) ocurría un incremento significativo de la temperatura en los 30 minutos posteriores a la inyección del anestésico local, en el pie $\left(4,41^{\circ} \mathrm{C}\right)$ (Tabla 17 , Fig. 31 ), pierna $\left(0,91^{\circ} \mathrm{C}\right)$ (Tabla 18 , Fig. 32) y muslo $\left(0,34^{\circ} \mathrm{C}\right)$ (Tabla 19, Fig. 33), sin embargo en el ombligo y pezón no sucedía una variación de la temperatura de forma significativa (Tablas 20 y 21 , Figs. 34 y 35$)$.

En los pacientes con arteriopatía periférica, en los 30 minutos posteriores a la inyección del anestésico epidural, sucedía un incremento significativo de la temperatura en el pie (grupo $\mathrm{II}_{\mathrm{a}}, 3.70$; grupo $\mathrm{II}_{\mathrm{b}}, 3.90$ ) 
(Tabla 17, Fig. 31) y un descenso significativo de la temperatura en la pierna (grupo $\mathrm{II}_{\mathrm{a}},-0.82$; grupo $\mathrm{II}_{\mathrm{b}},-0.50$ ) (Tabla 18, Fig. 32), muslo (grupo $\mathrm{II}_{\mathrm{a}},-0.43$; grupo $\mathrm{II}_{\mathrm{b}},-0.50$ ) (Tabla 19, Fig. 33) y pezón (-0.54) (Tabla 21, Fig. 35). Sin embargo, la temperatura del ombligo no se modificaba de forma significativa (Tabla 20, Fig. 34).

\subsubsection{Análisis de las variaciones de la temperatura intergrupo}

Se observó que el incremento de la temperatura en la pierna y muslo, era significativamente mayor en los controles (grupo I), que en los pacientes con arteriopatía periférica crónica (grupo $\mathrm{II}_{\mathrm{a}}$ y $\mathrm{II}_{\mathrm{b}}$ ) (Tablas 18 y 19, Figs. 32 y 33), sin embargo, en el pie, ombligo y pezón no se observaron diferencias en la variación de temperatura entre los controles y los pacientes con arteriopatía periférica (Tablas 17, 20 y 21, Figs. 31, 34 y 35). No se observaron diferencias significativas en la variación de la temperatura de las extremidades inferiores entre el grupo que iba a ser intervenido por problemas vasculares (grupo $\mathrm{II}_{\mathrm{a}}$ ) y el que no (grupo $\mathrm{II}_{\mathrm{b}}$ ) (Tablas 17-19, Figs. 31-33). 
Tabla 17: Temperatura cutánea del pie

\begin{tabular}{|l|l|l|l|l|l|l|}
\hline $\begin{array}{c}\text { VARIABLE } \\
\left({ }^{\circ} \mathrm{C}\right)\end{array}$ & \multicolumn{1}{|c|}{$\begin{array}{c}\text { Grupo I } \\
(\mathrm{n}=20)\end{array}$} & $\begin{array}{c}\text { Grupo II } \\
(\mathrm{n}=24)\end{array}$ & $\begin{array}{c}\mathrm{p} \\
\text { valor }^{\mathrm{a}}\end{array}$ & $\begin{array}{c}\text { Grupo II } \\
(\mathrm{n}=24)\end{array}$ & $\begin{array}{c}\mathrm{p} \\
\text { valor }^{\mathrm{b}}\end{array}$ & $\begin{array}{c}\mathrm{p} \\
\text { valor }^{\mathrm{c}}\end{array}$ \\
\hline $\mathrm{T}^{\mathrm{a}}$ basal & $29,55 \pm 1,69$ & $26,30 \pm 2,53$ & $\mathbf{0 , 0 0 0 1}$ & $27,13 \pm 3,75$ & $\mathbf{0 , 0 1 6}$ & 0,38 \\
\hline $\mathrm{T}^{\mathrm{a}} 15 \mathrm{~min}$ & $32,87 \pm 1,71^{*}$ & $28,78 \pm 3,33^{*}$ & $\mathbf{0 , 0 0 0 1}$ & $29,07 \pm 3,46^{*}$ & $\mathbf{0 , 0 0 0 1}$ & 0,77 \\
\hline $\mathrm{T}^{\mathrm{a}} 30 \mathrm{~min}$ & $33,96 \pm 1,01^{*}$ & $30,00 \pm 3,41^{*}$ & $\mathbf{0 , 0 0 0 1}$ & $31,03 \pm 2,98^{*}$ & $\mathbf{0 , 0 0 0 1}$ & 0,28 \\
\hline$\Delta \mathrm{T}^{\mathrm{a}}$ & $4,41 \pm 1,32$ & $3,70 \pm 4,30$ & 0,50 & $3,90 \pm 4,38$ & 0,63 & 0,87 \\
\hline
\end{tabular}

Los datos se han expresado como media \pm desviación estándar (DS). Grupo I, extremidad inferior sana; Grupo $\mathrm{II}_{\mathrm{a}}$, extremidad inferior vascular quirúrgica; Grupo $\mathrm{II}_{\mathrm{b}}$, extremidad inferior vascular no quirúrgica; $\mathrm{n}$, tamaño muestral (extremidades inferiores); min, minutos; ${ }^{\circ} \mathrm{C}$, grados centígrados; $\Delta \mathrm{T}^{\mathrm{a}}$, variación de la temperatura (temperatura a los 30 minutos menos la basal). $\mathrm{p}$ valor a, Grupo I vs Grupo $\mathrm{II}_{\mathrm{a}}$; $\mathrm{p}$ valor ${ }^{\mathrm{b}}$, Grupo I vs Grupo $\mathrm{II}_{\mathrm{b}} ; \mathrm{p}$ valor ${ }^{\mathrm{c}}$, Grupo $\mathrm{II}_{\mathrm{a}}$ vs Grupo $\mathrm{II}_{\mathrm{b}}$. *, cuando hay una diferencia significativa $(\mathrm{p} \leq 0,05)$ intragrupo respecto del momento basal.

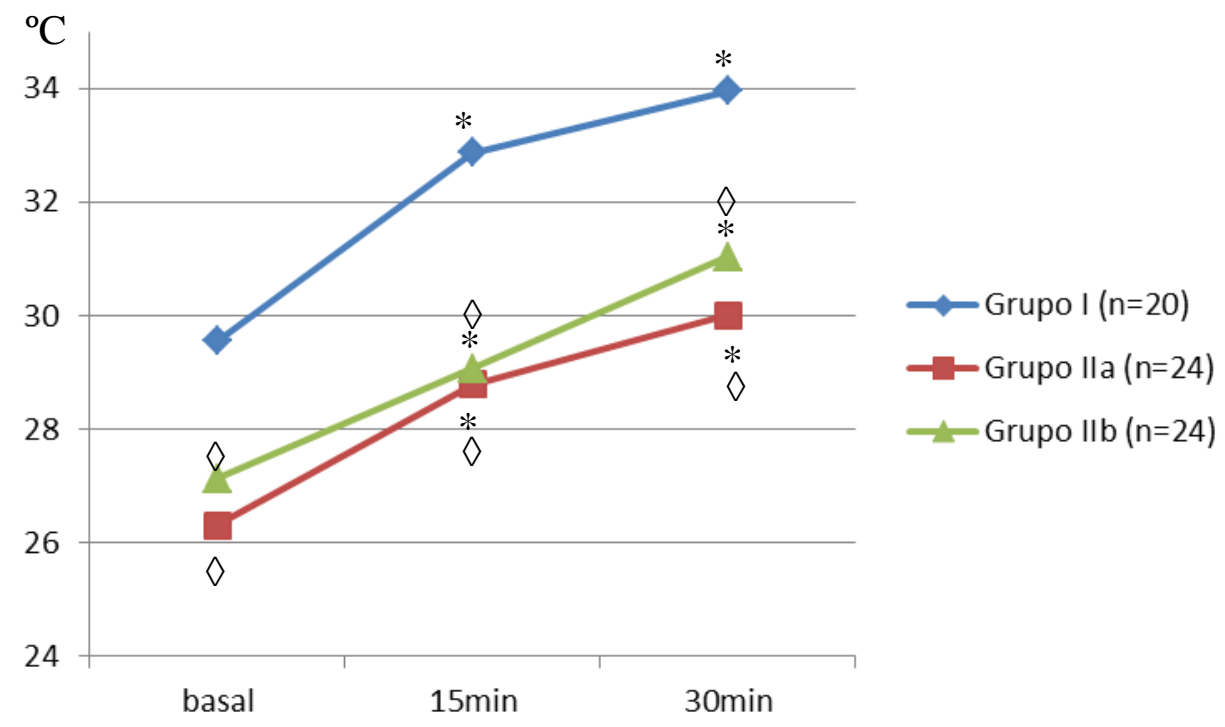

Figura 31: Temperatura cutánea del pie.

Se señala la media de las temperaturas en cada momento de medición. Grupo I, extremidad inferior sana; Grupo $\mathrm{II}_{\mathrm{a}}$, extremidad inferior vascular quirúrgica; Grupo $\mathrm{II}_{\mathrm{b}}$, extremidad inferior vascular no quirúrgica; $\mathrm{n}$, tamaño muestral (extremidades inferiores); min, minutos; ${ }^{\circ} \mathrm{C}$, grados centígrados; *, diferencia significativa $(\mathrm{p} \leq 0,05)$ intragrupo respecto del momento basal; $\diamond$, diferencia significativa $(\mathrm{p} \leq 0,05)$ respecto del grupo I 


\section{RESULTADOS}

Tabla 18: Temperatura cutánea de la pierna

\begin{tabular}{|l|c|c|c|c|c|c|}
\hline $\begin{array}{c}\text { VARIABLE } \\
\left({ }^{\circ} \mathrm{C}\right)\end{array}$ & $\begin{array}{c}\text { Grupo I } \\
(\mathrm{n}=20)\end{array}$ & $\begin{array}{c}\text { Grupo II } \\
(\mathrm{n}=24)\end{array}$ & $\begin{array}{c}\mathrm{p} \\
\text { valor }^{\mathrm{a}}\end{array}$ & $\begin{array}{c}\text { Grupo II } \\
(\mathrm{n}=24)\end{array}$ & $\begin{array}{c}\mathrm{p} \\
\text { valor }^{\mathrm{b}}\end{array}$ & $\begin{array}{c}\mathrm{p} \\
\text { valor }^{\mathrm{c}}\end{array}$ \\
\hline $\mathrm{T}^{\mathrm{a}}$ basal & $31,88 \pm 1,24$ & $32,42 \pm 0,87$ & 0,10 & $32,22 \pm 0,94$ & 0,31 & 0,46 \\
\hline $\mathrm{T}^{\mathrm{a}} 15 \min$ & $32,41 \pm 0,94 *$ & $31,59 \pm 0,89 *$ & $\mathbf{0 , 0 0 6}$ & $31,66 \pm 0,82^{*}$ & $\mathbf{0 , 0 0 9}$ & 0,77 \\
\hline $\mathrm{T}^{\mathrm{a}} 30 \mathrm{~min}$ & $32,80 \pm 1,03 *$ & $31,60 \pm 0,84^{*}$ & $\mathbf{0 , 0 0 0 1}$ & $31,72 \pm 0,84^{*}$ & $\mathbf{0 , 0 0 1}$ & 0,63 \\
\hline$\Delta \mathrm{T}^{\mathrm{a}}$ & $0,91 \pm 0,86$ & $-0,82 \pm 0,53$ & $\mathbf{0 , 0 0 0 1}$ & $-0,50 \pm 0,74$ & $\mathbf{0 , 0 0 0 1}$ & 0,10 \\
\hline
\end{tabular}

Los datos se han expresado como media \pm desviación estándar (DS). Grupo I, extremidad inferior sana; Grupo $\mathrm{II}_{\mathrm{a}}$, extremidad inferior vascular quirúrgica; Grupo $\mathrm{II}_{\mathrm{b}}$, extremidad inferior vascular no quirúrgica; $\mathrm{n}$, tamaño muestral (extremidades inferiores); min, minutos; ${ }^{\circ} \mathrm{C}$, grados centígrados; $\Delta \mathrm{T}^{\mathrm{a}}$, variación de la temperatura (temperatura a los 30 minutos menos la basal); $\mathrm{p}$ valor ${ }^{\mathrm{a}}$, Grupo I vs Grupo $\mathrm{II}_{\mathrm{a}}$; $\mathrm{p}$ valor ${ }^{\mathrm{b}}$, Grupo I vs Grupo $\mathrm{II}_{\mathrm{b}}$; $\mathrm{p}$ valor ${ }^{\mathrm{c}}$, Grupo $\mathrm{II}_{\mathrm{a}}$ vs Grupo $\mathrm{II}_{\mathrm{b}}$. *, cuando hay una diferencia significativa $(\mathrm{p} \leq 0,05)$ intragrupo respecto del momento basal.

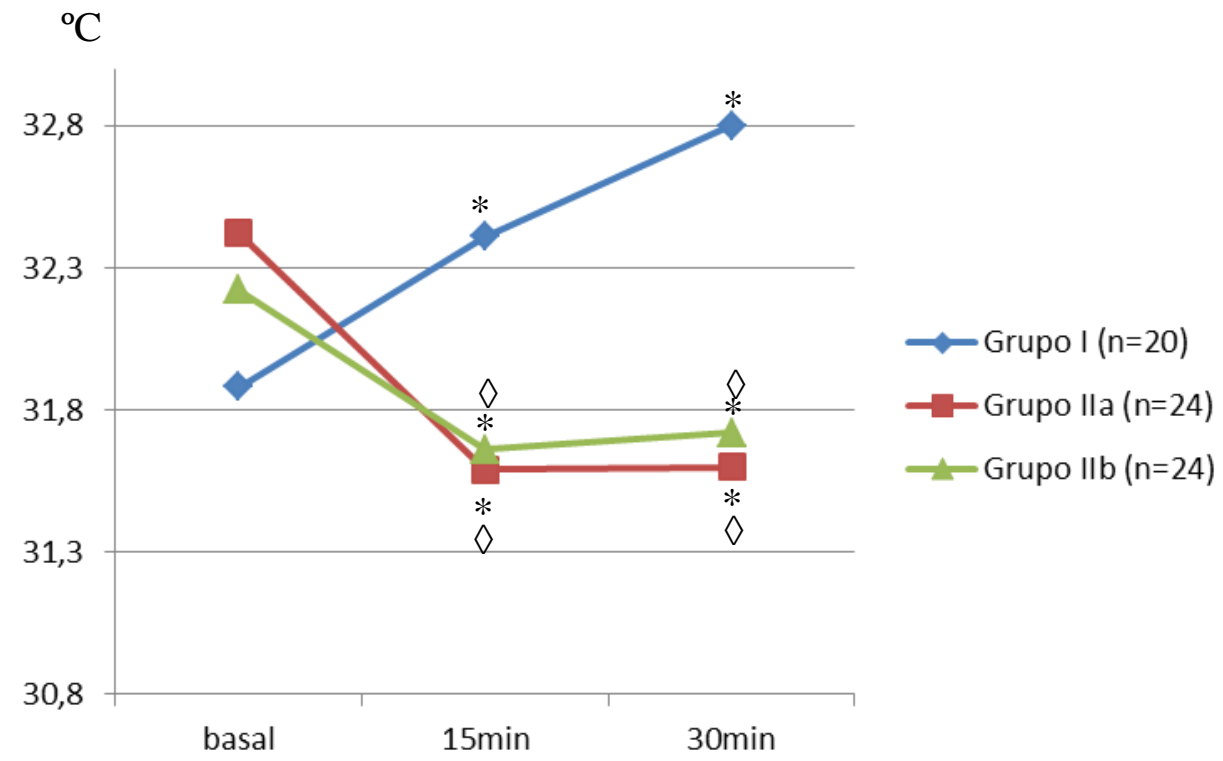

Figura 32: Temperatura cutánea de la pierna

Se señala la media de las temperaturas en cada momento de medición. Grupo I, extremidad inferior sana; Grupo $\mathrm{II}_{\mathrm{a}}$, extremidad inferior vascular quirúrgica; Grupo $\mathrm{II}_{\mathrm{b}}$, extremidad inferior vascular no quirúrgica; $\mathrm{n}$, tamaño muestral (extremidades inferiores); min, minutos; ${ }^{\circ} \mathrm{C}$, grados centígrados; *, diferencia significativa $(\mathrm{p} \leq 0,05)$ intragrupo respecto del momento basal; $\diamond$, diferencia significativa $(\mathrm{p} \leq 0,05)$ respecto del grupo I 


\section{RESULTADOS}

Tabla 19: Temperatura cutánea del muslo

\begin{tabular}{|l|l|c|l|l|l|l|}
\hline $\begin{array}{c}\text { VARIABLE } \\
\left({ }^{\circ} \mathrm{C}\right)\end{array}$ & \multicolumn{1}{|c|}{$\begin{array}{c}\text { Grupo I } \\
(\mathrm{n}=20)\end{array}$} & $\begin{array}{c}\text { Grupo II } \\
(\mathrm{n}=24)\end{array}$ & $\begin{array}{c}\mathrm{p} \\
\text { valor }^{\mathrm{a}}\end{array}$ & $\begin{array}{c}\text { Grupo II } \\
(\mathrm{n}=24)\end{array}$ & $\begin{array}{c}\mathrm{p} \\
\text { valor }^{\mathrm{b}}\end{array}$ & $\begin{array}{c}\mathrm{p} \\
\text { valor }^{\mathrm{c}}\end{array}$ \\
\hline $\mathrm{T}^{\mathrm{a}}$ basal & $32,58 \pm 0,81$ & $33,08 \pm 0,88$ & 0,07 & $33,01 \pm 0,92$ & 0,13 & 0,78 \\
\hline $\mathrm{T}^{\mathrm{a}} 15 \mathrm{~min}$ & $32,79 \pm 0,86$ & $32,80 \pm 1,00^{*}$ & 0,98 & $32,75 \pm 0,83^{*}$ & 0,88 & 0,86 \\
\hline $\mathrm{T}^{\mathrm{a}} 30 \mathrm{~min}$ & $32,92 \pm 0,85^{*}$ & $32,65 \pm 1,04^{*}$ & 0,37 & $32,50 \pm 0,95^{*}$ & 0,15 & 0,61 \\
\hline$\Delta \mathrm{T}^{\mathrm{a}}$ & $0,34 \pm 0,41$ & $-0,43 \pm 0,79$ & $\mathbf{0 , 0 0 1}$ & $-0,50 \pm 0,85$ & $\mathbf{0 , 0 0 1}$ & 0,75 \\
\hline
\end{tabular}

Los datos se han expresado como media \pm desviación estándar (DS). Grupo I, extremidad inferior sana; Grupo $\mathrm{II}_{\mathrm{a}}$, extremidad inferior vascular quirúrgica; Grupo $\mathrm{II}_{\mathrm{b}}$, extremidad inferior vascular no quirúrgica; $\mathrm{n}$, tamaño muestral (extremidades inferiores); min, minutos; ${ }^{\circ} \mathrm{C}$, grados centígrados; $\Delta \mathrm{T}^{\mathrm{a}}$, variación de la temperatura (temperatura a los 30 minutos menos la basal); $\mathrm{p}$ valor ${ }^{\mathrm{a}}$, Grupo I vs Grupo $\mathrm{II}_{\mathrm{a}}$; $\mathrm{p}$ valor ${ }^{\mathrm{b}}$, Grupo I vs Grupo $\mathrm{II}_{\mathrm{b}} ; \mathrm{p}$ valor ${ }^{\mathrm{c}}$, Grupo $\mathrm{II}_{\mathrm{a}}$ vs Grupo $\mathrm{II}_{\mathrm{b}}$. *, cuando hay una diferencia significativa $(\mathrm{p} \leq 0,05)$ intragrupo respecto del momento basal

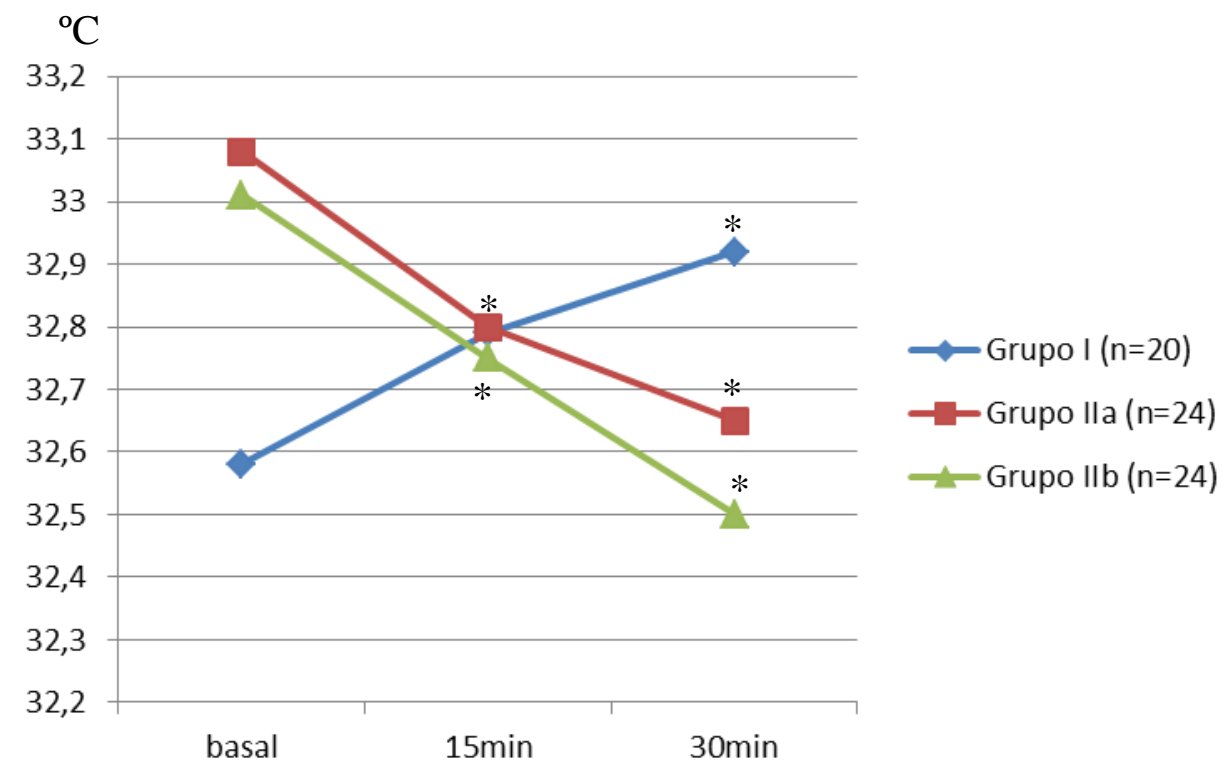

Figura 33: Temperatura cutánea del muslo

Se señala la media de las temperaturas en cada momento de medición. Grupo I, extremidad inferior sana; Grupo $\mathrm{II}_{\mathrm{a}}$, extremidad inferior vascular quirúrgica; Grupo $\mathrm{II}_{\mathrm{b}}$, extremidad inferior vascular no quirúrgica; $\mathrm{n}$, tamaño muestral (extremidades inferiores); min, minutos; ${ }^{\circ} \mathrm{C}$, grados centígrados; *, diferencia significativa $(\mathrm{p} \leq 0,05)$ intragrupo respecto del momento basal; $\diamond$, diferencia significativa $(\mathrm{p} \leq 0,05)$ respecto del grupo I 


\section{RESULTADOS}

Tabla 20: Temperatura cutánea del ombligo

\begin{tabular}{|l|c|c|c|}
\hline \multicolumn{1}{|c|}{$\begin{array}{c}\text { VARIABLE } \\
\left({ }^{\circ} \mathrm{C}\right)\end{array}$} & $\begin{array}{c}\text { CONTROLES } \\
(\mathrm{n}=20)\end{array}$ & $\begin{array}{c}\text { VASCULARES } \\
(\mathrm{n}=24)\end{array}$ & p valor \\
\hline $\mathrm{T}^{\mathrm{a}}$ basal & $32,90 \pm 1,41$ & $33,84 \pm 0,80$ & $\mathbf{0 , 0 1}$ \\
\hline $\mathrm{T}^{\mathrm{a}} 15 \min$ & $33,05 \pm 1,09$ & $33,75 \pm 0,96$ & $\mathbf{0 , 0 3}$ \\
\hline $\mathrm{T}^{\mathrm{a}} 30 \mathrm{~min}$ & $32,97 \pm 0,96$ & $33,68 \pm 1,11$ & $\mathbf{0 , 0 4}$ \\
\hline$\Delta \mathrm{T}^{\mathrm{a}}$ & $0,07 \pm 1,22$ & $-0,15 \pm 0,87$ & 0,48 \\
\hline
\end{tabular}

Los datos se han expresado como media \pm desviación estándar (DS); n, tamaño muestral (personas); min, minutos; ${ }^{\circ} \mathrm{C}$, grados centígrados; $\Delta \mathrm{T}^{\mathrm{a}}$, variación de la temperatura (temperatura a los 30 minutos menos la basal); *, cuando hay una diferencia significativa $(\mathrm{p} \leq 0,05)$ intragrupo respecto del momento basal.

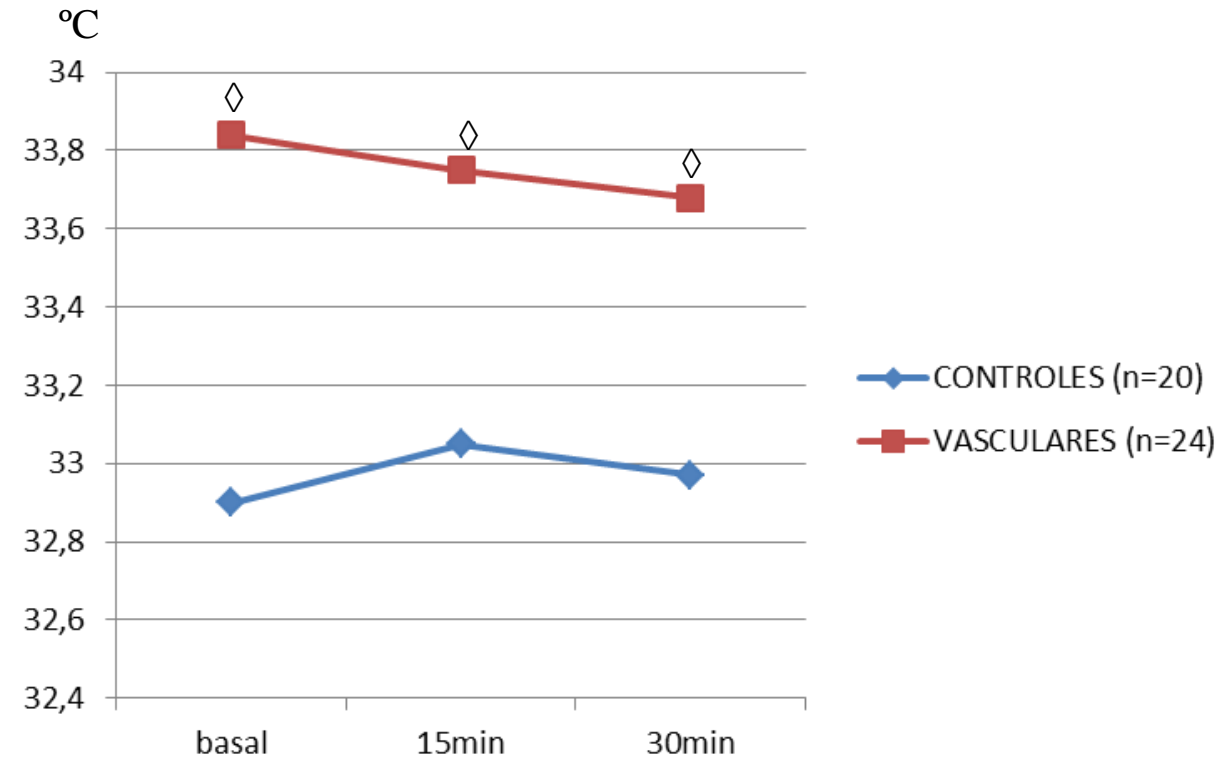

Figura 34: Temperatura cutánea del ombligo

Se señala la media de las temperaturas en cada momento de medición. n, tamaño muestral (personas); min, minutos; ${ }^{\circ} \mathrm{C}$, grados centígrados; *, diferencia significativa $(\mathrm{p} \leq 0,05)$ intragrupo respecto del momento basal; $\diamond$, diferencia significativa $(\mathrm{p} \leq 0,05)$ respecto de los controles 
Tabla 21: Temperatura cutánea del pezón

\begin{tabular}{|l|c|c|c|}
\hline $\begin{array}{c}\text { VARIABLE } \\
\left({ }^{\circ} \mathrm{C}\right)\end{array}$ & $\begin{array}{c}\text { CONTROLES } \\
(\mathrm{n}=20)\end{array}$ & $\begin{array}{c}\text { VASCULARES } \\
(\mathrm{n}=24)\end{array}$ & p valor \\
\hline $\mathrm{T}^{\mathrm{a}}$ basal & $33,00 \pm 0,75$ & $32,82 \pm 1,14$ & 0,57 \\
\hline $\mathrm{T}^{\mathrm{a}} 15 \mathrm{~min}$ & $32,87 \pm 0,67$ & $32,45 \pm 1,12^{*}$ & 0,18 \\
\hline $\mathrm{T}^{\mathrm{a}} 30 \mathrm{~min}$ & $32,74 \pm 0,76$ & $32,27 \pm 1,06^{*}$ & 0,13 \\
\hline$\Delta \mathrm{T}^{\mathrm{a}}$ & $-0,26 \pm 0,78$ & $-0,54 \pm 0,63$ & 0,21 \\
\hline
\end{tabular}

Los datos se han expresado como media \pm desviación estándar (DS); n, tamaño muestral (personas); min, minutos; ${ }^{\circ} \mathrm{C}$, grados centígrados; $\Delta \mathrm{T}^{\mathrm{a}}$, variación de la temperatura (temperatura a los 30 minutos menos la basal); *, cuando hay una diferencia significativa $(\mathrm{p} \leq 0,05)$ intragrupo respecto del momento basal

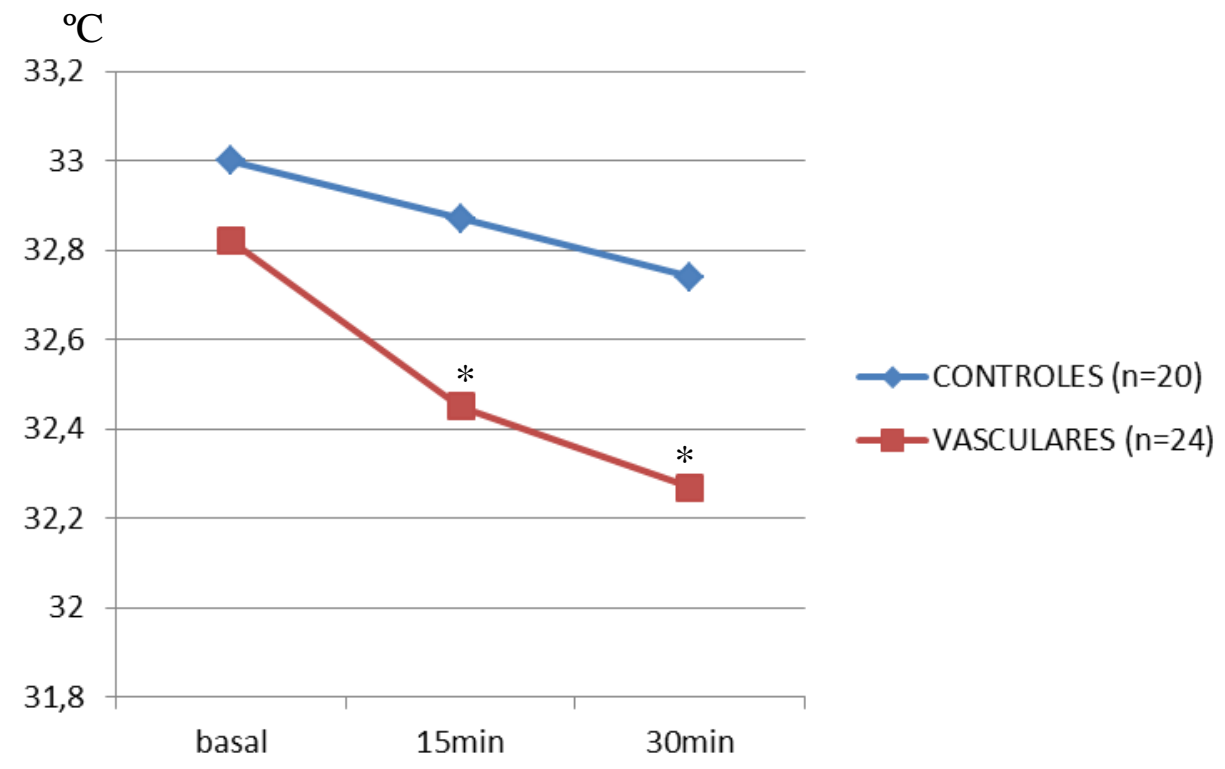

Figura 35: Temperatura del pezón

Se señala la media de las temperaturas en cada momento de medición. n, tamaño muestral (personas); min, minutos; ${ }^{\circ} \mathrm{C}$, grados centígrados; *, diferencia significativa $(\mathrm{p} \leq 0,05)$ intragrupo respecto del momento basal; $\diamond$, diferencia significativa $(\mathrm{p} \leq 0,05)$ respecto de los controles 


\subsubsection{Análisis de las variaciones de la temperatura intragrupo}

En los controles y en los pacientes con arteriopatía periférica, se observó que el incremento de la temperatura era significativamente mayor en el pie que en la pierna, muslo, ombligo o pezón (Tabla 22, Fig. 36).

Tabla 22: Variación de la temperatura en los diferentes lugares de medición intragrupo

\begin{tabular}{|l|c|c|c|}
\cline { 2 - 4 } \multicolumn{1}{c|}{} & $\begin{array}{c}\text { CONTROLES } \\
(\mathrm{n}=20)\end{array}$ & \multicolumn{2}{|c|}{$\begin{array}{c}\text { VASCULARES } \\
(\mathrm{n}=24)\end{array}$} \\
\hline VARIABLE & $\begin{array}{c}\text { Grupo I } \\
(\mathrm{n}=20)\end{array}$ & $\begin{array}{c}\text { Grupo } \mathrm{II}_{\mathrm{a}} \\
(\mathrm{n}=24)\end{array}$ & $\begin{array}{c}\text { Grupo } \mathrm{II}_{\mathrm{b}} \\
(\mathrm{n}=24)\end{array}$ \\
\hline$\Delta \mathrm{T}^{\mathrm{a}}$ pie $\left({ }^{\circ} \mathrm{C}\right)$ & $4,41 \pm 1,32$ & $3,70 \pm 4,30$ & $3,90 \pm 4,38$ \\
\hline$\Delta \mathrm{T}^{\mathrm{a}}$ pierna $\left({ }^{\circ} \mathrm{C}\right)$ & $0,91 \pm 0,86^{*}$ & $-0,82 \pm 0,53^{*}$ & $-0,50 \pm 0,74^{*}$ \\
\hline$\Delta \mathrm{T}^{\mathrm{a}}$ muslo $\left({ }^{\circ} \mathrm{C}\right)$ & $0,34 \pm 0,41^{*}$ & $-0,43 \pm 0,79^{*}$ & $-0,50 \pm 0,85^{*}$ \\
\hline$\Delta \mathrm{T}^{\mathrm{a}}$ ombligo $\left({ }^{\circ} \mathrm{C}\right)$ & $0,07 \pm 1,22^{*}$ & \multicolumn{2}{|c|}{$-0,15 \pm 0,87^{*}$} \\
\hline$\Delta \mathrm{T}^{\mathrm{a}}$ pezón $\left({ }^{\circ} \mathrm{C}\right)$ & $-0,26 \pm 0,78^{*}$ & \multicolumn{2}{|c|}{$-0,54 \pm 0,63^{*}$} \\
\hline
\end{tabular}

Los datos se han expresado como media \pm desviación estándar (DS). Grupo I, extremidad sana; Grupo $\mathrm{II}_{\mathrm{a}}$, extremidad inferior vascular quirúrgica; Grupo $\mathrm{II}_{\mathrm{b}}$, extremidad inferior vascular no quirúrgica; n, tamaño muestral (en controles y vasculares son personas, y en grupo $\mathrm{I}_{1} \mathrm{II}_{\mathrm{a}}$ y $\mathrm{II}_{\mathrm{b}}$ son extremidades inferiores); $\Delta \mathrm{T}^{\mathrm{a}}$, variación de la temperatura (temperatura a los 30 minutos menos la basal); ${ }^{\circ} \mathrm{C}$, grados centígrados; $*$, cuando hay una diferencia significativa $(\mathrm{p} \leq 0,05)$ intragrupo entre lugar distinto de pie y pie 


\section{RESULTADOS}

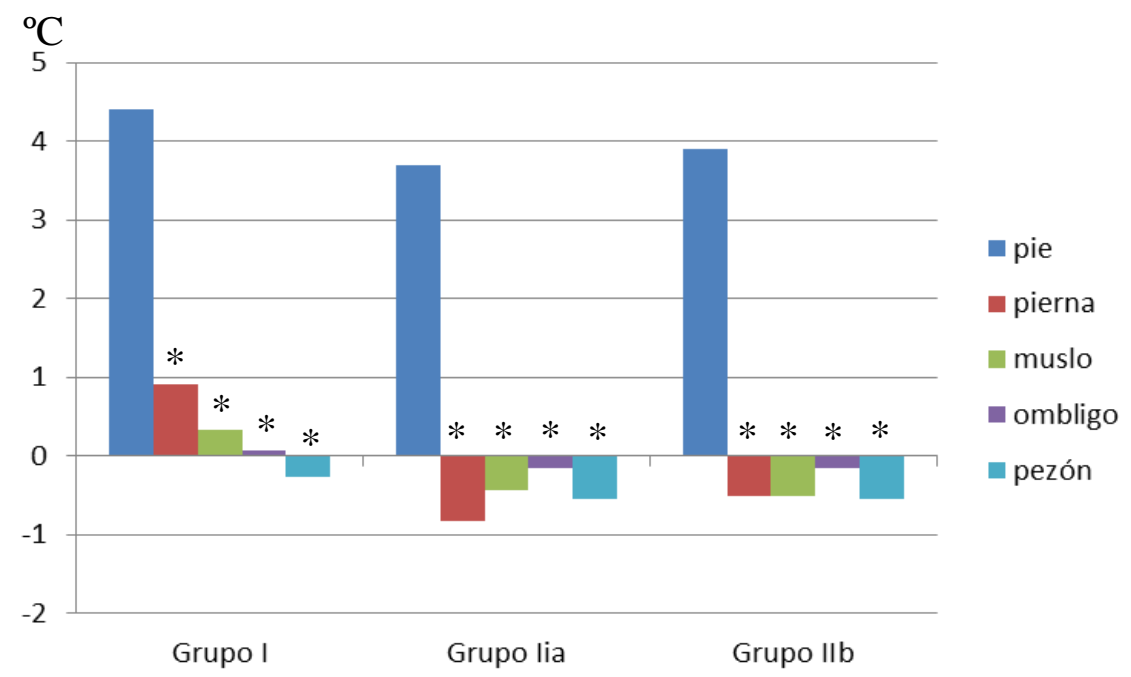

Figura 36: Variación de la temperatura intragrupo

Grupo I, controles y extremidades inferiores sanas; Grupo II vasculares (Grupo $\mathrm{II}_{\mathrm{a}}$, extremidad inferior vascular quirúrgica; Grupo $\mathrm{II}_{\mathrm{b}}$, extremidad inferior vascular no quirúrgica); ${ }^{\circ} \mathrm{C}$, grados centígrados; ${ }^{*}$, diferencia significativa $(\mathrm{p} \leq 0,05)$ intragrupo entre lugar distinto del pie y pie.

\subsection{ANÁLISIS DE LAS CONSTANTES HEMODINÁMICAS DE LOS PACIENTES VASCULARES}

Después de analizar las variables hemodinámicas de los pacientes vasculares (grupo II), se observó que a lo largo de los 30 minutos posteriores a la inyección del bolo de anestésico local en el espacio epidural, sucedió un descenso significativo de la tensión arterial sistólica $(21 \mathrm{mmHg})$, tensión arterial diastólica $(11 \mathrm{mmHg})$ y frecuencia cardiaca (4 latidos por minuto) (Tabla 23, Figs. 37-39). Ninguno de los pacientes precisó la administración de vasoconstrictores por hipotensión arterial, considerada como un descenso de la tensión arterial sistólica mayor del 30\% (79). 


\section{RESULTADOS}

Tabla 23: Variaciones hemodinámicas en los pacientes vasculares

\begin{tabular}{|c|c|c|c|}
\hline VARIABLE & TAS (mmHg) & TAD (mmHg) & FC (lat/min) \\
\hline Basal & $148,71 \pm 21,87$ & $79,79 \pm 13,17$ & $71,58 \pm 15,53$ \\
\hline $5 \mathrm{~min}$ & $138,71 \pm 25,54^{*}$ & $76,92 \pm 12,74$ & $71,63 \pm 22,05$ \\
\hline $10 \mathrm{~min}$ & $131,00 \pm 24,44^{*}$ & $70,04 \pm 14,61^{*}$ & $68,71 \pm 16,69$ \\
\hline $15 \mathrm{~min}$ & $129,17 \pm 23,16^{*}$ & $67,25 \pm 14,49^{*}$ & $68,50 \pm 17,33$ \\
\hline $20 \mathrm{~min}$ & $127,33 \pm 24,11^{*}$ & $66,17 \pm 14,37 *$ & $65,79 \pm 14,23 *$ \\
\hline $25 \mathrm{~min}$ & $121,92 \pm 32,69^{*}$ & $65,13 \pm 12,51^{*}$ & $67,21 \pm 16,33 *$ \\
\hline $30 \mathrm{~min}$ & $127,38 \pm 24,38^{*}$ & $68,92 \pm 14,55^{*}$ & $67,79 \pm 17,22^{*}$ \\
\hline$\Delta 30$-BASAL & $-21,33 \pm 18,87$ & $-10,87 \pm 11,83$ & $-3,79 \pm 9,26$ \\
\hline
\end{tabular}

Los datos se han expresado como media \pm desviación estándar (DS). TAS, tensión arterial sistólica; TAD, tensión arterial diastólica; FC, frecuencia cardiaca; $\mathrm{mmHg}$, milímetros de mercurio; lat/min, latidos por minuto; min, minutos; $\Delta$, variación de la variable (momento 30 menos basal); *, cuando hay una diferencia significativa $(\mathrm{p} \leq 0,05)$ intragrupo respecto al momento basal.

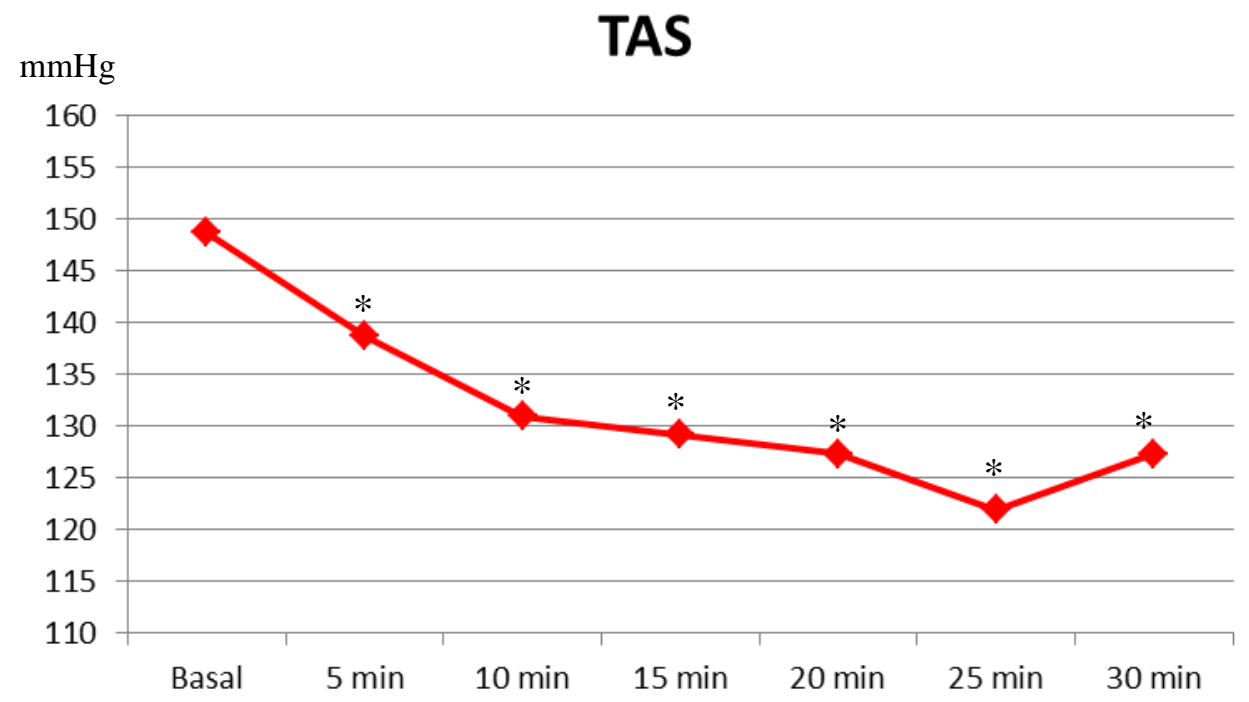

Figura 37: Variación de la tensión arterial sistólica (TAS) en los pacientes vasculares Se señala la media de las tensiones arteriales en cada momento de medición. $\mathrm{mmHg}$, milímetros de mercurio; min, minutos; *, diferencia significativa $(\mathrm{p} \leq 0,05)$ respecto del momento basal 
$\mathrm{mmHg}$

TAD

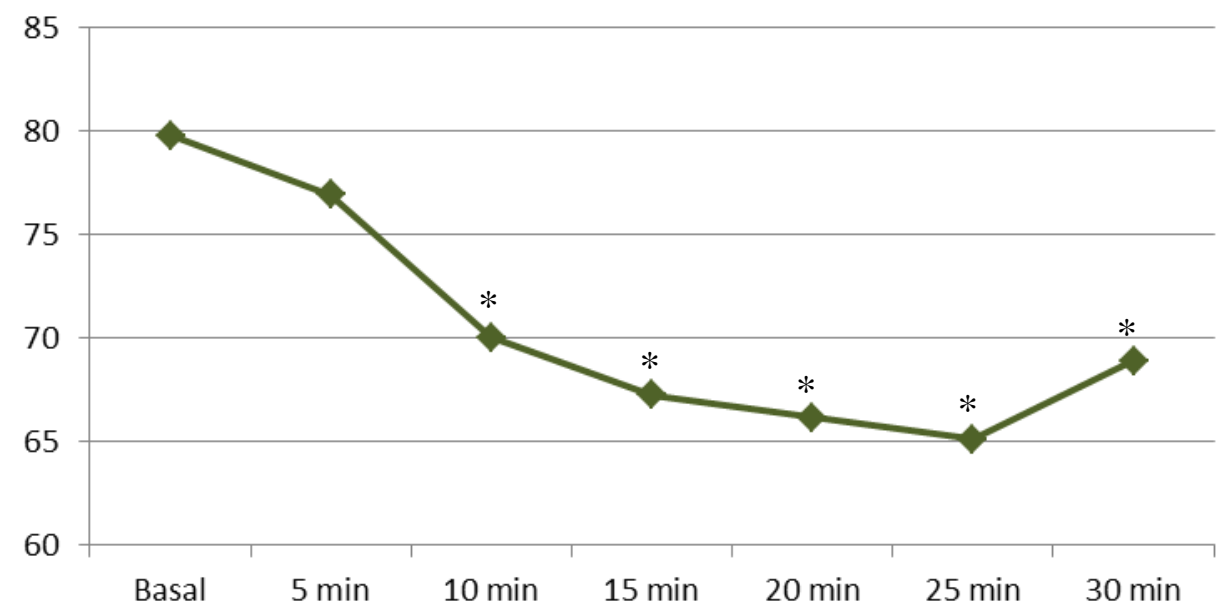

Figura 38: Variación de la tensión arterial diastólica (TAD) en los pacientes vasculares Se señala la media de las tensiones arteriales en cada momento de medición. mmHg, milímetros de mercurio; min, minutos; *, diferencia significativa $(\mathrm{p} \leq 0,05)$ respecto del momento basal

Lat/min $\quad$ FC

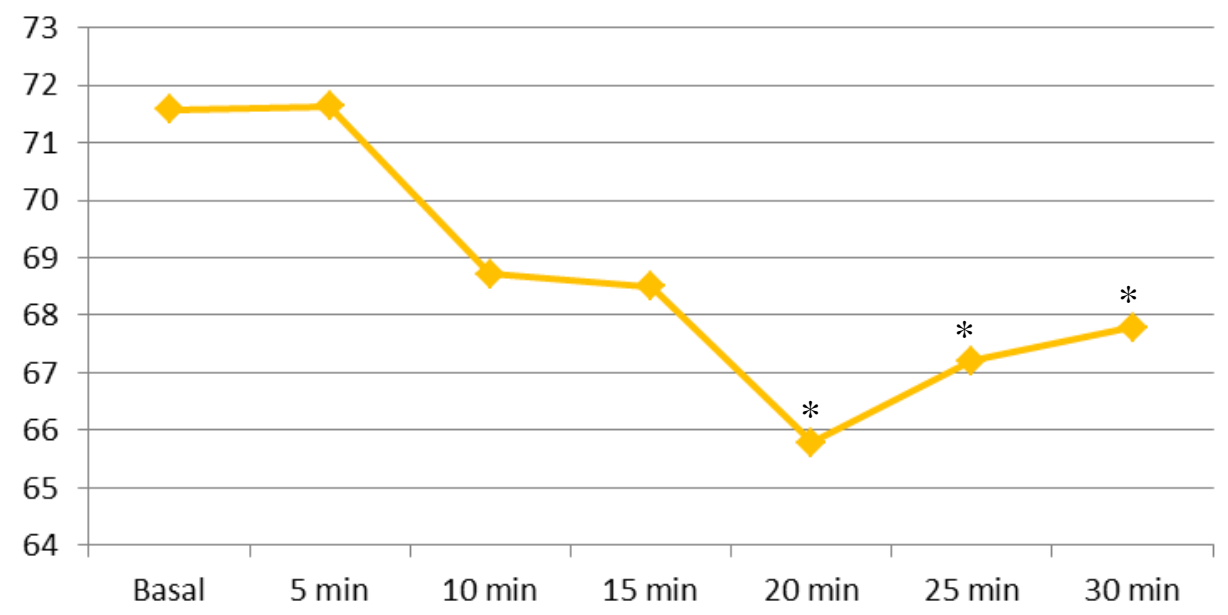

Figura 39: Variación de la frecuencia cardiaca (FC) en los pacientes vasculares

Se señala la media de las frecuencias cardiacas en cada momento de medición. lat/min, latidos por minutos; min, minutos; *, diferencia significativa $(\mathrm{p} \leq 0,05)$ respecto del momento basal 


\section{RESULTADOS}

\subsection{CARACTERÍSTICAS DE LA MUESTRA: GRUPO $\mathrm{II}_{\mathrm{R}+}, \mathrm{II}_{\mathrm{R}-} \mathrm{y}$ CONTROL}

Después de analizar las características antropométricas y demográficas de nuestra muestra, observamos que los pacientes del grupo control eran significativamente más jóvenes y más altos que los pacientes con arteriopatía periférica crónica (grupo $\mathrm{II}_{\mathrm{R}+}$ y $\mathrm{II}_{\mathrm{R}-\text { ). También había }}$

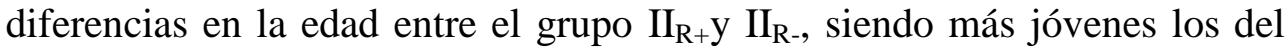
grupo $\mathrm{II}_{\mathrm{R}+}$. No encontramos diferencias significativas entre los grupos en el peso y sexo (Tabla 24).

Tabla 24: Características demográficas y antropométricas del grupo $\mathrm{II}_{\mathrm{R}+}, \mathrm{II}_{\mathrm{R}-}$ y control

\begin{tabular}{|l|c|c|c|c|c|c|}
\hline VARIABLE & $\begin{array}{c}\text { Grupo } \mathrm{II}_{\mathrm{R}+} \\
(\mathrm{n}=13)\end{array}$ & $\begin{array}{c}\text { Grupo II } \\
(\mathrm{n}=11)\end{array}$ & $\begin{array}{c}\mathrm{p} \\
\text { valor }^{\mathrm{a}}\end{array}$ & $\begin{array}{c}\text { CONTROL } \\
(\mathrm{n}=20)\end{array}$ & $\begin{array}{c}\mathrm{p} \\
\text { valor }^{\mathrm{b}}\end{array}$ & $\begin{array}{c}\mathrm{p} \\
\text { valor }^{\mathbf{c}}\end{array}$ \\
\hline Edad (años) & $67,04 \pm 11,45$ & $73,60 \pm 9,68$ & $\mathbf{0 , 0 4}$ & $\begin{array}{c}21,20 \pm \\
3,08\end{array}$ & $\mathbf{0 , 0 0 0 1}$ & $\mathbf{0 , 0 0 0 1}$ \\
Peso (kg) & $71,27 \pm 12,96$ & $72,10 \pm 11,36$ & 0,82 & $\begin{array}{c}71,75 \pm \\
8,53\end{array}$ & 0,9 & 0,7 \\
$\begin{array}{l}\text { Estatura } \\
\text { (cm) }\end{array}$ & $166,00 \pm 6,54$ & $167,90 \pm 5,57$ & 0,30 & $\begin{array}{c}172,75 \pm \\
3,89\end{array}$ & $\mathbf{0 , 0 0 1}$ & $\mathbf{0 , 0 0 7}$ \\
Sexo varón & $26(100)$ & $22(100)$ & 1.00 & $20(100)$ & 1.00 & 1.00 \\
\hline
\end{tabular}

Los datos se han expresado como media \pm desviación estándar (DS) y como valor absoluto y porcentaje de la muestra. Grupo $\mathrm{II}_{\mathrm{R}+}$, pacientes vasculares cuyos pies se calientan; grupo $\mathrm{II}_{\mathrm{R}-}$, pacientes vasculares cuyos pies no se calientan; $\mathrm{n}$, tamaño muestral (personas); $\mathrm{p}$ valor ${ }^{\mathrm{a}}$, grupo $\mathrm{II}_{\mathrm{R}+} v s \mathrm{II}_{\mathrm{R}-} ; \mathrm{p}$ valor ${ }^{\mathrm{b}}$, grupo $\mathrm{II}_{\mathrm{R}+} v s$ control; $\mathrm{p}$ valor ${ }^{\mathrm{c}}$, grupo $\mathrm{II}_{\mathrm{R}_{-}} v s$ control 


\section{RESULTADOS}

En cuanto a las comorbilidades y hábitos tóxicos de los pacientes con arteriopatía periférica crónica, se vio que la prevalencia de HTA era significativamente mayor en el grupo $\mathrm{II}_{\mathrm{R}-}$ que en el grupo $\mathrm{II}_{\mathrm{R}+}$. No había diferencias significativas en la prevalencia de diabetes ni en el número de fumadores (Tabla 25).

Tabla 25: Comorbilidades y hábitos de vida del grupo $\mathrm{II}_{\mathrm{R}+} \mathrm{y} \mathrm{II}_{\mathrm{R}}$

\begin{tabular}{|l|c|c|c|}
\hline \multicolumn{1}{|c|}{ VARIABLE } & Grupo $\mathrm{II}_{\mathrm{R}_{+}}(\mathrm{n}=13)$ & Grupo $\mathrm{II}_{\mathrm{R}_{-}}(\mathrm{n}=11)$ & $\mathrm{p}$ valor \\
\hline HTA & $13(50)$ & $19(86)$ & $\mathbf{0 , 0 1}$ \\
$\mathrm{DM}$ & $9(34)$ & $13(59)$ & 0,16 \\
Años DM & $4,20 \pm 3,03$ & $12,60 \pm 14,17$ & 0,23 \\
Fumador & $23(88)$ & $13(59)$ & 0,40 \\
Años fumador & $36,46 \pm 17,66$ & $28,70 \pm 22,01$ & 0,19 \\
Años exfumador & $5,77 \pm 10,82$ & $4,60 \pm 6,92$ & 0,67 \\
$\mathrm{~N}^{\circ}$ cigarros/día & $19,23 \pm 12,22$ & $20,50 \pm 17,61$ & 0,77 \\
\hline
\end{tabular}

Los datos se han expresado como media \pm desviación estándar (DS) y como valor absoluto y porcentaje de la muestra. Grupo $\mathrm{II}_{\mathrm{R}_{+}}$, pacientes vasculares cuyos pies se calientan; grupo $\mathrm{II}_{\mathrm{R}-}$, pacientes vasculares cuyos pies no se calientan; n, tamaño muestral (personas); HTA, hipertensión arterial; DM, diabetes mellitus

No se observaron diferencias significativas en el ITB entre el grupo $\mathrm{II}_{\mathrm{R}+} \mathrm{y} \mathrm{II}_{\mathrm{R}-}$, aunque la prevalencia de oclusión a nivel femoral, poplítea, tibial

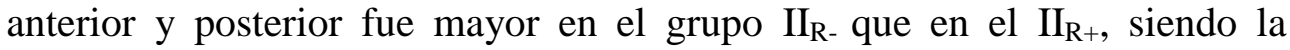
diferencia significativa únicamente en la tibial anterior (Tabla 26). 
Tabla 26: Diagnóstico y localización de la obstrucción vascular

\begin{tabular}{|l|c|c|c|}
\hline \multicolumn{1}{|c|}{ VARIABLE } & $\begin{array}{c}\text { Grupo } \mathrm{II}_{\mathrm{R}+} \\
(\mathrm{n}=26)\end{array}$ & $\begin{array}{c}\text { Grupo } \mathrm{II}_{\mathrm{R}-} \\
(\mathrm{n}=22)\end{array}$ & p valor \\
\hline ITB & $0,65 \pm 0,29$ & $0,48 \pm 0,30$ & 0,12 \\
Obstrucción femoral & $3(11)$ & $5(22)$ & 0,49 \\
Obstrucción poplítea & $12(46)$ & $14(63)$ & 0,31 \\
Obstrucción tibial anterior & $15(57)$ & $20(90)$ & $\mathbf{0 , 0 3}$ \\
\hline
\end{tabular}

Los datos se han expresado como media \pm desviación estándar (DS) y como valor absoluto y porcentaje de la muestra Grupo $\mathrm{II}_{\mathrm{R}+}$, extremidades inferiores vasculares cuyos pies se calientan; grupo $\mathrm{II}_{\mathrm{R}-}$, extremidades inferiores vasculares cuyos pies no se calientan; $\mathrm{n}$, tamaño muestral (extremidades inferiores); ITB, índice tobillo-brazo

\subsection{CARACTERÍSTICAS DE LA REALIZACIÓN DE LA TÉCNICA EPIDURAL Y DEL BLOQUEO SENSITIVO CONSEGUIDO DEL GRUPO II $\mathrm{R}_{+}, \mathrm{II}_{\mathrm{R}-}$ y CONTROL}

En todos los pacientes el bloqueo fue efectivo y no fue necesario el uso de fármacos vasopresores durante la recogida de los datos.

En el grupo control, se utilizó un volumen de anestésico local significativamente mayor que en los pacientes con arteriopatía periférica crónica (grupo $\mathrm{II}_{\mathrm{R}+} \mathrm{y} \mathrm{II}_{\mathrm{R}-\text { ) }}$ (Tabla 27), sin embargo, el nivel metamérico del bloqueo sensitivo, medido mediante pinprick de los pacientes vasculares, fue más cefálico (Tabla 28). También se empleó un volumen de anestésico local significativamente mayor en el grupo $\mathrm{II}_{\mathrm{R}_{+}}$que en el $\mathrm{II}_{\mathrm{R}_{-}}$(Tabla 27), sin 


\section{RESULTADOS}

que existieran diferencias significativas entre ambos, en el nivel metamérico de bloqueo sensitivo logrado (Tabla 28).

Tabla 27: Características de la técnica epidural

\begin{tabular}{|l|c|c|c|c|c|c|}
\hline VARIABLE & $\begin{array}{c}\text { Grupo II } \\
(\mathrm{n}=13)\end{array}$ & $\begin{array}{c}\text { Grupo II } \\
(\mathrm{n}=11)\end{array}$ & $\begin{array}{c}\mathrm{p} \\
\text { valor }^{\mathrm{a}}\end{array}$ & $\begin{array}{c}\text { CONTROL } \\
(\mathrm{n}=20)\end{array}$ & $\begin{array}{c}\mathrm{p} \\
\text { valor }^{\mathrm{b}}\end{array}$ & $\begin{array}{c}\mathrm{p} \\
\text { valor }^{\mathrm{c}}\end{array}$ \\
\hline $\begin{array}{l}\text { Espacio } \\
\text { interespinoso } \\
\mathrm{L} 3\end{array}$ & $26(100)$ & $22(100)$ & 1.00 & $20(100)$ & 1.00 & 1.00 \\
\hline $\begin{array}{l}\text { Anestésico } \\
\text { local (ml })\end{array}$ & $14,46 \pm 1,65$ & $13,00 \pm 1,65$ & $\mathbf{0 , 0 0 5}$ & $19,7 \pm 1,75$ & $\mathbf{0 , 0 0 0 1}$ & $\mathbf{0 , 0 0 0 1}$ \\
\hline
\end{tabular}

Los datos se han expresado como media \pm desviación estándar (DS) y como valor absoluto y porcentaje de la muestra. Grupo $\mathrm{II}_{\mathrm{R}+}$, pacientes vasculares cuyos pies se calientan; grupo $\mathrm{II}_{\mathrm{R}}$, pacientes vasculares cuyos pies no se calientan;. n, tamaño muestral (personas); ml, mililitros; $\mathrm{p}$ valor ${ }^{\mathrm{a}}$, Grupo $\mathrm{II}_{\mathrm{R}+} v s$ Grupo $\mathrm{II}_{\mathrm{R}-} ; \mathrm{p}$ valor ${ }^{\mathrm{b}}$, grupo $\mathrm{II}_{\mathrm{R}+} v s$ control; $\mathrm{p}$ valor ${ }^{\mathrm{c}}$, grupo $\mathrm{II}_{\mathrm{R}-} v s$ control.

Tabla 28: Características del bloqueo epidural

\begin{tabular}{|l|c|c|c|c|c|c|}
\hline VARIABLE & $\begin{array}{c}\text { Grupo } \mathrm{II}_{\mathrm{R}+} \\
(\mathrm{n}=13)\end{array}$ & $\begin{array}{c}\text { Grupo } \mathrm{II}_{\mathrm{R}-} \\
(\mathrm{n}=11)\end{array}$ & $\begin{array}{c}\mathrm{p} \\
\text { valor }^{\mathrm{a}}\end{array}$ & $\begin{array}{c}\text { CONTROL } \\
(\mathrm{n}=20)\end{array}$ & $\begin{array}{c}\mathrm{p} \\
\text { valor }^{\mathrm{b}}\end{array}$ & $\begin{array}{c}\mathrm{p} \\
\text { valor }^{\mathrm{c}}\end{array}$ \\
\hline $\begin{array}{l}\text { Dolor } \\
\text { 30min }\end{array}$ & $5,50 \pm 3,16$ & $5,80 \pm 2,60$ & 0,73 & $7,78 \pm 2,01$ & $\mathbf{0 , 0 1}$ & $\mathbf{0 , 0 1}$ \\
\hline Frío 30min & $5,08 \pm 2,84$ & $4,55 \pm 2,87$ & 0,53 & $6,22 \pm 2,07$ & 0,15 & $\mathbf{0 , 0 4}$ \\
\hline
\end{tabular}

Los datos se han expresado como media \pm desviación estándar (DS). Grupo $\mathrm{II}_{\mathrm{R}+}$, pacientes

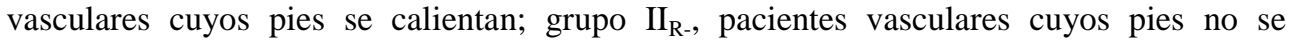
calientan; $\mathrm{n}$, tamaño muestral (personas); min, minutos; $\mathrm{p}$ valor ${ }^{\mathrm{a}}$, grupo $\mathrm{II}_{\mathrm{R}+} v s$ grupo $\mathrm{II}_{\mathrm{R}-} ; \mathrm{p}$ valor ${ }^{\mathrm{b}}$, grupo $\mathrm{II}_{\mathrm{R}+} v s$ control; $\mathrm{p}$ valor ${ }^{\mathrm{c}}$, grupo $\mathrm{II}_{\mathrm{R}-} v s$ control 


\subsection{ANÁLISIS DE LA TEMPERATURA CUTÁNEA EN LAS EXTREMIDADES, OMBLIGO Y PEZÓN DEL GRUPO $\mathrm{II}_{\mathrm{R}_{+}}, \mathrm{II}_{\mathrm{R}_{-}} \mathrm{y}$ CONTROL (Tablas 29-34 y Figs. 40-45)}

Después de analizar la temperatura del pie, pierna, muslo, ombligo y pezón, en el momento basal, a los 15 y 30 minutos de la realización de la anestesia epidural lumbar con bupivacaína, se observó lo siguiente:

\subsubsection{Análisis de la temperatura intergrupos, en los distintos momentos de medición}

Las temperaturas de los controles fueron significativamente mayores que las del grupo $\mathrm{II}_{\mathrm{R}_{+}}$en todos los momentos en el pie y pezón (Tablas 29 y33, Figs. 40 y 44), y en el momento 15 y 30 en la pantorrilla (Tabla 30, Fig. 41). Sin embargo en el ombligo, la temperatura del grupo control en el momento basal, fue significativamente menor que la del grupo $\mathrm{II}_{\mathrm{R}_{+}}$(Tabla 32, Fig. 43).

Las temperaturas del grupo control fueron significativamente mayores que las del grupo $\mathrm{II}_{\mathrm{R} \text {-, }}$ en el momento 15 y 30 en el pie y la pierna (Tablas 29 y 30, Figs. 40 y 41), sin embargo significativamente menores en el momento basal en el muslo (Tabla 31, Fig. 42), y en todos los momentos en el ombligo (tabla 32, fig. 43).

En la pierna y muslo no se observaron diferencias en ninguno de los

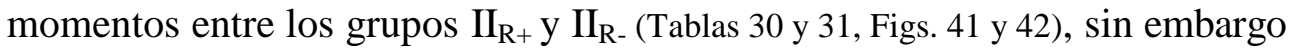
en el pie la temperatura basal fue significativamente menor en el grupo $\mathrm{II}_{\mathrm{R}+}$ y en el momento 30 significativamente mayor (Tabla 29, Fig. 40). En el ombligo y pezón la temperatura del grupo $\mathrm{II}_{\mathrm{R} \text { - }}$ fue significativamente mayor 
que la del grupo $\mathrm{II}_{\mathrm{R}+}$ en el momento $15 \mathrm{y}$ basal respectivamente (Tablas $32 \mathrm{y}$ 33, Figs. 43 y 44).

\subsubsection{Análisis de la temperatura intragrupo}

En los controles, ocurría un incremento significativo de la temperatura en los 30 minutos posteriores a la inyección del anestésico local en el pie $\left(4,41^{\circ} \mathrm{C}\right)$ (Tabla 29 , Fig. 40 ), pierna $\left(0,91^{\circ} \mathrm{C}\right)$ (Tabla 30, Fig. 41 ) y muslo $\left(0,34^{\circ} \mathrm{C}\right)$ (Tabla 31, Fig. 42$)$, sin embargo en el ombligo y pezón no sucedía una variación de la temperatura de forma significativa (Tablas 32 y 33, Figs. 43 y 44).

En los pacientes con arteriopatía periférica, en los 30 minutos posteriores a la inyección del anestésico epidural, en el grupo $\mathrm{II}_{\mathrm{R}_{+}}$sucedía un incremento significativo de la temperatura en el pie (Tabla 29, Fig. 40), y en ambos grupos $\left(\mathrm{II}_{\mathrm{R}+} \mathrm{y} \mathrm{II}_{\mathrm{R}-}\right)$ un descenso significativo de la temperatura en la pierna, muslo y pezón (Tablas 30, 31 y 33, Figs. 41, 42 y 44). Sin embargo la temperatura del ombligo no se modificaba de forma significativa (Tabla 32, Fig. 43).

\subsubsection{Análisis de las variaciones de la temperatura intergrupos}

En el pie se observó un mayor incremento de la temperatura en el grupo $\mathrm{II}_{\mathrm{R}+}$ que en el grupo control y $\mathrm{II}_{\mathrm{R}-}$ (Tabla 29, Fig. 40). Sin embargo, en la pierna y muslo el incremento de la temperatura fue mayor en los controles que en los pacientes vasculares (grupo $\mathrm{II}_{\mathrm{R}+} \mathrm{y} \mathrm{II}_{\mathrm{R}_{-}}$) (Tablas 30 y 31, Figs. 41 y 42). En el ombligo y pezón no se observaron diferencias, en la variación de temperatura, entre los grupos (Tablas 32 y 33, Figs. 43 y 44). 


\section{RESULTADOS}

Tabla 29: Temperatura cutánea del pie

\begin{tabular}{|l|c|c|c|c|c|c|}
\hline $\begin{array}{c}\text { VARIABLE } \\
\left({ }^{\circ} \mathrm{C}\right)\end{array}$ & $\begin{array}{c}\text { Grupo } \mathrm{II}_{\mathrm{R}} \\
(\mathrm{n}=26)\end{array}$ & $\begin{array}{c}\text { Grupo } \mathrm{II}_{\mathrm{R}} \\
(\mathrm{n}=22)\end{array}$ & $\begin{array}{c}\mathrm{p} \\
\text { valor }^{\mathrm{a}}\end{array}$ & $\begin{array}{c}\text { CONTROL } \\
(\mathrm{n}=20)\end{array}$ & $\begin{array}{c}\mathrm{p} \\
\text { valor }^{\mathrm{b}}\end{array}$ & $\begin{array}{c}\mathrm{p} \\
\text { valor }^{\mathrm{c}}\end{array}$ \\
\hline $\mathrm{T}^{\mathrm{a}}$ basal & $25,40 \pm 2,63$ & $28,43 \pm 3,09$ & $\mathbf{0 , 0 0 1}$ & $29,66 \pm 1,79$ & $\mathbf{0 , 0 0 0 1}$ & 0,182 \\
\hline $\mathrm{T}^{\mathrm{a}} 15 \min$ & $29,52 \pm 3,52^{*}$ & $28,15 \pm 3,06$ & 0,172 & $33,00 \pm 1,67 *$ & $\mathbf{0 , 0 0 1}$ & $\mathbf{0 , 0 0 0 1}$ \\
\hline $\mathrm{T}^{\mathrm{a}} 30 \min$ & $32,21 \pm 2,09^{*}$ & $28,33 \pm 3,11$ & $\mathbf{0 , 0 0 0 1}$ & $33,95 \pm 0,97 *$ & $\mathbf{0 , 0 0 2}$ & $\mathbf{0 , 0 0 0 1}$ \\
\hline$\Delta \mathrm{T}^{\mathrm{a}}$ & $6,81 \pm 3,26$ & $-0,10 \pm 1,09$ & $\mathbf{0 , 0 0 0 1}$ & $4,41 \pm 1,32$ & $\mathbf{0 , 0 0 5}$ & $\mathbf{0 , 0 0 0 1}$ \\
\hline
\end{tabular}

Los datos se han expresado como media \pm desviación estándar (DS). Grupo $\mathrm{II}_{\mathrm{R}+}$, extremidades inferiores vasculares cuyos pies se calientan; grupo $\mathrm{II}_{\mathrm{R}-\text {, }}$ extremidades inferiores vasculares cuyos pies no se calientan; n, tamaño muestral (extremidades inferiores); ${ }^{\circ} \mathrm{C}$, grados centígrados; $\Delta \mathrm{T}^{\mathrm{a}}$, variación de la temperatura (temperatura a los 30 minutos menos la basal); $\mathrm{p}$ valor ${ }^{\mathrm{a}}$, Grupo $\mathrm{II}_{\mathrm{R}+} v s$ Grupo $\mathrm{II}_{\mathrm{R}-} ; \mathrm{p}$ valor ${ }^{\mathrm{b}}$, grupo $\mathrm{II}_{\mathrm{R}+} v s$ control; $\mathrm{p}$ valor ${ }^{\mathrm{c}}$, grupo $\mathrm{II}_{\mathrm{R}}$ - vs control. *, cuando hay una diferencia significativa $(\mathrm{p} \leq 0,05)$ intragrupo respecto del momento basal

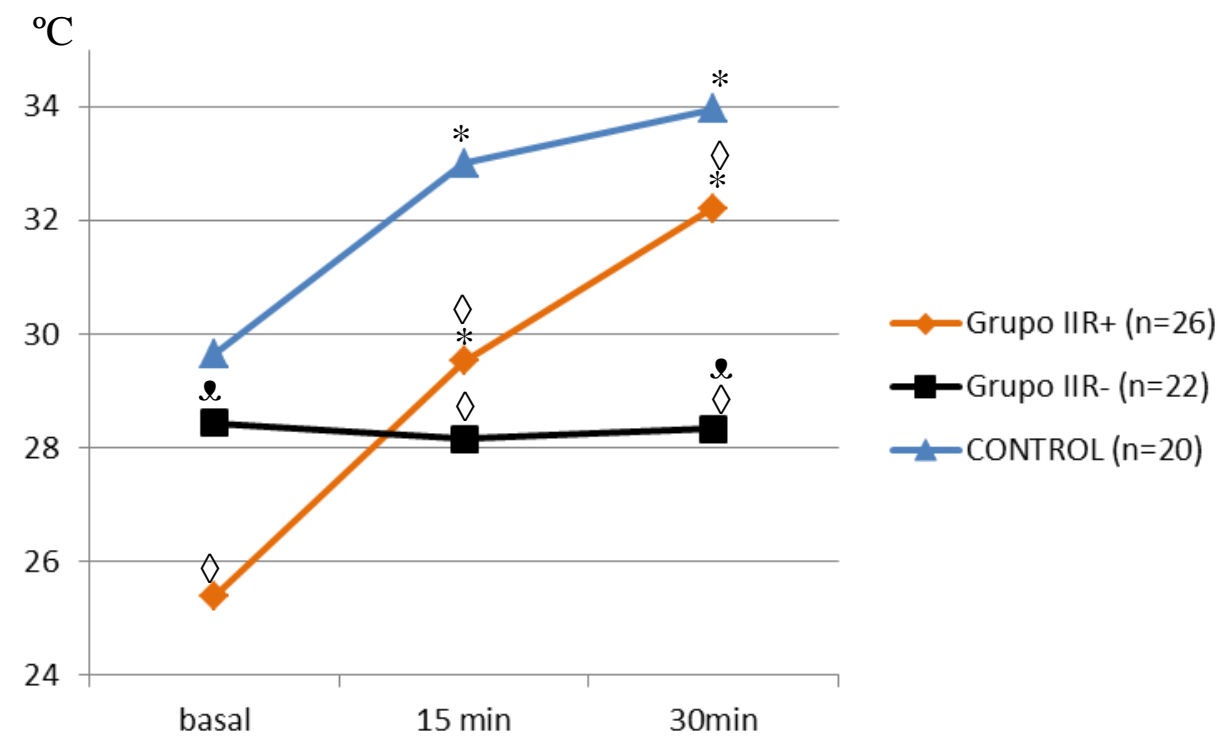

Figura 40: Temperatura del pie

Se señala la media de las temperaturas en cada momento de medición. Control, extremidad inferior sana; Grupo $\mathrm{II}_{\mathrm{R}+}$ extremidad inferior vascular cuyo pie se calienta; Grupo $\mathrm{II}_{\mathrm{R} \text {-, }}$ extremidad inferior vascular cuyo pie no se calienta; n, tamaño muestral (extremidades inferiores); min, minutos; ${ }^{\circ} \mathrm{C}$, grados centígrados; $*$, diferencia significativa $(\mathrm{p} \leq 0,05)$ intragrupo respecto del momento basal; $\diamond$, diferencia significativa $(\mathrm{p} \leq 0,05)$ respecto del grupo control; $\boldsymbol{\ell}$ diferencia significativa $(\mathrm{p} \leq 0,05)$ respecto del grupo $\mathrm{II}_{\mathrm{R}+}$ 


\section{RESULTADOS}

Tabla 30: Temperatura cutánea de la pierna

\begin{tabular}{|l|c|c|c|c|c|c|}
\hline $\begin{array}{c}\text { VARIABLE } \\
\left({ }^{\circ} \mathrm{C}\right)\end{array}$ & $\begin{array}{c}\text { Grupo } \mathrm{II}_{\mathrm{R}+} \\
(\mathrm{n}=26)\end{array}$ & $\begin{array}{c}\text { Grupo } \mathrm{II}_{\mathrm{R}-} \\
(\mathrm{n}=22)\end{array}$ & $\begin{array}{c}\mathrm{p} \\
\text { valor }^{\mathrm{a}}\end{array}$ & $\begin{array}{c}\text { CONTROL } \\
(\mathrm{n}=20)\end{array}$ & $\begin{array}{c}\mathrm{p} \\
\text { valor }^{\mathrm{b}}\end{array}$ & $\begin{array}{c}\mathrm{p} \\
\text { valor }^{\mathrm{c}}\end{array}$ \\
\hline $\mathrm{T}^{\mathrm{a}}$ basal & $32,43 \pm 0,89$ & $32,18 \pm 0,91$ & 0,35 & $31,88 \pm 1,24$ & 0,09 & 0,40 \\
\hline $\mathrm{T}^{\mathrm{a}} 15 \mathrm{~min}$ & $31,66 \pm 0,89^{*}$ & $31,53 \pm 0,83^{*}$ & 0,60 & $32,41 \pm 0,94^{*}$ & $\mathbf{0 , 0 1}$ & $\mathbf{0 , 0 0 4}$ \\
\hline $\mathrm{T}^{\text {a } 30 \min }$ & $31,82 \pm 0,88^{*}$ & $31,47 \pm 0,77^{*}$ & 0,16 & $32,80 \pm 1,03^{*}$ & $\mathbf{0 , 0 0 2}$ & $\mathbf{0 , 0 0 0 1}$ \\
\hline$\Delta \mathrm{T}^{\mathrm{a}}$ & $-0,61 \pm 0,66$ & $-0,71 \pm 0,69$ & 0,62 & $0,91 \pm 0,86$ & $\mathbf{0 , 0 0 0 1}$ & $\mathbf{0 , 0 0 0 1}$ \\
\hline
\end{tabular}

Los datos se han expresado como media \pm desviación estándar (DS). Grupo $\mathrm{II}_{\mathrm{R}+}$, extremidades inferiores cuyos pies se calientan; grupo $\mathrm{II}_{\mathrm{R} \text {-, }}$ extremidades inferiores cuyos pies no se calientan; $\mathrm{n}$, tamaño muestral (extremidades inferiores); ${ }^{\circ} \mathrm{C}$, grados centígrados; $\Delta \mathrm{T}^{\mathrm{a}}$, variación de la temperatura (temperatura a los 30 minutos menos la basal); $\mathrm{p}$ valor ${ }^{\mathrm{a}}$, Grupo $\mathrm{II}_{\mathrm{R}+} v s$ Grupo $\mathrm{II}_{\mathrm{R}-} ; \mathrm{p}$ valor ${ }^{\mathrm{b}}$, grupo $\mathrm{II}_{\mathrm{R}+} v s$ control; $\mathrm{p}$ valor ${ }^{\mathrm{c}}$, grupo $\mathrm{II}_{\mathrm{R}-} v s$ control. $*$, cuando hay una diferencia significativa $(\mathrm{p} \leq 0,05)$ intragrupo respecto del momento basal

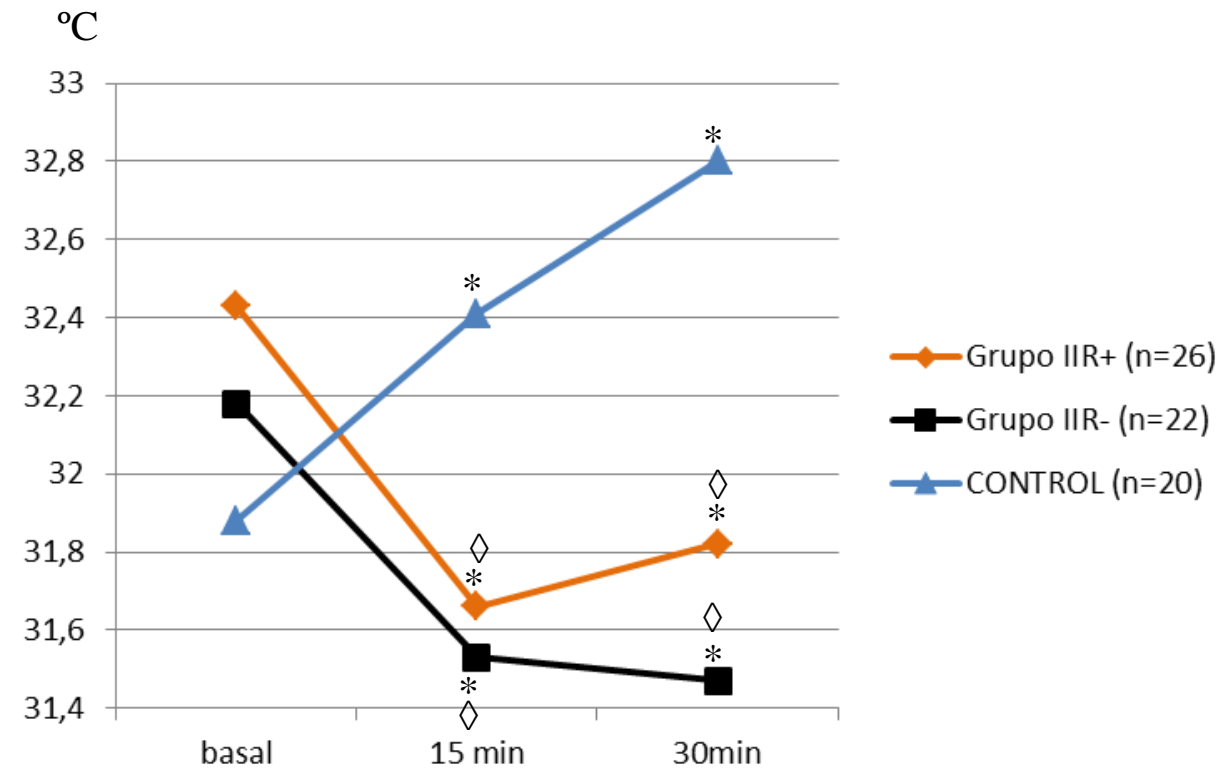

Figura 41: Temperatura de la pierna

Se señala la media de las temperaturas en cada momento de medición. Control, extremidad inferior sana; Grupo $\mathrm{II}_{\mathrm{R}+}$ extremidad inferior vascular cuyo pie se calienta; Grupo $\mathrm{II}_{\mathrm{R} \text {-, }}$ extremidad inferior vascular cuyo pie no se calienta; n, tamaño muestral (extremidades inferiores); min, minutos; ${ }^{\circ} \mathrm{C}$, grados centígrados; $*$, diferencia significativa $(\mathrm{p} \leq 0,05)$ intragrupo respecto del momento basal; $\diamond$, diferencia significativa $(\mathrm{p} \leq 0,05)$ respecto del grupo control; $\boldsymbol{\ell}$ diferencia significativa $(\mathrm{p} \leq 0,05)$ respecto del grupo $\mathrm{II}_{\mathrm{R}+}$ 


\section{RESULTADOS}

Tabla 31: Temperatura cutánea del muslo

\begin{tabular}{|l|c|c|c|c|c|c|}
\hline $\begin{array}{c}\text { VARIABLE } \\
\left({ }^{\circ} \mathrm{C}\right)\end{array}$ & $\begin{array}{c}\text { Grupo } \mathrm{II}_{\mathrm{R}} \\
(\mathrm{n}=26)\end{array}$ & $\begin{array}{c}\text { Grupo } \mathrm{II}_{\mathrm{R}-} \\
(\mathrm{n}=22)\end{array}$ & $\begin{array}{c}\mathrm{p} \\
\text { valor }^{\mathrm{a}}\end{array}$ & $\begin{array}{c}\text { CONTROL } \\
(\mathrm{n}=20)\end{array}$ & $\begin{array}{c}\mathrm{p} \\
\text { valor }^{\mathrm{b}}\end{array}$ & $\begin{array}{c}\mathrm{p} \\
\text { valor }^{\mathrm{c}}\end{array}$ \\
\hline $\mathrm{T}^{\mathrm{a}}$ basal & $32,95 \pm 0,96$ & $33,17 \pm 0,85$ & 0,42 & $32,58 \pm 0,81$ & 0,20 & $\mathbf{0 , 0 3}$ \\
\hline $\mathrm{T}^{\mathrm{a}} 15 \min$ & $32,75 \pm 0,82$ & $32,87 \pm 1,04^{*}$ & 0,67 & $32,79 \pm 0,86$ & 0,87 & 0,81 \\
\hline $\mathrm{T}^{\mathrm{a}} 30 \min$ & $32,57 \pm 0,80^{*}$ & $32,70 \pm 1,13^{*}$ & 0,64 & $32,92 \pm 0,85^{*}$ & 0,18 & 0,51 \\
\hline$\Delta \mathrm{T}^{\mathrm{a}}$ & $-0,37 \pm 0,79$ & $-0,46 \pm 0,76$ & 0,70 & $0,34 \pm 0,41$ & $\mathbf{0 , 0 0 1}$ & $\mathbf{0 , 0 0 0 1}$ \\
\hline
\end{tabular}

Los datos se han expresado como media \pm desviación estándar (DS). Grupo $\mathrm{II}_{\mathrm{R}+}$, extremidades inferiores cuyos pies se calientan; grupo $\mathrm{II}_{\mathrm{R} \text {-, }}$ extremidades inferiores cuyos pies no se calientan; n, tamaño muestral (extremidades inferiores); ${ }^{\circ} \mathrm{C}$, grados centígrados; $\Delta \mathrm{T}^{\mathrm{a}}$, variación de la temperatura (temperatura a los 30 minutos menos la basal); $\mathrm{p}$ valor ${ }^{\mathrm{a}}$, Grupo $\mathrm{II}_{\mathrm{R}+} v s$ Grupo $\mathrm{II}_{\mathrm{R}-} ; \mathrm{p}$ valor ${ }^{\mathrm{b}}$, grupo $\mathrm{II}_{\mathrm{R}+} v s$ control; $\mathrm{p}$ valor ${ }^{\mathrm{c}}$, grupo $\mathrm{II}_{\mathrm{R}-} v s$ control. $*$, cuando hay una diferencia significativa $(\mathrm{p} \leq 0,05)$ intragrupo respecto del momento basal.

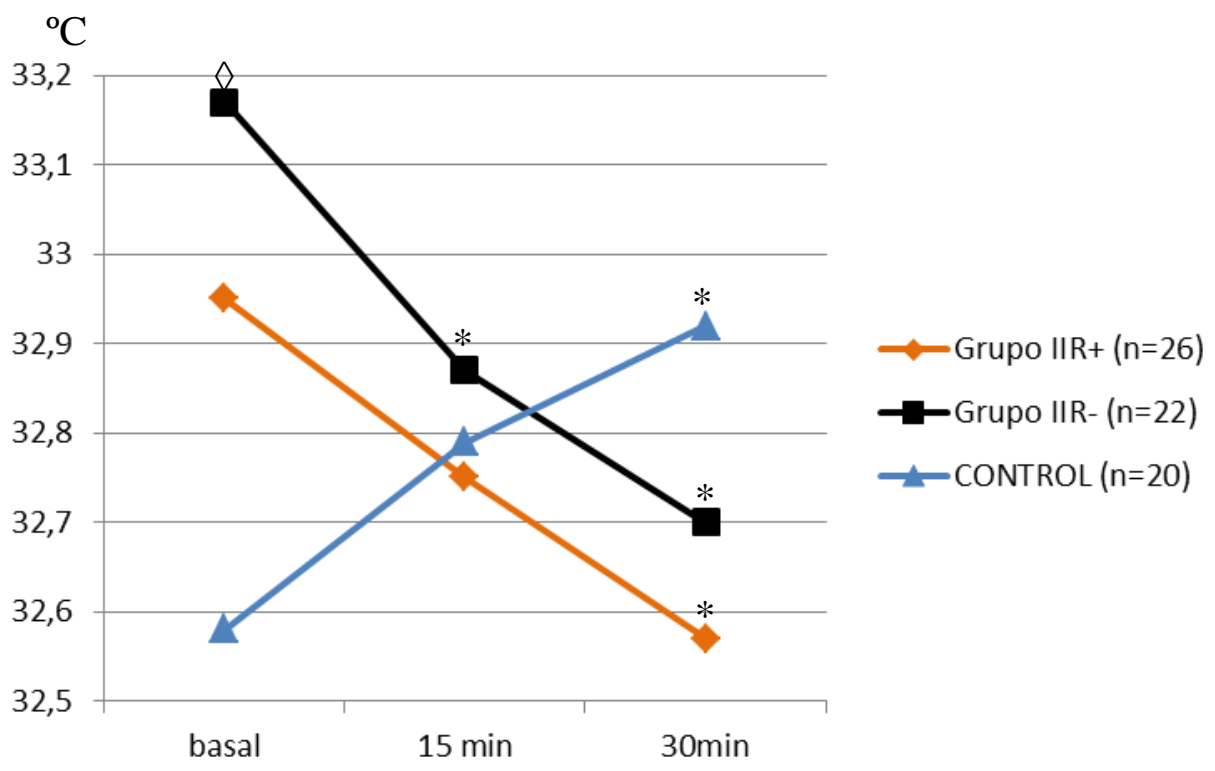

Figura 42: Temperatura del muslo

Se señala la media de las temperaturas en cada momento de medición. Control, extremidad inferior sana; Grupo $\mathrm{II}_{\mathrm{R}+}$ extremidad inferior vascular cuyo pie se calienta; Grupo $\mathrm{II}_{\mathrm{R} \text {-, }}$ extremidad inferior vascular cuyo pie no se calienta; n, tamaño muestral (extremidades inferiores); min, minutos; ${ }^{\circ} \mathrm{C}$, grados centígrados; $*$, diferencia significativa $(\mathrm{p} \leq 0,05)$ intragrupo respecto del momento basal; $\diamond$, diferencia significativa $(\mathrm{p} \leq 0,05)$ respecto del grupo control; $\boldsymbol{\ell}$ diferencia significativa $(\mathrm{p} \leq 0,05)$ respecto del grupo $\mathrm{II}_{\mathrm{R}+}$ 


\section{RESULTADOS}

Tabla 32: Temperatura cutánea del ombligo

\begin{tabular}{|l|c|c|c|c|c|c|}
\hline $\begin{array}{c}\text { VARIABLE } \\
\left({ }^{\circ} \mathrm{C}\right)\end{array}$ & $\begin{array}{c}\text { Grupo II }{ }_{\mathrm{R}+} \\
(\mathrm{n}=13)\end{array}$ & $\begin{array}{c}\text { Grupo } \mathrm{II}_{\mathrm{R}-} \\
(\mathrm{n}=11)\end{array}$ & $\begin{array}{c}\mathrm{p} \\
\text { valor }^{\mathrm{a}}\end{array}$ & $\begin{array}{c}\text { CONTROL } \\
(\mathrm{n}=20)\end{array}$ & $\begin{array}{c}\mathrm{p} \\
\text { valor }^{\mathrm{b}}\end{array}$ & p valor $^{\mathrm{c}}$ \\
\hline $\mathrm{T}^{\mathrm{a}}$ basal & $33,69 \pm 0,69$ & $34,06 \pm 0,92$ & 0,12 & $32,90 \pm 1,41$ & $\mathbf{0 , 0 1}$ & $\mathbf{0 , 0 0 5}$ \\
\hline $\mathrm{T}^{\mathrm{a}} 15 \mathrm{~min}$ & $33,50 \pm 0,95$ & $34,11 \pm 0,87$ & $\mathbf{0 , 0 3}$ & $33,05 \pm 1,09$ & 0,16 & $\mathbf{0 , 0 0 3}$ \\
\hline $\mathrm{T}^{\mathrm{a}} 30 \mathrm{~min}$ & $33,50 \pm 0,99$ & $33,93 \pm 1,25$ & 0,21 & $32,97 \pm 0,96$ & 0,09 & $\mathbf{0 , 0 1}$ \\
\hline$\Delta \mathrm{T}^{\mathrm{a}}$ & $-0,18 \pm 0,91$ & $-0,13 \pm 0,85$ & 0,85 & $0,07 \pm 1,22$ & 0,42 & 0,54 \\
\hline
\end{tabular}

Los datos se han expresado como media \pm desviación estándar (DS). Grupo $\mathrm{II}_{\mathrm{R}+}$, pacientes vasculares cuyos pies se calientan; grupo $\mathrm{II}_{R-}$, pacientes vasculares cuyos pies no se calientan; $\mathrm{n}$, tamaño muestral (personas); ${ }^{\circ} \mathrm{C}$, grados centígrados; $\Delta \mathrm{T}^{\mathrm{a}}$, variación de la temperatura (temperatura a los 30 minutos menos la basal); $\mathrm{p}$ valor ${ }^{\mathrm{a}}$, Grupo $\mathrm{II}_{\mathrm{R}} v s$ Grupo $\mathrm{II}_{\mathrm{R}-} ; \mathrm{p}$ valor ${ }^{\mathrm{b}}$, grupo $\mathrm{II}_{\mathrm{R}+} v s$ control; $\mathrm{p}$ valor ${ }^{\mathrm{c}}$, grupo $\mathrm{II}_{\mathrm{R}-} v s$ control. *, cuando hay una diferencia significativa $(\mathrm{p} \leq 0,05)$ intragrupo respecto del momento basal.

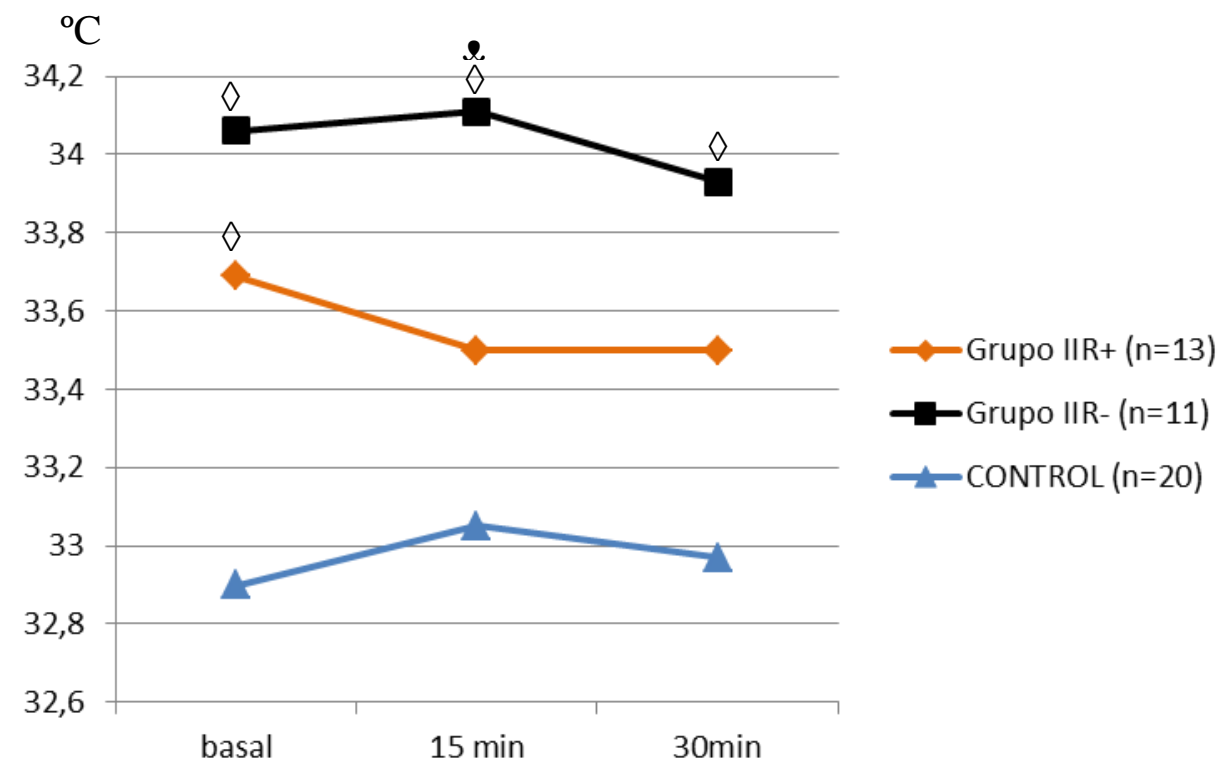

Figura 43: Temperatura del ombligo

Se señala la media de las temperaturas en cada momento de medición. Grupo $\mathrm{II}_{\mathrm{R}+}$, pacientes vasculares cuyos pies se calientan; Grupo $\mathrm{II}_{\mathrm{R}}$, pacientes vasculares cuyos pies no se calientan; $\mathrm{n}$, tamaño muestral (personas); min, minutos; ${ }^{\circ} \mathrm{C}$, grados centígrados; *, diferencia significativa $(\mathrm{p} \leq 0,05)$ intragrupo respecto del momento basal; $\diamond$, diferencia significativa $(\mathrm{p} \leq 0,05)$ respecto del grupo control; $\boldsymbol{e}$ diferencia significativa $(\mathrm{p} \leq 0,05)$ respecto del grupo $\mathrm{II}_{\mathrm{R}+}$ 


\section{RESULTADOS}

Tabla 33: Temperatura cutánea del pezón

\begin{tabular}{|l|c|c|c|c|c|c|}
\hline $\begin{array}{c}\text { VARIABLE } \\
\left({ }^{\circ} \mathrm{C}\right)\end{array}$ & $\begin{array}{c}\text { Grupo } \mathrm{II}_{\mathrm{R}+} \\
(\mathrm{n}=13)\end{array}$ & $\begin{array}{c}\text { Grupo } \mathrm{II}_{\mathrm{R}-} \\
(\mathrm{n}=11)\end{array}$ & $\begin{array}{c}\mathrm{p} \\
\text { valor }^{\mathrm{a}}\end{array}$ & $\begin{array}{c}\text { CONTROL } \\
(\mathrm{n}=20)\end{array}$ & $\begin{array}{c}\mathrm{p} \\
\text { valor }^{\mathrm{b}}\end{array}$ & $\begin{array}{c}\mathrm{p} \\
\text { valor }^{\mathrm{c}}\end{array}$ \\
\hline $\mathrm{T}^{\mathrm{a}}$ basal & $32,49 \pm 0,74$ & $33,13 \pm 1,38$ & $\mathbf{0 , 0 5}$ & $33,00 \pm 0,75$ & $\mathbf{0 , 0 3}$ & 0,73 \\
\hline $\mathrm{T}^{\mathrm{a}} 15$ min & $32,18 \pm 0,92^{*}$ & $32,70 \pm 1,25^{*}$ & 0,11 & $32,87 \pm 0,67$ & $\mathbf{0 , 0 1}$ & 0,62 \\
\hline $\mathrm{T}^{\mathrm{a}} 30 \mathrm{~min}$ & $32,04 \pm 0,74^{*}$ & $32,46 \pm 1,30^{*}$ & 0,18 & $32,74 \pm 0,76$ & $\mathbf{0 , 0 0 5}$ & 0,44 \\
\hline$\Delta \mathrm{T}^{\mathrm{a}}$ & $-0,45 \pm 0,60$ & $-0,67 \pm 0,63$ & 0,23 & $-0,26 \pm 0,78$ & 0,39 & 0,08 \\
\hline
\end{tabular}

Los datos se han expresado como media \pm desviación estándar (DS). Grupo $\mathrm{II}_{\mathrm{R}+}$, pacientes

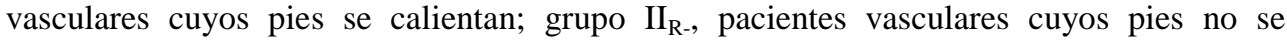
calientan; n, tamaño muestral (personas); ${ }^{\circ} \mathrm{C}$, grados centígrados; $\Delta \mathrm{T}^{\mathrm{a}}$, variación de la temperatura (temperatura a los 30 minutos menos la basal); $\mathrm{p}$ valor ${ }^{\mathrm{a}}$, grupo $\mathrm{II}_{\mathrm{R}+} v s$ grupo $\mathrm{II}_{\mathrm{R}-} ; \mathrm{p}$ valor ${ }^{\mathrm{b}}$, grupo $\mathrm{II}_{\mathrm{R}+} v s$ control; $\mathrm{p}$ valor ${ }^{\mathrm{c}}$, grupo $\mathrm{II}_{\mathrm{R}-} v s$ control. *, cuando hay una diferencia significativa $(\mathrm{p} \leq 0,05)$ intragrupo respecto del momento basal.

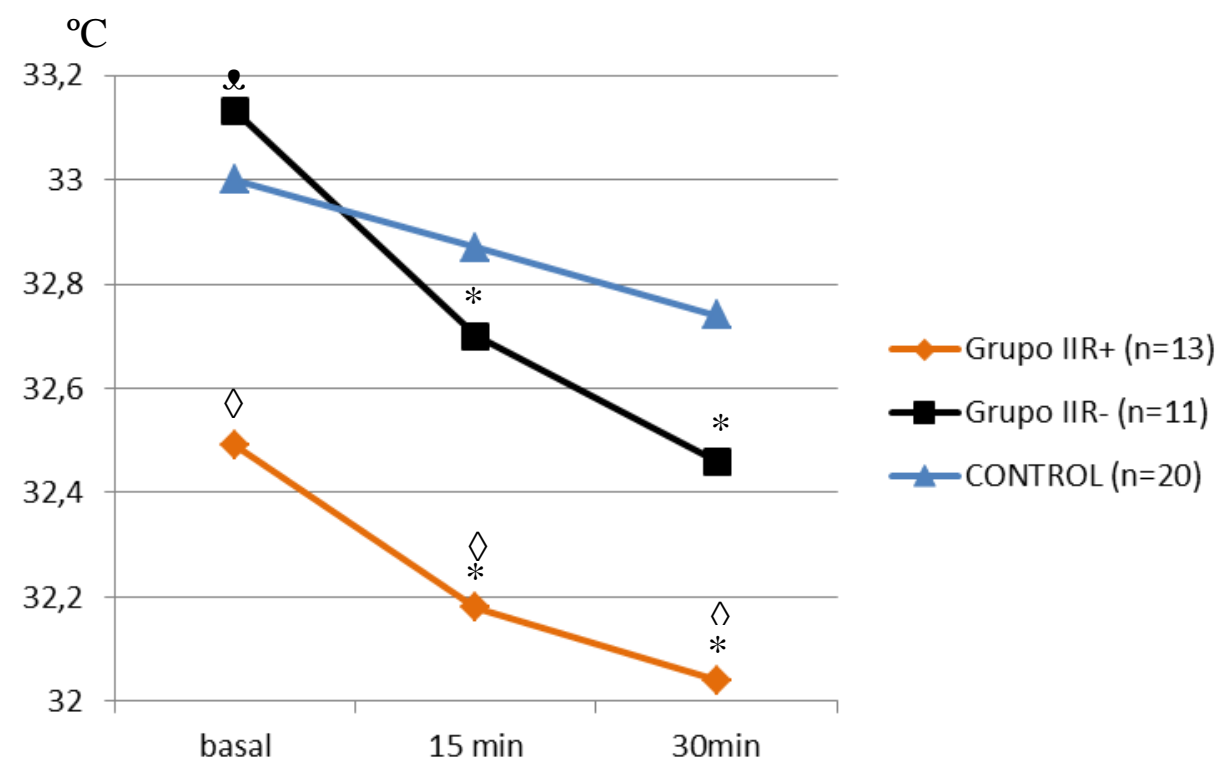

Figura 44: Temperatura del pezón

Se señala la media de las temperaturas en cada momento de medición. Grupo $\mathrm{II}_{\mathrm{R}+}$, pacientes vasculares cuyos pies se calientan; Grupo $\mathrm{II}_{\mathrm{R}}$, pacientes vasculares cuyos pies no se calientan; $\mathrm{n}$, tamaño muestral (personas); min, minutos; ${ }^{\circ} \mathrm{C}$, grados centígrados; *, diferencia significativa $(\mathrm{p} \leq 0,05)$ intragrupo respecto del momento basal; $\diamond$, diferencia significativa $(\mathrm{p} \leq 0,05)$ respecto del grupo control; $\boldsymbol{e}$ diferencia significativa $(\mathrm{p} \leq 0,05)$ respecto del grupo $\mathrm{II}_{\mathrm{R}+}$ 


\subsubsection{Análisis de las variaciones de la temperatura intragrupo}

En los controles y en el grupo $\mathrm{II}_{\mathrm{R}+}$, se observó que el incremento de la temperatura era significativamente mayor en el pie que en la pierna, muslo, ombligo o pezón (Tabla 34, Fig. 45). En el grupo $\mathrm{II}_{\mathrm{R}-\text {, }}$ se observó que la variación de la temperatura en el pie, era significativamente menor que en los otros puntos de medición (Tabla 34, Fig. 45).

Tabla 34: Variaciones de la temperatura en los diferentes lugares de medición

\begin{tabular}{|c|c|c|c|}
\hline & \multicolumn{2}{|c|}{$\begin{array}{l}\text { PACIENTES VASCULARES } \\
\qquad(\mathrm{n}=24)\end{array}$} & $\begin{array}{c}\text { PACIENTES } \\
\text { CONTROL }(\mathrm{n}=20)\end{array}$ \\
\hline VARIABLE & $\begin{array}{l}\text { Grupo } \mathrm{II}_{\mathrm{R}+} \\
\quad(\mathrm{n}=26)\end{array}$ & $\begin{array}{l}\text { Grupo } \mathrm{II}_{\mathrm{R}-} \\
\quad(\mathrm{n}=22)\end{array}$ & $\begin{array}{l}\text { CONTROL } \\
\quad(n=20)\end{array}$ \\
\hline$\Delta \mathrm{T}^{\mathrm{a}}$ pie $\left({ }^{\circ} \mathrm{C}\right)$ & $6,81 \pm 3,26$ & $-0,10 \pm 1,09$ & $4,41 \pm 1,32$ \\
\hline$\Delta \mathrm{T}^{\mathrm{a}}$ pierna $\left({ }^{\circ} \mathrm{C}\right)$ & $-0,61 \pm 0,66^{*}$ & $-0,71 \pm 0,69^{*}$ & $0,91 \pm 0,86^{*}$ \\
\hline$\Delta \mathrm{T}^{\mathrm{a}}$ muslo $\left({ }^{\circ} \mathrm{C}\right)$ & $-0,37 \pm 0,79^{*}$ & $-0,46 \pm 0,76^{*}$ & $0,34 \pm 0,41^{*}$ \\
\hline$\Delta \mathrm{T}^{\mathrm{a}}$ ombligo $\left({ }^{\circ} \mathrm{C}\right)$ & $-0,18 \pm 0,91^{*}$ & $-0,13 \pm 0,85^{*}$ & $0,07 \pm 1,22^{*}$ \\
\hline$\Delta \mathrm{T}^{\mathrm{a}}$ pezón $\left({ }^{\circ} \mathrm{C}\right)$ & $-0,45 \pm 0,60^{*}$ & $-0,67 \pm 0,63^{*}$ & $-0,26 \pm 0,78^{*}$ \\
\hline
\end{tabular}

Los datos se han expresado como media \pm desviación estándar (DS). Grupo $\mathrm{II}_{\mathrm{R}+}$, extremidades inferiores vasculares cuyos pies se calientan; grupo $\mathrm{II}_{\mathrm{R}_{-}}$, extremidades inferiores vasculares cuyos pies no se calientan; $n$, tamaño muestral (en pacientes control y vasculares son personas, y en grupo $\mathrm{II}_{\mathrm{R}+}, \mathrm{II}_{\mathrm{R}-}$ y control son extremidades inferiores); $\Delta \mathrm{T}^{\mathrm{a}}$ : variación de la temperatura (temperatura a los 30 minutos menos la basal); ${ }^{\circ} \mathrm{C}$, grados centígrados; * Cuando hay una diferencia significativa $(\mathrm{p} \leq 0,05)$ intragrupo entre lugar distinto de pie y pie. 


\section{RESULTADOS}

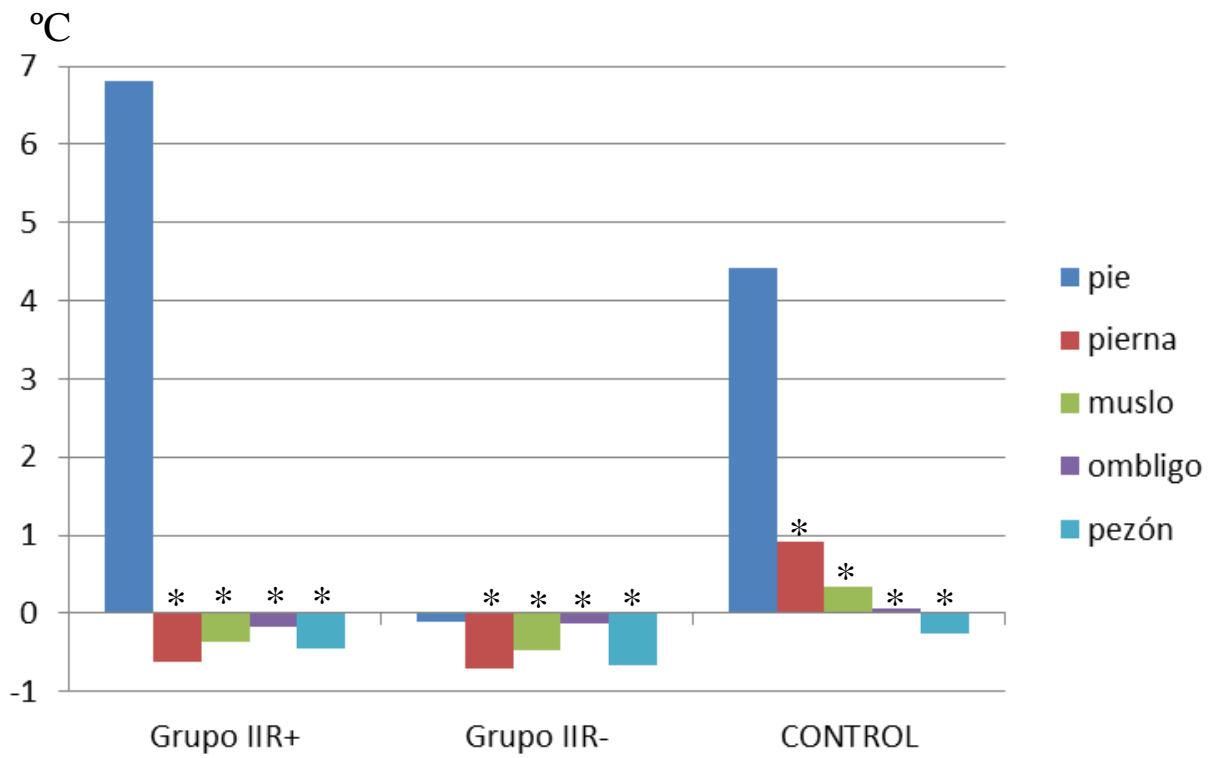

Figura 45: Variación de la temperatura intragrupo

Grupo $\mathrm{II}_{\mathrm{R}}$, pacientes vasculares cuyos pies se calientan; Grupo $\mathrm{II}_{\mathrm{R}}$, pacientes vasculares cuyos pies no se calientan; ${ }^{\circ} \mathrm{C}$, grados centígrados; $*$, diferencia significativa $(\mathrm{p} \leq 0,05)$ intragrupo entre lugar distinto del pie y pie 


\subsection{ANÁLISIS DE LAS CONSTANTES HEMODINÁMICAS DE LOS PACIENTES CON ARTERIOPATÍA PERIFÉRICA CRÓNICA: GRUPO $\mathrm{II}_{\mathrm{R}+}$ y $\mathrm{II}_{\mathrm{R}-}$}

Analizando las variables hemodinámicas, se observó que a lo largo de los 30 minutos posteriores a la inyección del bolo de anestésico local en el espacio epidural, sucedió un descenso significativo de la tensión arterial sistólica y tensión arterial diastólica en ambos grupos (tablas 35 y 36, figuras 46 y 47), y de la frecuencia cardiaca exclusivamente en el grupo cuyos pies se calentaban (grupo $\mathrm{II}_{\mathrm{R}+}$ ) (tabla 37, figura 48).

No se observaron diferencias entre los grupos $\mathrm{II}_{\mathrm{R}+} \mathrm{y} \mathrm{II}_{\mathrm{R}-}$ en la TAS en ninguno de los momentos de medición (tabla 35, figura 46). A los 10 minutos de la inyección del bolo de anestésico vía epidural, se observó una TAD significativamente mayor en el grupo $\mathrm{II}_{\mathrm{R}_{+}}$(tabla 36, figura 47). También se vio que la frecuencia cardiaca fue significativamente más baja en el grupo $\mathrm{II}_{\mathrm{R}+}$ que en el $\mathrm{II}_{\mathrm{R}-\text {, }}$ en todos los momentos de medición (tabla 37, figura 48). 
Tabla 35: Variación de la tensión arterial sistólica en los pacientes con arteriopatía periférica

\begin{tabular}{|c|c|c|c|}
\hline VARIABLE & Grupo $\mathrm{II}_{\mathrm{R}+}(\mathrm{n}=13)$ & Grupo $\mathrm{II}_{\mathrm{R}-}(\mathrm{n}=11)$ & $\mathrm{p}$ valor \\
\hline TAS basal & $145,15 \pm 20,92$ & $152,65 \pm 20,97$ & 0,23 \\
\hline TAS $5 \mathrm{~min}$ & $137,23 \pm 21,86^{*}$ & $140,00 \pm 27,33^{*}$ & 0,70 \\
\hline TAS $10 \mathrm{~min}$ & $130,69 \pm 21,69^{*}$ & $131,55 \pm 25,41^{*}$ & 0,90 \\
\hline TAS $15 \mathrm{~min}$ & $127,35 \pm 23,45^{*}$ & $131,35 \pm 21,84^{*}$ & 0,55 \\
\hline TAS $20 \mathrm{~min}$ & $127,27 \pm 21,57^{*}$ & $126,70 \pm 26,65^{*}$ & 0,93 \\
\hline TAS 25min & $117,00 \pm 36,66^{*}$ & $127,60 \pm 25,65^{*}$ & 0,27 \\
\hline TAS 30min & $127,00 \pm 25,20^{*}$ & $128,25 \pm 23,68^{*}$ & 0,86 \\
\hline$\Delta$ TAS & $-18,15 \pm 18,45$ & $-24,40 \pm 19,07$ & 0,26 \\
\hline
\end{tabular}

Los datos se han expresado como media \pm desviación estándar (DS). Grupo $\mathrm{II}_{\mathrm{R}+}$, pacientes

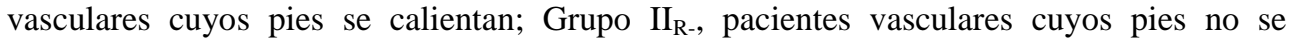
calientan; n, tamaño muestral (personas); min, minutos; TAS, tensión arterial sistólica; $\triangle \mathrm{TAS}$, variación de la tensión arterial sistólica (30 minutos menos la basal). *, cuando hay una diferencia significativa $(\mathrm{p} \leq 0,05)$ intragrupo respecto del momento basal

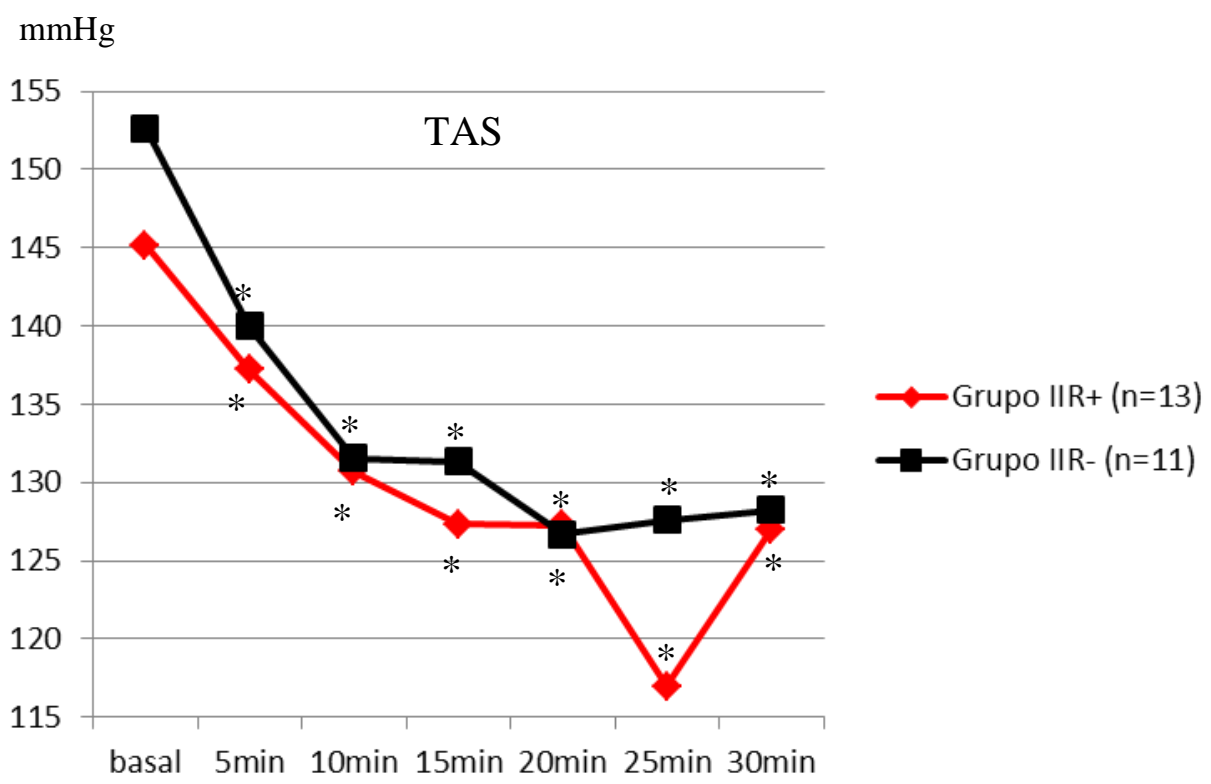

Figura 46: Variación de la TAS en los pacientes vasculares (grupo $\mathrm{II}_{\mathrm{R}+}$ y $\mathrm{II}_{\mathrm{R}-\text { ) }}$

Se señala la media de las tensiones arteriales en cada momento de medición. Grupo $\mathrm{II}_{\mathrm{R}}$, pacientes vasculares cuyos pies se calientan; Grupo $\mathrm{II}_{R_{-}}$, pacientes vasculares cuyos pies no se calientan; $\mathrm{n}$, tamaño muestral (personas); mmHg, milímetros de mercurio; min, minutos; ${ }^{*}$, diferencia significativa $(\mathrm{p} \leq 0,05)$ intragrupo respecto del momento basal; $\boldsymbol{\iota}$ diferencia significativa $(\mathrm{p} \leq 0,05)$ respecto del grupo $\mathrm{II}_{\mathrm{R}+}$ 


\section{RESULTADOS}

Tabla 36: Variación de la tensión arterial diastólica en los pacientes con arteriopatía periférica

\begin{tabular}{|c|c|c|c|}
\hline VARIABLE & Grupo $\mathrm{II}_{\mathrm{R}+}(\mathrm{n}=13)$ & Grupo $\mathrm{II}_{\mathrm{R}-}(\mathrm{n}=11)$ & $\mathrm{p}$ valor \\
\hline TAD basal & $81,50 \pm 10,34$ & $78,35 \pm 16,33$ & 0,42 \\
\hline TAD 5min & $79,12 \pm 13,79$ & $75,30 \pm 10,39$ & 0,30 \\
\hline TAD 10min & $75,04 \pm 13,08^{*}$ & $64,50 \pm 14,48^{*}$ & $\mathbf{0 , 0 1}$ \\
\hline TAD 15min & $71,04 \pm 12,11^{*}$ & $63,20 \pm 16,38^{*}$ & 0,06 \\
\hline TAD 20min & $69,65 \pm 12,69 *$ & $62,70 \pm 15,71^{*}$ & 0,10 \\
\hline TAD 25min & $63,23 \pm 11,92^{*}$ & $63,50 \pm 13,05^{*}$ & 0,31 \\
\hline TAD 30min & $71,00 \pm 12,42^{*}$ & $65,35 \pm 15,66^{*}$ & 0,17 \\
\hline$\Delta$ TAD & $-10,53 \pm 8,98$ & $-13,00 \pm 12,81$ & 0,44 \\
\hline
\end{tabular}

Los datos se han expresado como media \pm desviación estándar (DS). Grupo $\mathrm{II}_{\mathrm{R}+}$, pacientes

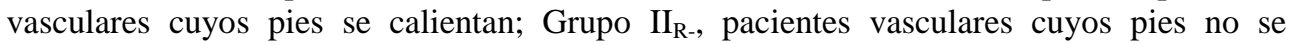
calientan; n, tamaño muestral (personas); min, minutos; TAD, tensión arterial diastólica; $\triangle \mathrm{TAD}$, variación de la tensión arterial diastólica (30 minutos menos la basal). *, cuando hay una diferencia significativa $(\mathrm{p} \leq 0,05)$ intragrupo respecto del momento basal

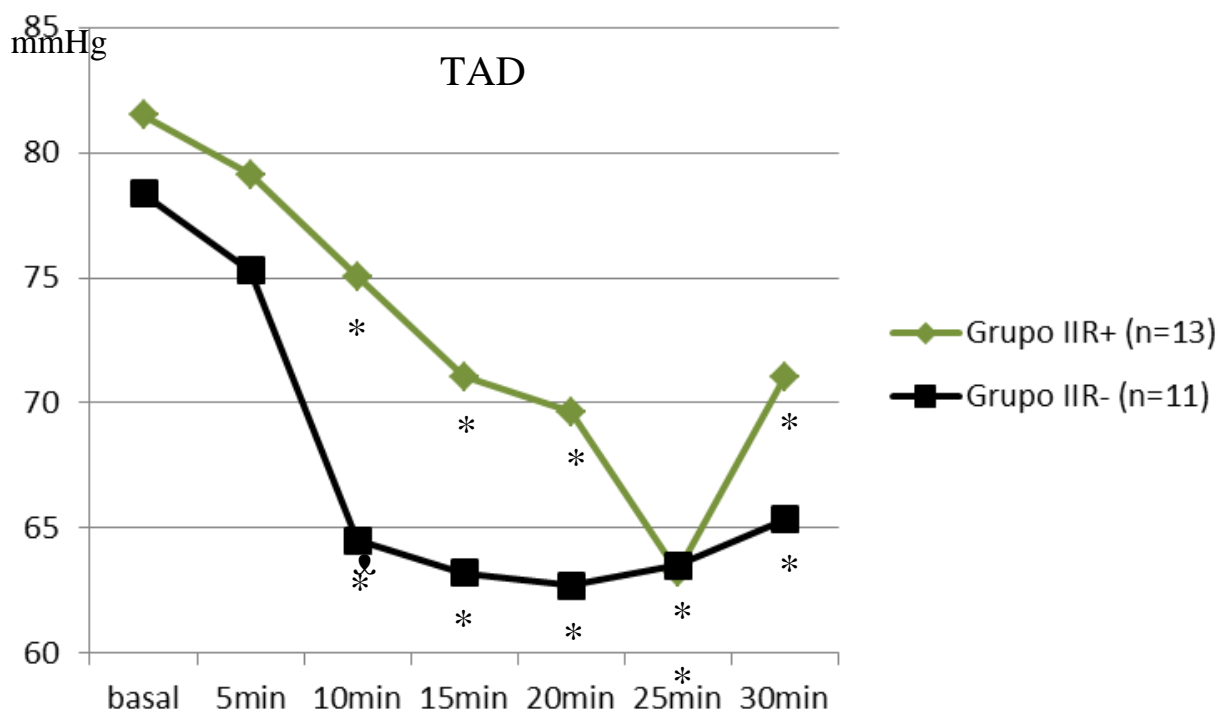

Figura 47: Variación de la TAD en los pacientes vasculares (grupo $\mathrm{II}_{\mathrm{R}+}$ y $\mathrm{II}_{\mathrm{R}-\text {-) }}$

Se señala la media de las tensiones arteriales en cada momento de medición. Grupo $\mathrm{II}_{\mathrm{R}+}$, pacientes vasculares cuyos pies se calientan; Grupo $\mathrm{II}_{\mathrm{R} \text {-, }}$ pacientes vasculares cuyos pies no se calientan; $\mathrm{n}$, tamaño muestral (personas); $\mathrm{mmHg}$, milímetros de mercurio; min, minutos; $*$, diferencia significativa $(\mathrm{p} \leq 0,05)$ intragrupo respecto del momento basal; $\boldsymbol{\ell}$ diferencia significativa $(\mathrm{p} \leq 0,05)$ respecto del grupo $\mathrm{II}_{\mathrm{R}+}$ 


\section{RESULTADOS}

Tabla 37: Variación de la frecuencia cardiaca en los pacientes con arteriopatía periférica

\begin{tabular}{|c|c|c|c|}
\hline VARIABLE & Grupo $\mathrm{II}_{\mathrm{R}+}(\mathrm{n}=13)$ & Grupo $\mathrm{II}_{\mathrm{R}-}(\mathrm{n}=11)$ & p valor \\
\hline FC basal & $66,92 \pm 12,37$ & $77,20 \pm 16,86$ & $\mathbf{0 , 0 2}$ \\
\hline FC 5min & $64,73 \pm 14,34^{*}$ & $81,85 \pm 27,11$ & $\mathbf{0 , 0 0 8}$ \\
\hline FC 10min & $64,00 \pm 15,22^{*}$ & $75,85 \pm 17,02$ & $\mathbf{0 , 0 1}$ \\
\hline FC 15min & $62,46 \pm 16,50^{*}$ & $76,10 \pm 16,00$ & $\mathbf{0 , 0 0 7}$ \\
\hline FC 20min & $60,54 \pm 12,47^{*}$ & $72,15 \pm 14,17 *$ & $\mathbf{0 , 0 0 5}$ \\
\hline FC 25min & $60,69 \pm 15,77^{*}$ & $75,10 \pm 13,81$ & $\mathbf{0 , 0 0 2}$ \\
\hline FC 30min & $61,69 \pm 16,00^{*}$ & $75,30 \pm 16,28$ & $\mathbf{0 , 0 0 7}$ \\
\hline$\Delta$ FC & $-5,23 \pm 9,42$ & $-1,90 \pm 9,80$ & 0,24 \\
\hline
\end{tabular}

Los datos se han expresado como media \pm desviación estándar (DS). Grupo $\mathrm{II}_{\mathrm{R}+}$, pacientes vasculares cuyos pies se calientan; Grupo $\mathrm{II}_{\mathrm{R}}$, pacientes vasculares cuyos pies no se calientan. $\mathrm{n}$, tamaño muestral (personas); min, minutos; FC, frecuencia cardiaca; $\triangle \mathrm{FC}$, variación de la frecuencia cardiaca (30 minutos menos la basal). *, cuando hay una diferencia significativa $(\mathrm{p} \leq 0,05)$ intragrupo respecto del momento basal.

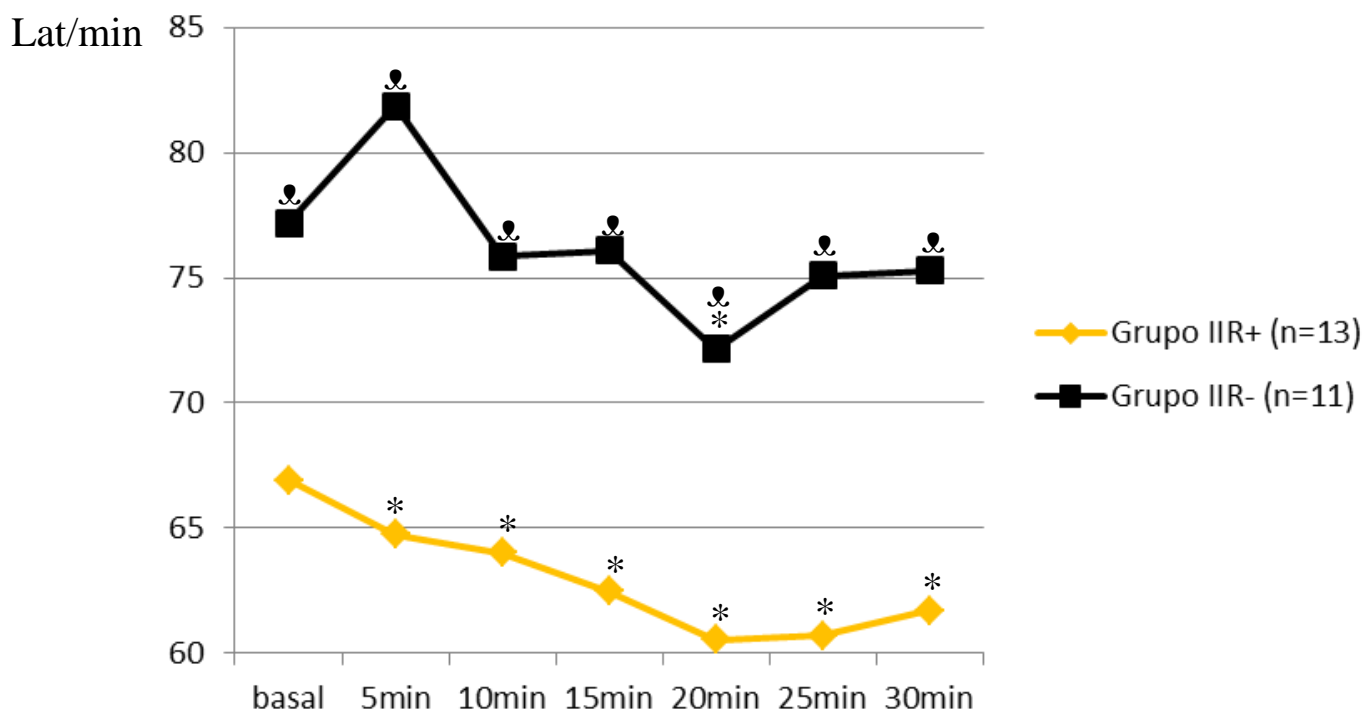

Figura 48: Variación de la FC en los pacientes vasculares (grupo $\mathrm{II}_{\mathrm{R}+}$ y $\mathrm{II}_{\mathrm{R}-\text {-) }}$

Se señala la media de las frecuencias cardiacas en cada momento de medición. Grupo $\mathrm{II}_{\mathrm{R}}$, pacientes vasculares cuyos pies se calientan; Grupo $\mathrm{II}_{\mathrm{R}_{-}}$, pacientes vasculares cuyos pies no se calientan; n, tamaño muestral (personas); Lat/min, latidos por minuto; min, minutos; *, diferencia significativa $(\mathrm{p} \leq 0,05)$ intragrupo respecto del momento basal; \& diferencia significativa $(\mathrm{p} \leq 0,05)$ respecto del grupo $\mathrm{II}_{\mathrm{R}+}$ 
7.9 ANÁLISIS DE CORRELACIÓN DE LA VARIACIÓN DE LA TEMPERATURA EN EL PIE DE LOS PACIENTES

VASCULARES (tabla 38)

Tabla 38: Análisis univariante

\begin{tabular}{|c|c|c|c|}
\hline VARIABLE & $\mathrm{r} 2$ & $\mathrm{~F}$ & $\mathrm{p}$ valor \\
\hline Edad & 0,07 & 3,46 & 0,06 \\
\hline Peso & 0,0001 & 0,01 & 0,89 \\
\hline Altura & 0,0001 & 0,01 & 0,92 \\
\hline HTA & 0,09 & 4,64 & $\mathbf{0 , 0 3}$ \\
\hline DM & 0,05 & 2,65 & 0,11 \\
\hline Años DM & 0,12 & 2,88 & 0,10 \\
\hline Fumador & 0,02 & 0,48 & 0,49 \\
\hline Años fumador & 0,001 & 0,06 & 0,80 \\
\hline Años exfumador & 0,001 & 0,06 & 0,80 \\
\hline $\mathrm{N}^{\mathbf{o}}$ cigarros/día & 0,001 & 0,49 & 0,82 \\
\hline Volumen AL & 0,10 & 5,08 & $\mathbf{0 , 0 2}$ \\
\hline ITB & 0,10 & 3,42 & 0,07 \\
\hline Obst. femoral & 0,005 & 0,28 & 0,63 \\
\hline Obst. poplítea & 0,006 & 0,26 & 0,61 \\
\hline Obst. tibial ant & 0,04 & 1,93 & 0,17 \\
\hline Obst. tibial post & 0,04 & 2,06 & 0,15 \\
\hline TAS basal & 0,01 & 0,44 & 0,50 \\
\hline TAS 30 min & 0,01 & 0,76 & 0,38 \\
\hline TAD basal & 0,009 & 0,41 & 0,52 \\
\hline TAD 30 min & 0,01 & 0,60 & 0,44 \\
\hline FC basal & 0,19 & 10,68 & $\mathbf{0 , 0 0 2}$ \\
\hline FC 30 min & 0,16 & 8,74 & $\mathbf{0 , 0 0 5}$ \\
\hline
\end{tabular}

$\mathrm{r}^{2}$, coeficiente de correlación lineal; F, estadístico de Fisher. HTA, hipertensión arterial; DM, diabetes mellitus; AL, anestésico local; ITB, índice tobillo-brazo; Obst, obstrucción; TAS, tensión arterial sistólica; min, minutos; TAD, tensión arterial diastólica; FC, frecuencia cardiaca 


\section{RESULTADOS}

Después de analizar las variables preoperatorias e intraoperatorias de los pacientes vasculares, se observó una correlación estadísticamente significativa $(\mathrm{p} \leq 0,05)$ entre la variación de la temperatura en el pie a lo largo de los 30 minutos de medición y la hipertensión arterial, el volumen de anestésico local, la frecuencia cardiaca basal y la frecuencia cardiaca a los 30 minutos (Tabla 38).

\subsection{ANÁLISIS MULTIVARIANTE: MODELO DE REGRESIÓN LOGÍSTICA (tabla 39)}

Después de realizar el análisis de correlación, los factores que resultaron estadísticamente signficativos (tabla 38), se incluyeron en un modelo de regresión logística. Se identificaron como factores independientes que influían en el incremento de la temperatura de los pies de los pacientes con arteriopatía periférica crónica, la HTA y el volumen de anestésico local.

Tabla 39: Análisis multivariante

\begin{tabular}{|c|c|c|}
\hline VARIABLE & OR $(95 \%$ IC $)$ & p valor \\
\hline Volumen AL & $0,70(0,21-1,19)$ & $\mathbf{0 , 0 0 6}$ \\
\hline HTA & $2,48(0,63-4,32)$ & $\mathbf{0 , 0 1}$ \\
\hline
\end{tabular}

OR, odds ratio; IC, intervalo de confianza; AL, anestésico local; HTA, hipertensión arterial 


\section{DISCUSIÓN}





\section{DISCUSIÓN}

Nuestro trabajo es un estudio prospectivo, de carácter descriptivo y comparativo, con la finalidad principal de conocer si existen diferencias en el comportamiento termocutáneo, secundario al bloqueo simpático epidural con bupivacaína al 0,5\% sin vasoconstrictor, entre personas sin enfermedad arterial periférica oclusiva crónica (controles) y personas con esta enfermedad (vasculares).

Los hallazgos más destacados fueron los siguientes:

1. La temperatura cutánea de los pies en los pacientes vasculares fue significativamente menor que la de los controles. Después de la anestesia epidural se produjo un incremento significativo de la temperatura cutánea de los pies, tanto en el grupo de control como en el de pacientes vasculares. En el resto de la extremidad (pantorrilla y muslo), la temperatura sólo aumentó en los pacientes sin enfermedad arterial periférica oclusiva crónica (grupo control).

2. En los pacientes vasculares no hubo diferencia significativa entre la temperatura cutánea de las extremidades (pie, pantorrilla y muslo) que iban a ser revascularizadas y las que no iban a ser intervenidas. Después de la anestesia epidural tampoco encontramos diferencias en los cambios térmicos de la piel entre los dos tipos de extremidades. 


\section{DISCUSIÓN}

3. Después de la anestesia epidural, hemos observado dos comportamientos termocutáneos distintos en los pies de los pacientes vasculares. En unos pies aumentó la temperatura de la piel y en otros no lo hizo, comportándose los dos pies de cada paciente de la misma forma. La temperatura cutánea basal de los pies que se calentaron fue significativamente menor que la de los que no lo hicieron.

4. La hipertensión arterial y el volumen de anestésico local, fueron factores independientes determinantes de la variación de la temperatura cutánea en los pies de los pacientes vasculares durante los 30 minutos de seguimiento.

5. Después de la anestesia epidural, en los pacientes vasculares se produjo un descenso significativo de la tensión arterial sistólica y diastólica. La frecuencia cardiaca disminuyó de forma significativa en los pacientes vasculares a los que se les calentaban los pies y no lo hizo en los pacientes vasculares a los que no se les calentaban los pies.

\subsection{CARACTERÍSTICAS DE LA MUESTRA}

La arteriopatía periférica oclusiva crónica es una enfermedad que se caracteriza por la obstrucción progresiva de las arterias, ocasionada generalmente por placas de ateroma, en el lecho de una aterosclerosis generalizada, que afecta fundamentalmente a las arterias de las extremidades inferiores (97). 


\section{DISCUSIÓN}

Suele comenzar en la juventud, siendo muy frecuente en la edad adulta, y habitualmente cursa de forma asintomática (13,21-23). Debido a esto, para asegurarnos la ausencia de la enfermedad en la muestra de pacientes representativa de la población sin enfermedad arterial periférica, elegimos a personas jóvenes, sin ninguna patología ni hábito tóxico. La muestra representativa de la población con enfermedad arterial periférica oclusiva crónica, la constituían personas en un estado avanzado de la enfermedad, pues estaban programadas para una cirugía de revascularización, mediante bypass, de una de sus extremidades. Por todos estos motivos es por lo que en nuestro trabajo, los controles tenían una edad significativamente inferior a los vasculares.

Los pacientes con arteriopatía periférica oclusiva sintomática precisan un cambio de hábitos de vida y con frecuencia tratamiento quirúrgico y/o médico, para tratar de disminuir la progresión de la enfermedad, sus síntomas y mejorar su calidad de vida (13). En este momento de la enfermedad, suelen ser pacientes con una gran cantidad de comorbilidad (insuficiencia respiratoria, coronariopatía, enfermedad cerebrovascular, insuficiencia renal), secundaria a la aterosclerosis generalizada y a la presencia de factores relacionados con el desarrollo de la enfermedad aterosclerótica (HTA, fumar, DM...) (13). González-Grosso y colaboradores (84) observaron que la HTA y ser fumador, fueron los antecedentes personales más frecuentes, en un estudio realizado en pacientes con arteriopatía periférica crónica, que precisaban tratamiento médicoquirúrgico para aumentar el flujo de sangre a sus extremidades inferiores. Estas características coinciden con las que observamos en nuestra muestra de pacientes vasculares. 


\section{DISCUSIÓN}

\subsection{CARACTERÍSTICAS DE LA ANESTESIA EPIDURAL}

Como ya hemos dicho, la anestesia epidural es una técnica de bloqueo regional o metamérico de la conducción nerviosa sensitiva (dolor/frío), simpática, propioceptiva y motora, mediante la inyección en el espacio epidural de anestésicos locales, a concentración y volumen adecuados, asociados en ocasiones a otros fármacos (opiáceos, clonidina, adrenalina, bicarbonato) (14). A mayor concentración y volumen del anestésico local, mayor intensidad y extensión del bloqueo nervioso respectivamente (17).

Existen dos familias de anestésicos locales: los aminoésteres y los aminoamidas. Los anestésicos locales de tipo amida, menos alergénicos, son los más utilizados en la práctica diaria. A este grupo pertenece la mepivacaína, la prilocaína, la lidocaína, la bupivacaína, la levobupivacaína y la ropivacaína (17). La bupivacaína al 0,5\% provoca un bloqueo intenso, es decir, anestésico; y es el fármaco que utilizamos en nuestro estudio. Ampliar el conocimiento sobre sus efectos debería ser de interés para cualquier profesional sanitario encargado del cuidado de pacientes a los que se les haya realizado una técnica de anestesia-analgesia regional o puedan beneficiarse de ella.

El volumen de bupivacaína que inyectamos en el espacio epidural en los pacientes vasculares, fue intencionada y significativamente menor que el que utilizamos en los controles; ya que teníamos la sospecha clínica que el 


\section{DISCUSIÓN}

bloqueo alcanzado por un mismo volumen de anestésico local, era más cefálico en las personas de edad avanzada que en los jóvenes. Este es un tema de controversia: Unos estudios defienden que la edad determina una extensión más cefálica del bloqueo después de una epidural lumbar (98-102), sin embargo, en otros no se demuestra que la edad influya en la extensión del bloqueo $(103,104)$. Nosotros observamos en este estudio, que a pesar de utilizar volúmenes de anestésico local más pequeños, obtuvimos, medido por pinprick, un bloqueo sensitivo más cefálico en los pacientes mayores. Pensamos que pudo ser debido, entre otras razones: 1) a una disminución de la pérdida de anestésico local a través de los agujeros interventebrales, que debían de estar más calcificados en las personas mayores (105-107), 2) a la disminución de tejido graso en el espacio epidural (108) y 3) a la estatura inferior de estos pacientes (103).

\subsection{CAMBIOS DE LA TEMPERATURA CUTÁNEA DESPUÉS DE REALIZAR UNA ANESTESIA EPIDURAL EN PERSONAS SIN Y CON ENFERMEDAD ARTERIAL PERIFÉRICA CRÓNICA}

La piel es un tejido que tiene la capacidad de aumentar y disminuir las pérdidas de calor al ambiente, mediante la dilatación o constricción de sus vasos, para mantener constante la temperatura central del organismo (72). La vascularización de la dermis está compuesta por arteriolas, capilares y vénulas que drenan en un amplio plexo venoso continuo situado en la hipodermis. En ciertas regiones del organismo muy expuestas al ambiente (manos, pies, nariz y orejas), las arteriolas aportan sangre directamente a ese plexo venoso continuo, conformando unas anastomosis arteriovenosas, que llamamos glomus (Figura 49). En el resto de regiones cutáneas del organismo, 


\section{DISCUSIÓN}

el aporte de sangre desde las arteriolas al plexo venoso se hace a través de un capilar y después una vénula (72).

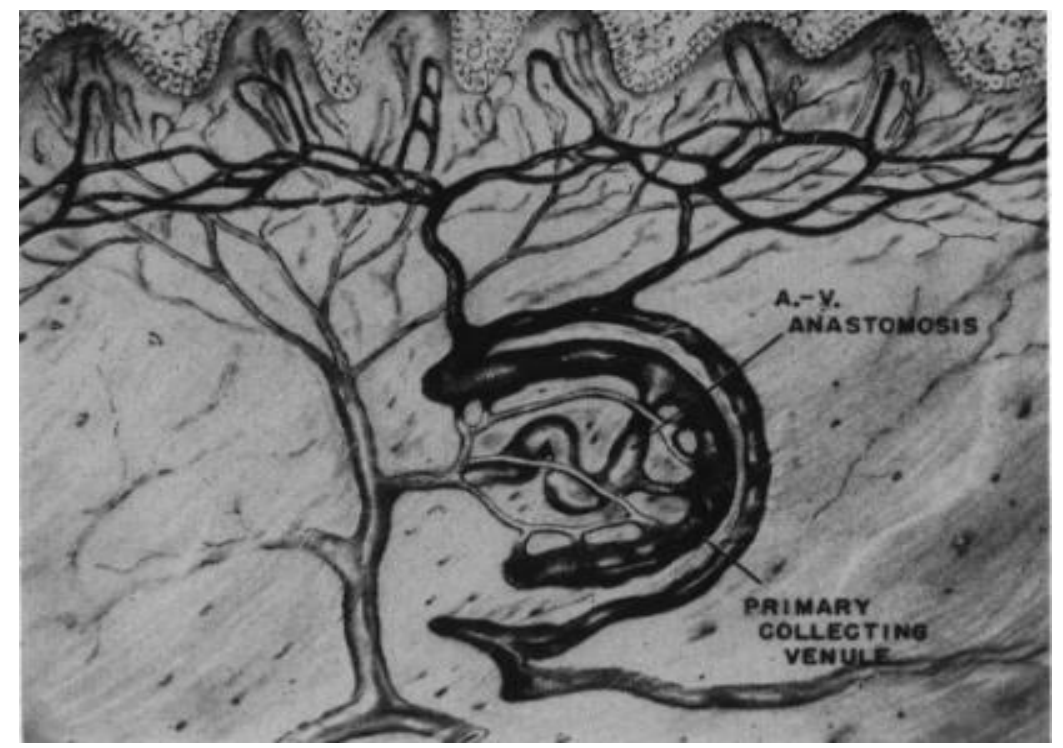

Figura 49: Glomus

Los glomus se consideran unas estructuras fundamentales para la regulación de la temperatura central del organismo. Están inervados exclusivamente por fibras nerviosas simpáticas. En situación basal, se encuentran en un estado de máxima vasoconstricción, pero cuando aumenta la temperatura central del organismo (fiebre, ejercicio...), o cuando se produce un bloqueo de sus fibras nerviosas, los glomus se dilatan, y la sangre que pasa por ellos puede llegar a suponer hasta el 30\% del gasto cardiaco, aumentando así la pérdida de calor al medio ambiente (72).

Por todos es conocido que uno de los efectos fisiológicos de la anestesia neuroaxial (epidural / intradural), es el bloqueo del sistema nervioso simpático, con la consiguiente vasodilatación arterial y venosa, que 


\section{DISCUSIÓN}

provoca un aumento del flujo sanguíneo y de la temperatura de una zona del cuerpo (17). Después de una anestesia epidural lumbar, esa vasodilatación se extiende al menos a la zona pélvica y a las extremidades inferiores (109).

Hay investigadores que, al igual que a nosotros, les ha preocupado la variación de la temperatura cutánea de las extremidades inferiores, secundaria al bloqueo simpático, producida por las técnicas de anestesia/analgesia locorregional (neuroaxial $(6,10,78,82,84,86,110)$, bloqueo de nervios periféricos $(10,110)$ ) o el bloqueo/extirpación de ganglios simpáticos lumbares $(6,111,112)$. Además, algunos de estos investigadores demostraron que, independientemente de la técnica utilizada para el bloqueo del sistema nervioso simpático $(6,10,113)$ o del anestésico local usado (mepivacaína, bupivacaína, ropivacaína...) (114), el comportamiento termocutáneo era similar.

\subsubsection{Comportamiento termocutáneo de las extremidades en personas sin enfermedad arterial periférica, durante los 30 minutos que siguieron a la inyección vía epidural de bupivacaína $0,5 \%$}

La mayor parte de los estudios, en los que se analizaron los efectos termocutáneos secundarios a un bloqueo simpático, en pacientes sin enfermedad arterial periférica u otra enfermedad cardiovascular $(6,10,78,86,110)$, incluyeron a personas con edades muy superiores a las de nuestro grupo de sanos. Ellos, al igual que nosotros, observaron un incremento de la temperatura en el pie; sin embargo, a diferencia de nosotros, en la pantorrilla y en el muslo no observaron un aumento de la temperatura $(6,78,110)$. Por su parte Werdehausen y colaboradores (110), realizaron un estudio sobre temperaturas cutáneas, medidas mediante 


\section{DISCUSIÓN}

termografía en 24 pacientes sin diagnóstico de arteriopatía periférica, después de realizarles un bloqueo simpático de las extremidades inferiores mediante una anestesia epidural, espinal o el bloqueo combinado del nervio femoral y ciático, con diferentes anestésicos locales (prilocaína 1\%, ropivacaína $0,75 \%$, bupivacaína $0,5 \%$ ). Observaron un aumento de la temperatura en el pie y en los trayectos que seguían las venas superficiales de la piel del resto de la extremidad. Aunque la edad de las personas integradas en este estudio (27-84 años) no era comparable con la de nuestro grupo control (17-24 años), nos hizo pensar que el aumento de temperatura en la pantorrilla y muslo, pequeño, pero significativo que observamos en nuestro grupo de pacientes sin enfermedad arterial periférica (pacientes control), pudiera haberse debido a una difusión del calor desde las venas dilatadas de la piel hacia la zona cutánea dónde realizamos las mediciones con el termómetro, aunque tratamos de evitar los lugares con vasos dilatados.

Otros autores hallaron comportamientos termocutáneos en la pantorrilla y el muslo distintos a los de Werdehausen y a los de nuestros pacientes sanos. Bengstsson (78), estudiando a 20 pacientes entre 49-79 años, sin signos de arteriopatía periférica u otra enfermedad cardiovascular, observó un descenso de la temperatura en la pierna y muslo después de realizarles una anestesia espinal con bupivacaína 0,5\%. También Frank y colaboradores (6), estudiando a 13 pacientes de $61 \pm 2$ años, con el mismo criterio de exclusión, observaron un descenso de la temperatura en el muslo, después de realizarles una epidural lumbar con bupivacaína al 0,25\%. Estos cambios en la temperatura de la pantorrilla y el muslo que observaron tanto Bengstsson como Frank y colaboradores se asemejan al que obtuvimos nosotros en nuestro grupo de pacientes vasculares. Pensamos que debido a 


\section{DISCUSIÓN}

la edad elevada de las personas estudiadas por estos autores, es probable que al menos parte de la muestra presentara una arteriopatía periférica oclusiva asintomática subyacente; que, como ya explicamos en el apartado 8.1. "Características de la muestra", es una enfermedad que suele comenzar en la juventud, aumenta su presencia a medida que avanza la edad y cursa generalmente de forma asintomática (13,21-23).

A lo largo de los 30 minutos que siguieron a la inyección de bupivacaína $0,5 \%$ vía epidural en el grupo de pacientes control de nuestro estudio, el incremento de temperatura que sufrieron los pies, fue muy superior al que experimentaron la pierna y el muslo. Pensamos que los glomus, situados en las regiones del organismo más expuestas (manos, pies, nariz, orejas), fueron los responsables de esa elevación de la temperatura, mucho más marcada en los pies.

\subsubsection{Comportamiento termocutáneo de las extremidades en personas con enfermedad arterial periférica, durante los 30 minutos que siguieron a la inyección de bupivacaína $0,5 \%$ vía epidural}

Encontramos pocos estudios que, posteriormente a la realización de una anestesia epidural, hayan investigado el comportamiento termocutáneo de las extremidades inferiores de personas con insuficiencia arterial periférica. González-Grosso y colaboradores (84) estudiaron una muestra 58 pacientes con edades comprendidas entre 30 y 60 años, con diagnóstico de insuficiencia arterial periférica y con dolor secundario a la enfermedad. Observaron un incremento significativo de la temperatura cutánea en el pie, pantorrilla y muslo, 30 minutos después de la inyección de un bolo de 


\section{DISCUSIÓN}

ropivacaína al 0,75\% vía epidural. Nosotros también observamos en nuestro grupo de pacientes vasculares (grupo $\mathrm{II}$ : $\mathrm{II}_{\mathrm{a}}$ y $\mathrm{II}_{\mathrm{b}}$ ), un aumento de la temperatura en el pie; sin embargo, en la pantorrilla y el muslo observamos un descenso significativo de la temperatura. Pensamos que esta diferencia en el comportamiento termocutáneo de la pantorrilla y el muslo, entre el trabajo de González-Grosso y el nuestro, podría deberse a una diferencia en la etiología de base que estaba provocando la insuficiencia arterial periférica, ya que la edad de la muestra del trabajo de González-Grosso era bastante inferior a la de nuestra muestra de pacientes vasculares.

Las placas de ateroma son la causa más frecuente de insuficiencia arterial periférica en personas de edad avanzada (13), sin embargo, cuando esta enfermedad se presenta en gente joven, con más frecuencia son otras etiologías las que ocasionan la enfermedad: Inflamación de los vasos, aumento de espasticidad arterial... como sucede en la enfermedad de Buerger y Raynaud respectivamente (13). Hoy en día, el alivio del dolor provocado por estas dos últimas enfermedades, son una de las pocas indicaciones bien establecidas de realizar un bloqueo del sistema nervioso simpático, ya que la respuesta suele ser buena $(55,111,115)$.

Pensamos que los glomus fueron los responsables de la elevación de la temperatura en sólo los pies de nuestros pacientes vasculares, debido a la capacidad que tienen estas anastomosis arteriovenosas, de aumentar de forma importante el flujo sanguíneo cuando se bloquean sus fibras simpáticas. El flujo sanguíneo por el resto de vasos de la extremidad podría no ser muy elevado como consecuencia de la rigidez y obstrucción vascular que estarían provocando las placas de ateroma, o incluso que el flujo 


\section{DISCUSIÓN}

sanguíneo pudiera estar siendo "robado" por los glomus, debido a su gran capacidad de vasodilatación (2).

\subsubsection{Comportamiento termocutáneo de las regiones cefálicas del cuerpo, durante los 30 minutos que siguieron a la inyección vía epidural de bupivacaína $0,5 \%$}

Cuando el nivel de bloqueo no alcanza las fibras simpáticas por encima de la metámera $\mathrm{T} 4$, uno de los efectos fisiológicos de la anestesia neuroaxial (epidural/intradural), es la vasoconstricción de las extremidades superiores modulada por barorreceptores, ante la disminución del retorno venoso como consecuencia de la vasodilatación arterial y venosa de las zonas con bloqueo simpático: es lo que llamamos, vasoconstricción compensadora. Su objetivo es tratar de mantener las presiones de perfusión de los órganos vitales (17).

Sato y colaboradores (82), en una muestra de 62 pacientes de $44.4 \pm 14,7$ años, después de realizar una anestesia epidural lumbar con lidocaína 1,5\% y alcanzar un nivel de bloqueo sensitivo inferior a la metámera T4, observaron un aumento de la temperatura en el dedo gordo del pie y un descenso significativo de la temperatura en la mano a los 5 y 15 minutos respectivamente de realizar la técnica anestésica. Este descenso de la temperatura cutánea de la mano, la relacionaban con una vasoconstricción compensadora de las zonas del organismo sin bloqueo simpático.

Nosotros, y sólo en los pacientes vasculares, hemos observado una disminución de la temperatura en el pezón, aunque la media del nivel de 


\section{DISCUSIÓN}

bloqueo sensitivo alcanzado, tanto en sanos como en vasculares, fue inferior a la metámera T4. Pensamos que esta disminución de la temperatura, exclusivamente en los pacientes con arteriopatía periférica oclusiva crónica, pudo deberse a que los pacientes vasculares precisaron una vasoconstricción más intensa de las zonas sin bloqueo simpático, ya que es probable tuvieran un volumen intravascular menor que los pacientes del grupo control. La edad avanzada y la arteriopatía periférica, con frecuencia se pueden asociar a deshidratación, rigidez arterial, HTA, insuficiencia cardiaca...., que es frecuente provoquen una disminución en el volumen intravascular (13). Si bien, no podemos afirmar con certeza, qué fibras simpáticas estaban bloqueadas en los distintos grupos de pacientes.

\subsection{FACTORES QUE INFLUYERON EN LOS CAMBIOS DE LA TEMPERATURA CUTÁNEA DE LAS EXTREMIDADES INFERIORES, DE PERSONAS CON ENFERMEDAD ARTERIAL PERIFÉRICA OCLUSIVA CRÓNICA, DESPUÉS DE UNA ANESTESIA EPIDURAL LUMBAR}

Casi todos los trabajos consultados sobre el comportamiento termocutáneo de las extremidades inferiores después de realizar una anestesia neuroaxial en personas con y sin diagnóstico de arteriopatía periférica, no refirieron ningún comportamiento termocutáneo distinto dentro de cada grupo, en los que se habían dividido las muestras $(6,10,84,86,110)$.

Sin embargo, cuando nosotros analizamos los cambios térmicos de la piel de los pacientes vasculares, observamos dos comportamientos 


\section{DISCUSIÓN}

termocutáneos distintos en los pies, durante los 30 minutos que siguieron a la inyección del anestésico local vía epidural lumbar. En unos pacientes sus dos pies se calentaron de forma importante $\left(>1,5^{\circ} \mathrm{C}\right.$ ) (grupo $\mathrm{II}_{\mathrm{R}+}$ ) y en otros, sus dos pies no experimentaron prácticamente variación de la temperatura cutánea (grupo $\mathrm{II}_{\mathrm{R}-}$ ).

Bengstsson (78), observó también en una muestra de veinte pacientes entre 49-79 años, sin diagnóstico de enfermedad cardiovascular, que a los 30 minutos de la inyección de bupivacaína $0,5 \%$ vía espinal, se calentaron los pies de todos los pacientes, excepto de dos. En relación con el estudio de este autor, ya hemos comentado en el apartado 8.3.1 "Comportamiento termocutáneo de las extremidades en personas sin enfermedad arterial periférica", que teníamos la sospecha, por la edad de las personas que integraban la muestra, y por el comportamiento termocutáneo de la pantorrilla y el muslo de sus pacientes después de una anestesia espinal, que parte de la muestra al menos, es probable tuviera una arteriopatía periférica asintomática. Pues otro motivo más para pensarlo, es este hallazgo de los dos pacientes a los que no se les calentaron los pies.

Después de observar esos dos comportamientos termocutáneos distintos en los pies de nuestros pacientes vasculares (grupo $\mathrm{II}_{R_{+}} \mathrm{y} \mathrm{II}_{\mathrm{R}_{-}}$), y de realizar un análisis de correlación y posteriormente, una regresión logística con los resultados que nos habían salido significativos en el primer análisis, identificamos la HTA y el mayor volumen de anestésico local, como factores independientes que influían en el incremento de la temperatura cutánea de los pies de los pacientes vasculares. 


\section{DISCUSIÓN}

Se ha dicho que la HTA es, después del consumo de cigarrillos y de la diabetes, el factor más importante relacionado con una mayor probabilidad de desarrollar una arteriopatía periférica oclusiva crónica (20). Pues bien, en los pacientes con arteriopatía periférica oclusiva crónica de nuestro estudio, no hemos observado diferencia en la prevalencia y años con diabetes, y en la prevalencia y años fumando, entre el grupo al que se le calentaban los pies (grupo $\mathrm{II}_{\mathrm{R}+}$ ) y al que no se le calentaban (grupo $\mathrm{II}_{\mathrm{R}-\text {-). }}$ Sin embargo, se observó que la prevalencia de hipertensos era significativamente mayor en el grupo $\mathrm{II}_{\mathrm{R} \text {. }}$ Esto podría haber provocado un adelanto en la formación de placas de ateroma en las arterias de los pacientes del grupo $\mathrm{II}_{\mathrm{R}-}$, o sea de la enfermedad, y presentar en el momento del estudio 1) una extensión y grado de severidad mayor de la arteriopatía, 2) una vasodilatación máxima compensadora de las arterias de las extremidades inferiores, incluidos los glomus (2) y/o 3) una isquemia de los nervios simpáticos de las mismas.

Aunque no hubo diferencias significativas en el índice tobillo-brazo entre los vasculares a los que se les calentaban los pies (grupo $\mathrm{II}_{\mathrm{R}+}$ ) y a los que no se les calentaban (grupo $\mathrm{II}_{\mathrm{R}-\text { ), }}$ se observó que la prevalencia de ausencia de flujo, medido por doppler a distintos niveles arteriales de las extremidades inferiores, fue mayor en el grupo $\mathrm{II}_{\mathrm{R} \text {-, }}$ siendo significativa esa diferencia únicamente en la arteria tibial anterior. Esto apoya nuestra opinión de la probable existencia de una enfermedad arterial periférica oclusiva más extensa y con un grado de severidad mayor, en el grupo $\mathrm{II}_{\mathrm{R}}$ que en el $\mathrm{II}_{\mathrm{R}+}$.

La vasodilatación arterial compensadora de las extremidades inferiores, que en ocasiones sucece en la enfermedad arterial periférica con 


\section{DISCUSIÓN}

el objetivo de facilitar el flujo sanguíneo(2), en el grupo $\mathrm{II}_{\mathrm{R}-\text { pudo verse }}$ incrementada, gracias al más probable consumo de medicación antihipertensiva con acción vasodilatadora directa o indirecta (calcio antagonistas, inhibidores de la enzima convertidora de la angiotensina, alfa bloqueantes, nitroglicerina, betabloqueantes), ya que había una mayor cantidad de personas diagnosticadas y probablemente tratadas de hipertensas.

Todo esto ha podido hacer que el bloqueo simpático secundario a la inyección de la bupivacaína en el espacio epidural lumbar, no fuera capaz de provocar una mayor vasodilatación arterial en las extremidades inferiores de los pacientes del grupo $\mathrm{II}_{\mathrm{R}-\mathrm{y}} \mathrm{y}$ aumentar por tanto su temperatura cutánea. Incluso podría haberse producido un robo de sangre desde las arterias estenóticas de las extremidades inferiores, hacia zonas inferiores del tronco, lo más probable vasodilatado también por el bloqueo simpático epidural (2).

La inyección de una cantidad mayor de anestésico local también se identificó como factor independiente que influía en el incremento de la temperatura cutánea de los pies de los pacientes vasculares, después de una epidural lumbar con bupivacaína al 0,5\%.

Los pacientes del grupo $\mathrm{II}_{\mathrm{R}+}$ eran más jóvenes y con menor comorbilidad acompañante que los del grupo $\mathrm{II}_{\mathrm{R} \text {.. }}$ Lo más probable es que a simple vista, tuvieran un mejor estado general, y por tanto nuestro miedo a una excesiva extensión cefálica del bloqueo, sobre todo del bloqueo simpático con hipotensión importante, disminuyera, y por ello utilizáramos mayores cantidades de anestésico local. Sin embargo la extensión del bloqueo sensitivo medido por pinprick no fue más cefálico en el grupo $\mathrm{II}_{\mathrm{R}+}$ que en el $\mathrm{II}_{\mathrm{R}-\text {. }}$ 


\section{DISCUSIÓN}

\subsection{CAMBIOS HEMODINÁMICOS EN LAS PERSONAS CON ENFERMEDAD ARTERIAL PERIFÉRICA OCLUSIVA CRÓNICA, DESPUÉS DE UNA ANESTESIA EPIDURAL LUMBAR}

Uno de los efectos fisiológicos de la anestesia neuroaxial (epidural/intradural), secundario al bloqueo de fibras nerviosas simpáticas preganglionares, es la afectación del sistema cardiovascular, provocando hipotensión arterial y bradicardia o taquicardia (17). Esta variación de la tensión arterial y de la frecuencia cardiaca va a estar condicionada por la extensión del bloqueo, la integridad y el estado basal del sistema nervioso simpático, así como por el volumen sanguíneo y la función cardiovascular del paciente (109). La hipotensión arterial se produce por vasodilatación arterial y venosa, ocasionando una disminución de las resistencias vasculares sistémicas y del retorno venoso. La bradicardia puede suceder por dos motivos: 1) Por la interrupción de las fibras simpáticas cardiacas, cuando el nivel de bloqueo alcanza la metámera T4 (17,100,109,116) y/o, lo que es más frecuente, 2) por un reflejo vagal protector cardiaco (reflejo de Bezold-Jarisch), iniciado por mecanorreceptores del ventrículo izquierdo, en respuesta a una disminución del retorno venoso y por tanto del volumen telesistólico. Este reflejo provoca una disminución de la frecuencia cardiaca, con el objetivo de alargar el tiempo de llenado del corazón $(17,18)$. Cuando el nivel de bloqueo no alcanza la metémera T4, sucede una activación de las fibras simpáticas cardiacas (taquicardia) y una vasoconstricción de las extremidades superiores modulado por barorreceptores (17). 


\section{DISCUSIÓN}

Lundin y colaboradores (117), en un grupo de nueve personas voluntarias sanas entre 24-35 años, a los 30 minutos de la inyección de mepivacaína $2 \%$ vía epidural, y habiendo alcanzado un nivel de bloqueo sensitivo (pinprick) entre la metámera T4-8, observaron un aumento del flujo sanguíneo en los pies medido por laser Doppler, un descenso significativo de la tensión arterial sistólica, un descenso no significativo de la tensión arterial diastólica y un aumento, tampoco significativo, de la frecuencia cardiaca. También Ginosar y colaboradores (86), en 60 pacientes programados para litotricia con edades entre 33-67 años, y sin antecedentes de arteriopatía periférica, observaron a los 20 minutos de la inyección de bupivacaína $(0,5 \%, 0,25 \%, 0,0625 \%)$ vía epidural, después de haber alcanzado un nivel de bloqueo sensitivo (pinprick) entre la metámera T9T11, un aumento significativo de la temperatura en el dedo gordo del pie en aquellos pacientes a los que se les había administrado bupivacaína 0,5\% y $0,25 \%$, y un descenso significativo de la tensión arterial media en todos los pacientes.

Todo lo anteriormente expuesto es el comportamiento habitual después de un bloqueo simpático en pacientes sanos; pero en situaciones patológicas, como es la arteriopatía periférica crónica, hay quien dice, y hemos comprobado nosotros de forma indirecta mediante termometría, que el bloqueo simpático tiene efectos impredecibles sobre las arterias de las extremidades inferiores (2). Pensamos que esos comportamientos termocutáneos diferenciados de los pies en los pacientes vasculares, secundarios a una epidural lumbar, podría tener una repercusión distinta sobre el sistema cardiovascular. 


\section{DISCUSIÓN}

En nuestro grupo de pacientes vasculares observamos, a los 30 minutos de la inyección de la bupivacaína $0,5 \%$ vía epidural, un descenso significativo de la tensión arterial sistólica y diastólica. No vimos diferencias significativas en el decremento de la tensión arterial sistólica y diastólica entre el grupo cuyos pies se calentaban (grupo $\mathrm{II}_{\mathrm{R}+}$ ) y aquel otro

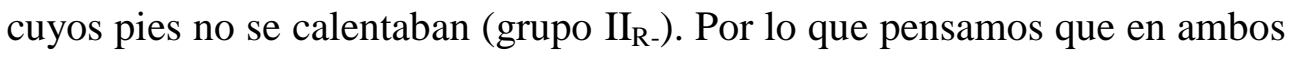
grupos debía de estar sucediendo una vasodilatación vascular, secundaria al bloqueo simpático por la técnica epidural, aunque sin saber qué zona del cuerpo era la más vasodilatada.

Creemos que este descenso de la tensión arterial observada en los pacientes vasculares, podría haber condicionado el comportamiento termocutáneo de sus extremidades inferiores, ya que la probabilidad de atravesar la sangre una zona estenótica, disminuirá con un descenso de la presión arterial, y podría estar sucediendo un robo de sangre desde zonas ocluídas hacia otras con un nivel de oclusión menor (2).

Nosotros también observamos en el conjunto de los pacientes vasculares (grupo II), un descenso significativo de la frecuencia cardiaca en los 30 minutos que seguían a la inyección del anestésico local vía epidural. Pero analizando más detenidamente el grupo de pacientes con arteriopatía periférica, advertimos que aquellos pacientes cuyos pies se calentaban después de la técnica epidural (grupo $\mathrm{II}_{\mathrm{R}+}$ ) tenían unas frecuencias, en todo momento, significativamente menores que las de los pacientes cuyos pies no se calentaban (grupo $\mathrm{II}_{\mathrm{R}-\text { ) }}$; y además, era únicamente en ese grupo (grupo $\mathrm{II}_{\mathrm{R}+}$ ) donde se observaba un descenso significativo de la frecuencia cardiaca en los 30 minutos posteriores a la inyección de la bupivacaína 0,5\% vía epidural. 


\section{DISCUSIÓN}

Pensamos que las frecuencias cardiacas más bajas del grupo $\mathrm{II}_{\mathrm{R}+}$, podrían haberse debido a varios motivos:

1. El probable consumo más frecuente de fármacos antihipertensivos

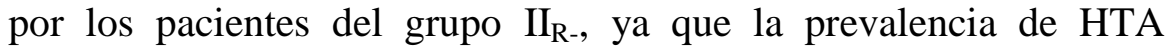
diagnosticada en este grupo era mayor. Los beta bloqueantes son el grupo de antihipertensivos más frecuentemente utilizados para el tratamiento de la HTA, y que además han demostrado una disminución en la mortalidad de causa cardiaca (13). Pero debido al popular efecto perjudicial, aunque no documentado, que han tenido durante mucho tiempo sobre la circulación de las extremidades de los pacientes con arteriopatía periférica (20), es habitual que el tratamiento de la HTA de este tipo de pacientes se haga con otro tipo de antihipertensivos, (calcio antagonistas, inhibidores de la enzima convertidora de la angiotensina, alfa bloqueantes, nitroglicerina), que, entre sus efectos secundarios y/o adversos, tienen un aumento de la frecuencia cardiaca.

2. Una presencia mayor de cardiopatía (arritmias, insuficiencia cardiaca...) en el grupo $\mathrm{II}_{\mathrm{R}-\text {, }}$ como consecuencia de una hipertensión arterial más prevalente $\mathrm{y}$, de una hipotética enfermedad aterosclerótica de más larga duración en este grupo, pudiendo estar las coronarias más afectadas que en el grupo $\mathrm{II}_{\mathrm{R}+}$ ¿ ¿Tendrán los pacientes del grupo $\mathrm{II}_{\mathrm{R}-}$ con más frecuencia eventos coronarios isquémicos que los del grupo $\mathrm{II}_{\mathrm{R}+}$ ? 


\section{DISCUSIÓN}

El descenso significativo de la frecuencia cardiaca, exclusivamente en el grupo $\mathrm{II}_{\mathrm{R}+}$, pensamos que pudo ser debido a una extensión ligeramente más cefálica del anestésico local, debido al uso de mayores cantidades de este, con bloqueo de fibras nerviosas simpáticas cardiacas y un reflejo de Bezold Jarisch mayor; aunque, no se observa diferencia en las medias de los niveles metaméricos de bloqueo sensitivo alcanzado entre grupos, ni en el decremento de la temperatura en el pezón, ni de la tensión arterial, que nos haga pensar que el área de bloqueo simpático sea mayor.

\subsection{CONSIDERACIONES A NUESTRO ESTUDIO Y FUTUROS TRABAJOS}

Toda línea de investigación en cualquier área de conocimiento es de suyo abierta. Teniendo esto en cuenta, creemos que habría que considerar en futuras investigaciones los siguientes aspectos:

\subsubsection{La muestra de la población de estudio}

Dos aspectos pensamos se deben tener en cuenta:

1. El tamaño de la muestra elegida para nuestro estudio fue suficiente para detectar, después de una anestesia epidural, una diferencia en el comportamiento termocutáneo de las extremidades inferiores entre pacientes con y sin arteriopatía periférica crónica. Pero sería necesario un mayor tamaño de la muestra vascular, para que el análisis de correlación y posterior regresión logística que determinan 


\section{DISCUSIÓN}

las variables que condicionan uno otro comportamiento termocutáneo en las extremidades de los pacientes vasculares, sean más fiables.

2. Nuestro trabajo se ha realizado en un solo centro. Pensamos, sin embargo, que un estudio multicéntrico podría hacer que los datos que obtuviéramos fueran más fiables a la hora de extrapolarlos al resto de la población vascular; ya que las actuaciones perioperatorias propias de cada centro (el momento de selección de los pacientes para realizar una cirugía revascularizadora, la indicación de un tipo u otro de intervención quirúrgica, el manejo del paciente durante el perioperatorio, etc.) podrían ser factores que influyeran en el comportamiento termocutáneo de las extremidades de los pacientes con arteriopatía periférica crónica.

\subsubsection{Material utilizado para detectar un aumento de flujo sanguíneo a una zona del cuerpo}

Después de una anestesia neuroaxial (epidural/intradural), es frecuente que los pacientes se queden hipotérmicos. Debido al bloqueo simpático, se produce una vasodilatación cutánea y una pérdida del mecanismo vasoconstrictor cutáneo termorregulador normal del organismo. Sucede una redistribución del calor del compartimento central del cuerpo (vísceras, músculos...) al periférico (piel), que está vasodilatado, y de éste al ambiente (17,72). Cuanto más flujo sanguíneo haya en las zonas vasodilatadas, mayor será la pérdida de calor. Esta pérdida de calor se produce fundamentalmente $(60 \%)$ en forma de rayos de calor infrarrojos, que salen en todas las direcciones (72). Por este motivo, la elevación de la 


\section{DISCUSIÓN}

temperatura cutánea se considera un indicador indirecto de aumento del flujo sanguíneo cutáneo y de bloqueo simpático $(10,117,118)$. Es un método no invasivo, sencillo y barato (119). Se realiza generalmente mediante cámaras de termografía $(9,11,78,110,120,121)$, termómetros cutáneos de contacto $(6,79,82,84,86,111,112)$ o, como nosotros, mediante termómetros de absorción de radiación infrarroja $(10,122,123)$.

El problema que vemos en este método de medición del flujo sanguíneo y de la actividad del sistema nervioso simpático, es que nos ofrece información exclusivamente de la piel y no podemos saber qué está sucediendo en vasos más profundos. Podría ser que la piel no estuviera vasodilatada y sin embargo existiera un aumento de flujo sanguíneo en los vasos que irrigan los músculos o las vísceras. En los pacientes vasculares del grupo $\mathrm{II}_{\mathrm{R}-}$ de nuestro estudio, no se observó una elevación de la temperatura en ninguno de los lugares de medición (pie, pantorrilla, muslo, ombligo y pezón), pero suponemos que estaba sucediendo una vasodilatación a algún nivel, ya que observamos un descenso de la tensión arterial a lo largo de los 30 minutos posteriores a la inyección de la bupivacaína $0,5 \%$ vía epidural.

Además, al ser un método indirecto de información sobre el flujo sanguíneo y el sistema nervioso simpático, podría suceder también, que el aumento de la temperatura fuera por acúmulo de sangre en el lecho venoso y no por vasodilatación arterial, y entonces no estuviera existiendo un aumento del aporte de oxígeno y nutrientes a través de la sangre, que es lo que realmente nos interesaría comprobar en estos pacientes. 


\section{DISCUSIÓN}

Por tanto, sería interesante utilizar, a parte del termómetro cutáneo, sistemas que aporten información directa sobre el flujo sanguíneo no sólo de la piel, sino también de tejidos más profundos (ej. Doppler), y sobre el estado del sistema nervioso simpático (ej. microneurografia). Así, podríamos comprobar si la medición de la temperatura cutánea, que es un método más sencillo y no invasivo, puede orientar realmente o no sobre la irrigación sanguínea de las distintas partes del cuerpo, y sobre el estado del sistema nervioso simpático. Esto podría ser útil, ya que la medición de la temperatura cutánea de los pies en los pacientes vasculares, podría orientarnos sobre qué pacientes podrían beneficiarse de la realización de una simpatectomía química/quírúrgica para la curación de úlceras en el pie, como consecuencia de un aumento del flujo sanguíneo a éste.

\subsubsection{Tiempo de seguimiento de la muestra}

El tiempo de seguimiento de los pacientes de nuestro estudio fue durante los 30 minutos que seguían a la inyección de bupivacaína $0,5 \%$ vía epidural.

El comienzo del bloqueo nervioso de una anestesia epidural depende del anestésico local utilizado. Así, el inicio del bloqueo es más corto cuando se inyecta lidocaína (5-15min), y más largo cuando se inyecta bupivacaína (15-20 min) (ver apartado 2.7. "Determinantes del inicio, duración e intensidad del bloqueo epidural”). Además, el inicio de esta supresión nerviosa sucede antes en las fibras más finas, como las sensitivas y simpáticas, que en las motoras, de grosor mayor (17). A los 30 minutos de la inyección en bolo del anestésico local vía epidural, incluso con los anestésicos locales de comienzo de acción más tardío, el bloqueo epidural se 


\section{DISCUSIÓN}

considera ya completo (sensitivo, simpático, propioceptivo y motor) $(6,10,46,79,84,87,112,117)$.

Pero es en esos 30 minutos cuando también coincide el descenso de la tensión arterial. Sería pues interesante, para poder determinar la utilidad de una simpatectomía definitiva, observar el comportamiento termocutáneo de las extremidades inferiores de los pacientes vasculares durante más de 30 minutos, y así permitir que la tensión arterial haya recuperado sus valores iniciales mediante relleno vascular, sin usar vasoconstrictores.

También sería interesante, después de la revascularización de las extremidades inferiores mediante un bypass, comprobar la evolución de aquellos pacientes vasculares cuyos pies se calentaron con la epidural lumbar (grupo $\mathrm{II}_{\mathrm{R}_{+}}$), y de aquellos cuyos pies no se calentaron (grupo $\mathrm{II}_{\mathrm{R}_{-}}$). ¿Se comportarán ambos grupos en el postoperatorio como los pacientes sanos, utilizando la inyección de anestésicos locales vía epidural como técnica analgésica? o ¿Terminarán con más frecuencia y a pesar del bypass,

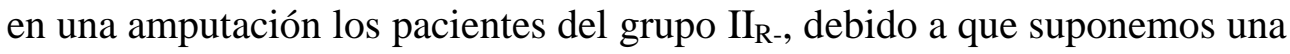
enfermedad aterosclerótica más generalizada? Conocer esto es de capital importancia, pues podría condicionar una u otra actuación médica. 


\section{DISCUSIÓN}

\subsection{APLICACIÓN CLÍNICA DE NUESTROS RESULTADOS}

\subsubsection{Para confirmar el establecimiento efectivo y la extensión del bloqueo anestésico epidural}

Después de realizar la anestesia epidural y antes de comenzar la cirugía, es recomendable comprobar que la técnica se ha realizado con éxito, y que la extensión del bloqueo sensitivo cubre toda la zona quirúrgica; ya que de no ser así, habría que repetir la técnica epidural o realizar otro procedimiento anestésico: bloqueo de nervios periféricos o anestesia general (17). En la práctica clínica, esta comprobación se hace habitualmente mediante la observación de la pérdida de sensibilidad a objetos punzantes (pinprick) o a objetos fríos (cubito de hielo), y mediante la incapacidad de movimiento de las extremidades inferiores a petición nuestra (escala de Bromage) (17). Pero esta forma de comprobar el éxito y extensión de esta técnica anestésica, puede resultar dificultosa en personas poco colaboradoras (discapacitados, demencias, personas de edad muy avanzada o muy temprana) o cuando el paciente esté sometido a una anestesia general.

Hay quien postula la medición de la temperatura cutánea en las zonas distales de los miembros bloqueados (dedo gordo del pie), como una medida más objetiva (10) y precoz del establecimiento efectivo de un bloqueo anestésico epidural $(10,11)$. También la medición de la temperatura cutánea en las regiones distales de los miembros, se considera como un buen método para creer efectivo o fallido el bloqueo de nervios periféricos (10), y el 


\section{DISCUSIÓN}

bloqueo aislado del sistema nervioso simpático que inerve esas áreas distales $(112,124,125)$.

Nosotros pensamos que la elevación de la temperatura cutánea en el pie, como método único para determinar el establecimiento efectivo o fallido del bloqueo epidural, puede ser válido exclusivamente en personas jóvenes sin comorbilidad.

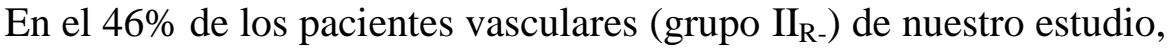
la temperatura de los pies no se elevó durante los 30 minutos que siguieron a la inyección del bolo de bupivacaína $0.5 \%$ vía epidural, y sin embargo la cirugía se realizó con éxito, sin precisar ninguna otra técnica anestésica. Pensamos por tanto, que la medición de la temperatura cutánea en los pies no es un método válido para determinar el éxito o fracaso de un bloqueo epidural en los pacientes con arteriopatía periférica crónica.

El bloqueo diferencial que parece se produce después de una anestesia neuroaxial, también ha despertado interés desde hace muchos años. Ya habló Greene (126) en 1958 de un nivel de bloqueo sensitivo al dolor y al frío diferenciado, después de una anestesia intradural; posteriormente vuelve a demostrarlo junto con Brull (8), después de una anestesia epidural. Bengstsson (78) por otro lado mostró que en la anestesia intradural, el nivel metamérico de bloqueo simpático que se alcanzaba y determinaba mediante laser Doppler y cámaras de termografía, era más caudal que el nivel de bloqueo sensitivo determinado por pinprick. Chamberlain y colaboradores (9), sin embargo, demostraron un nivel de bloqueo simpático 6-7 metámeras más cefálico que el nivel de bloqueo sensitivo al dolor alcanzado después de una anestesia intradural. 


\section{DISCUSIÓN}

Si consideramos entonces la temperatura cutánea como indicador indirecto del bloqueo simpático de una zona, observamos en nuestro grupo control una altura metamérica de bloqueo sensitivo, determinado por pinprick, más cefálica que la altura metamérica de bloqueo simpático: T7 vs L4 ó al menos más caudal que T10, ya que esa es la altura que se corresponde con el ombligo que no se calentó. En los pacientes vasculares, sólo se calentaron los pies, o no se calentó ninguna zona del organismo, y alcanzaron niveles de bloqueo sensitivo (pinprick) unas dos metámeras más cefálicas que los que alcanzaron los sanos. Pensamos que en todos los pacientes vasculares estaba sucediendo también un bloqueo simpático, ya que sufrieron un descenso significativo de la tensión arterial, que se considera otro signo indirecto de simpatectomía (86). Por todo esto podemos afirmar que, al menos, en las personas con arteriopatía periférica crónica, la medición de la temperatura cutánea mediante un termómetro que capta radiación infrarroja, no es un buen método para poder calcular la extensión del bloqueo sensitivo.

\subsubsection{Para prever la utilidad de una simpatectomía definitiva en personas con arteriopatía periférica crónica}

El bloqueo simpático se utiliza en el tratamiento de la arteriopatía periférica de causa obstructiva aterosclerótica (7). Durante muchos años fue la única alternativa a la amputación, sin embargo actualmente, con la mejora de las técnicas quirúrgicas, la realización de bloqueos simpáticos en el tratamiento de esta patología está casi relegada a los casos de isquemia crónica crítica, en los que las técnicas de revascularización pueden estar contraindicadas (pacientes de alto riesgo quirúrgico-anestésico o por la 


\section{DISCUSIÓN}

extensión de la lesión), y también para el tratamiento de úlceras cutáneas de fondo isquémico, rebeldes y extensas $(7,47)$. Según la revisión realizada por Ruiz Aragón y colaboradores (7), los resultados de mejoría clínica a los que han llegado trabajos que evalúan la efectividad de realizar simpatectomías quirúrgicas/químicas, frente a no hacer nada son contradictorios: unos observan una mejoría $(127,128)$ y otros no $(129,130)$. Nosotros después de realizar este trabajo, y teniendo en cuenta la temperatura como un indicador indirecto de aumento del flujo sanguíneo en la piel, pensamos que la simpatectomía podría ser útil, al menos para la curación de úlceras cutáneas de origen isquémico de los pies que se calentaron después de la anestesia epidural (grupo $\mathrm{II}_{\mathrm{R}_{+}}$). En el resto de localizaciones, observamos un descenso de la temperatura. Por ello pensamos que una simpatectomía para la curación de úlceras cutáneas en esas otras zonas, podría ser perjudicial, por causa de una disminución del flujo sanguíneo a la piel de esas mismas zonas. No podemos suponer nada en las úlceras que se extiendan a planos más profundos (músculo), o en las úlceras cutáneas de los pies que no se calentaron después de la epidural lumbar con bupivacaína 0,5\% (grupo $\mathrm{II}_{\mathrm{R}-\text { ) }}$, ya que la temperatura sólo nos da información indirecta del flujo sanguíneo cutáneo.

Posteriores estudios serían necesarios para averiguar qué sucede en los pacientes cuyos pies se calientan, y en aquellos cuyos pies no se calientan, en cuanto a la curación de úlceras cutáneas o en cuanto al aumento del riego sanguíneo a las extremidades en general, secundario a un bloqueo simpático. 
DISCUSIÓN 

9 CONCLUSIONES 



\section{CONCLUSIONES}

Después de una anestesia epidural lumbar con bupivacaína al 0,5\% sin vasoconstrictor y de haber alcanzado un nivel de bloqueo sensitivo más cefálico que el ombligo (T10) sucede lo siguiente:

1. Los cambios térmicos de la piel en personas sin arteriopatía periférica oclusiva crónica son distintos que en personas con esta enfermedad.

2. En personas jóvenes sin arteriopatía periférica oclusiva crónica, la piel de las extremidades inferiores sufre un incremento de su temperatura, siendo el pie dónde más se eleva la temperatura cutánea.

3. En personas con arteriopatía periférica oclusiva crónica, la piel de los pies se comporta de dos maneras distintas en relación con la temperatura: en unas personas los pies sufren un incremento de su temperatura cutánea, y en otras no. La piel del resto de la extremidad (pantorrilla y muslo) sufre un descenso de la temperatura.

4. En personas con arteriopatía periférica oclusiva crónica, no existen diferencias entre el comportamiento termocutáneo de las extremidades pendientes de ser revascularizadas inmediatamente, y las que no.

5. La hipertensión arterial y el mayor volumen de anestésico local muestran tendencia a ser factores independientes que influyen en el aumento de la temperatura cutánea de los pies de las personas con arteriopatía periférica oclusiva crónica. Pero son necesarios nuevos 


\section{CONCLUSIONES}

estudios que cuenten con un tamaño muestral mayor de la población vascular

6. En personas con arteriopatía periférica crónica, la tensión arterial sistólica y diastólica desciende de forma significativa, y la frecuencia cardiaca sólo desciende de forma significativa en los vasculares que se les calientan los pies. 


\section{BIBLIOGRAFÍA}



1. Caba F. ¿Se debe mantener la analgesia epidural como técnica de base en la UDA? Rev Soc Esp Dolor 2010;17(4):206-12

2. Löfström JB, Lloyd JW, Cousins MJ. Sympathetic neural blockade of upper and lower extremity. En: Cousins MJ, Bridenbaugh PO, (eds). Neural Blockade in Clinical Anesthesia and Management of Pain. $1^{\text {a }}$ ed. Piladelphia: Lippincott Company; 1980. p. 355-82

3. Cousins MJ. Epidural Neural Blockade. En: Cousins MJ, Breidenbaugh PO, (eds). Neural blockade in clinical anesthesia and management of pain. $1^{a}$ ed. Philadelphia: Lippincott Company; 1980. p. $176-275$

4. Covino BG, Scout DB. Consideraciones fisiológicas. En: Covino BG, Scout DB, (eds). Manual de analgesia y anestesia epidurales. $1^{\mathrm{a}} \mathrm{ed}$. Barcelona: Salvat; 1988. p. 35-55

5. Yeste-Campos M, Escudero Rodríguez JR, Dilmé Muñoz JF, Barreiro Veiguela J, Sánchez I. Tratamientos alternativos en isquemia crítica. Angiología 2003;55 supl 1:100-11

6. Frank SM, El-Rahmany HK, Tran KM, Vu B, Raja SN. Comparison of lower extremity cutaneous temperature changes in patients receiving lumbar sympathetic ganglion blocks versus epidural anesthesia. J Clin Anesth 2000;12:525-30

7. Ruiz-Aragón J, Márquez Calderón S. Efectividad de la simpatectomía lumbar en el tratamiento de la arteriopatía periférica oclusiva de miembros inferiores: revisión sistemática. Med Clin (Barc) 2010;134(11):477-82

8. Brull SJ, Greene NM. Zones of differential sensory block during extradural anaesthesia. Br J Anaesth 1991;66:651-5

9. Chamberlain DP, Chamberlain BD. Changes in the skin temperature of the trunk and their relationship to sympathetic blockade during spinal anesthesia. Anesthesiology 1986;65:139-43

10. Stevens MF, Henning Hermanns RW, Lipfert P. Skin temperature during regional anesthesia of the lower extremity. Anesth Analg 2006;102:1247-51

11. Galvin EM, Niehof S, Medina HJ, Zijlstra FJ, van Bommel J, Klein J, et al. Thermographic temperature measurement compared with pinprick and cold sensation in predicting the effectiveness of regional blocks. Anesth Analg 2006;102:598-604 


\section{BIBLIOGRAFÍA}

12. Greengrass RA, Feinglass NG, Murray PM, Trigg SD. Continuous regional anesthesia before surgical peripheral sympathectomy in a patient with severe digital necrosis associated with Raynaud's phenomenon and scleroderma. Reg Anesth Pain Med 2003;28(3):35458

13. Lallos C, Berry AJ. Anesthesia for patients with diseases of peripheral arteries and veins. En: Kaplan JA, Lake CL, Murray MJ (eds). Vascular Anesthesia. 2a ed. Philadelphia: Churchill Livingstone; 2004. p 219-37

14. Aguilar JL, Mendiola MA, Valentí P, Pedrero A, March Y, Cester D. Anestesia epidural y combinaciones. En: Torres LM, Aguilar JL, de Andrés JA, de León O, Gómez Luque A, Montero A (eds). Tratado de anestesia y reanimación. $1^{\text {a }}$ ed. Madrid: Arán; 2001. p. 1185-1209

15. Bernards CM. Epidural and spinal anesthesia. En: Barash PG, Cullen BF, Stoelting RK (eds). Clinical Anesthesia. 5a ed. Philadelphia: Lippincott Williams \& Wilkins; 2006. p. 691-717

16. Cortes Román C. Anestesia epidural lumbar 1931-1936. Segundo debut. Rev Esp Anestesiol Reanim 2005;52(3):159-68

17. Nishida T, Pian-Smith M. Spinal, Epidural, and Caudal Anesthesia. En: Dunn F. Alston T, Baker K (eds). Clinical anesthesia procedures of the Massachussets General Hospital. $7^{\circ}$ ed. Philadelphia: Lippincott Williams \& Wilkins; 2007. p. 247-72

18. Jacobsen J, Sofelt S, Brocks V, Fernandes A, Warberg J, Secher NH. Reduced left ventricular diameters at onset of bradicardia during epidural anesthesia. Acta Anaesthesiol Scand 1992;36(8):831-6

19. Covino BG, Scout DB. Consideraciones técnicas. En: Covino BG, Scout DB, (eds). Manual de analgesia y anestesia epidurales. $1^{\mathrm{a}}$ ed. Barcelona: Salvat; 1988. p. 83-108

20. Norgren L, Hiatt WR, Dormandy JA, Nehler MR, Harris KA, Fowkes FGR, et al. Inter-Society Consensus for the Management of Peripheral Arterial Disease (TASC II). J Vasc Surg 2007;45(1 supl A):5-67

21. Serrano Hernando FJ, Martín Conejero A. Peripheral Artery Disease: Pathophysiology, diagnosis and treatment. Rev Esp Cardiol 2007;60(9):969-82

22. Hirsch A, Criqui M, Treat-Jacobson D, Regensteiner J, Creager M, Olin J, et al. Peripheral arterial disease detection, awareness, and treatment in primary care. JAMA 2001;286(11):1317-24 
23. Bhatt D, Steg P, Ohman E, Hirsch A, Ikeda Y, Mas J, et al. International prevalence, recognition, and treatment of cardiovascular risk factors in outpatients with atherothrombosis. JAMA 2006;295(2):180-9

24. Aronow WS, Ahn C. Prevalence of coexistence of coronary artery disease, peripheral arterial disease, and atherothrombotic brain infarction in men and women $>$ or $=62$ years of age. Am J Cardiol 1994;74(1):64-65

25. Tierney S, Fennessy F, Hayes DB. ABC of arterial and vascular disease: Secondary prevention of peripheral vascular disease. BMJ 2000;320(7244):1262-5

26. Burns P, Gough S, Bradbury AW. Management of peripheral arterial disease in primary care. BMJ 2003;326(7389):584-8

27. Simpson KH, Ward J. A randomized, double-blind, crossover study of the use of transcutaneous spinal electroanalgesia in patients with pain from chronic critical limb ischemia. J Pain Symptom Manage 2004;28(5):511-6

28. Emmerich J. Current state and perspective on medical treatment of critical leg ischemia: Gene and cell therapy. Int J Low Extrem Wounds 2005;4(4):234-41

29. Lara-Hernández R, Lozano-Vilardell P, Cordobés-Gual J. Nuevos tratamientos de la enfermedad arterial periférica oclusiva: angiogenia terapéutica. Med Clin (Barc) 2008;131(17):665-9

30. Criqui MH, Fronek A, Barrett-Connor E, Klauber MR, Gabriel S, Goodman D. The prevalence of peripheral arterial disease in a defined population. Circulation 1985;71(3):510-5

31. Hiatt WR, Hoag S, Hamman RF. Effect of diagnostic criteria on the prevalence of peripheral arterial disease. The San Luis Valley Diabetes Study. Circulation 1995;91(5):1472-9

32. Selvin E, Erlinger TP. Prevalence of and risk factors for peripheral arterial disease in the United States: results from the National Health and Nutrition Examination Survey, 1999-2000. Circulation 2004;110(6):738-43

33. Guijarro Herráiz C, Brotons Cuixart C, Camarelles Guillem F, Medrano Albero MJ, Moreno González JL, del Río Ligorit A, et al (coord). $1^{\text {a }}$ Conferencia de la prevención y promoción de la salud en la práctica clínica en España: Prevención cardiovascular. Madrid: Semfyc ediciones; 2007 
34. Ouriel K. Peripheral arterial disease. Lancet 2001;358(9289):1257-64

35. Criqui MH, Vargas V, Denenberg JO, Ho E, Allison M, Langer RD, et al. Ethnicity and peripheral arterial disease: the San Diego Population Study. Circulation 2005;112(17):2703-7

36. Ridker PM, Stampfer MJ, Rifai N. Novel risk factors for systemic atherosclerosis: a comparison of C-reactive protein, fibrinogen, homocysteine, lipoprotein(a), and standard cholesterol screening as predictors of peripheral arterial disease. JAMA 2001;285(19):2481-5

37. Vigilance JE, Reid HL. Segmental blood flow and rheological determinants in diabetic patients with peripheral occlusive arterial disease. J Diabetes Complications 2008; 22(3):210-6

38. Sartori M, Favaretto E, Legnani C, Cini M, Conti E, Amato A, Palareti G. Thrombophillic risk factors and peripheral arterial disease severity. Thromb Haemost 2010; 104(1):71-7

39. Khandanpour N, Loke YK, Meyer FJ, Jennings B, Armon MP. Homocysteine and peripheral arterial disease: systematic review and meta-analysis. Eur J Vasc Endovasc Surg 2009;38(3):316-22

40. O'Hare AM, Vittinghoff E, Hsia J, Shlipak MG. Renal insufficiency and the risk of lower extremity peripheral arterial disease: results from the Heart and Estrogen/Progestin replacement Study (HERS). J Am Soc Nephrol 2004;15(4):1046-51

41. Vicente I, Lahoz C, Taboada M, García A, San Martín MA, Terol I, et al. Prevalencia de un índice tobillo-brazo patológico según el riesgo cardiovascular calculado mediante la función de Framingham. Med Clin(Barc) 2005;124(17):641-4

42. España Caparrós G. Enfermedad vascular periférica: Isquemia de miembros inferiores. En: Espinosa Caliani JS, Bravo Navas JC (eds). Rehabilitación cardiaca y atención primaria. $2^{\mathrm{a}}$ ed. Madrid: Panamericana; 2002: p 161-71

43. Mc Dermott MM, Kerwin DR, Liu K, Martin GJ, O`Brien E, Kaplan $\mathrm{H}$, et al. Prevalence and significance of unrecognized lower extremity peripheral arterial disease in general medicine practice. J Gen Intern Med 2001;16(6):384-90

44. Mc Dermott MM, Liu K, Greenland P, Guralnik JM, Criqui MH, Chan $\mathrm{C}$, et al. Functional decline in peripheral arterial disease: associations with the ankle brachial index and leg symptoms. JAMA 2004;292(4):453-61 


\section{BIBLIOGRAFÍA}

45. Ministerio de Sanidad y Consumo- Instituto de Salud "Carlos III". Agencia de Evaluación de Tecnologías Sanitarias (AETS). Prótesis endovasculares (stents) en el tratamiento de la arteriopatía periférica de los miembros inferiores. Madrid: AETS- Instituto de Salud "Carlos III", Julio de 1996

46. Valley MA, Bourke KL, Hamill MP, Raja SN. Time course of sympathetic blockade during epidural anesthesia: laser Doppler flowmetry studies of regional skin perfusion. Anesth Analg 1993;76(2):289-94

47. Vaquero-Morillo F, Sanz-Guadarrama O, González-Fueyo MJ, Canga-Presa JM, Fernández-Morán MC. Técnicas de cirugía vascular por laparoscopia: derivación aórtica y simpatectomía lumbar. Angiología 2002;54(6):446-54

48. Satiani B, Liapsis CD, Hayes JP. Prospective randomized study of concomitant lumbar sympathectomy with aortoiliac reconstruction. Am J Surg 1982;143(6):755-60

49. Robert B, Rutherford MD. Lumbar sympathectomy: indications and technique. En: Rutherford RB, Cronenwett JL, Gloviczki P, Johnston KW, Kempczinski RF, Krupski WC, (eds). Vascular surgery. $5^{\mathrm{a}}$ ed. Philadelphia: Saunders Company; 2000. p. 1069-78

50. Beglaibter N, Berlatzky Y, Zamir O, Spira, RM, Freund HR. Retroperitoneoscopic lumbar sympathectomy. J Vasc Surg 2002; 35(4):815-7

51. AbuRahma AF, Robinson PA. Clinical parameters for predicting response to lumbar sympathectomy in patients with severe lower limb ischemia. J Cardiovasc Surg (Torino) 1990; 31(1): 101-6

52. Baker DM, Lamerton AJ. Operative lumbar sympathectomy for severe lower limb ischaemia: still a valuable treatment option. Ann R Coll Surg Engl 1994; 76(1):50-3

53. Pérez-Burkhardt JL, González-Fajardo JA, Martín JF, CarpinteroMediavilla LA, Mateo Gutiérrez AM. Lumbar sympathectomy as isolated technique for the treatment of lower limbs chronic ischemia. J Cardiovasc Surg 1999;40(1): 7-13

54. Jacobs MJ, Jörning PJ, Beckers RC, Ubbink DT, van Kleef M, Slaaf DW, et al. Foot salvage and improvement of microvascular blood flow as a result of epidural spinal cord electrical stimulation. J Vasc Surg 1990;12(3):354-60 


\section{BIBLIOGRAFÍA}

55. Robaina FJ, Miranda G. Avances en el diagnóstico y tratamiento del dolor simpático. Rev Soc Esp Dolor 2000;7(6):390-402

56. Dormandy J, Belcher G, Broos P, Eikelboom B, Laszlo G, Konrad P, et al. Prospective study of 713 below-knee amputations for ischaemia and the effect of a prostacyclin analogue on healing. Hawaii Study Group. Br J Surg 1994;81(1):33-7

57. Gulden H, Carter C. Anestesia en cirugía vascular. En: Hurford WE, Bailin MT, Davison JK, Haspel KL, Rosow C. Massachusetts General Hospital procedimientos en Anestesia. 5 ed. Madrid: Marban; 1999. p. $369-84$

58. Orduña González MJ, López Carballo C, Camblor Suárez E, López Rouco M. Tratamiento epidural del dolor en la isquemia vascular periférica (I). Rev Soc Esp Dolor 2009; 16(2):101-11

59. Bode RH, Lewis KP, Zarich SW, Pierce ET, Roberts M; Kowalchuk GJ, et al. Cardiac outcome after peripheral vascular surgery. Comparison of general and regional anesthesia. Anesthesiology 1996;84(1):3-13

60. Tovey G, Thompson JP. Anaesthesia for lower limb revascularization. Continuing education in anaesthesia. Contin Educ Anaesth Crit Care Pain 2005; 5(3): 89-92

61. Rosenfeld BA. Perioperative hemostatic changes and coronary ischemic syndromes. Int Anesthesiol Clin 1992;30(1):131-54

62. Rosenfeld BA, Beattie C, Christopherson R, Norris EJ, Frank SM, Breslow MJ, et al. The effects of different anesthetic regimens on fibrinolysis and the development of postoperative arterial thrombosis. Perioperative ischemia randomized anesthesia trial study group. Anesthesiology 1993;79(3):435-43

63. Rosenfeld BA, Faraday N, Campbell D, Dise K, Bell W, Goldschmidt P. Hemostatic effects of stress hormone infusion. Anesthesiology 1994;81(5):1116-26

64. Savoia G, Loreto M, Gravino E, Canfora G, Frangiosa A, Cortesano $\mathrm{P}$, et al. Monitored anesthesia care and loco-regional anesthesia. Vascular surgery use. Minerva Anestesiol 2005;71(9):539-42

65. Veering BT. Are epidurals worthwhile in vascular surgery? Curr Opin Anaesthesiol 2008;21(5):616-8 
66. López Álvarez S, Agustí Martínez-Arcos S, Bustos Molina F, Collado Collado F, de Andrés Ibáñez J, Martín Pérez E. Dolor agudo postoperatorio en cirugía ambulatoria. $1^{\text {a }}$ ed. Madrid: Ergon; 2006

67. Carr DB, Goudas LC. Acute pain. Lancet 1999; 353(9169):1051-8

68. Macrae WA. Chronic pain after surgery. Br J Anaesth 2001;87(1):8898

69. Richman JM, Wu CL. Analgesia epidural en el tratamiento del dolor postoperatorio. Anesthesiology Clin N Am 2005;23:125-140

70. Aurilio C, Pace MC, Passavanti MB, Paladini A, Maisto M, Iannotti $\mathrm{M}$, et al. Treatment of ischemic pain in patients suffering from peripheral vasculopathy with transdermal buprenorphine plus epidural morphine with ropivacaine $v s$ epidural morphine with ropivacaine. Pain Pract 2009;9(2):105-14

71. Bejarano B, Manrique M. Simpatectomía toracoscópica: una revisión de la literatura. Neurocirugía (Astur) 2010;21(1):5-13

72. Guyton AC, Hall JE. Temperatura corporal, regulación de la temperatura y fiebre. En: Guyton AC, Hall JE. Tratado de fisiología médica. $9^{a}$ ed. Madrid: Mc Graw-Hill-Interamericana de España; 1999. p. 993-1006

73. Greenwood B. The origins of sympathectomy. Med Hist 1967;11(2):165-9

74. Stephan D, Griffon C, Welch M, Boila S, Fend E. Non-surgical treatment of critical limb ischemia. Ann Cardiol Angiol (Paris) 2007;56(2):70-3

75. Kim GU, Ibrahim IM, Imparato AM. Lumbar sympathectomy in end stage arterial occlusive disease. Ann Surg 1976:183 (2):157-60

76. Boas RA. Sympathetic nerve blocks: in search of a role. Reg Anesth Pain Med 1998;23(3):292-305

77. Nitecki SS, Kleisser A, Ofer A, Karram T, Engel A, Eisenberg E, et al. Severe ergot-induced lower limb ischaemia treated by epidural local anaesthetic. Eur J Vasc Endovasc Surg 2000;20(3):312-5

78. Bengstsson M. Changes in skin blood flow and temperature during spinal analgesia evaluated by laser Doppler flowmetry and infrared thermography. Acta Anaesthesiol Scand 1984;28(6):625-30 


\section{BIBLIOGRAFÍA}

79. Perhoniemi V, Linko K. Effect of spinal vs epidural anaesthesia with $0.5 \%$ bupivacaine on lower limb blood flow. Acta Anaesthesiol Scand 1987;31(2):117-21

80. González de Zárate Apiñániz J, Sayalero San Miguel JM, Álvarez López JC, Arribas Carrión C. Efectos térmicos del bloqueo anestésico epidural. Rev Esp Anestesiol Reanim 1991;38(4):238-40

81. Emerick TH, Ozaki M, Sessler DI, WaltersK, Schroeder M. Epidural anesthesia increases apparent leg temperature and decreases the shivering threshold. Anesthesiology 1994;81(2):289-98

82. Sato S, Okubo N, Yamashita S, Yamamoto S, Kumagai M, Kihara S, et al. Age-related decrease in toe-thumb temperature difference with lumbar epidural anaesthesia. Can J Anaesth 1994;41(7):579-82

83. Matsukawa T, Sessler DI, Christensen R, Ozaki M, Schroeder M. Heat flow and distribution during epidural anesthesia. Anesthesiology 1995;83(5):961-7

84. González-Grosso NG, Labrada A, Santana JE. Bloqueo epidural con ropivacaína en la insuficiencia arterial crónica de miembros inferiores: ensayo clínico. Rev Soc Esp Dolor 2005;12(2):86-92

85. Sebastian Braun RW, Hermanns H, Freynhagen R, Lipfert P, Stevens MF. Uniform distribution of skin-temperature increase after different regional-anesthesia techniques of the lower extremity. Reg Anesth Pain Med 2007;32(1):73-8

86. Ginosar Y, Weiniger CF, Kurz V, Babchenko A, Nitzan M, Davidson E. Sympathectomy-mediated vasodilatation: a randomized concentration ranging study of epidural bupivacaine. Can J Anaesth 2009;56(3):213-21

87. Asato F, Takenami T. The detection of successful epidural blockade by subjective assessment of toe-temperature elevation. Anesthesiology 1997;87(5):1264

88. Olmos de la Peña, A. Análisis de los efectos térmicos cutáneos y centrales de la inducción anestésica. Estudio comparativo entre: propofol, tiopental y etomidato [Tesis Doctoral]. Valladolid (España): Universidad de Valladolid; 2000

89. González Rodríguez JL. Efectos térmicos centrales y cutáneos en la cabeza de la inducción anestésica: estudio comparativo entre propofol, etomidato y sevofluorano [Tesis Doctoral]. Salamanca (España): Universidad de Salamanca; 2006 


\section{BIBLIOGRAFÍA}

90. Ruiz López N. Efectos térmicos-cutáneos y fotopletismográficos inducidos por el bloqueo del plexo braquial por vía axilar [Tesis Doctoral]. Valladolid (España): Universidad de Valladolid; 2002

91. Heredia Rodríguez M. Efectos térmico-cutáneos en las extremidades inferiores de la anestesia epidural lumbar con bupivacaína: influencia de la adrenalina [trabajo de Grado de Licenciatura]. Salamanca (España): Universidad de Salamanca; 2007

92. López González I. Vasoconstricción cutánea termorreguladora en anestesia [Suficiencia Investigadora]. Granada (España). Granada (España): Universidad de Granada; 2006

93. Fernández del Busto E, González de Zárate J, Álvarez López JC, Rivera J, Cortiñas JR. La vasoconstricción cutánea termorreguladora durante la cirugía urológica de larga duración. Anales de la Real Academia de Medicina y Cirugía de Valladolid 1998;36(1):207-216

94. González de Zárate J, Olmos de la Peña A, Díez Pastrana Y, Ruiz López N, González MT. Influencia de las técnicas anestésicas en la termorregulación del paciente quirúrgico. Anales de la Real Academia de Medicina y Cirugía de Valladolid 2004;41(1):33-46

95. Díez Pastrana Y. Análisis del proceso de recalentamiento después de hipotermia moderada: Utilidad del colchón de aire caliente [tesis doctoral]. Valladolid (España): Universidad de Valladolid;2005

96. Fisher SP, Bader AM, Sweitzer B. Preoperative evaluation. En: Miller MD (eds). Miller's Anesthesia. $7^{\mathrm{a}}$ ed. Philadelphia: Churchill Livingstone Elsevier; 2009. p. 1001-66

97. Hirsch AT, Haskal ZJ, Hertzer NR, Bakal CW, Creager MA, Halperin JL, et al. ACC/AHA 2005 guidelines for the management of patients with peripheral arterial disease (lower extremity, renal, mesenteric, and abdominal aortic): Executive summary a collaborative report from the American Association for Vascular Surgery/Society for Vascular Surgery, Society for CardiovascularAngiography and Interventions, Society for Vascular Medicine and Biology, Society of Interventional Radiology, and the ACC/AHA Task Force or Practice Guidelines (Writing Committee to Develop Guidelines for the Management of Patients with Peripheral Arterial Disease) endorse by the American Association of Cardiovascular and Pulmonary Rehabilitation; National Heart, Lung, and Blood Institute; Society for Vascular Nursing; TransAtlantic InterSociety Consensus; and Vascular Disease Foundation. J Am Coll Cardiol 2006;47(6):1239-312 


\section{BIBLIOGRAFÍA}

98. Sharrock NE. Epidural anesthetic dose response in patients 20 to 80 years old. Anesthesiology 1978;49(6):425-8

99. Nydahl PA, Philipson L, Axelsson K, Johansson JE. Epidural anesthesia with $0,5 \%$ bupivacaine: influence of age on sensory and motor blockade. Anesth Analg 1991;73(6):780-6

100. Simon MJ, Veering BT, Stienstra R, van Kleef JW, Burm AG. The effects of age on neural blockade and hemodynamic changes after epidural anethesia with ropivacaine. Anesth Analg 2002; 94(5):132530

101. Finucane BT, Hammonds WD, Welch MB. Influence of age on vascular absorption of lidocaine from the epidural space. Anesth Analg 1987;66(9):843-6

102. Visser WA, Lee RA, Gielen MJM. Factors affecting the distribution of neural blockade by local anesthetics in epidural anesthesia and a comparison of lumbar versus thoracic epidural anesthesia. (Review article). Anesth Analg 2008;107(2):708-21

103. Duggan J, Bowler GM, Mc Clure JH, Wildsmith JA. Extradural block with bupivacaine: influence of dose, volume, concentration and patient characteristics. Br J Anaesth 1988;61(3):324-31

104. Andersen S, Cold GE. Dose response studies in elderly patients subjected to epidural analgesia. Acta Anaesthesiol Scand 1981;25(3):279-81

105. Burn JM, Gruyer PB, Langdon L. The spread of solutions injected into the epidural space. A study using epidurograms in patients with the lumbosciatic sindrom. Br J Anaesth 1973;45(4):338-45

106. Bromage PR. Tissue space connections. En: Bromage PR (eds). Epidural analgesia. $1^{\text {a }}$ ed. Philadelphia: WB Saunders; 1978. p. 31-2

107. Hogan QH. Epidural anatomy examined by cryomicrotome section: influence of age, vertebral level, and disease. Reg Anesth 1996;21(5):395-406

108. Igarashi T, Hirabayashi Y, Shimizu R, Saitoh K, Fukuda H, Mitsuhata $\mathrm{H}$. The lumbar extradural structure changes with increasing age. $\mathrm{Br} \mathbf{J}$ Anaesth 1997;78(2):149-52

109. Veering BT, Cousins MJ. Cardiovascular and pulmonary effects of epidural anaesthesia. Anaesth Intensive Care 2000;28(6):620-35

110. Werdehausen R, Braun S, Hermanns H, Freynhagen R, Lipfert P, Stevens MF. Uniform distribution of skin-temperature increse after 


\section{BIBLIOGRAFÍA}

different regional-anesthesia techniques of the lower extremity. Reg Anesth Pain Med 2007;32(1):73-8

111. Tran KM, Frank SM, Raja SN, El-Rahmany HK, Kim LJ, Vu B. Lumbar sympathetic block for sympathetically maintained pain: changes in cutaneous temperatures and pain perception. Anesth Analg 2000;90(6):1396-401

112. Park SY, Nahm FS, Kim YC, Lee SC, Sim SE, Lee SJ. The cut-off rate of skin temperature change to confirm successful lumbar sympathetic block. J Int Med Res 2010;38(1):266-75

113. Stevens RA, Beradsley D, White JL, Kao TC, Gantt R, Holman S. Does spinal anesthesia result in a more complete sympathetic block than that from epidural anesthesia? Anethesiology 1995;82(4):877-83

114. Stevens RA, Frey K, Liu SS, Kao TC, Mikat-Stevens M, Beardsley D, et al. Sympathetic block during spinal anesthesia in volunteers using lidocaine, tetracaine, and bupivacaine. Reg Anesth 1997;22(4):325-31

115. Orduña González MJ, López Carballo C, Camblor Suárez E, López Rouco M. Tratamiento epidural del dolor en la isquemia vascular periférica. Parte II. Revisión bibliográfica basada en la evidencia del tratamiento epidural en la isquemia vascular periférica. Rev Soc Esp Dolor 2009;16(3):160-81

116. Bonica JJ. Autonomic innervation of the viscera in relation to nerve block. Anesthesiology 1968;29(4):793-813

117. Lundin S, Kirnö K, Wallin BG, Elam M. Effects of epidural anesthesia on sympathetic nerve discharge to the skin. Acta Anaesthesiol Scand 1990;34(6):492-7

118. Lundin S, Wallin BG, Elam M. Intraneural recording of muscle sympathetic activity during epidural anesthesia in humans. Anesth Analg 1989;69(6):788-93

119. Kapural L, Mekhail N: Assessment of sympathetic blocks. Tech Reg Anesth Pain Manag 2001; 5(3):82-7

120. Ring F. Thermal imaging today and its relevance to diabetes. $\mathbf{J}$ Diabetes Sci Technol 2010;4(4):857-62

121. Kraemer R, Knobloch K, Papst S, Kabbani M, Koennecker S, Vogt PM. Free flap microcirculatory monitoring correlates to free flap temperature assessment. J Plast Reconstr Aesthet Surg 2011;64(10):1353-8 


\section{BIBLIOGRAFÍA}

122. Lavery LA, Higgins KR, Lanctot DR, Constantinides GP, Zamorano $\mathrm{RG}$, Athanasiou KA, et al. Preventing diabetic foot ulcer recurrence in high-risk patients. Diabetes Care 2007;30(1):14-20

123. Minville V, Gendre A, Hirsch J, Silva S, Bourdet B, Barbero C, et al. The efficacy of skin temperature for block assessment after infraclavicular brachial plexus block. Anesth Analg 2009;108(3):1034-6

124. Kim YC, Bahk JH, Lee SC, Lee YW.: Infrared thermographic imaging in the assessment of successful block on lumbar sympathetic ganglion. Yonsei Med J 2003;44(1):119-24

125. Schick CH, Fronek K, Held A, Birklein F, Hohenberger W, Schmelz M. Differential effects of surgical sympathetic block on sudomotor and vasoconstrictor function. Neurology 2003;60(11):1770-6

126. Greene NM. Area of differential block in spinal anestesia with hyperbaric tetracaine. Anesthesiology 1958;19(1):45-50

127. Huttner S, Huttner M, Neher M, Antes G. [CT-guided sympathicolysis in peripheral arterial disease-Indications, patient selection and longterm results] [artículo en alemán]. Rofo 2002;174(4):480-4

128. Cross FW, Cotton LT. Chemical lumbar sympathectomy for ischemic rest pain. A randomized, prospective controlled clinical trial. Am J Surg 1985;150(3):341-5

129. Waibel P. [Influence of lumbar sympathectomy on the proportion of amputation] [artículo en francés]. Acta Chir Belg 1977;76(1):131-2

130. Fyfe T, Quin RO. Phenol sympathectomy in the treatment of intermitent claudication: a controlled clinical trial. $\mathrm{Br} \mathrm{J}$ Surg 1975;62(1):68-71 